\title{
Strategic Principles Workshops: \\ Discussion Drafts and Workshop Notes
}

September 1991

U.S. Department of Energy

Office of Civilian Radioactive Waste Management

Washington, DC 20585 



\section{DISCLAIMER}

This report was prepared as an account of work sponsored by an agency of the United States Government. Neither the United States Government nor any agency thereof, nor any of their employees, make any warranty, express or implied. or assumes any legal liability or responsibility for the accuracy, completeness, or usefuiness of any information, apparatus, product, or process disclosed, or represents that its use would not infringe privately owned rights. Reference herein to any specific commercial product, process, or service by trade name, trademark, manufacturer, or otherwise does not necessarily constitute or imply its endorsement, recommendation, or favoring by the United States Government or any agency thereof. The views and opinions of authors expressed herein do not necessarily state or reflect those of the United States Government or any agency thereof. 


\section{DISCLAIMER}

Portions of this document may be illegible in electronic image products. Images are produced from the best available original document. 


\title{
Department of Energy
}

Washington, DC 20585

\author{
SEP 201991
}

To the Reader:

In 1990 and 1991, the Office of Civilian Radioactive Waste Management (OCRWM) undertook three workshops to discuss with individuals from affected governments and interested parties the strategic principles that would be used to guide the program in the coming years. In turn, these strategic principles formed the core of the draft Mission Plan Amendment, which proposes how the OCRWM will respond to our mandate from Congress to develop a system for permanently disposing of spent fuel from commercial nuclear power plants and high-level radioactive wastes from our Nation's defense activities in a manner that protects the health and safety of the public and workers and the quality of the environment. The Department of Energy issued the draft Mission PTan Amendment for public comment on September 9, 1991, with comments to be submitted by November 8,1991 .

The Strategic Principles Workshops represented an approach to the draft Mission Plan Amendment different from that used for previous versions of the Mission Plan. The approach taken provided an opportunity for individuals external to the Department to contribute early input. In order to ensure full and free discussion, the workshops were moderated by a professional facilitator experienced in guiding such public discussions. We found the input of the various workshop participants and the exchange of views informative, stimulating, and productive. The workshops, and the contributions of the individuals who attended them, directly and significantly affected the structure and content of the draft Mission Plan Amendment. We thank al1 those who contributed to the workshops.

The workshops produced materials that, taken together, constitute an important record of the development of the draft Mission Plan Amendment. This package is intended to make these materials available in one volume for easy reference. Included are the

1. "Discussion Draft on Strategic Principles for Planning and Decisionmaking in the Civilian Radioactive Waste Management Program," dated November 21, 1990.

2. "Strategic Principles for Planning and Decisionmaking in the Civilian Radicactive Waste Management Program," dated March 25, 1991 .

3. "Discussion Notes on the First Strategic Principles Workshop," which was held in Salt Lake City, Utah, on December 4-5, 1990.

4. "Discussion Notes on the Second Strategic Principles Workshop," which was held in Washington, D.C., on January 15-16, 1991.

5. "Discussion Notes on the Third Strategic Principles Workshop," which was held in Denver, Colorado, on April 4-5, 1991. 
The first and second workshops dealt with the Discussion Draft of November 21, 1990. Input from these two workshops was incorporated into the "Strategic Principles for Planning and Decisionmaking in the Civilian Radioactive Waste Management Program," dated March 25, 1991. The third workshop focused on this March 25, 1991, document. The three sets of discussion notes are not verbatim transcripts of the proceedings, nor do they represent an analys is of the discussion. Because participants were assured that the discussion was on a "not for attribution" basis, bullets (•) are used to identify comments by participants other than Department of Energy staff or the discussion facilitator. The participants for each workshop are listed following the discussion notes for the workshop.

If you have any questions or comments on these materials, please call Amy Moran at (202) 586-1252.

Sincere Ty,

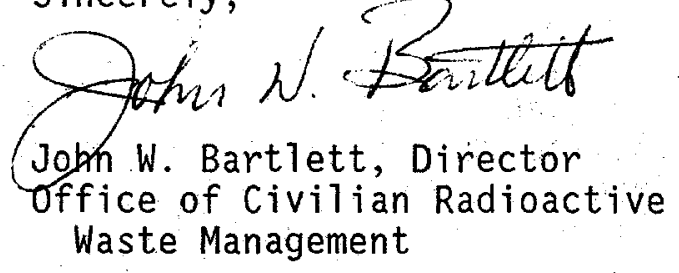




\section{CONTENTS}

$\underline{T a b}$

Discussion Draft on Strategic Principles for Planning and Decisionmaking in the Civilian Radioactive Waste Management Program ..........................A

Strategic Principles for Planning and Decisionmaking

In the Civilian Radioactive Waste Management Program . . . . . . . . . . B

Discussion Notes on the First Strategic Principles

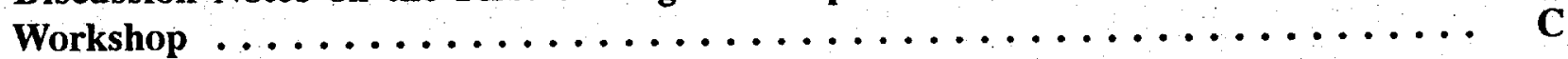

Discussion Notes on the Second Strategic Principles

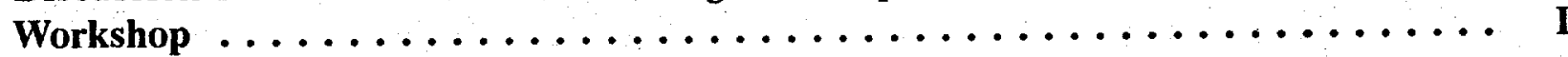

Discussion Notes on the Third Strategic Principles Workshop $\ldots \ldots \ldots \ldots \ldots \ldots$ 


\section{DISCUSSION DRAFT}

ON

STRATEGIC PRINCIPLES FOR PLANNING AND DECISIONMAKING

IN THE

CIVILIAN RADIOACTIVE WASTE MANAGEMENT PROGRAM

U.S. Department of Energy

Office of Civilian Radioactive Waste Management

November 21, 1990 
FOREWORD $\ldots \ldots \ldots \ldots \ldots \ldots \ldots \ldots \ldots \ldots \ldots \ldots \ldots \ldots \ldots \ldots$ iv

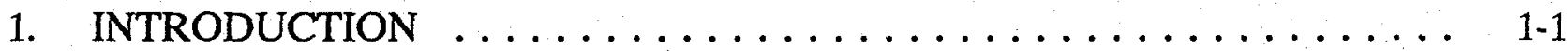

2. MISSION, OBJECTIVES, POLICIES, AND STRATEGIC PRINCIPLES FOR PLANNING AND DECISIONMAKING $\ldots \ldots \ldots \ldots \ldots \ldots \ldots \ldots \ldots . \ldots \ldots$

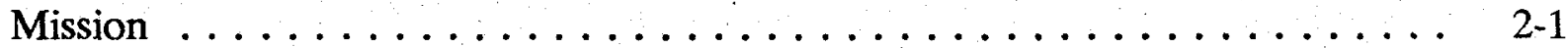

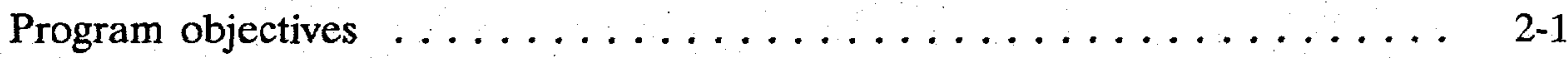

Basic policies ....................... $2-1$

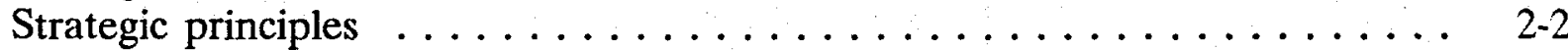

3. PROPOSED ISSUES OF STRATEGIC IMPORTANCE AND POSSIBLE STRATEGIC PRINCIPLES $\ldots \ldots \ldots \ldots \ldots \ldots \ldots \ldots \ldots \ldots \ldots \ldots \ldots \ldots$ 3-1

3.1 ISSUES RELATED TO THE PROTECTION OF PUBLIC SAFETY AND THE ENVIRONMENT $\ldots \ldots \ldots \ldots \ldots \ldots \ldots \ldots \ldots \ldots \ldots \ldots \ldots \ldots$

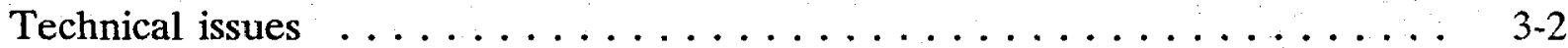

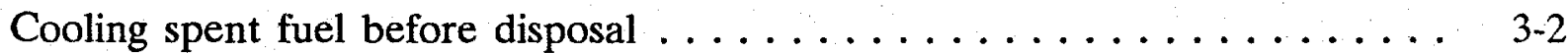

Designing waste packages to exceed the regulatory standard . . . . . . . 3-3

Approach to the demonstration of performance $\ldots \ldots \ldots \ldots \ldots \ldots . \ldots .3-5$

Using a demonstration facility to increase confidence $\ldots \ldots \ldots \ldots \ldots \ldots$ 3-6

Timing and criteria for determining the suitability of the candidate site for a repository ....................... 3-9

Geologic disposal for wastes other than spent fuel and high-level waste (greaterthan-Class $\mathrm{C}$ wastes) . . . . . . . . . . . . . . . . . . . 3-13

Risk assessment in selecting transportation modes and preferred routes . . . 3-17

Management issues ......................... 3-18

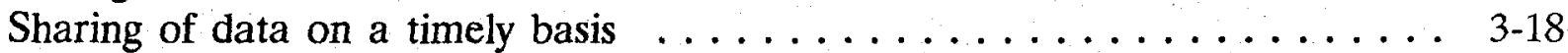

Institutional issues . . . . . . . . . . . . . . . . . . . 3-19

Timing and means for predecisional participation by affected and involved parties

Gaining public acceptance of waste transportation $\ldots \ldots \ldots \ldots \ldots \ldots$ 3-21

Emergency-response planning and training $\ldots \ldots \ldots \ldots \ldots \ldots \ldots \ldots \ldots .21$ 


\subsection{ISSUES RELATED TO THE STEWARDSHIP OF RESOURCES AND THE}

EFFECTIVENESS OF OPERATIONS $\ldots \ldots \ldots \ldots \ldots \ldots \ldots \ldots \ldots \ldots$ 3-22

Technical issues . . . . . . . . . . . . . . . . $3-23$

Development of dual-purpose casks for transportation and for storage . . . 3 3-23

Contingency planning for the event that the Yucca Mountain candidate site is found to be unsuitable for a repository $\ldots \ldots \ldots \ldots \ldots \ldots \ldots$ 3-24

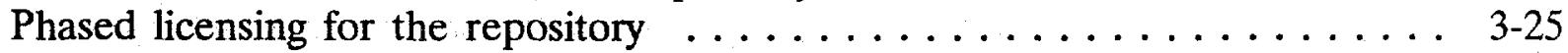

Management issues ...................... 3-27

Roles of utilities and the Federal Government in the management of spent fuel before disposal . . . . . . . . . . . . . . . . . . . . 3-27

Private-sector involvement in the development and operation of an MRS facility3-29

Use of the nuclear waste fund for storage $\ldots \ldots \ldots \ldots \ldots \ldots \ldots \ldots$ 3-30

Use of peer reviews $\ldots \ldots \ldots \ldots \ldots \ldots \ldots \ldots \ldots \ldots \ldots \ldots . \ldots \ldots$ 3-31

Alternative means of managing the waste-management program $\ldots \ldots \ldots 3-32$

4. BACKGROUND INFORMATION $\ldots \ldots \ldots \ldots \ldots \ldots \ldots \ldots \ldots$ 4-1

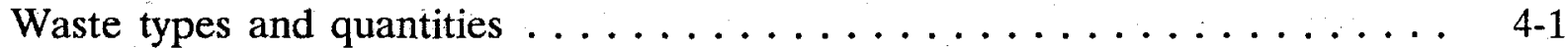

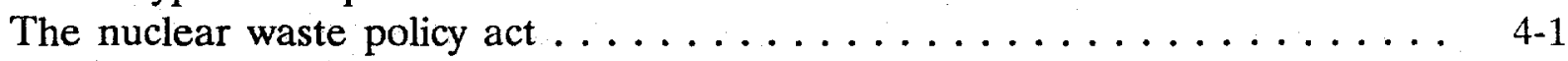

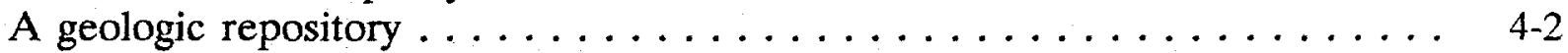

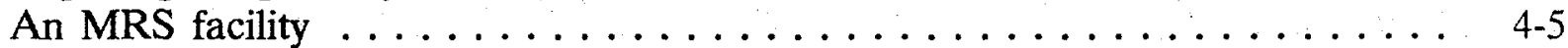

Transportation . . . . . . . . . . . . . . . . . . .

Protection of the public health and safety and the environment ....... 4-10

Potential socioeconomic effects and benefits . . . . . . . . . . . 4-11

Involvement of affected and interested parties $\ldots \ldots \ldots \ldots \ldots \ldots \ldots .4 .11$

Management .......................... 4-13 


\section{FOREWORD}

The Office of Civilian Radioactive Waste Management (OCRWM) intends to govern the planning, decisionmaking, and implementation of the nation's high-level radioactive waste-disposal program through the use of a set of strategic principles. These strategic principles will serve as the "constitution" of the program.

In keeping with the policy of open dialogue Secretary of Energy James D. Watkins has established, OCRWM will develop the strategic principles in consultation with stakeholders. We will sponsor two public workshops to provide an opportunity for affected and interested parties to contribute to the substance of the strategic principles.

We have prepared this working paper, entitled "Discussion Draft on Strategic Principles for Planning and Decisionmaking in the Civilian Radioactive WasteManagement Program," to serve as a basis for dialogue at the workshops. The paper reviews the waste-management program's mission, objectives, policies, and current strategic principles; presents issues from which additional strategic principles may be developed; and provides background information to assist in workshop discussions.

After the workshops, and with the receipt of other comments, we will use the statement of policies and principles in preparing the Mission Plan Amendment, which will be issued in draft form for public comment.

The Federal waste-management program is an undertaking unprecedented in its requirements, complexity, and challenges. To succeed it must have a firm and unassailable foundation for progress, decisions, and plans. Essential to the development of this foundation is meaningful involvement by stakeholders. Their participation in the development of the fundamental strategic principles that will guide the program is a critical step for its success. 


\section{INTRODUCTION}

The Office of Civilian Radioactive Waste-Management in the Department of Energy (DOE) is responsible for disposing of this nation's spent fuel and high-level radioactive waste $^{*}$ in a manner that protects the health and safety of the public and the quality of the environment. Although embodied in the Federal repository program that began with studies in the late 1950s, this mission was explicitly established by the Nuclear Waste Policy Act of 1982 and reaffirmed by the Nuclear Waste Policy Amendments Act of 1987.

To fulfill our mission, we are developing a waste management system consisting of a geologic repository for permanent disposal deep beneath the surface of the earth, a facility for monitored retrievable storage, and a system for transporting the waste.

This discussion draft was developed to help involve parties affected by or interested in the waste-management program in the formulation of the basic principles on which the program will be based. Chapter 2 reviews existing objectives, policies, and strategic principles under which the system is currently being developed. Chapter 3 then discusses issues of strategic importance for which additional strategic principles may be needed. For these issues in particular, views from affected and interested parties is solicited, but comments regarding alternative approaches to the issues presented as well as suggestions for additional issues will also be welcome. Chapter 4 presents background information on the waste-management program pertinent to the issues discussion.

*For brevity, this document often uses the words "radioactive waste" or simply "waste" to mean spent fuel or high-level radioactive waste. 


\section{MISSION, OBJECTIVES, POLICIES, AND STRATEGIC PRINCIPLES FOR PLANNING AND DECISIONMAKING}

\section{MISSION}

Dispose of the Nation's spent fuel and high-level radioactive waste in a manner that protects the health and safety of the public and the quality of the environment.

\section{PROGRAM OBJECTIVES}

To direct the implementation of our mission, we have established the following objectives:

- Timely disposal: to establish as soon as practicable the ability to dispose of radioactive waste in a geologic repository licensed by the Nuclear Regulatory Commission (NRC).

- Timely and adequate waste acceptance: to begin the operation of the wastemanagement system as soon as practicable in order to obtain the system development and operational benefits that have been identified for the MRS facility.

- Schedule confidence: to establish confidence in the schedule for waste acceptance and disposal such that the management of radioactive waste is not an obstacle to the nuclear energy option.

- System flexibility: to ensure that the program has the flexibility necessary for adapting to future circumstances while fulfilling established commitments.

\section{BASIC POLICIES}

The basic policies under which the program is conducted are as follows:

- The protection of public health and safety and the quality of the environment are of paramount importance.

- The program must be distinguished by its technical integrity and excellence and directed at reaching consensus in the scientific community, establishing public understanding and confidence, and obtaining the licenses needed for wastemanagement facilities.

- Opportunities and means must be provided for meaningful participation by affected and interested parties. 
- The program must be managed and conducted in an efficient and cost-effective manner.

\section{STRATEGIC PRINCIPLES}

In addition to the basic policies, strategic principles are needed for planning and decisionmaking. This section presents the established principles under which the program is currently being developed. The following section addresses strategic issues for which additional principles may be needed. Yet other issues or principles, not identified in this discussion draft, may be suggested by affected and interested parties.

\section{Purpose of the strategic principles}

The purpose of the principles is to permit decisions to be made in a rational, goal-oriented manner directed at achieving the objectives of the program while giving adequate opportunity for meaningful predecisional involvement by affected and interested parties, including those public and private segments of our society that have an interest in the safe and reliable completion of this program.

The principles will serve as guides for the more-detailed plans and studies that will be necessary to successfully administer waste management activities. In view of the complexity of the program and its first-of-a-kind nature, the principles are to be used as guides for decisions and actions rather than rigid constraints.

\section{Management principles}

Maintain the focus of the program on permanent disposal. Disposal is the primary objective, it is the DOE's principal responsibility under the law, and success in achieving it is vital to maintaining the nuclear energy option. All program activities must be conducted in a manner that supports and facilitates permanent disposal.

Provide facilities for the timely acceptance of spent fuel. This principle is critical to achieving timely and adequate waste acceptance and obtaining the system-development and operational benefits that have been identified for an MRS facility, including the flexibility essential for spent fuel management logistics.

Maintain and implement strict environmental compliance programs. Although preliminary analyses indicate that the development of facilities and waste-management and disposal operations are not likely to result in significant environmental impacts, implementing this principle will ensure that environmental protection is given priority and that field activities are closely monitored for compliance with all applicable environmental protection standards. 
Maintain standards of excellence. Technical excellence has always been a fundamental requirement of the program, and its importance increases with the increasingly difficult challenges that arise as the program moves forward. It is essential for success in licensing, establishing scientific consensus, increasing public confidence, and the prudent management of resources. Similar standards of excellence will be applied to all other aspects of the program, including institutional activities, outreach, and management.

Ensure that all quality-assurance requirements are met. Quality assurance comprises all the planned and systematic actions necessary to provide adequate confidence that the product or result of a quality-affecting activity meets its intended purpose and/or function; it is a prerequisite for licensing. All quality-affecting work must be performed in accordance with established quality-assurance requirements. We fully embrace the NRC's quality-assurance requirements.

Assign equal importance to institutional and technical activities. The history of the program has shown that institutional challenges are as difficult as the technical ones, and their importance must be recognized in all program plans and activities. Although the yardsticks of performance in technical and institutional activities are different, the highest level of quality and professionalism will be pursued in both.

Coordinate the technical, institutional, and management activities of the program. Implementation of this principle should enhance the integration of technical and institutional activities, contribute to the control of program schedules, and enhance the prospects for the success of the mission.

\section{Technical principles}

Apply the concept of defense in depth in waste-management and disposal. Backup safety systems will be provided in all operations involving waste handling, and multiple barriers against waste migration will be used in the repository. This approach should facilitate licensing and help to establish public confidence in safety.

Provide alternatives and contingency plans. This principle is needed to ensure success despite the inevitable surprises and unexpected problems that will arise in a complex, first-of-a-kind enterprise. It requires the parallel analysis of alternatives to key components of the system so that if the primary candidate encounters difficulties, a workable alternative can be available with minimized delay. It also requires anticipating the difficulties that might be encountered and developing in advance plans for minimizing their effects. While the provision of backups and contingency planning increase the initial costs of the program, they are insurance against unforeseen 
problems that could otherwise lead to delays and real or perceived programmatic failure.

Use state-of-the-art systems-engineering techniques in developing and designing waste-management facilities and operations. Systems engineering is an orderly process for the development of complex systems. It consists of defining objectives and requirements, developing a design that meets the requirements, evaluating the design against the requirements, revising the design as needed, and repeating the process with increasing detail to ensure that the requirements are complete and that the system and its components will meet all of them. Important features of the process are its emphasis on ensuring that all components work together, on special studies of the entire system's ability to meet requirements, and on rigorous control of the technical information used in the process. Systems engineering is essential for the success of the program because it provides the means for identifying and controlling the many interfaces among the elements of the system; coordinating the multiple scientific and engineering disciplines involved in the program; and optimizing the design and operation of the system.

Use simple and proven designs and technologies. The use of simple and proven technologies, particularly those already licensed by the NRC, and the use of designs that approximate those of licensed facilities should facilitate licensing and increase cost effectiveness. This principle is applicable to an MRS facility, a repository, and a transportation system.

Provide external forums for the discussion of technical issues. The purpose of this principle is to ensure external peer participation in the resolution of technical issues. Peer review will be widely used in the program to provide technical oversight. It will be provided by the Nuclear Waste Technical Review Board, groups of independent experts, the technical experts of the States, and the National Academy of Sciences. Providing external forums for discussion of scientific and technical issues should add to the peer-review process and help to establish public confidence in the technical program. In addition, review by the NRC and its Advisory Committee on Nuclear Waste provides yet another level of external review.

\section{Institutional principles}

Provide for the involvement of affected parties in the decisionmaking process. As the organization charged with the development of the waste-management system, we have certain responsibilities that cannot be shared. One of these responsibilities is making technical and programmatic decisions. However, the views of affected and interested parties are essential to the decisionmaking process and will be actively solicited. The involvement of affected parties early in the decisionmaking process will facilitate the identification of emerging issues and alternatives, making issue resolution more 
productive. It will also allow the program to benefit from the knowledge and experience of the affected parties.

Provide support to educational programs. Greater understanding of the health, safety, and environmental issues surrounding waste generation and management is key to the success of the program. It is also needed to help develop the skills necessary to meet the future human-resource needs of the program. This principle will be implemented by stimulating the teaching of science at the secondary, undergraduate, and graduate levels and developing curricula and instructional materials-both print and electronic-for primary, secondary, and undergraduate studies. A related effort will be to foster undergraduate and graduate studies for the public policy aspects of wastemanagement.

Continue to work cooperatively with affected parties. To foster productive links with affected parties, we will consult and cooperate with them and will seek to exchange information and ideas. Cooperative agreements will be used to bring additional groups into the program both for technical advice and for dissemination of information to their members.

In siting and designing waste-management facilities, consider potential benefits to the host states and communities. The Nuclear Waste Policy Amendments Act requires the Secretary of Energy, in siting Federal research projects, to give special consideration to proposals from States where a repository is located. Also, the Secretary of Energy is authorized to enter into a benefits agreement with the State of Nevada concerning a repository or with any state or Indian Tribe concerning an MRS facility. Such a benefits agreement would include specific benefits, including enhanced program participation, identified in the Nuclear Waste Policy Amendments Act. Other benefits to jurisdictions willing to host a repository or Monitored Retrievable Storage facility could be developed through the Nuclear Waste Negotiator, with DOE providing support in response to the Negotiator's requests. 


\section{PROPOSED ISSUES OF STRATEGIC IMPORTANCE AND POSSIBLE STRATEGIC PRINCIPLES}

We have identified a number of issues of strategic importance for which strategic principles similar to those presented in Chapter 2 may need to be developed. We are seeking external input on these issues and plan to discuss them with affected and interested parties in two workshops focused on (1) protecting public safety and the environment and (2) stewardship of the resources made available to the program and effectiveness of operations.

The presentation of each issue includes background information, suggested options for initiating discussions, and factors to be considered in selecting an option or options for implementation. The suggested options are merely a means for initiating discussions; they do not represent policy or plans for action, and have not in any way been endorsed by us. We will appreciate suggestions for other options.

\subsection{ISSUES RELATED TO THE PROTECTION OF PUBLIC SAFETY AND THE ENVIRONMENT}

This section proposes 11 issues for which strategic principles may need to be developed. These issues have been divided into three groups:

\section{Technical issues}

- Cooling spent fuel before disposal.

- Designing waste packages to exceed the regulatory standard.

- Approach to the demonstration of performance.

- Using a demonstration facility to increase confidence.

- Timing and criteria for determining the suitability of the candidate site for a repository.

- Geologic disposal for wastes other than spent fuel and high-level wastes (greaterthan-Class-C wastes).

- Risk assessment in selecting transportation modes and preferred routes.

\section{Management issue}

- Sharing of data on a timely basis. 


\section{Institutional issues}

- Timing and means for predecisional participation by affected and involved parties.

- Gaining public acceptance of waste transportation.

- Emergency-response planning and training.

\section{TECHNICAL ISSUES}

Almost all of the technical issues for which strategic principles may need to be established are focused on a repository, but, as noted in the discussions that follow, some are equally applicable to the entire waste-management system or to another system element.

\section{COOLING SPENT FUEL BEFORE DISPOSAL}

The waste that will be emplaced in a repository consists of spent nuclear fuel and high-level waste. Both types emit heat, but the spent fuel emits more heat than the high-level radioactive waste. The heat may affect the behavior of the host rock and the flow of fluids (both liquids and gases), which is the principal mechanism for transporting radioactive materials from the repository to the human environment. In theory, the heat may create flow patterns near the emplaced waste that differ significantly from the existing flow patterns, and these altered patterns may affect the system's ability to retain radionuclides. Our current strategy is based on exploiting the heat emitted by the waste to dry out the surrounding rock for more than 100 years and thus protect the disposal containers in which the wastes will be encapsulated.

However, the heat load in the repository-and the attendant uncertainties about long-term performance-can be significantly reduced by cooling the spent fuel for extended periods before disposal. Cooling may therefore facilitate licensing by simplifying the scope and difficulty of issues involved in the proof of performance. Cooling would also decrease the minimum distance between emplaced waste packages, reduce the unit volume of rock excavated per package emplaced, and decrease the costs of underground development and operation. The downside of cooling is that it requires prolonged storage on the surface and increases the costs of storage.

The cooling can be provided at reactor sites to the extent storage capacity is available or at an MRS facility. 


\section{Suggested options for initiating a discussion}

Option 1. We could accept spent fuel at the repository directly from reactor pools (i.e., spent fuel cooled for at least 5 years).

Option 2. We could set a minimum cooling period longer than 5 years for acceptance at the repository from reactor sites.

Option 3. We could set a period for long-term cooling (e.g., 80 years) and provide facilities for storing the fuel during that period:

Option 4. We could establish a policy of accepting first the oldest fuel, which will be 40 years old on the average when a repository starts operations, with the proviso to take younger spent fuel to prevent reactor shutdowns.

\section{Considerations in selecting options for implementation}

Option 1 corresponds to our current approach. Our standard contract with the utilities specifies a minimum spent-fuel age of 5 years. However, after a repository starts accepting waste in 2010 , most of the fuel accepted by the Federal system will be more than 10 years old. This option would not require the development of facilities exclusively for long-term cooling, but it would be compatible with an MRS facility, whose functions are not limited to cooling.

Option 2 would also be applicable to the waste-management system we are currently developing (a repository and retrievable storage for a limited quantity of spent fuel). To implement this option, we are conducting studies to determine the characteristics of spent fuel, the characteristics of the host rock, the design of a repository, the operation strategy for a repository, the operation strategy for an MRS facility, the storage mode chosen for an MRS facility, and efficiencies in transportation.

Option 3 is similar to the strategy followed in other countries. To implement this strategy, we would have to develop several MRS facilities to provide sufficient storage capacity.

In Option 4, eventually, as the waste backlog is worked off, the spent fuel arriving at a repository would be less than 40 years old.

\section{DESIGNING WASTE PACKAGES TO EXCEED THE REGULATORY STANDARD}

The waste package is defined by the NRC as "the waste form (spent fuel or highlevel waste) and any containers, shielding, packing, and other absorbent materials 
immediately surrounding an individual waste container." For the Yucca Mountain candidate site, the current conceptual design for the waste package consists of the waste form and a disposal container; it is the principal engineered barrier.

The waste package must meet various functional and regulatory requirements related to the operation of a repository and to the containment of radionuclides after a repository has been closed. Included in these requirements are the performance objectives of providing substantially complete containment for the waste for not less than 300 years to 1000 years and thereafter controlling the rate of radionuclide release from the engineered-barrier system. The demonstration that these objectives will be met is expected to be one of the most difficult technical challenges during licensing, and for this reason great importance is attached to the design of the waste package and to determining the conditions to which it will be subjected in a repository.

In the current reference design for the Yucca Mountain candidate site, the container consists of a corrosion-resistant metal selected to be compatible with the environment in a repository and with the geologic, hydrologic, and geochemical conditions expected to prevail in a repository over the long term. This design is expected to meet, but not necessarily exceed, regulatory standards for the life of the waste package.

\section{Suggested options for initiating a discussion}

Option 1. We could design the waste package to be compatible with the wasteemplacement environment and to meet, but not attempt to significantly exceed, the regulatory criterion for the life of the waste package. This design would be done in parallel with studies of the waste-emplacement environment, which are included in section 8.3.4.2.4 of the Site Characterization Plan.

Option 2. We could design a waste package that would exceed by a significant margin the regulatory criterion. This design would be done in parallel with studies of the waste-emplacement environment, which are included in section 8.3.4.2.4 of the Site Characterization Plan.

Option 3. We could pursue both options in parallel with studies of the wasteemplacement environment and other scientific studies during site evaluation. Once the results of the studies are available and a cost-benefit analysis has been performed, a single design path would be chosen.

\section{Considerations in selecting options for implementation}

Option 1 represents the current design approach. The current reference design is at a conceptual stage; alternative materials and design concepts would be evaluated in 
the next, more-advanced design phase.

Option 2 would help to offset uncertainties that may exist about the performance of the natural system at the site. It might thereby help to demonstrate the long-term performance of a repository and contribute to public confidence in the safety of a repository.

To implement option 2, we would initiate a study to evaluate a range of lowprobability potentially disruptive processes and events that could affect the performance of the waste package, to complete a functional analysis, and to establish performance requirements and criteria for a package that can exceed the current regulatory requirements. When these activities have been completed, we would develop alternative conceptual designs. These designs might include simple single-walled containers or complex multilayered packages consisting of different metals and nonmetals (e.g., ceramic liners, which are impervious to corrosion). In pursuing this option it is important to ensure that, in designing to a broader range of repository conditions, including unexpected events, compatibility with the expected conditions is maintained.

Option 3 would allow us to retain option 1 if scientific investigations ultimately indicate that the current design approach is adequate.

In considering the options for the waste package, the issue presented in the next section-allocating performance to natural and engineered barriers-should be included.

\section{APPROACH TO THE DEMONSTRATION OF PERFORMANCE}

In order to issue a construction authorization for a repository, the NRC must find that the site and the design of a repository comply with requirements specified in 10 CFR 60. These regulations require a demonstration of compliance with the standards promulgated for geologic disposal by the Environmental Protection Agency (EPA) in 40 CFR 191. Included in the NRC's requirements are performance objectives for the total repository system - that is, both natural barriers and engineered barriers-as well as each of the system elements.

In a regulatory strategy paper (SECY-88-285), the NRC identified several topics as requiring a rulemaking. One of these topics is demonstration of compliance with the EPA standards. We believe that rulemaking in this case is not appropriate and have advised the Commissioners that this is our position. 


\section{Suggested options for initiating a discussion}

Option 1. We could petition the NRC to change its regulations by specifying only total-system performance objectives, without performance objectives for particular elements of the system.

Option 2. Without petitioning for a change in regulations, we could request the $\mathrm{NRC}$ to abstain from rulemaking on the topic of performance demonstration but to provide us with guidance through regulatory guides.

Option 3. We could hold further discussions with the NRC on the topic and evaluate alternative approaches.

\section{Considerations in selecting options for implementation}

The NRC's regulation is generally not prescriptive, recognizing that a repository has never been built and operated. The regulation states, for example, that, provided the overall system performance objective is satisfied, the Commission may approve or specify performance objectives other than those specified in 10 CFR 60.111, 112, and 113. We fully agree with this philosophy and believe it is prudent to retain the flexibility to propose alternative approaches to demonstrating compliance rather than being required to meet specific interpretations established by rule.

We feel that the topic of demonstrating compliance does not require a rulemaking because 10 CFR 60 will be revised to reflect the revised EPA standards. We also believe that to retain the necessary flexibility, regulatory requirements on the time of ground-water travel, the waste-package lifetime, and limits on releases from the engineered-barrier system should be made guidelines instead. We also believe that in demonstrating compliance with the EPA site performance standard it would be particularly useful to allow credit in the regulatory analysis for an improved engineeredbarrier system.

\section{USING A DEMONSTRATION FACILITY TO INCREASE CONFIDENCE}

As discussed in Section 3.2 under "Phased Licensing for a Repository," we are evaluating a step-by-step approach to repository development instead of attempting to site, design, license, and construct a repository on an aggressive schedule and then emplace considerable quantities of waste as soon as an operating license is received. Proceeding at a more deliberate pace and in smaller, but surer, steps might contribute significantly to confidence that a repository will perform safely over both the near and the long term. One way to implement this step-by-step approach is to develop and license a repository in phases (see page 3-22); another is to include in a repositorydevelopment process a demonstration project that would allow us to develop and 
demonstrate disposal technology with real waste in a geologic setting that is the same as, or similar to, that of the proposed repository. Although we plan to construct an exploratory facility at the depth proposed for a repository, none of the tests conducted in that facility will use actual waste.

The objective of a demonstration project would be to increase confidence, thereby supporting licensing and gaining greater acceptance by the public. It would also significantly increase the amount of site information that is available for licensing.

The role that a demonstration project would play in increasing confidence depends on the type of facility that would be used, the tests that would be performed, and the time at which the demonstrations could be performed.

\section{Suggested options for initiating a discussion}

Option 1. We could perform the demonstration in the exploratory facility that will be built for site evaluation (see Chapter 4). We could start by constructing a ramp to the proposed depth of a repository, excavating repository-size drifts, and boring wasteemplacement holes in which tests would be performed.

Option 2. We could develop an underground research laboratory near, but separate from, a repository block. This research laboratory would be completed before the exploratory facility and would be used for prototype testing, demonstrating the suitability of the rock horizon proposed for a repository, and examining the spatial variability of the rock.

Option 3. We could develop at the Yucca Mountain candidate site a test-andevaluation facility pursuant to Sections 211 and 305 of the Nuclear Waste Policy Act as amended. The Act authorizes the construction of such a facility for demonstrating the technology needed for geologic disposal and for tests related to site evaluation and the operational aspects of waste disposal. For these tests it allows the emplacement of up to 100 metric tons of spent fuel under continuing NRC review. This facility would be used for testing before the construction authorization is received. It would be used only if the Yucca Mountain site is determined to be suitable for a repository.

Option 4. Before proceeding to construct, license, and operate a full-scale repository, we could construct and operate a repository as a pilot-scale facility with limited waste emplacement and licensing in increments.

\section{Considerations in selecting options for implementation}

Option 1 is closest to our current plans. As described in Chapter 4 , we plan to construct an exploratory facility to provide access to the horizon proposed for a 
repository and to provide underground excavations for various tests needed to determine the suitability of the site. In principle, the tests that would be performed in demonstration facilities could be carried out in this exploratory facility. More underground excavation may be necessary to construct repository-sized drifts, and the scope of the testing may be increased.

To implement option 1 -that is, to use the exploratory facility needed for site evaluation as a demonstration facility-a legislative amendment may be necessary since the Nuclear Waste Policy Act as amended (Section 113(c)) restricts the activities to be conducted during site evaluation to those considered "necessary to provide the data required for evaluation of the suitability of such candidate site... ." And, as required by the Act, we would have to obtain the concurrence of the NRC before using radioactive materials. Since at least part of the exploratory facility will be incorporated into a repository, we would also have to ensure and demonstrate to the NRC that neither the development nor the testing in this facility would compromise the integrity of the site or affect the future performance of a repository. A demonstration project in the exploratory facility could allow us to resolve, before the license application is submitted, such issues as the variability of the host rock or the constructability of ramps, shafts, waste-emplacement boreholes, etc.

Because at least part of the exploration-and-demonstration facility would be incorporated into a repository, option 1 would allow some conservation of resources. On the other hand, using the exploratory facility for a demonstration project would cost more than using it as currently planned for site evaluation, and, if the site is later found to be unsuitable, significant resources will have been wasted. In addition, this option might contribute to the perception that we have already "selected" the site for a repository even though most of the site-evaluation program has not been conducted.

Option 2 could be implemented at the DOE's Engine Maintenance and Disassembly (EMAD) test facility. Being near, though not at, the Yucca Mountain candidate site, this facility would allow us to develop and demonstrate disposal technology under conditions analogous to those at the site. Separation from the repository would diminish concerns about affecting the integrity of the site. The use of existing Federal facilities to conduct tests relevant to the activities contemplated in a test-and-evaluation facility is authorized by the Act as amended. What is not clear is whether an underground laboratory constructed at the EMAD facility would be considered an "existing" facility and therefore eligible under Section 217 of the Act as amended. It is also not clear whether the tests in such a facility would entail the emplacement of significant quantities of radioactive material, and, if they did, whether the underground laboratory would become in effect a test-and-evaluation facility. If we do construct an underground laboratory, we will nonetheless have to later construct an exploratory facility at the site for site evaluation because an expiorotary shaft facility is required by NRC regulations. 
Under option 2, the demonstration could precede the construction of the exploratory facility, and less testing would be needed in the exploratory facility for candidate site evaluation. In addition, this option would avoid the perception that the site has been "preselected" and would allow technical issues to be separated from institutional ones. On the other hand, an underground laboratory would add to costs, and these costs would not be recoverable because the laboratory would not become part of a repository. And because of arguments about the representativeness of the data collected away from the site, it might be necessary to duplicate much of the work in the exploratory shaft facility.

Option 3 would allow us to test at an early phase the emplacement of waste in a repository and contribute to our understanding of the waste-package environment. It would require ensuring and demonstrating that the integrity of the site is not compromised, and it would require changes in the site characterization plan. And it may encounter opposition from the State.

In regard to option 3, most important are the restrictions on the time of construction in the NWPA as amended. Because of these restrictions, we would not be able to start constructing a test-and-evaluation facility unless site designation for a repository had become effective (i.e., unless and until the suitability of the site had been determined, the site had been recommended to the Congress, and the State had an opportunity to file a notice of disapproval-see Chapter 4); furthermore, we would not be able to begin constructing any surface facilities for such a project until the construction authorization for a repository has been received. These restrictions limit the usefulness of a test-and-evaluation facility.

Option 4 would contribute to a step-by-step approach to the development of a repository. However, as discussed in Section 3.2, under "Phased Licensing for a Repository," this option would not necessarily facilitate the licensing of a repository.

\section{TIMING AND CRITERIA FOR DETERMINING THE SUITABILITY OF THE CANDIDATE SITE FOR A REPOSITORY}

We have prepared plans for conducting a comprehensive program of scientific investigations to evaluate whether the Yucca Mountain candidate site in Nevada is suitable for a repository. This program will consist of both surface-based tests and tests conducted in an exploratory facility that includes at least one shaft and underground excavations at the depth proposed for a repository.

The surface-based tests are aimed at detecting as early as possible conditions that would be potentially adverse to the performance of a repository at the site. If such conditions are discovered and are shown to have unacceptable effects on performance, 
then we will have to make a finding that the site is unsuitable and report to the Governor and the legislature of Nevada and the Congress of the United States.

The difficulty with site-suitability evaluations is the problem of demonstrating with any reasonable testing programs that possible potentially adverse conditions that do not affect site performance are not present. This problem is particularly severe for sites that have favorable characteristics for waste isolation: stability, low transmissibility for water and gases, and high retardation of the transport of contaminants present in very low quantities. These very properties make it difficult to conduct tests that examine much of the rock (low communication potential).

If no unacceptable conditions are found, we will complete the site-evaluation program and then evaluate the data to determine whether a repository at the site would safely contain and isolate the waste for thousands of years. This determination will be a formal finding that will serve as the basis for recommending the site to the President, who, if he agrees, will recommend to the Congress that the site be developed as a repository. This process is specified by the NWPA as amended.

Before making the formal determination, it may be advisable to make preliminary findings of suitability, and thus timing is an issue that must be addressed by the strategic principle developed for the determination of site suitability. In addition, this principle should address the criteria and method used in the determination.

\section{Suggested options for timing}

Option 1. We could make preliminary evaluations of suitability at regular intervals (e.g., every 24 months) on the basis of the available data.

Option 2. We could make preliminary evaluations of suitability at major program milestones (e.g., before starting to construct the exploratory facility).

Option 3. We could make all of these evaluations.

\section{Considerations in selecting options for implementation}

Option 1 could result in preliminary findings of limited meaningfulness and applicability. It would, however, allow us to make maximum use of information from early testing, including the ability to make early adjustments in our testing and design programs. If our investigations uncover conditions that would make the site unsuitable or licensing extremely difficult, then option 1 might lead to an earlier decision as to the prudence of investing more time and money in the site. In addition, periodic evaluations of suitability would provide a mechanism for keeping management and interested parties apprised of developments in our scientific investigations. And by 
performing periodic preliminary evaluations we would gain useful experience for the formal finding of site suitability. For option 1 to be practical, we would have to conduct the preliminary evaluations in an expeditious manner without impeding the progress of the program.

Option 2 is very similar to option 1 , but it would have the specific purpose of evaluating at major program milestones whether further investment in the site is warranted. Even though it would be preliminary, a formal finding at major milestones might also facilitate licensing. This option, however, would be time consuming.

Option 3 combines the characteristics of the other options.

\section{Suggested options for suitability criteria}

Techniques for evaluating the suitability of sites do exist. They involve the development of criteria for suitability (e.g., a limit of 10 percent on fractures that can transmit significant amounts of water), specifications of probability distributions or ranges of parameters that define the performance measures (e.g., density of connected fractures), sampling these distributions to produce distributions of the performance measures, the use of experimental techniques (e.g., boreholes) to determine the probability that the tests will detect the features associated with these performance measures, and then comparing the results of the tests to make comparisons against the criteria. Such techniques have been successfully applied to analyses of sites in Switzerland.

Option 1. We could apply those aspects of our siting guidelines (10 CFR 960) that are appropriate for evaluating a single site.

Option 2. We could revise the guidelines and use the NRC's licensing criteria in 10 CFR 60.

Option 3. We could revise the guidelines by changing generic guidelines to sitespecific factors.

Option 4. We could revise the guidelines and use criteria developed by external parties.

Option 5. We could work together with affected parties to develop new sitespecific suitability guidelines. 


\section{Considerations in selecting options for implementation}

The selection of options for suitability criteria depends to a considerable degree on the timing of the evaluation. The DOE's siting guidelines call for a comprehensive evaluation of the suitability of the site at the conclusion of the site characterization program. This site-suitability evaluation must be completed before the site is recommended to the President for any repository development. The objective of these site-suitability evaluations is to identify any features that may provide early evidence that the Yucca Mountain site is not suitable, thus avoiding extended investment of time and resources should that be the case. We must decide how such early evaluations will proceed, what criteria and methodology will be used to make findings, and how the status of uncertainties will be evaluated and the testing program will evolve to address these concerns.

For an early evaluation of site suitability, it might be advisable to apply a different set of criteria than that used for determining that the site is indeed suitable. For an early evaluation, a set of "unsuitability" criteria might be more practical. These specific criteria must address: unsuitability in terms of evidence of potentially unacceptable performance of the repository system, which will be provided through quantitative and qualitative performance assessments; unsuitability in terms of evidence of potentially unacceptable changes in site conditions such as might be caused by tectonic or volcanic activity within the repository block; and unsuitability in terms of significant uncertainties that might require too great an investment of time, money, or effort to reduce to acceptable levels.

We are already initiating an intensive effort to develop a set of criteria for the early site evaluations and a methodology for applying these criteria. This effort will involve evaluation of the conditions specified in the siting guidelines of 10 CFR 960; performance assessments; and a series of expert panels to develop unsuitability measures and criteria in terms of those measures, methodology for applying those criteria, and a pilot study to test the feasibility of the approach. At the same time, independent efforts by the Electric Power Research Institute and by Golder Associates to develop a suitability methodology are underway, and we will compare and evaluate such independent approaches to develop the DOE strategy.

Another key issue relating to site suitability is the status of data and uncertainties and the testing program to address those uncertainties. We are prioritizing the surfacebased and in-situ testing programs to address these concerns.

The guidelines referred to in options 1 and 3 were generic guidelines developed in response to a requirement in the NWPA. They were used in evaluating the nine potentially acceptable sites for the first repository, in nominating five sites as suitable for characterization, and recommending three sites for characterization. They are 
based on, and closely similar to, the NRC's siting criteria in 10 CFR 60 . The development of these guidelines included broad involvement by the affected parties, comment by the public, and concurrence by the NRC. The application of the guidelines might not be practical for early evaluations since for a number of guidelines establishing that a qualifying condition is met may require extensive data from underground testing.

Option 2 is similar to option 1 because the guidelines are derived directly from the NRC's technical criteria.

Options 3 and 4 are similar, except that the latter involves criteria developed independent of us. If either of these options is chosen, it may be necessary to develop two sets of criteria: those to be used early in the process (i.e., before the construction of the exploratory facility) to make sure that no disqualifying conditions are present at the site (i.e., "unsuitability" criteria) and those to be used after site evaluation to determine whether the site is suitable. Alternatively, we could use a set of "unsuitability" criteria, developed by us or another party, for the early determinations and the siting guidelines for the suitability evaluation at the end of the site-evaluation program.

Option 5 would expand opportunities for input from affected parties, but would also increase the difficulty of reaching a timely conclusion.

\section{GEOLOGIC DISPOSAL FOR WASTES OTHER THAN SPENT FUEL AND HIGH- LEVEL WASTE (GREATER-THAN-CLASS C WASTES)}

The NRC has defined three classes-A, B, and $\mathrm{C}$-of low-level radioactive wastes in order of increasing radiation hazard and longevity. Wastes that exceed the radioactivity concentrations permitted for Class $\mathrm{C}$ are known as "greater-than-Class-C wastes." They come from a wide variety of sources, including the operation and decommissioning of reactors, medical activities, and research. They vary in their physical characteristics, composition, and radioactivity. At present, these wastes are kept in storage at the sites where they are generated.

The actual quantities and characteristics of greater-than-Class-C wastes are very uncertain at present, but it is known that a significant portion of these wastes are "mixed wastes"-that is, wastes that contain both radioactive materials and hazardous chemical substances as defined in the Resource Conservation and Recovery Act (RCRA) of 1976. We are currently conducting a comprehensive study directed at determining the quantities and characteristics of these wastes.

The Department of Energy, through DOE's Office of Environmental Restoration and Waste Management, is responsible for the disposal of greater-than-Class-C wastes 
under the Low Level Waste Policy Amendments Act of 1985. (Management of greater-than-Class-C wastes is not covered under the Nuclear Waste Fund established by the NWPA.) In the past, DOE has proposed providing for such waste special "intermediate-level" disposal-that is, disposal at depths on the order of 100 feet below the surface. Such disposal would provide greater isolation than do low-level-waste sites but would be much less costly than a repository.

Responsibility for classifying wastes and determining which wastes require geologic disposal rests with the NRC. The NRC has not determined that greater-than-Class-C wastes require geologic disposal. However, in its rule on the disposal of low-level wastes, 10 CFR 61, the NRC proposed geologic disposal for these wastes "unless proposals for the disposal of such waste in a disposal site licensed pursuant to (10 CFR 61) are submitted to the Commission for approval." We have encouraged the NRC to resume the effort of redefining the classes of radioactive wastes, distinguishing between greater-than-Class- $\mathrm{C}$ wastes that require geologic disposal and those that do not require such costly disposal.

\section{Suggested options for initiating a discussion}

Option 1. We could complete the characterization of greater-than-Class-C wastes. We should then evaluate how much space these wastes would require in a repository, how they might affect licensing, and how they might affect the performance of the repository.

Option 2. We could petition the NRC to develop specific performance criteria for the packaging and emplacement of these wastes, regardless of the method of disposal. We should also petition the NRC to identify the greater-than-Class-C wastes, if any, that should be isolated in a repository.

Option 3. We could petition the NRC to develop specific regulations for the disposal of greater-than-Class-C wastes.

Option 4. We could start planning to accept some greater-than-Class-C wastes in the first repository.

Option 5. DOE's Office of Environmental Restoration and Waste Management could start planning to develop special "intermediate-level" facilities for these wastes.

Option 6. We could defer planning for the disposal of these wastes until the decision on the need for a second repository is made. We could then plan to emplace all these wastes in a second repository if one is needed. 
Option 7. We could plan to provide interim surface storage for these wastes.

\section{Considerations in selecting options for implementation}

The first part of option 1 should be implemented regardless of what other options are selected because planning for the management and disposal of these wastes is not possible without reliable estimates of quantities and characteristics. Option 2 should also be implemented. Although the NRC, in response to a request from us, is evaluating requirements for packaging and emplacement, their evaluation is based on geologic disposal, which may preclude other options. Option 3 would be necessary if DOE decided to develop special intermediate-level facilities for these wastes (option 5).

The decision to emplace greater-than-Class- $\mathrm{C}$ wastes in the first repository (option 4) could substantially affect the planning and design of the repository. This judgment cannot be made until the quantities and characteristics of the wastes have been defined. It would also be necessary to establish whether the statutory loading limit for the first repository (no more than 70,000 metric tons of heavy metal may be emplaced until the start of waste acceptance at a second repository) pertains to greater-thanClass waste.

Other factors that need to be evaluated in considering option 4 include the following:

1. Determining how the receipt of these wastes would affect the design of the surface facilities of a repository since these wastes would be in a different configuration than spent fuel and high-level waste, because they would require packaging into uniform containers, and because in some instances they might require supplemental shielding.

2. Determining how these wastes would affect the operational safety of a repository, both for repository workers and the public.

3. Determining the mode of emplacement: should a separate area be designated for these wastes; should the containers of these wastes be inserted into boreholes, like spent fuel and high-level waste; should they be placed on the floors of the disposal rooms and access tunnels after a repository has been filled with spent fuel and high-level waste.

4. How would the emplacement of these wastes affect the retrievability of all wastes should retrieval be necessary?

5. Determining whether and how the presence of chemicals and organic substances in these wastes would affect the performance of a repository through the 
generation of gases, interactions with other waste materials, interactions with ground water and the host rock, etc.

6. Determining how the emplacement of these wastes would complicate the licensing of a repository because of the considerations stated in item 5 above.

7. Determining how the need to comply with the RCRA would complicate the demonstration of regulatory compliance.

8. Determining how the factors listed above would affect the repository schedule.

Before implementing option 4, it would be necessary to develop a fee structure for wastes from sources other than commercial nuclear reactors and a method for paying the fee. Unless this is done at an early stage of planning, complaints from the contributors to the Nuclear Waste Fund and State public utility commissions are to be expected,

Option 4 also has institutional implications, and is likely to complicate further our difficulties in obtaining the environmental permits needed for site evaluations.

Option 5, the "intermediate-level" facilities mentioned in the introduction to this issue, would provide the required isolation in facilities less expensive than a repository. It would require the siting of a separate facility, which is a difficult task at best.

Option 6 would be attractive if it is determined that a second repository is needed. (The NWPA as amended requires us to advise the Congress on the need for a second repository between the years 2007 and 2010.) It would allow ample time for study, preparation, and planning. It would also allow us to benefit from the experience of the first repository and hence to be better prepared in resolving licensing and regulatorycompliance issues specific to "greater-than-Class-C" wastes. And it would obviate the need for siting a third waste-management facility-a facility for the disposal of greaterthan-Class- $C$ wastes.

Option 7 is premature at present. It should be considered only after these wastes have been completely characterized and requirements for their disposal have been established.

\section{RISK ASSESSMENT IN SELECTING TRANSPORTATION MODES AND PREFERRED ROUTES}

We are taking various steps to ensure the development of a comprehensive program for the assessment and management of transportation risks. These steps include the development, enhancement, or evaluation of various computer models, 
including models based on well-established probabilistic techniques of risk assessment. To support these models, we are also developing a transportation data base; this includes the preparation of a standard reference document for transportation assumptions, the collection of data on accident rates for rail and road transport, and the development of risk factors for national transportation network analyses.

We have kept the Nuclear Waste Technical Review Board (NWTRB) informed regarding our work in the development or revision of computer models and codes, and the Board has responded with comments and suggestions. We anticipate a similar working relationship with the NWTRB regarding the development of plans for the application of these models and codes.

The methods and models used for risk assessment could be applied to the selection of transportation modes (truck or rail) and preferred transportation routes. We have not yet made a final determination about transportation modes. However, it is currently our intent to ship waste by rail where possible. For shipments from the MRS facility to the repository, we currently plan to use dedicated trains.

\section{Suggested options for initiating a discussion}

Option 1. We could use risk assessment as the primary method of selecting transportation modes.

Option 2. We could use risk assessment as the primary method of identifying preferred transportation routes.

Option 3. We could use risk assessment as a tool in supporting decisions on transportation modes and routes.

Option 4. We should not use risk assessment in these transportation applications.

\section{Considerations in selecting option to be implemented}

Generally, the transportation mode selected will depend on waste quantities, distance, routing, economics, and overall logistics as well as rail access at the facilities from which waste is to be accepted. Risk assessment may not be essential for purely technical purposes as the primary method of selecting modes (option 1) because the selection can be based on simpler methods and readily available data on rail and truck accidents. However, risk assessment may nonetheless be useful as the primary method of selecting modes because it is a tool that clearly establishes the basis for decisionmaking, clarifies selection criteria and thereby facilitates communication with external parties, and can serve to enhance public confidence in the program. 
One problem with option 2 is that risk assessment may not be useful as the exclusive or primary means of identifying preferred routes. The risks associated with transportation are very low, and the uncertainties in the analysis are considerable because the model used in the assessments makes generic assumptions about certain conditions, such as the population density in rural and urban areas. The results would therefore not be useful discriminators among routes. In selecting routes, safety will be the primary consideration. Still, as above, the use of risk assessment could serve to improve decisionmaking, communication, and public confidence.

Option 3 would afford us the benefits of using risk assessment as a supporting measure for decisions on modes and routes. It would be necessary to determine what weight it should be given as a decision factor and how it relates to other factors, but this could augment decisionmaking, communication, and public confidence.

Option 4 would deny us the use of a tool that can be useful as a supporting measure, with a potentially negative impact on decisionmaking, communication, and public confidence. However, this would conserve resources that might otherwise be committed to risk assessment.

\section{MANAGEMENT ISSUES}

\section{SHARING OF DATA ON A TIMELY BASIS}

It is our intention to make the technical data collected in our program available to any and all concerned parties, including the affected States, local governments, and Indian Tribes; the NWTRB and any other oversight entities that might be established; the Nuclear Waste Negotiator; and the NRC. To share the data on a timely basis we must implement a system for data management that allows access to data in an efficient and effective manner.

\section{Suggested options}

Option 1. We could make raw data and supporting information available to all concerned parties as soon as is practical after data acquisition.

Option 2. We would release data only after they have been processed, reduced, and analyzed.

Option 3. We could release data along with analyses and conclusions as formal published reports. 


\section{Considerations in selecting options for implementation}

In regard to options 1 and 2 , it must be remembered that in the collection and treatment of data the ultimate purpose of the data will be to support an evaluation of site suitability and, if the site is suitable, in preparing a license application to the NRC. As such, the control and assurance of the quality of the data must remain paramount in the management and dissemination of data to interested parties. While access should not be restricted to any data, we must be able to certify those data to be used in determining suitability and in the license application and to justify the dismissal of data not used, whether suspect for technical or quality-assurance reasons.

Also, scientific investigators consider that they have the right to present or publish data, analyses, and interpretations, and the premature release of data jeopardizes this right. The publication and presentation of project data and results in peer-reviewed journals and at professional conferences by scientific investigators also contributes to the credibility of the project. For these reasons, we should allow examination of the data as they are acquired, but limit dissemination of data until such time as the investigators and we are satisfied with its quality and initial analyses and interpretations are complete.

On the other hand, predecisional data release demonstrates our spirit of cooperation and is necessary to those organizations with oversight roles. Decisions regarding system and site suitability, in particular, will rest on consensus in the interpretation of the data by both oversight organizations and DOE.

\section{INSTITUTIONAL ISSUES}

\section{TIMING AND MEANS FOR PREDECISIONAL PARTICIPATION BY AFFECTED AND INVOLVED PARTIES}

Success in our waste-management program requires the participation and involvement of external parties. The external parties include both potentially affected parties, such as States, local governments, and Indian Tribes, and involved or interested parties, such as the utilities or public-interest groups. Since their involvement and participation are required by law, affected parties have a special status in the program.

Secretary Watkins has repeatedly made clear his intention to establish a DOE culture that is open and responsive to the concerns of interested and affected parties. He has begun to deliver on his promises by involving external parties extensively in planning for the cleanup of DOE sites and the national energy strategy. We have made similar commitments.

In order for external-party involvement truly to build consensus and lend expertise 
to the program, we need to go beyond information sharing through publications, information offices, electronic data bases, and speeches and briefings. We must implement fully the new policy of external participation in our programs, by actively seeking out and providing opportunities for meaningful participation. The issue is the form of that participation.

\section{Suggested options for initiating a discussion}

Option 1. We could attempt to establish a partnership in which Federal, State, and local governments jointly develop decision alternatives for the program in consultation with the public.

Option 2. We could establish mechanisms for predecisional dialogue.

Option 3. We could limit involvement to postdecisional dialogue.

\section{Considerations in selecting options for implementation}

Option 1 would mean that external parties would be involved in the earliest stages of policy development and would be equal partners in decisionmaking. To implement this option, a mechanism would have to be found for integrating affected parties into the program. Although participation by affected parties is mandated by law, responsibility for the program remains ours. Furthermore, in view of the controversial nature of our program, direct, integrated involvement would interfere with the independence of the affected parties in their oversight role.

In option 2, we would discuss alternatives with affected parties before making decisions and use their input. This would allow external parties the opportunity to present information at an early stage of the decision making process. Such a dialogue could be established through informal workshops held after we provide the external parties with advance copies of our predecisional papers.

In option 3, we would maintain a dialogue with external parties, requesting comments and issuing comment-response documents. This option would limit opportunities for meaningful involvement and ability to influence decisions.

\section{GAINING PUBLIC ACCEPTANCE OF WASTE TRANSPORTATION}

Although the shipment of radioactive materials in the United States has an outstanding safety record, concern about the transportation of radioactive waste remains a dominant issue. To allay these concerns, we are communicating to the general public information about the safety features of our transportation program, including the characteristics of the shipping casks; the safety procedures to be 
implemented for every shipment; and our commitment to compliance with all applicable Federal regulations. Furthermore, before starting any shipments, we expect to be able to learn from the transportation of wastes to the DOE's Waste Isolation Pilot Plant in New Mexico.

\section{Suggested options for initiating a discussion}

Option 1. We could continue with the current interactions under way in both the technical and institutional elements of the transportation program.

Option 2. We could increase those activities in our program that are directed at demonstrating the safety of transportation.

Option 3. We could increase public information and interaction efforts on a much larger scale, increase the opportunities for.meaningful involvement by affected and interested parties, and increase awareness of the efforts undertaken.

\section{Considerations in selecting options to be implemented}

The options listed above are not mutually exclusive, and all three in combination are needed to achieve the stated goal. The effort to increase public acceptance of transportation could involve initiatives related to option 1 , such as increased opportunities for external participation in planning the development and operation of the transportation program; initiatives related to option 2, such as full-scale testing of the ability of shipping casks to retain their integrity under severe accident conditions; and initiatives related to option 3 , such as widespread public education about measures used to ensure that waste transportation will not pose any significant hazard to public health or safety.

\section{EMERGENCY-RESPONSE PLANNING AND TRAINING}

We are developing a program plan and policy to implement the requirements in Section 180 (c) of the NWPA as amended, which requires us to provide technical assistance and funds to States for training the public-safety officials of local governments and Indian Tribes through whose jurisdictions waste shipments will pass. The plan will incorporate issues raised by the regional groups overseeing our transportation activities. It will address both routine transportation and assistance for accidents requiring emergency response.

The major issue related to our responsibilities under Section $180(\mathrm{c})$ is the timing of assistance for training in emergency response.

Suggested options for initiating a discussion 
Option 1. We could start assistance 3 to 5 years before shipments begin.

Option 2. We could start assistance immediately.

Considerations in selecting options to be implemented

For emergency-response training to be successful in the many States through which waste shipments will pass, the resources allocated to this activity should be used judiciously. Timing is very important in this regard. Our current plan is to implement option 1, which we believe allows sufficient time for public-safety personnel to receive adequate training. For shipments from reactor sites to an MRS facility, this means starting assistance between 1993 and 1995. Starting assistance immediately, as in option 2, would be premature, and a considerable number of the trainees might not stay in positions warranting the training.

\subsection{ISSUES RELATED TO THE STEWARDSHIP OF RESOURCES AND THE EFFECTIVENESS OF OPERATIONS}

Of the strategic issues that have been identified, eight are related to the stewardship of resources and the effectiveness of operations. As shown below, three of these issues are technical, and the rest are in the management category.

Technical

- Development of dual-purpose casks for transportation and for storage.

- Contingency planning for the event that the Yucca Mountain site is found to be unsuitable for a repository.

- Phased licensing for the repository.

\section{Management}

- Roles of utilities and the Federal Government in the management of spent fuel before disposal.

- Private-sector involvement in the development and operation of an MRS facility.

- Use of the Nuclear Waste Fund for storage.

- Use of peer reviews. 
- Alternative means of managing the waste-management program.

\section{TECHNICAL ISSUES}

\section{DEVELOPMENT OF DUAL-PURPOSE CASKS FOR TRANSPORTATION AND FOR STORAGE}

A dual-purpose cask is a vessel that can be used for both transporting and storing spent fuel. It is much like the metal casks currently used for dry storage. Its use for the dual purpose of transporting and storing has not been certified by the NRC, and some certification issues remain to be resolved. However, Virginia Power, the Electric Power Research Institute, and a cask vendor (NAC) are currently involved in obtaining an NRC certification for a dual-purpose cask.

We are considering the use of dual-purpose casks for the first phase of an MRS facility. These casks would allow earlier waste acceptance because they could be shipped to an MRS site and stored in a simple storage yard. Since the fuel shipped in them does not need to be unloaded or handled in any way, they would permit waste acceptance before the waste-handling building of an MRS facility is completed.

However, these casks are not at present included in our program to develop casks for transportation from reactor sites. Our decision on the use of dual-purpose casks will be based on their safety, cost effectiveness, usefulness in the waste-management system, feasibility for the intended use, the use of these casks by utilities, and regulatory issues. We expect to make our decision in 1991.

\section{Suggested options for initiating a discussion}

Option 1. We could abstain from including any dual-purpose casks in our shippingcask fleet.

Option 2. We could include a limited number of dual-purpose casks in our caskdevelopment program for the initial phase of MRS operations.

\section{Considerations in selecting options for implementation}

Option 1 represents our current cask-development program: it does not include dual-purpose casks.

Option 2 could be used to provide early acceptance for a limited amount of spent fuel at an MRS facility. It raises several issues that we are evaluating. We will first consider the overall system costs and benefits. We will also examine the issues associated with safety and NRC certification in particular. If these issues cannot be resolved quickly enough to permit us to acquire a sufficient number of the casks by 
1998, then there will be no advantage in developing these casks. If these issues are satisfactorily resolved, we will determine if cooperative projects with industry should be funded to further develop and utilize dual-purpose casks.

\section{CONTINGENCY PLANNING FOR THE EVENT THAT THE YUCCA MOUNTAIN CANDIDATE SITE IS FOUND TO BE UNSUITABLE FOR A REPOSITORY}

As discussed in Chapter 4 (see page 4-2), we are evaluating whether the Yucca Mountain candidate site in Nevada is suitable for a repository. To complete this evaluation we plan an extensive program of testing both from the surface of the site and underground, at the depth proposed for a repository. Issues related to the determination of suitability have been discussed earlier in this chapter.

We were directed to evaluate the Yucca Mountain candidate site by the NWPA as amended. This law also specifies that if the Yucca Mountain site is found to be unsuitable, then we must notify the Governor and the legislature of the State of Nevada and recommend to the Congress, within 6 months, actions that should be taken to ensure safe disposal. We are inhibited from making site-specific recommendations by the NWPA, which prohibits us from continuing any investigations at, or any studies of, other sites that had been included in the repository program. Thus, we would not be able to recommend specific alternatives to the Yucca Mountain candidate site, but we have identified a number of actions we can take.

\section{Suggested options for initiating a discussion}

Option 1. We could abstain at present from specific actions to prepare for the possibility that the Yucca Mountain site might prove to be unsuitable, other than responding to requests from the Nuclear Waste Negotiator.

Option 2. We could increase our participation in international scientific investigations of disposal to be better prepared for considering host rocks other than the volcanic tuff present at Yucca Mountain.

Option 3. We could change our approach to the development of the waste package: instead of developing a design specific to the Yucca Mountain candidate site, we could develop waste-package designs suitable for a variety of potential host rocks.

Option 4. We could identify, on the basis of available information from our earlier activities and data from international programs, host rocks and areas that might provide potentially suitable sites for a repository.

Considerations in selecting options for implementation 
In option 1, we would do nothing in the way of contingency planning at present. If the Yucca Mountain candidate site is found to be suitable, this option would represent the best use of resources. Should the site prove to be unsuitable, we would support a process by the Nuclear Waste Negotiator to locate a volunteer host with a technically suitable site. We would be prepared to provide any support the Negotiator may request. For example, we would be ready to provide to the public information on the design, operation, and long-term safety of a repository. We would conduct socioeconomic analyses to answer concerns that may be raised during negotiations with potential hosts. And we would prepare, at the request of the Negotiator, an environmental assessment of any site that is the subject of negotiations.

Options 2, 3, and 4 are not mutually exclusive. They represent opportunities to improve our position if the Yucca Mountain candidate site is found unsuitable and the Congress directs us to investigate other sites. Option 3 might give us a significant advantage in terms of readiness for repository development at other sites. It is, however, costly; furthermore, there is a possibility that a generic approach would result in a waste package with inferior performance in comparison with a site-specific design.

\section{PHASED LICENSING FOR THE REPOSITORY}

As specified in the NRC regulations in 10 CFR 60 , the licensing of a repository will include authorization to construct a repository; a license to receive and possess radioactive waste at the site, to be issued after the repository is constructed; and an amendment of the license permitting the repository to be decommissioned and permanently closed. One reason for phasing the licensing in this manner is to allow the NRC to evaluate additional information about the expected safety performance of the repository.

Since a repository is a first-of-its-kind facility, its licensing, especially the first phase, is expected to be the most difficult challenge of the repository program, and the information included in our license application may be deemed insufficient for a favorable finding. To increase the probability that we will be able to provide the information required for licensing we are evaluating a number of options, including several that are based on licensing the repository in phases.

\section{Suggested options for initiating a discussion}

Option 1. If the site is determined to be suitable, we could seek to obtain a construction authorization for a full-scale repository, as assumed in our current plans.

Option 2. Instead of attempting to obtain a construction authorization for a fullscale permanent repository, we could attempt to first license pilot-scale facilities at a repository site. These pilot-scale facilities would be used to obtain information needed 
to complete and refine the design of a repository and a waste package, and to conduct tests in order to collect more data for the next licensing phase. They would be eventually scaled up to a repository subject to additional licensing.

Option 3. We could petition the NRC to divide the licensing process into two distinct phases. In the first phase we would seek to receive a construction authorization, under 10 CFR 60 , for a temporary storage facility in the underground repository. This facility would not be licensed as a repository. In the second phase, which would occur years later, we would seek a license for a repository.

Option 4. We would seek to license a repository, but we would use the approach of incremental licensing for individual blocks of underground waste-emplacement areas, using waste-acceptance procedures and criteria agreed upon by the NRC.

\section{Considerations in selecting an option for implementation}

Except for option 1, none of these options precludes the use of demonstration facilities or of improved engineered barriers, which were discussed in Section 3.1.

Option 1 represents the approach we have been following since the NWPA. The licensing of a repository, a first-of-a-kind undertaking with unprecedented requirements, represents one of the greatest challenges in the program.

Option 2 would involve developing and licensing a repository in steps. It differs from the current approach only as to scale. It is not clear, however, whether the demonstrations possible for a pilot-scale facility will be sufficient to obtain a license. This option allows an extended evaluation of repository performance with actual spent fuel. Unless the performance is satisfactory, the facility would not be converted to a repository.

Option 3 would require an amendment to 10 CFR 60 . The first phase of licensing, for the storage facility, would not involve any demonstrations of long-term performance; it would be concerned only with operational safety in the receipt, handling, and emplacement of waste. Eventually, after the waste has been emplaced and monitoring has indicated that the performance of the repository and the waste package is as expected, we would seek a license for the repository. This license would be concerned only with the long-term performance of a closed repository since all active repository operations would have been conducted in the first phase.

Option 4 represents a novel approach to the licensing of a repository, but not to its development. We currently plan to develop a repository in blocks, with waste emplacement beginning in one block while another block is being excavated. Licensing waste emplacement in blocks would have some of the advantages of a demonstration 
project, with the NRC evaluating the performance of a filled block before allowing waste emplacement to begin in another block. This approach resembles the pilotplant approach of option 2. It might help increase public confidence in the safety of a repository because of the cycle of limited waste emplacement and regulatory evaluation.

Options 2 and 3 , and possibly option 4 , would require legislative amendments.

\section{MANAGEMENT ISSUES}

\section{ROLES OF UTILITIES AND THE FEDERAL GOVERNMENT IN THE MANAGEMENT OF SPENT FUEL BEFORE DISPOSAL}

This issue concerns the appropriate and effective distribution of responsibilities between the Federal Government and the utilities in the management of nuclear fuel before disposal in a repository.

\section{Suggested options for initiating a discussion}

Option 1. Utilities are responsible for the storage of spent fuel until the fuel is transferred to the Federal Government. Transfer occurs when the spent fuel is loaded into government-owned transport casks and leaves the reactor site for a Federal wastemanagement facility.

Option 2. Utilities store spent fuel and also prepare it for further storage or disposal in a Federal waste-management facility in order to facilitate the operation of Federal facilities. Two variations are available for implementing this option: (1) the utilities retain title to the spent fuel and perform the waste preparation under contract to us or (2) they transfer title to us before preparing the fuel.

Option 3. Utilities are responsible for providing for spent-fuel storage until we pick up the fuel. However, for storage after 1998 we would pay with monies from (1) the Nuclear Waste Fund or (2) general revenues.

Option 4. After a specified date, we assume responsibility for, and take title to, spent fuel at the reactor sites. Until transferred to a Federal facility, the fuel would remain in storage at the reactor site in (1) a utility storage facility or (2) a storage area controlled by us.

Option 5. Utilities are directed to collect and store spent fuel at a small number of commercial-reactor sites as (1) part of Federal waste management, with costs paid from the Nuclear Waste Fund, or (2) at their own expense. 


\section{Considerations in selecting options for implementation}

The most important consideration in the choice of these options will be ability to start shipping waste to a central storage facility, such as an MRS facility, in 1998. If spent-fuel transfer to a central facility cannot begin as currently planned, it will be necessary to develop substantial additional capacity for storage at all or some reactor sites. Furthermore, options 3, 4, and 5 would be considered only if timely transfer is not feasible.

Option 1 is consistent with current planning for the Federal waste-management system and the existing institutional, contractual, and legal structure. However, if the schedule linkages between an MRS facility and a repository are not changed and we therefore cannot start accepting spent fuel in 1998, this option could lead to a substantial requirement for additional at-reactor storage and a potential proliferation of alternative storage technologies, which could complicate the transfer of spent fuel to the Federal system.

Option 2 is like option 1 except for the waste-preparation operations. The preparation could consist of consolidating spent-fuel rods into tighter arrays, loading spent fuel into canisters, or even encapsulation into disposal containers suitable for emplacement in a repository. If properly coordinated, the decision to prepare waste at reactor sites could lead to standardization, such as the use of uniform canisters. This would simplify spent-fuel transfer to the Federal system and preclude the proliferation of different storage and waste-packaging technologies. However, such operations do raise concerns about liability and the potential for disrupting the operations of the reactor plant. Furthermore, requirements for disposal packaging will remain unclear until the design of waste packages for permanent disposal has been completed and licensing issues have been resolved.

Options 3 and 4 would require changes in the contract and legislation. Option 3 may raise concerns that our controlling or managing storage at reactor sites would interfere with the operations of the reactor plants.

Option 5 would require legislation or an initiative by the utilities. If it is considered, liability for activities that may disrupt the operations of the host reactor site would be of concern.

\section{PRIVATE-SECTOR INVOLVEMENT IN THE DEVELOPMENT AND OPERATION OF AN MRS FACILITY}

Discussions and descriptions of an MRS facility have been based on the assumption that, like other DOE facilities, an MRS facility would be owned by the Federal Government and operated by a contractor. However, the private sector could be 
responsible for the development and operation of the facility.

The issue here is the privatization of the MRS facility, and four options have been identified. A closely related and important issue is funding for the commercial facility, which is presented later (see page 4-7). If the Nuclear Waste Fund cannot be used for its development, the facility will not be supported by the utilities.

\section{Suggested options for initiating a discussion}

Option 1. The MRS facility should continue to be a federally owned facility operated by a contractor.

Option 2. A storage facility could be sited, constructed, and operated by private industry. The utilities would contract directly with the owner of the facility for spentfuel storage.

Two variations are possible for option 2:

1. The facility could be developed by private industry, as in option 1 , but, we, instead of the utilities, would purchase storage space and services. The utilities would deal with us.

2. We would lease storage space from the private developers of an MRS facility and hire a contractor to operate the facility for us.

\section{Considerations in selecting options for implementation}

Option 1 represents current plans for the development of an MRS facility. Option 2, a facility developed by private industry, would have similar benefits as option 1 for waste management. For example, if fully used, privately developed facilities could reduce the potential for the proliferation of different storage technologies at reactor sites. The use of various storage technologies could complicate for the receipt and handling of spent fuel at a repository. A fully used commercial storage facility would lead to standardization of design.

The siting of a commercial facility may be easier because the private sector may have more latitude in negotiating with a potential host and is not subject to the negative perceptions associated by many with the Federal Government. Nonetheless, we recognize that the siting of a commercial facility for radioactive waste storage may be as controversial as that of Federal facilities.

With a commercial storage facility, waste acceptance and transportation will be the responsibility of the facility operator or the utility. This may entail additional costs for 
the utilities, and transportation by private contractors or the utilities may elicit more opposition than transportation by the Federal Government. And it is not clear that the Congress would authorize funding from the Nuclear Waste Fund, especially if the commercial facility would service only a limited number of utilities. In any case, the use of funds from the Nuclear Waste Fund will require new authorities and will raise questions of equity.

Privatization would not contribute to the development and operation of the Federal waste-management system. As explained in Chapter 4, the currently envisioned Federal MRS facility would be fully integrated into the waste-management system, and its development is expected to bring considerable benefits to the whole system as well as to demonstrate that the Federal Government can successfully address the waste problem. These benefits would not be provided by privately developed storage facilities.

\section{USE OF THE NUCLEAR WASTE FUND FOR STORAGE}

If an MRS facility is developed as an integral part of the waste-management system and the acceptance priorities for spent fuel are based on the current contract with the utilities, then there seems to be no question that the Nuclear Waste Fund should be used to pay for its development and operation. However, as discussed in the preceding sections, a number of other options for providing storage could be used, and the means for paying for their costs should be determined.

\section{Suggested options for initiating a discussion}

Option 1. An MRS facility is developed as an integral part of the Federal system. All of the costs of this option are paid from the Nuclear Waste Fund.

Option 2. An MRS facility is developed as an integral part of the Federal system. The costs of MRS development are paid for from the Fund, but the utilities using it for storage pay for the incremental operating costs of storage from the start of waste acceptance, assumed to be in 1998 , to the start of operations at a repository.

Option 3. An MRS facility is developed to provide storage for utilities needing additional capacity. The full costs of development and operation are borne by the users.

Option 4. The Fund is used to develop and operate commercial storage facilities or facilities provided at selected reactor sites.

\section{Considerations in selecting options for implementation}

Option 1 represents our current plan. Option 2 differs from option 1 in that the 
incremental costs of storage are paid for by the utilities using the facility. Because of the systemwide benefits of the MRS facility, its development is paid for from the Nuclear Waste Fund.

Option 3 is essentially the user-funded MRS facility recommended by the MRS Review Commission in its report to the Congress.** Under this option, an MRS facility would be developed solely for the purpose of providing additional storage for utilities that need additional storage capacity after 1998, prefer not to develop it at their reactor sites, and are willing to pay for it. Such a facility would not be a part of the Federal waste-management system, and it is unlikely that a sufficient number of utilities would commit themselves to funding such a facility. If they did, the Department might consider buying it from them for use as part of the Federal system after the repository starts operating.

Option 4 would require changes in the Nuclear Waste Policy Act as amended. It may also elicit opposition on grounds of equity and cost effectiveness.

\section{USE OF PEER REVIEWS}

A peer review is a documented critical review performed by persons who have technical expertise in the subject matter of concern but are not directly involved in the analysis, study, or plan under review. Peer reviews are management tools for interpreting and verifying or validating assumptions, plans, results, or conclusions critical to the success of a program. Although the following discussion is directed at the Yucca Mountain project, peer reviews will be used as appropriate in other parts of our program.

Since our program has traditionally relied on peer reviews, the issue here is not instituting peer reviews as a new practice. Rather, it is a question of establishing guidelines for the use of peer reviews.

\section{Suggested options for initiating a discussion}

Option 1. Conduct special peer reviews as necessary on high-visibility issues of critical importance to ensure that the best available resources are mobilized for key decisionmaking.

Option 2. Institute regular peer reviews in the routine conduct of the program such as the certification of data, comment on research conclusions, etc.

\footnotetext{
**Report of the MRS Review Commission, November 1989.
} 


\section{Considerations in selecting options for implementation}

Peer reviews yield multiple benefits. The expert appraisal of plans, methods, analyses, and results bolsters technical confidence, and the use of recognized independent authorities strengthens our credibility. Peer reviews may also generate fresh ideas and approaches to problems. However, peer reviews are generally limited in scope and duration, and they may not be sensitive to regulatory, institutional, and management concerns. In responding to their results, we must consider these other factors and communicate their role in the response.

The benefits and costs of a peer review should be compared before the review is initiated. Furthermore, the use of peer reviews should be viewed in the context of other review mechanisms that are present. For example, plans, procedures, and reports receive extensive internal technical reviews by the national laboratories and participating contractors, by our project offices, and by other DOE organizations. These reviews may carry a document through several cycles of qualified technical review. In addition, reviews are performed by the NRC staff, the NWTRB, and affected parties (e.g., the State of Nevada).

Beyond the completion of the review, we must make a commitment to respond to the recommendations of the review and incorporate those deemed appropriate into our plans and operations.

\section{ALTERNATIVE MEANS OF MANAGING THE WASTE-MANAGEMENT PROGRAM}

Several alternative approaches to managing the program were identified and evaluated in response to the requirements of the Nuclear Waste Policy Act by an advisory panel that submitted its report to the Secretary of Energy in December 1984.*** The panel's report was reviewed by a senior DOE group.

The panel identified several options for managing the program, but its preferred option would have required amending the NWPA. Because spokespersons for both the States and the utilities had advised strongly against attempting any amendments to the Act at that time, the DOE review group concluded that no major organizational changes should be initiated until several significant program milestones had been completed. Furthermore, the DOE review group concluded that most of the problems faced by the program were inherent in the nature of radioactive-waste management and the NWPA and could not be solved by changing the nature of the organization or

\footnotetext{
***Report of the Advisory Panel on Alternative Means of Financing and Managing Radioactive Waste Facilities, December 1984.
} 
management.

\section{Suggested options for initiating a discussion}

The following options for managing the program were identified in 1984 by the advisory panel:

Option 1. The present management structure is retained.

Option 2. An independent Federal agency or commission is established to manage the program.

Option 3. A mixed public-private corporation is established.

Option 4. A private corporation is established.

\section{Considerations in selecting options for implementation}

The panel concluded that several organizational forms would be more suited than the DOE for managing the construction and operational phases of the program. The option preferred by the panel was the creation of an independent Federal corporation. The panel also concluded that no modification of the DOE/OCRWM organization would provide adequate stability and continuity.

The issues identified by the panel have since been repeated by other parties. Most often cited are the DOE's credibility problems, lack of internal flexibility, and lack of cost-effective management. It was partly in response to such comments that the Secretary undertook a comprehensive reassessment of the program in 1989 and implemented a number of initiatives directed at enhancing the management of the program. They included direct-line reporting from the Yucca Mountain project office to the OCRWM Director, the appointment of a permanent OCRWM Director, consolidation of contracts, and an independent review of the management structure and procedures. Additional initiatives for improving management systems, including a reorganization of the OCRWM, have since been implemented by the OCRWM Director. Further improvements, expected in the near future, include signing a contract with a management-and-operating contractor. 


\section{BACKGROUND INFORMATION}

This chapter presents background information on the waste-management system and the program for its development. It discusses waste types and quantities; our plans for a geologic repository, an MRS facility, and a transportation system; protection of public health and the environment; potential socioeconomic effects and benefits; the involvement of affected and interested parties; and management.

\section{WASTE TYPES AND QUANTITIES}

Most of the waste accepted by the Federal waste-management system will be spent fuel from the commercial generation of electricity by nuclear reactors. The spent fuel from the nation's 112 reactors, which produce about 20 percent of our electric power, is accumulating at a rate of about 2000 metric tons of heavy metal per year. (One metric ton is equal to 1.1 English tons, or 2200 pounds.) The quantity of spent fuel discharged through 1989 is about 19,500 metric tons. Using realistic estimates, this total is projected to grow to 40,000 metric tons by $2000,58,000$ metric tons by 2010 , and 84,000 metric tons by 2036 , when the last of the licenses for the current generation of U.S. reactors is scheduled to expire.

Most of the remainder of the waste planned for Federal acceptance and disposal is high-level waste, which results from the reprocessing of spent fuel for national defense purposes. A small amount of high-level waste was generated at a commercial fuel processing facility, but practically all high-level waste will come from defense sources. For planning purposes we estimate that, by the year 2030, defense activities will generate the equivalent of about 9000 metric tons of high-level waste requiring deep geologic disposal. In 1985, President Reagan determined that defense high-level waste should be disposed of in a repository along with civilian waste.

\section{THE NUCLEAR WASTE POLICY ACT}

The Nuclear Waste Policy Act authorized the construction of one geologic repository and specified in detail the process for siting that repository, including the scientific evaluation (characterization) of three potential sites. In addition, it specified the process for siting a second repository, authorized the development of a waste transportation system, and required us to submit a proposal to construct one or more MRS facilities; this proposal was to include a Federal program for the siting, development, construction, and operation of MRS facilities. The Act also included provisions for the participation of States and affected units of local government and Indian Tribes in the waste-management program. Finally, the Act established the Nuclear Waste Fund to ensure that the full costs of waste-management and disposal are recovered from the owners and the generators of the waste. 
The Nuclear Waste Policy Act Amendments Act of 1987 (the Amendments Act) streamlined the program. It specified that only one site, rather than three, was to be evaluated (the Yucca Mountain site in Nevada) and only one repository was to be developed at present, and it authorized the siting, construction, and operation of an MRS facility subject to certain conditions. In addition, it established the Office of the Nuclear Waste Negotiator, whose primary role is to attempt to find a State or Indian Tribe willing to host a repository or an MRS facility at a technically qualified site on reasonable terms, and the Nuclear Waste Technical Review Board, appointed by the President to evaluate the technical and scientific validity of our activities.

\section{A GEOLOGIC REPOSITORY}

A repository is a system for permanently isolating radioactive wastes deep beneath the surface of the earth, in a suitable rock formation. To perform its functions before closure, a repository will consist of surface and underground facilities connected by shafts and ramps.

The surface facilities would be used to receive the waste, prepare it for disposal, and emplace it underground. They would be equipped with fail-safe devices designed to protect the health and safety of the repository workers and the general public. The waste emplaced underground must be retrievable for a period of up to fifty years, until the NRC determines that the repository is indeed performing as expected. We would then decommission the surface facilities and apply to the NRC for an amendment to the license to permanently close the underground repository.

An underground repository would be developed much like a large mine consisting of underground passageways and rooms. It would consist of horizontal passageways, or drifts, that would be excavated parallel to one another and would serve a number of waste-emplacement areas, or panels. Spaced within each emplacement panel would be a number of access drifts. Holes would be drilled into the floors or walls of the emplacement panels, and the waste containers would be emplaced in them. (Both vertical and horizontal emplacement is being considered.)

Waste-emplacement would begin before all of the underground repository has been excavated: it would begin in one panel as soon as two of the waste-emplacement panels had been completely developed. This approach would allow underground development and waste-emplacement to proceed essentially in parallel, with the development of the underground repository continuing for many years. To isolate the underground construction workers from waste handling activities, sufficient separation between development and emplacement operations would be provided.

To provide the required isolation, a repository would have multiple barriers, both natural and engineered, against the migration of the radioactive material in the wastes. 
The natural barriers would be the host rock in which a repository is constructed and the surrounding rock formations. The engineered barriers would be a repository (i.e., various underground structures and components, such as the rock with which the tunnels and underground disposal rooms would be filled up before a repository is closed) and the waste packages.

The waste package would consist of the waste, the disposal container in which the waste is encapsulated, and any other materials or features designed to separate the waste from the host rock. It will be designed to meet various functional and regulatory requirements, including maintaining the option to retrieve the emplaced waste.

The reliance that is placed on the waste package in waste containment and isolation is one of the issues of strategic importance proposed in Chapter 3. A related issue is the allocation of performance to natural and engineered barriers in demonstrating the performance of the total repository system.

\section{The process for repository development}

As mandated by law, the process for the development and operation of a repository is a sequence of activities that begins with site screening and selection for further study and the development of preliminary designs for a repository and a waste package as a basis for evaluating the potential safety performance of a repository. For the Yucca Mountain candidate site, these steps have been completed.

The next major activity is site characterization-a comprehensive program of scientific evaluation that will examine the geologic and other pertinent characteristics of the site and conduct analyses to determine whether the site is suitable. The determination of site suitability is one of the issues for which we are proposing to develop strategic principles.

If the results of site evaluation show that the site is suitable, the Secretary of Energy would recommend to the President that the site be selected for a repository. As part of the basis for that recommendation, an environmental impact statement would be prepared and submitted to the President. If the President agrees, he will recommend the site to the Congress, at which time the State of Nevada may submit a notice of disapproval, which can be overridden only by a majority vote in both houses of the Congress. If no notice of disapproval is submitted or if the notice is overridden, the process of site selection would be completed. If the site is selected for a repository, then a license application would be prepared and submitted to the Nuclear Regulatory Commission, including the environmental impact statement proposed to support the recommendation of the site, designs for the repository and the waste package, and the results of safety assessments. If the Commission approves the application, it will grant a construction authorization, and the Department will start constructing the 
repository. When the surface facilities have been constructed and the underground excavations are sufficient for waste-emplacement to begin, an updated application to receive and possess radioactive waste at the site would be submitted to the NRC. If this application is approved, the repository can begin to receive waste.

If, however, site evaluation shows that the site is not suitable, then the Department must stop all work at the site, notify the Governor and the legislature of Nevada, and recommend to the Congress the actions that should be taken to provide permanent disposal for the waste. One of the issues for which we are seeking to develop a strategic principle is the course of action to be followed in such an event.

\section{Evaluation of the Yucca Mountain site}

The Yucca Mountain candidate site is in southern Nevada, in Nye County, approximately 100 miles by road northwest of Las Vegas. It is in a region with very little rainfall, sparse vegetation, and a low population density. At Yucca Mountain the host rock for the proposed repository is the volcanic rock called tuff. This rock formed from volcanic eruptions occurring between 8 and 16 million years ago. Information about the geologic history and conditions in the region surrounding Yucca Mountain has been collected since the early 1900s. Since late 1977 geologic and hydrologic information about the region and the site has been collected specifically for the repository program.

However, we need to collect much more information before we can determine whether the site is suitable. This information will be collected during the siteevaluation program, which is expected to last several years. To ensure that all the required information will be collected and available when needed for design or performance assessment, we prepared and issued in 1988 a site characterization plan. The activities planned for site evaluation consist of surface-based studies, underground tests and studies to be conducted in an exploratory facility at the depth of a proposed repository, laboratory studies, and mathematical modeling of the geologic system.

The Department will focus first on features of the site that can be investigated through surface-based testing, which includes drilling from the surface. The objective is to obtain early information about conditions that have the potential to so adversely affect performance that the site may not be able to meet the regulatory requirements and would therefore be unsuitable for a repository.

To evaluate underground conditions, we will construct an underground exploratory facility at Yucca Mountain. This facility will allow us to characterize the host rock at the depth proposed for waste-emplacement. 


\section{Approach to developing confidence in achieving timely disposal}

The licensing of a repository will be a first-of-a-kind undertaking with the unprecedented challenge of demonstrating safe waste isolation for 10,000 years. To be successful, it will require well-documented evidence from many sources.

Many issues remain to be resolved concerning the demonstration of compliance with EPA and NRC regulations. We believe that licensing will be facilitated if we, as the agency responsible for implementing disposal, take the initiative in stimulating the resolution of these uncertainties and in developing the approach for demonstrating compliance. We recognize, however, that success in the implementation of this strategy will depend on close interactions with the NRC staff to identify and resolve issues. We are conducting a study of alternative licensing strategies in order to identify, evaluate, and compare potential alternatives to the current licensing strategy described in the site characterization plan. The major objective of this study is to ultimately recommend a licensing strategy that results in the most efficient, scientifically-based development of a repository.

We have proposed for the development of strategic principles several issues that are directly or indirectly related to the licensing of a repository. They include longterm cooling of the waste before disposal, the use of demonstration facilities, and phased repository licensing and waste-emplacement.

\section{AN MRS FACILITY}

An MRS facility is needed to meet the objective of timely and adequate waste acceptance. It will receive and inspect spent fuel shipped from reactor sites and store the fuel temporarily at or near the surface, in specially designed casks or vaults. When a repository starts operating, the MRS facility will continue receiving spent fuel and will ship it to such repository. From the MRS facility the spent fuel would be shipped in large-capacity casks and by dedicated trains; the net effect would be to reduce the total shipment miles and the number of shipments received at the repository. The MRS facility will be an "integral" facility--that is, a part of a waste-management system in which all elements are optimized as part of a single system focused on achieving the strategic objectives of the program.

\section{Authorization}

The Amendments Act authorized us to site, construct, and operate an MRS facility, subject to certain constraints, including the following licensing conditions:

- Construction may not begin until the NRC has authorized the construction of the repository. 
- Construction or waste acceptance at an MRS facility is prohibited if the repository license is revoked or the construction of the repository ceases.

- The quantity of waste present at the MRS site at any one time may not exceed 10,000 metric tons of heavy metal until the repository starts accepting waste and 15,000 metric tons thereafter.

The Amendments Act established an MRS Review Commission to provide an independent assessment of the need for an MRS facility. As stated in its report dated November 1989, the Commission found that "cumulatively the advantages of an MRS would justify the building of an MRS if: (1) there were no linkages between the MRS and the repository; (2) the MRS could be constructed at an early date; and (3) the opening of the repository were delayed considerably beyond its presently scheduled date of operation" (i.e., considerably beyond 2003, the year scheduled for the start of repository operations at the time the MRS Review Commission held its deliberations).

The Commission recommended that the Congress authorize the construction of a Federal emergency storage facility with a capacity limit of 2000 metric tons, authorize the construction of a user-funded interim storage facility with a capacity limit of 5000 metric tons, and consider the need for additional interim storage in the year 2000 .

\section{Secretary's decision}

The report of the MRS Review Commission was written while the Secretary was conducting a reassessment of the program, which showed that the start of waste acceptance at the repository would be delayed by 7 years, from the year 2003 to 2010 . To allow timely and predictable acceptance of spent fuel, the Secretary announced an initiative to develop an integral MRS facility, with the objective of beginning the acceptance of spent fuel in 1998.

\section{Siting the MRS facility}

Technically suitable sites for the MRS facility can probably be found throughout the continental United States. The Amendments Act authorizes a dual approach to siting and specifies that these are two independent approaches. One approach is for the Secretary of Energy to conduct a survey and evaluation of potential MRS sites. The other approach, which we prefer, is to site through negotiation with a State, Indian Tribe, or community that can offer a technically suitable site on reasonable terms. The Amendments Act created the Office of the Nuclear Waste Negotiator for this purpose. 


\section{MRS development}

The MRS facility envisioned in our current plans could start accepting waste by 1998 if the statutory schedule linkages between the repository and the MRS facility are changed. The statutory linkages could be changed if the volunteer host for the facility is willing to negotiate a change and incorporate it into the proposed agreement that would be signed between the United States and the proposed host. The agreement then would be submitted to the Congress for enactment into law.

As in other aspects of MRS development, we will solicit through the Nuclear Waste Negotiator the views of the potential host and will consider them in selecting the design of the MRS facility and the storage technology. Among the available options are metal storage casks, concrete casks, horizontal modular units, and modular vaults. Each of these technologies has been or is being reviewed by the Nuclear Regulatory Commission for use at reactor sites.

Another technology that could be considered is the dual-purpose cask, which can be used for both storage and transportation. The use of such casks is one of the strategic issues proposed for consideration in Chapter 3.

\section{Licensing strategy}

We plan to submit a single license application for the MRS facility, and a single formal adjudicatory hearing is expected to cover the full scope of the MRS facility design. Before submitting the formal license application, we will submit design packages to the NRC staff for review. If particular topics can be addressed separately from, and earlier than, the formal application, we will also submit topical reports for review by the NRC staff.

To facilitate licensing, we intend to analyze, define, and help clarify regulatory requirements. We also intend to identify and resolve regulatory, technical, and institutional uncertainties that will simplify licensing. And before formally submitting the license application, we will submit to the NRC relevant information to facilitate the review of the license application.

We will continue to examine strategies to expedite the licensing of an MRS facility.

\section{Funding and charges for the MRS facility}

An MRS facility will add to the cost of the Federal waste-management system, but these costs will be partially offset to some extent. Some utilities and others have stated that the allocation of MRS costs to all utilities would not be equitable because the 
MRS facility will not be able to accommodate spent fuel from all utilities. Several options for funding could therefore be considered, and this issue is one of those proposed in Chapter 3 for the development of a strategic principle.

\section{Private-sector involvement}

In concert with the Negotiator, we plan to examine opportunities for private-sector involvement in the development of the MRS facility and are proposing several options for consideration in Chapter 3. We will also examine possible opportunities for thirdparty provisions of MRS services that can be leased or purchased to meet the needs of the Federal waste-management system.

\section{TRANSPORTATION}

The transportation of radioactive materials, including spent fuel, over the Nation's highways and railroads has an excellent record of safety, and yet it causes widespread concern in the public. Recognizing these concerns, we are conducting a transportation program aimed at protecting public safety and gaining public confidence.

In order to provide safe transportation, we are developing a fleet of special shipping casks. Support systems and facilities will also be provided. And before any waste is transported, we, together with affected and interested parties, will need to resolve a number of institutional issues.

\section{Transportation casks and modes}

Transportation casks are rugged containers for shipping spent fuel and high-level radioactive waste. They are designed to protect the public, the transportation workers, and the environment by providing shielding from radiation and containing their contents under both normal and accident conditions. The designs of these casks will have to be certified by the Nuclear Regulatory Commission, which will require evidence that they comply with standards promulgated for the protection of public health and safety. In order to be certified, the casks will have to pass a series of tests representative of the forces imposed on casks for normal transportation conditions and during accidents.

Several modes can be used for shipping the waste, including dedicated trains or regular train service, intermodal shipments (e.g., truck to rail, barge to rail), shipments in legal-weight and overweight trucks, and shipments in heavyweight rail casks. The mode to be used will depend on the weight of the cask and the facilities and equipment available at individual reactor sites (e.g., railspurs and heavy-duty cranes). 


\section{Plan for development}

The transportation system will be able to start shipping to an MRS facility as early as 1998. This capability can be developed to serve a variety of scenarios for the acceptance of spent fuel.

To service the first phase of an MRS facility, we are considering the use of transportable storage systems, such as dual-purpose casks. These systems would be designed to minimize the handling of spent fuel during the transfer from storage at reactor sites to the MRS facility.

Since a fleet of transportation casks will be needed over the operating life of an MRS facility and a repository, we are undertaking a major effort in cask development. Four distinct types of casks are under consideration:

- Casks suitable for shipping spent fuel from reactor sites either to an MRS facility or a repository, e.g., legal weight truck, rail/barge, and dual-purpose casks.

- Casks for shipping from an MRS facility to a repository.

- Casks for shipping nonstandard fuel and non-fuel-bearing waste.

- Casks for shipping high-level waste.

To be ready for transportation, we are concentrating on the development of the casks for shipping from reactor sites to a repository or an MRS facility. At present, both a legal-weight truck cask and a rail-and-barge cask are being developed, and a limited number of these casks will be available in 1998. The need for other types of casks will be determined between 1991 and 1993.

The design of the facilities needed to support transportation operations will be coordinated with the development of the cask system. A cask-maintenance facility will be used for the inspection of casks and their seals, routine maintenance, and decontamination. Such a facility could be built at the site of an MRS facility, the site of a repository, or a third location.

The development of other transportation support facilities will proceed as functional requirements are made specific.

\section{Resolution of issues}

A guiding principle in the development of the transportation system is the need for the early resolution of technical and institutional issues. The resolution of these issues 
requires communication and interaction with a large number of diverse affected and interested parties. An issue of strategic importance is training for emergency response; it is presented in Chapter 3.

\section{PROTECTION OF THE PUBLIC HEALTH AND SAFETY AND THE ENVIRONMENT}

The protection of public health and safety and the quality of the environment is a fundamental policy of the waste-management program. All waste-management activities-including the siting, construction, and operation of the facilities needed for waste-management and disposal-will be conducted in a manner that provides this protection.

In addition to requirements to comply with regulations governing the repository, the MRS facility, and the transportation system, the Secretary of Energy has established policies that demonstrate the DOE's commitment to environmental protection. These include his 10-point initiative, announced on June 27, 1989, to ensure that all DOE activities are carried out in full compliance with environmental statutes and regulations and his notice (SEN-15-90) of February 5, 1990, on compliance with the National Environmental Policy Act of 1969. To fulfill our commitment to environmental protection, we will meet or exceed all applicable environmental laws and regulations.

Each element of the system-a repository, an MRS facility, and transportation operations-will comply with the pertinent specific regulations governing the protection of public health and safety.

In the case of a repository, requirements for the protection of public health and safety are specified in regulations developed by the NRC in 10 CFR Part 60 . The NRC regulations also implement and enforce the environmental standards issued by the Environmental Protection Agency (EPA) as 40 CFR Part 191." The objective of the regulations is to provide reasonable assurance that the repository will isolate the waste for at least 10,000 years without posing undue risk to public health and safety.

The MRS facility must meet the requirements of 10 CFR Part 72, "Licensing Requirements for Independent Spent Fuel Storage Facilities." This regulation has been recently revised by the Nuclear Regulatory Commission to accommodate an MRS facility. Included in the requirements of 10 CFR Part 72 are the environmental standards promulgated by the Environmental Protection Agency in Subpart A of 40

*Subpart B of 40 CFR Part 191 has been vacated and remanded to the Environmental Protection Agency, which is preparing to issue a revised regulation for comment. 
CFR Part 191 for the management of spent fuel and high-level wastes.

Regulations for the safety of radioactive waste transportation have been issued by the Department of Transportation (49 CFR Parts 171-179) and the Nuclear Regulatory Commission (10 CFR Parts 71 and 73).

\section{POTENTIAL SOCIOECONOMIC EFFECTS AND BENEFITS}

Both adverse and favorable socioeconomic effects may be associated with wastemanagement. They would generally result from the employment that is created, the resulting direct and indirect population growth, and local expenditures for materials, equipment, and services. Adverse effects result when the demands on government and community facilities and services (e.g., schools, wastewater treatment, medical care) exceed local resources; when the inflow of people increases demands on scarce resources like water, land, and housing; and from the disturbance of local lifestyles and social structures. Favorable effects are related to the availability of more jobs, greater county or municipal revenues, development of improved education systems, expanded recreation facilities, and the inflow of money into local businesses.

A framework for addressing potential adverse effects is provided by the Act as amended. The Act as amended specifies a process and requirements for avoiding, minimizing, or mitigating socioeconomic effects to the maximum extent practicable; these requirements go beyond provisions in the National Environmental Policy Act of 1969. It also makes specific provisions for financial assistance to affected parties. In addition, the Act as amended provides for payments-equal-to-taxes. And it provides for other financial benefits under certain conditions.

\section{INVOLVEMENT OF AFFECTED AND INTERESTED PARTIES}

The Nuclear Waste Policy Act of 1982 recognized the importance of public participation and involvement in the waste-management program. Meaningful participation by affected and interested parties is indispensable to a program that accommodates diverse interests while earning general public confidence and acceptance.

The original Act included extensive provisions for the involvement of State and local governments and Indian Tribes, and the general public. These provisions require us to provide, through specific mechanisms, information about major program decisions and actions; to provide opportunities for participation through public hearings and public comments; to consult and cooperate with affected parties and seek to develop formal agreements with them; and to avoid or mitigate significant adverse impacts. The Act also required the provision of financial assistance necessary for States and Indian Tribes to exercise their rights to participation and oversight. 
The Amendments Act of 1987 further articulates and expands on the original law's commitment to meaningful public involvement by, for the first time, providing for direct funding assistance to affected units of local government; by providing for a benefits agreement and a review panel; by creating the Nuclear Waste Technical Review Board, an independent oversight body; and by establishing the Office of the Nuclear Waste Negotiator, who is empowered to find volunteer States or Indian Tribes willing to host a repository or an MRS facility. A negotiated agreement could further extend opportunities for participation.

The scientific evaluation of the Yucca Mountain site has been reprogrammed to evaluate key suitability issues early, so that early results can guide the scope of later investigations. This initiative responds directly to comments received from several external review groups, including the State of Nevada, the Nuclear Regulatory Commission, and the Edison Electric Institute.

In the case of an MRS facility, we intend to rely on the efforts of the Nuclear Waste Negotiator to identify and reach agreements with a volunteer host; we are actively working to identify, collect, and analyze the types of technical, financial, and institutional information that the Negotiator may need to interact effectively and collaboratively with a prospective host. This information may be important in structuring an agreement that is broadly supported by all potentially affected and interested parties.

To enhance the involvement of affected and interested parties in the development of the transportation system, we actively seek the development of cooperative agreements with various national and regional organizations. These organizations study national and regional transportation issues and formulate recommendations to us.

Before starting to transport any waste, we will meet certain institutional obligations. The most prominent among them is the requirement of the Amendments Act to provide technical assistance and funds to States for the training of public-safety officials in local governments and Indian Tribes through whose jurisdictions the waste may be transported. The method and timing for implementing this assistance will be developed in consultation with affected parties.

Another obligation is the early resolution of transportation issues. This requires communication and interaction with a large number of diverse affected and interested parties, including the many Tribal, State, and local governments through whose jurisdictions the shipments will pass; other Federal agencies; technical associations; the transportation industry; utilities; and the public.

As the waste-management program evolves, so will participation by affected and 
interested parties. Representatives from the affected States, Indian Tribes, and local governments may be involved in the designation of alternative routes, the coordination of shipping arrangements, and the clarification of responsibilities for transportation activities.

\section{MANAGEMENT}

\section{Organization and structure}

The Office of Civilian Radioactive Waste-Management (OCRWM) in the Department of Energy is responsible for developing the waste-management system. To perform the technical work of the program, we have retained the Nation's best scientific and engineering expertise in waste-management and disposal. Under our direction, this expertise is provided by the U.S. Geological Survey, certain of the Department's National Laboratories, and specialized contractors who supply technical support and assistance. In addition, we use outside experts to support or improve program analysis, management, and administration and to support or improve the operation of management systems.

\section{Management initiatives}

In his 1989 Report to the Congress on the reassessment of the program, the Secretary announced a number of initiatives to improve the management of the program. First, he announced the imminent nomination of a new OCRWM Director, who was approved by the Senate in April 1990.

Second, the Secretary established direct-line reporting from the Yucca Mountain Project Office to headquarters. Under the previous management structure, multiple lines of authority existed. Direct-line reporting from the Yucca Mountain Project Office to headquarters brings together for the first time program authority and responsibility and facilitates coordination and communication.

Third, the Secretary directed that an independent assessment of the program's management be conducted by a private management-consulting company. This assessment covered the management structure and processes; management systems; contractual arrangements, including the numbers, types, and purposes of contracts; and the authorities, responsibilities, and accountabilities of the major participants in the program.

Since his appointment, the OCRWM Director has identified and taken a number of actions to implement and strengthen the Secretary's initiatives. They are focused on developing a strategy for managing spent fuel; establishing a national consensus on that strategy; developing effective working relationships with parties who have a stake in the 
program; ensuring that methods and criteria for demonstrating compliance with regulatory requirements are developed and ready when needed; focusing actions on goals and essential activities; and improving cost effectiveness and accountability. Accomplishments to date include a reorganization of the OCRWM and the development of a management systems improvement strategy. Detailed implementation plans will be given in an amendment to the OCRWM Mission Plan.

\section{Oversight and review}

Independent oversight of the technical work is provided by the Nuclear Waste Technical Review Board and the State of Nevada. In addition, we seek peer review from the National Academy of Sciences, groups of independent experts, and other DOE organizations and their consultants. Major program plans and documents are reviewed by the NRC staff and their consultants as well as the NRC's Advisory Committee on Nuclear Waste.

\section{Quality assurance}

Quality assurance consists of all the planned and systematic actions necessary to provide adequate confidence that a structure, system, or component will perform satisfactorily in service. An effective quality-assurance program is essential for ensuring the achievement of high-quality performance in the pursuit of our mission and is required for demonstrating compliance with regulatory standards in licensing. We are therefore implementing a quality-assurance program for the entire waste-management system.

Our quality-assurance program is designed not only to satisfy NRC requirements but also to be completely integrated into every technical activity in the waste-management program. In addition, it should help to establish public confidence in the technical quality of the program. 
STRATEGIC PRINCIPLES FOR PLANNING AND DECISIONMAKING

IN THE

CIVILIAN RADIOACTIVE WASTE MANAGEMENT PROGRAM

U.S. Department of Energy

Office of Civilian Radioactive Waste Management

March 25, 1991 


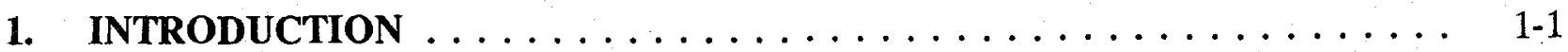

2. MISSION, POLICIES, OBJECTIVES, AND STRATEGIC PRINCIPLES . . . $2-1$

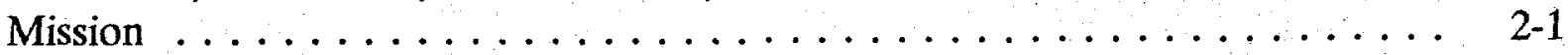

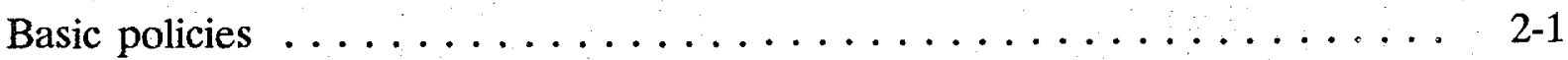

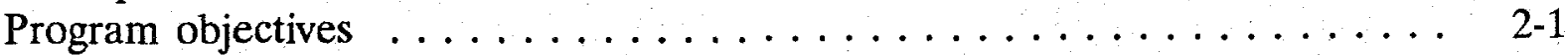

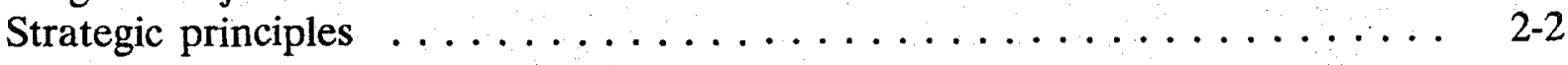

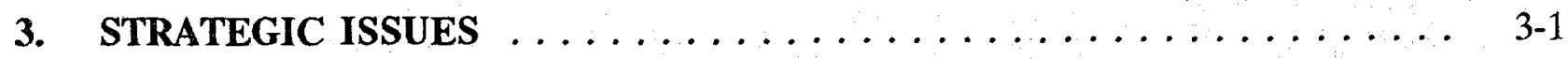

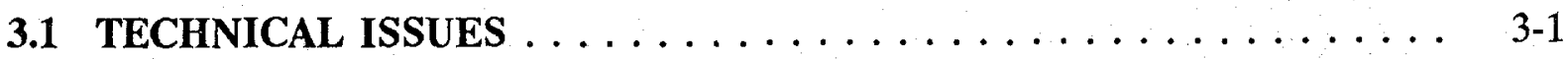

Cooling Spent Fuel Before Disposal . . . . . . . . . . . . . 3-1

Designing Waste Packages to Exceed Regulatory Requirements . . . . . 3 3-4

Timing and Criteria for Determining the Suitability of the Candidate Site

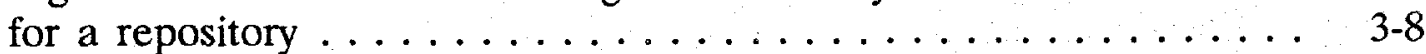

Approach to the Demonstration of Performance .......... 3-10

Phased Licensing for the Repository . . . . . . . . . . . . 3-13

Contingency Planning ... . . . . . . . . . . . . . . . 3-15

Geologic Disposal for Wastes Other Than Spent Fuel and High-level

Waste (Greater-Than-Class C Waste) . . . . . . . . . . . 3-16

Using a Demonstration Facility to Increase Confidence . . . . . . . . . 3 3-19

Risk Assessment in Selecting Transportation Modes and Preferred Routes 3-21

Development of Dual-purpose Casks for Transportation and Storage . . . 3-24

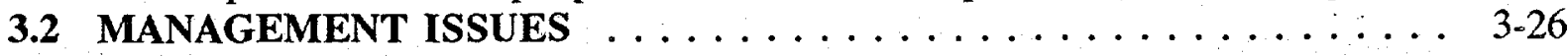

Roles of Utilities and the Federal Government in the Management of Spent Fuel Before Disposal . . . . . . . . . . . . . . 3-26

Private-sector Involvement in the Development and Operation of an MRS

Facility ....................... 3-28

Use of the Nuclear Waste Fund for Storage $\ldots \ldots \ldots \ldots \ldots \ldots$. . . . . . .

Use of Peer Reviews . . . . . . . . . . . . . . . . 3-31

Alternative Means of Managing the Waste Management Program .... . 3-33

Cost Containment . . . . . . . . . . . . . . . . . . 3-36

3.3 INSTITUTIONAL ISSUES $\ldots \ldots \ldots \ldots \ldots \ldots \ldots \ldots \ldots \ldots . \ldots \ldots$

Building Public Trust and Confidence . . . . . . . . . . . 3-39

Sharing of Data on a Timely Basis $\ldots \ldots \ldots \ldots \ldots \ldots \ldots \ldots \ldots . \ldots \ldots$

Socioeconomics ....................... 3-44

Emergency-response Planning and Training $\ldots \ldots \ldots \ldots \ldots \ldots .46$ 


\section{INTRODUCTION}

The Office of Civilian Radioactive Waste Management (OCRWM) in the Department of Energy is responsible for disposing of this nation's spent fuel and high-level radioactive waste in a manner that protects the health and safety of the public and the quality of the environment. Our mission originated in the Federal repository program studies of the late 1950s, was explicitly established by the Nuclear Waste Policy Act of 1982, and was reaffirmed by the Nuclear Waste Policy Amendments Act of 1987.

To fulfill our mission, we are developing an integrated waste management system consisting of a geologic repository for permanent disposal deep beneath the surface of the earth, a facility for monitored retrievable storage, and a system for transporting the waste.

We intend to govern the planning, decisionmaking and implementation of the high-level radioactive waste management program through use of a set of strategic principles. These strategic principles will serve as the program's constitution. In keeping with the policy of open dialogue Secretary of Energy James D. Watkins has established, we are developing the strategic principles in consultation with affected governments and interested parties. We have sponsored two workshops to provide an opportunity for affected governments and interested parties to contribute to the substance of the strategic principles. The original version of this paper served as the basis for dialogue at the workshops.

This revised document reflects the comments, suggestions and criticisms of the participants at the first two workshops and includes our preliminary response to these concerns. It was prepared as the basis for discussion at a third workshop to be held on April 3-4, 1991 in Denver, Colorado. In many cases the message we received at the first two workshops reflected both the diversity of participant opinion and the fact that we did not seek to reach consensus. In other cases, however, for example, public confidence and cost-effective expenditure of funds, we received such straightforward advice that we are proposing the addition of a new strategic principle to respond to the concerns expressed. Thus, Chapter 2, which is a statement of our mission, policies, objectives and strategic principles, now includes five new strategic principles, that reflect points of major emphasis at the workshops. In addition, we have added a strategic principle concerning the assessment of how well we are doing in implementing the policies, objectives, and strategic principles. These new strategic principles are identified by shading.

Chapter 3 contains the remaining strategic issues. For each issue, in addition to the background and options sections largely retained from the first draft, we have added a section providing a synopsis of what we heard from the participants and a section detailing our preliminary response. In a few cases it is our judgement that the 
issue was not important enough to be considered strategic. In the majority of cases, after receiving further input from the participants at the Denver workshop, we will elaborate in the Mission Plan Amendment on our plans for handling the issue. 


\section{MISSION, POLICIES, OBJECTIVES, AND STRATEGIC PRINCIPLES}

\section{MISSION}

To dispose of the nation's spent fuel and high-level radioactive waste in a manner that protects the health and safety of the public and the quality of the environment.

\section{BASIC POLICIES}

The basic policies under which we conduct the program are as follows:

- The protection of the health and safety of the public, including workers, and the quality of the environment is of paramount importance.

- The program must be conducted such that public confidence is warranted, with opportunities and means provided for meaningful participation by affected governments and interested parties.

- The program must be distinguished by its technical integrity and excellence and directed at reaching scientific consensus and public understanding.

- The program must be managed and conducted in an efficient and cost-effective manner.

\section{PROGRAM OBJECTIVES}

To direct the implementation of our mission, we have established the following objectives:

- Timely disposal capability: to establish as soon as practicable the ability to dispose of radioactive waste in a geologic repository licensed by the Nuclear Regulatory Commission (NRC).

- Timely and adequate waste acceptance: to begin the operation of the wastemanagement system as soon as practicable, obtaining the system-development and operational benefits that have been identified for the MRS facility.

- Schedule confidence: to establish confidence in the schedule for waste acceptance and disposal such that the management of radioactive waste is not an obstacle to the nuclear energy option.

- System flexibility: to ensure that the program has the flexibility necessary for adapting to future circumstances while fulfilling established commitments. 


\section{STRATEGIC PRINCIPLES}

In addition to the basic policies, we need strategic principles for planning and decisionmaking. This section presents the principles that we have identified to date, including those suggested at the first two workshops.

The principles will provide a framework in which we can make decisions in a rational, goal-oriented manner directed at achieving the objectives of the program, while giving affected governments and interested parties adequate opportunity for meaningful predecisional involvement.

The principles will serve as guides for the more-detailed plans and studies that we will need to successfully conduct waste-management activities. In view of the complexity of the program and its first-of-a-kind nature, we will use the principles as guides for decisions and actions rather than rigid constraints.

\section{Management principles}

Maintain the focus of the program on permanent disposal. Disposal is the primary objective, it is the DOE's principal responsibility under the law, and success in achieving it is vital to maintaining the nuclear energy option. All program activities must be conducted in a manner that supports and facilitates permanent disposal.

Provide facilities for the timely acceptance of spent fuel. This principle is critical to achieving timely and adequate waste acceptance and obtaining the system-development and operational benefits that have been identified for an MRS facility, including the flexibility essential for spent-fuel management.

Maintain strict environmental compliance programs. Preliminary analyses indicate that the development of facilities and waste-management and disposal operations are not likely to result in significant environmental impacts. Nonetheless, this principle is important because its implementation will ensure that we give environmental protection priority and that we closely monitor field activities for compliance with all applicable environmental protection standards.

Enswe that funds are spert in a coss effect e manmer: Given that stamdards of excellence are establkhted and applied, ve tiust ramian effective neans for centrolling the cests of the program. This principle will be based on optinizing the ase

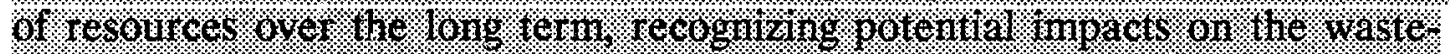

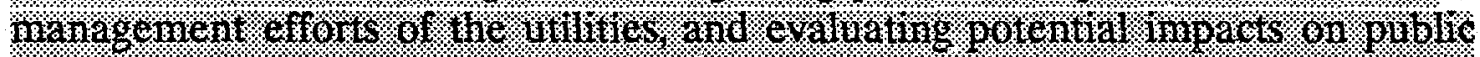
connidence 
Maintain standards of excellence. Technical excellence has always been a fundamental requirement of the program, and its importance increases with the increasingly difficult challenges that arise as the program moves forward. It is essential for success in licensing, establishing scientific consensus, increasing public confidence, and the prudent management of resources. We will apply standards of excellence to all other aspects of the program, including institutional activities, outreach, and management.

Ensure that all quality-assurance requirements are met. Quality assurance comprises the planned and systematic actions necessary to provide adequate confidence that the product or result of an activity covered by a quality assurance program will meet its intended purpose and/or function; it is a prerequisite for licensing. The extent to which quality assurance and procedural controls will be applied to particular items and activities will depend upon their relative importance to safety, waste isolation, or program objectives.

Consider publt trust and confitence in progrom deckions: In making nanagenent.

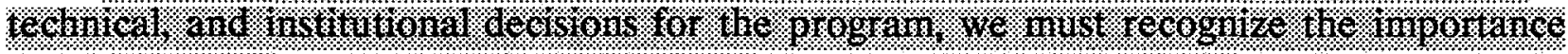
6f public conceris and consider the polentidi mplications for bulling and naintaning

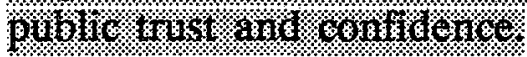

Assign equal importance to institutional and technical activities. The history of the program has shown that institutional challenges are as difficult as the technical ones, and we must recognize their importance in program plans, activities, and resource allocations.

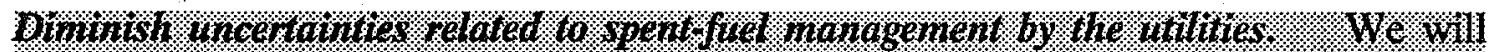

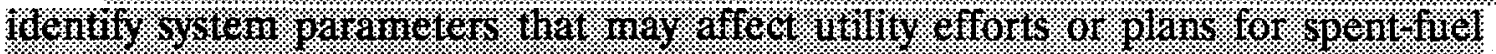

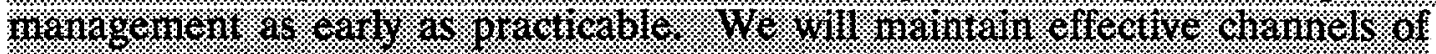

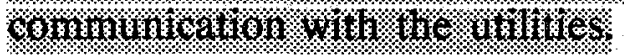

Provide alternatives and contingency plans. We need this principle to ensure success despite the inevitable surprises and unexpected problems that will arise in a complex, first-of-a-kind enterprise. It requires that we analyze in parallel alternatives to key components of the system so that if our primary candidate encounters difficulties, we can come up with a workable alternative with minimized delay. It also requires that we anticipate the difficulties which might be encountered, and that we develop in advance plans for minimizing their effects. While the provision of backups and contingency planning increase the initial costs of the program, they are insurance against unforeseen problems that could otherwise lead to delays and real or perceived programmatic failure. 
Coordinate the technical, institutional, and management activities of the program. Implementation of this principle should enhance the integration of technical and institutional activities, contribute to the control of program schedules, and enhance the prospects for the success of the mission.

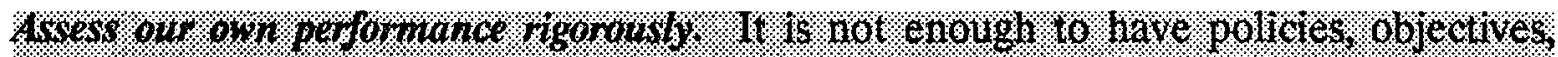

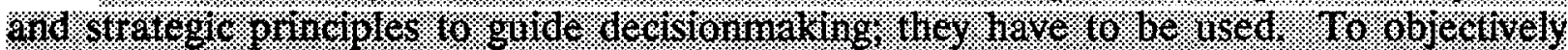

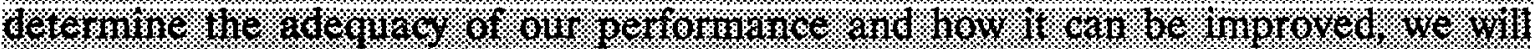

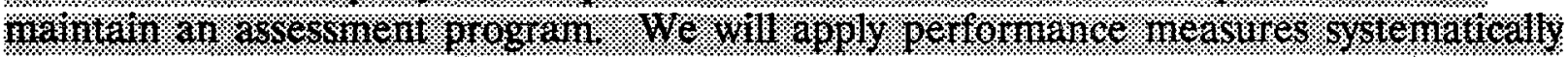

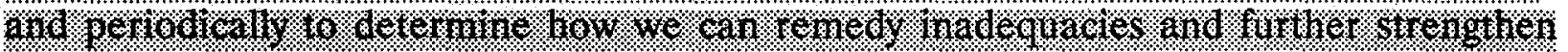
our $8 \mathrm{f} 6 \mathrm{~mL}$

\section{Technical principles}

Apply the concept of defense in depth in waste-management and disposal. We will emphasize safety in the design and planning for all operations involving waste handling, include backup safety systems and fail-safe designs where appropriate, and use multiple barriers against waste migration. This approach should facilitate licensing and help to establish public confidence in safety.

Use state-of-the-art systems-engineering techniques in developing and designing waste-management facilities and operations. Systems engineering is an orderly process for the development of complex systems. It consists of defining objectives and requirements, developing a design that meets the requirements, evaluating the design against the requirements, revising the design as needed, and repeating the process with increasing detail to ensure that the requirements are complete and satisfied by the system and its components. Important features of the process are its emphasis on ensuring that all components work together, on special studies of the entire system's ability to meet requirements, and on rigorous control of the technical information used in the process. Systems engineering is essential for the success of the program because it provides the means for identifying and controlling the many interfaces among the elements of the system, coordinating the multiple scientific and engineering disciplines involved in the program, and optimizing the design and operation of the system.

Use simple and proven designs and technologies. The use of simple and proven technologies, particularly those already licensed by the NRC, and the use of designs that approximate those of licensed facilities should facilitate licensing and increase cost effectiveness. This principle is applicable to an MRS facility, a repository, and a transportation system.

Provide for outside review. The purpose of this principle is to ensure that, in resolving important issues and making important decisions in the program, we have the benefit of appraisal by outside experts. Such appraisal, which includes peer reviews, is 
important in verifying or validating assumptions, plans, results, or conclusions critical to the success of a program. It bolsters technical confidence, and may also generate fresh ideas and approaches to problems. Further, the use of recognized independent authorities strengthens our credibility. We will not limit the outside reviews to technical issues; we will extend them to institutional and managerial issues as well.

\section{Institutional principles}

Provide for the involvement of affected governments and interested parties in the decisionmaking process. As the organization charged with the development of the waste-management system, we have certain responsibilities that cannot be shared. One of these responsibilities is making technical and programmatic decisions. However, the views of affected governments and interested parties are essential to the decisionmaking process and will be actively solicited. The involvement of affected governments and interested parties early in the decisionmaking process will help us identify emerging issues and formulate appropriate alternatives. This will make issue resolution more productive and will also allow the program to benefit from the knowledge and experience of the affected parties.

Work cooperatively with affected governments and interested parties. To foster productive links with affected governments and interested parties, we will consult and cooperate with them and will seek to exchange information and ideas. We will use cooperative agreements to bring additional groups into the program, both for technical advice and for the dissemination of information to their members.

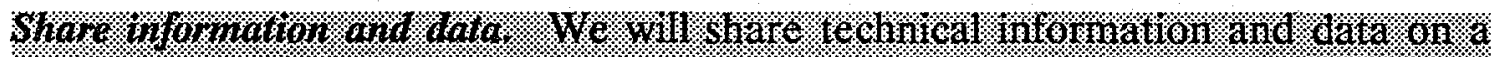
Grely basis and in an appropnitic form.

Provide support to educational programs. Greater understanding of the health, safety, and environmental issues surrounding waste generation and management is key to the success of the program. It is also needed to help develop the skills necessary to meet the future human-resource needs of the program. We will implement this principle by stimulating the teaching of science at the secondary, undergraduate, and graduate levels and developing curricula and instructional materials - both print and electronic-for primary, secondary, and undergraduate studies. A related effort will be to foster undergraduate and graduate studies for the public policy aspects of waste management.

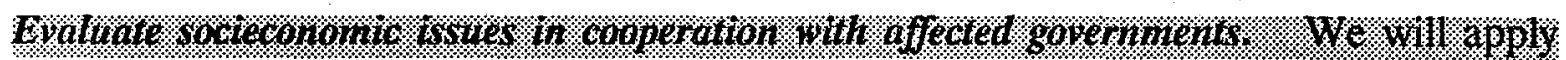

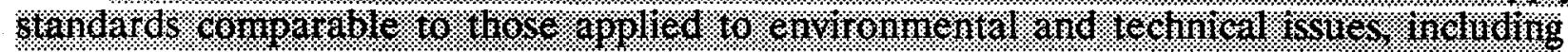

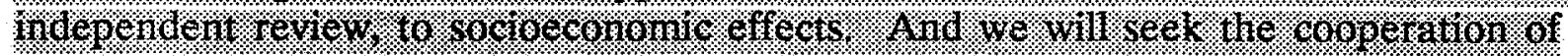
afrected governinentr ro ensure that we contider significant local issies: 
In siting, designing, and constructing waste-management facilities, consider potential benefits to the host States and communities. The Nuclear Waste Policy Amendments Act requires the Secretary of Energy, in siting Federal research projects, to give special consideration to proposals from States where a repository is located. It also authorizes the Secretary of Energy to enter into a benefits agreement with the State of Nevada concerning a repository or with any State or Indian Tribe concerning an MRS facility. Such a benefits agreement would include specific benefits, including enhanced program participation, identified in the Nuclear Waste Policy Amendments Act. Other benefits to jurisdictions willing to host a repository or MRS facility could be developed through the Nuclear Waste Negotiator. 


\section{STRATEGIC ISSUES}

\section{I TECHNICAL ISSUES}

\section{COOLING SPENT FUEL BEFORE DISPOSAL}

\section{Background}

The waste that will be emplaced in a repository consists of spent nuclear fuel and vitrified high-level radioactive waste, both of which emit heat. This heat will affect the properties of the host rock and the flow of fluids (both liquids and gases), which is the principal mechanism for transporting radioactive materials from the repository to the human environment. In theory, the heat will create, near the emplaced wastes, fluidflow patterns that differ from the natural flow patterns, and these altered patterns may affect the repository system's ability to retain radionuclides.

Our current strategy is to design the repository and the engineered-barrier system to be able to meet the Nuclear Regulatory Commission's performance objectives for waste containment and isolation over the range of anticipated environmental conditions, including relatively high initial temperatures and the presence of water in the pore spaces of the rock surrounding the waste packages. This strategy is expected to add conservatism to the design of the engineered-barrier system in that the heat from the waste form may actually help keep water from reaching the majority of containers for up to hundreds of years. However, there are uncertainties as to what happens in the host rock before and after the temperature rise due to the waste-induced heat has reached a peak (the thermal pulse) and the rock cools. As part of the site-suitability determination, we will have to evaluate the capability of the natural system to continue to provide for adequate waste containment and isolation under the expected thermal loading. We will need to be able to demonstrate during licensing that we understand the effects of the thermal pulse on the repository and the engineered-barrier system and that the performance of all elements of the system is acceptable with respect to established standards.

The heat produced by the waste emplaced in the repository and the resulting repository temperatures may be reduced by cooling the spent fuel and high-level waste for extended periods before disposal. Such cooling may, to some extent, reduce the attendant uncertainties about the long-term performance of the repository and the engineered-barrier system. Cooling may also enable repository designers to put more fuel in each emplaced waste package, thus reducing the volume of rock excavated and the costs of underground development and operation. However, to get the maximum benefit from cooling, extended storage (on the order of several decades) is required, which increases the costs of storage. 


\section{Originally suggested options for initiating a discussion}

Option 1. We could accept spent fuel directly from reactor pools (i.e., spent fuel cooled for at least 5 years).

Option 2. We could set a minimum cooling period longer than 5 years for acceptance from reactor sites.

Option 3. We could set a period for long-term cooling (e.g., 40 years) and provide facilities for storing the spent fuel during that period.

Option 4. We could establish a policy of accepting first the oldest spent fuel, which will be 40 years old on the average when a repository starts operations, with the proviso to take younger spent fuel to prevent reactor shutdowns.

\section{Synopsis of workshop discussions}

The discussions at the workshops concluded that a specific recommendation on predisposal cooling would have to await the results of site characterization. Until more is known about the thermal response of the host rock, no decision on the age of spent fuel at the time of emplacement, or on the areal heat density in the repository, could be made. The issues raised during the discussions included the following:

- A "hot" repository may not be desirable because less waste can be emplaced in it (compared to emplacing cooled spent fuel), and this consideration is particularly pertinent in the case of Yucca Mountain, which has some limit on its capacity (to be determined during site characterization).

- A "hot" repository may not be consistent with simple and proven (reasonably available) technology. Also, a "hot" repository may lead to more elevated surface temperatures, possibly resulting in impacts to flora and fauna.

- In addition to cooling, there are two other ways to achieve a "cold" repository (1) load less spent fuel in each of the packages and (2) emplace the packages less densely in the repository. In either case, it would be necessary to do something else with the remaining spent fuel (i.e., develop more storage or construct more repositories). The repository-capacity question led to a discussion of the need for a second repository and strong recommendations that this issue be raised in the Mission Plan Amendment. 
- The comparative costs of a "hot" repository at Yucca Mountain versus a "cold" one should be established, and the tradeoffs between costs and risks should be analyzed.

- If the repository is to be "hot", we will need to accept spent fuel that is younger than average, because by 2010 , the time the repository is scheduled to open, the average age of the spent fuel will be about 40 years. To accomplish this, we would have to be able to stipulate which spent fuel we want.

- Option 3, which could result in a call for several MRS facilities, may not be feasible, because not even one such facility has been sited. If extended cooling is needed, the utilities may not pay for storage at the level of current program costs (i.e., hundreds of millions of dollars per year).

\section{DOE response and current plans}

The issue of long-term cooling is closely related to the design of the waste packages, which is discussed next. The discussions at both workshops suggest that the original set of options should be replaced by the two options below.

Option 1. We should proceed with our current plans, which would result in a relatively "hot" repository.

To obtain a preferential temperature distribution over a significant portion of the disposal area, "heat management" may be necessary for the waste packages, with us specifying parameters for each of the spent fuel assemblies loaded into each disposal container. This function could be performed at the repository or at the MRS facility. This option would require no legislative changes but the concept of "heat management" may require changes in the standard contract with the owners/generators of spent nuclear fuel.

This option is consistent with the original option 1, given above. Within limits, it is also consistent with the original option 2 , provided the standard contract with the utilities is modified to contain a different acceptance specification for the minimum age of the spent fuel.

Option 2. We should change our plans to a "cold" repository.

Option 2 could be implemented in three ways. One way is to accept only spent fuel that has been cooled for a specified period of time, as in the original option 3 . The length of the period for the desired cooling has not been firmly established, though preliminary calculations show that it may be as long as 80 years. If cooling is to be provided for such a long period, multiple storage facilities may be needed, and the 
current repository program might be slowed or put on hold for a number of years. Even if the period of cooling is on the order of 40 years, multiple storage facilities still may be needed, and the costs of the waste management program could increase substantially. The other two ways are (1) emplacing fewer waste packages in the repository and (2) loading less spent fuel into each waste package.

The question of a "hot" versus "cold" repository is one that cannot be fully answered until the characterization of Yucca Mountain is completed. The exact capacity of Yucca Mountain as a potential repository site is unknown, but it appears that 70,000 MT, perhaps more, can be accommodated. Also, the implications of an elevated surface temperature from a "hot" repository are not likely to be significant, as the increase in surface temperature would be about $1^{\circ} \mathrm{C}$. Tests intended to provide information on these issues, such as those that will address the response of the rock and the hydrologic system to thermal stress, have been defined and are described in the Site Characterization Plan. Meanwhile we expect to get some useful ideas and suggestions on alternative waste package designs in a workshop with industry experts. This workshop is to be held in June 1991.

The issue of long-term cooling has serious implications for the entire program, including the number, capacity, and operating life of storage facilities; spent fuel management by the utilities; transportation; the design and performance of the repository and the waste package; and costs. It also has serious implications for the capacity of the repository and hence the need for more repositories. We therefore plan to perform system studies to analyze the tradeoffs involved.

\section{DESIGNING WASTE PACKAGES TO EXCEED REGULATORY REQUIREMENTS}

\section{Background}

The waste package is defined by the Nuclear Regulatory Commission (NRC) as "the waste form [spent nuclear fuel or high-level radioactive waste] and any containers, shielding, packing, and other absorbent materials immediately surrounding an individual waste container." For the Yucca Mountain candidate site, the current conceptual design for the waste package consists of the waste form and a disposal container.

The waste package must meet various functional and regulatory requirements related to the operation of a repository and to the containment of radionuclides after a repository has been closed. Included in these requirements are the performance objectives of providing substantially complete containment for the waste for not less than 300 to 1000 years and thereafter controlling the rate of radionuclide release from the engineered-barrier system. The demonstration that these objectives will be met, along with the demonstration of satisfactory total system repository performance for 
10,000 years, are expected to be among the most difficult technical challenges during licensing, and for this reason great importance is attached to the design of the waste package and to determining the conditions to which it will be subjected in a repository.

In the current conceptual design for the Yucca Mountain candidate site, the container is a single-walled vessel made of a corrosion-resistant alloy yet to be selected, which will be compatible with the geologic, hydrologic, and geochemical conditions expected to prevail in a repository over the long term. This design will be developed to meet, but not necessarily exceed, the regulatory criteria for the life of the waste package.

An alternative approach would be to design a waste package (and possibly other components of the engineered-barrier system) that clearly exceeds the regulatory criteria. In this approach, we would initiate a study to evaluate a range of very-lowprobability potentially disruptive processes and events that could affect the performance of the engineered-barrier system and conduct a functional analysis to establish performance requirements. When these activities have been completed, we would develop alternative conceptual designs. Alternative designs for the waste package might include simple single-walled containers or complex multilayered packages consisting of different metals and nonmetals (e.g., ceramic liners, which are highly resistant to corrosion).

\section{Suggested original options for initiating discussions}

Option 1. We could design the waste package to be compatible with the wasteemplacement environment and to meet, but not attempt to significantly exceed, the regulatory criteria for the life of the waste package.

Option 2. We could design a waste package that would exceed by a significant margin the regulatory criteria. This design would be done in parallel with studies of the waste-emplacement environment, which are included in Section 8.3.4.2.4 of the Site Characterization Plan.

Option 3. We could pursue both options in parallel with studies of the wasteemplacement environment and other scientific studies during site evaluation. Once the results of the studies are available and a costbenefit analysis has been performed, a single design path would be chosen. 


\section{Synopsis of workshop discussions}

Most participants agreed that long-lived waste packages for the repository would be desirable, because they would provide defense in depth against the loss of containment and radionuclide migration, and add a margin of safety. However, there was no consensus on the specific advantages to be gained by developing such packages or the reasons for selecting such an option.

Some felt that people understand backups and therefore redundancy and defense in depth would help build public confidence; common sense dictates that the repository should have as many barriers as practical. Some participants also felt that an enhanced waste package would help diminish uncertainties about the site. A more common opinion, however, was that the public views 10,000 -year predictions with skepticism, as they do our technical capabilities and technology in general, and the uncertainties are too great to significantly improve public confidence. Because some technical people doubt the feasibility of building even a 1000-year container, let alone a 10,000-year container, it will be difficult to persuade the public that a package will survive intact for many thousands of years.

Similarly, while some said that a long-lived waste package could facilitate licensing, and perhaps diminish concerns about the consequences of inadvertent human intrusion into the repository (no specific scenarios were discussed), others doubted that significant benefits in licensing would be gained. We were also admonished not to use the waste package to compensate for deficiencies at a particular site. On the other hand, public confidence might be increased by constructing the waste package to a higher standard without, at the same time, decreasing our reliance on the performance of the site, the natural barrier.

Two other issues emerged in the discussion: costs and the desirability of regulatory criteria for a single component of the repository system (i.e., the waste package), as opposed to performance criteria for the overall system. Some questioned whether the advantages of a waste package that exceeds regulatory requirements would be worth the cost, and others felt that the additional cost might be acceptable if the value can be demonstrated clearly. In regard to regulatory requirements, we were advised that the public will view with alarm and suspicion any tinkering with regulations; we should work within the existing regulations, go beyond doing the minimum, but not compensate for geologic inadequacies.

\section{DOE response and current plans}

Option 3 represents the current design approach. The current reference design is at a conceptual stage. Alternative materials and design concepts were to be further evaluated in the next, more-advanced design phase, which we had planned to start in 
1990. However, we have deferred most work on advanced designs until more information is available about the suitability of the site and the waste-emplacement environment; the pertinent studies are described in Section 8.3 of the Site Characterization Plan. Another issue that needs to be resolved before design work should proceed is long-term cooling, as discussed above under the preceding issue. Deferring detailed design will conserve resources and allow the concentration of efforts on the scientific investigations.

In terms of total-system performance, option 2 and perhaps option 3 may help to offset residual uncertainties that may exist about the performance of the natural system at the site. This would not be "compensating for a bad site"; it would merely add strength to the multiple-barrier approach. It might thereby help to demonstrate the long-term performance of a repository and contribute to public confidence in the safety of a repository. Interest in a waste package that could provide containment for 10,000 years or more has been expressed by the Nuclear Waste Technical Review Board, which has also asked us to address questions of the potential benefits and tradeoffs associated with the long-term cooling of spent fuel. Important considerations in evaluating tradeoffs for a long-lived package will be cost and feasibility.

We will hold a workshop on June 18-20, 1991, to discuss concepts for the engineered-barrier system and their applicability to extended performance life.

Option 3 allows us to retain option 1 if scientific investigations ultimately indicate that the current design approach is adequate and the benefits to be gained from a longer-lived package do not clearly justify significant increases in cost.

We agree that changes to regulatory requirements should not be tailored to a particular site. With regard to the waste package containment period, a change in the regulations to either a longer or a shorter period could affect public confidence. A change to a shorter containment period could be viewed as an attempt to compensate for inadequate engineering. A change to a longer containment period might cause the public to question our position on the waste-isolation characteristics of the site. We could choose to design a longer-lived waste package and such a package would become, in systems-engineering terms, an internal requirement, not an imposed (external) constraint. Any credit taken by demonstrating waste package containment for more than 1000 years would not be intended to compensate for geologic inadequacies. While the engineered-barrier system is important to the repository system, especially for the defense-in-depth concept, reliance on the natural barriers is the basic tenet of the concept of geologic disposal. Thus, though performance assessments conducted for licensing would probably incorporate the benefits of a longlived waste package, evaluations of site-suitability will consider the natural barriers on their own merits, not in conjunction with any enhanced engineered barriers. We intend 
to perform system and tradeoff studies to evaluate the benefits and costs of the options, including licensability considerations.

\section{TIMING AND CRITERIA FOR DETERMINING THE SUITABILITY OF THE CANDIDATE SITE FOR A REPOSITORY}

\section{Background}

As described in the Site Characterization Plan, we will conduct a comprehensive program of scientific investigations to evaluate whether the Yucca Mountain candidate site in Nevada is suitable for a repository. This program will consist of both surfacebased tests and tests conducted in an exploratory facility that includes underground excavations at the depth proposed for a repository.

We will establish priorities for the surface-based and underground tests in order to detect, as early as possible, conditions that would indicate that the site is unsuitable for development as a repository. If the site is determined to be unsuitable, then we will have to report to the Governor and the legislature of Nevada and the Congress of the United States.

If the site is not determined to be unsuitable, we will continue the site-evaluation program to determine whether a repository at the site would safely contain and isolate the waste for thousands of years. After the completion of site evaluations, we will make a formal finding that will serve as the basis for recommending the site to the President, and if the President agrees, he will recommend to the Congress that the site be developed as a repository. This process is specified by the Nuclear Waste Policy Act as amended.

Before making the formal determination, it may be advisable to make preliminary findings of suitability. We also need to decide on the criteria and method used in the determination.

Suggested original options for timing

Option 1. We could make preliminary evaluations of suitability at regular intervals (e.g., every 24 months) on the basis of the available data.

Option 2. We could make preliminary evaluations of suitability at major program milestones (e.g., before starting to construct the exploratory facility).

Option 3. We could make all of these evaluations. 


\section{Suggested original options for suitability criteria}

Option 1. We could apply those aspects of our siting guidelines (10 CFR Part $960)$ that are appropriate for evaluating a single site.

Option 2. We could revise the guidelines to use the NRC's licensing criteria in 10 CFR Part 60.

Option 3. We could revise the guidelines by changing generic guidelines to sitespecific factors.

Option 4. We could revise the guidelines and use criteria developed by external parties.

Option 5. We could work together with affected parties to develop new sitespecific suitability guidelines.

\section{Synopsis of workshop discussions}

Strong views regarding the options did not emerge from the workshop discussion, and the participants were more interested in discussing general regulatory problems, such as the lack of environmental standards (the Environmental Protection Agency (EPA) is revising Subpart B of 40 CFR Part 191, which was vacated and remanded), the degree of protection provided by the original EPA standards, and the difficulties associated with demonstrating compliance with the original EPA standards.

In the case of the suggested options for timing, none of the options were specifically endorsed, but there was agreement that we should determine as expeditiously as possible whether the site merits further study.

In the case of the suggested options for criteria, some participants clearly favored option 1. There also seemed to be agreement that attempting to change any regulations would be imprudent because it might seem to the public that we are trying to get around requirements for safety.

We were advised that good criteria for determining unsuitability are vital. One participant suggested that a false-negative determination on suitability early on in the process is worse than a false positive; a false positive may cost no more than another year of wasted effort, while a false negative could destroy a multiyear investment. Thus, it is not necessary to make a final determination of suitability at the outset; it is necessary merely to determine whether the site is suitable for further studies. Others cautioned that the process of deciding whether to continue studies should include participants financially independent of those studies. 


\section{DOE response and current plans}

The determination of site-suitability has a high priority in the repository program. We also recognize the importance of making an early suitability determination. We are currently following option 1 with respect to the timing of suitability evaluations and option 1 with respect to suitability criteria. We have restructured our site-evaluation program to this end and plan to start surface-based testing as soon as we obtain the necessary access to the site. Our goal is to conduct reliable and insightful tests early in site characterization. In establishing priorities for the testing program, we did consider the likelihood of reaching false-positive or false-negative conclusions.

The vehicle for communicating with the public on site-suitability will be semiannual reports on the progress of site characterization. The progress reports will discuss any results of site-suitability evaluations completed during the 6-month reporting periods and reference the reports that fully describe these efforts.

We are also involved in an intensive effort to develop a general approach for conducting iterative site-suitability evaluations during site characterization. A core group of experts has been established for this purpose, and the general approach being developed should be available this summer. We plan to seek broad external comment on it. We also plan to conduct an early site-suitability evaluation, now scheduled to be completed in early 1992, that will include an external peer review. Efforts by the Electric Power Research Institute and by Golder Associates to develop a suitability methodology are also under way, and we will compare and evaluate these independent approaches before finalizing our own strategy.

The current methodology is based on using our siting guidelines for both the early and later evaluations of site-suitability (i.e., option 1). In choosing this approach we carefully considered that, for a number of the siting guidelines, establishing that a qualifying condition is met may require extensive data from underground testing. We decided on this option after evaluating various alternatives, considering comments from the State of Nevada, and considering expert opinion. This approach seems to be compatible with the opinions expressed at the workshop.

\section{APPROACH TO THE DEMONSTRATION OF PERFORMANCE}

\section{Background}

In order to issue a construction authorization for a repository, the NRC must find that the site and the design of a repository comply with requirements specified in 10 CFR Part 60. These regulations require a demonstration of compliance with 40 CFR Part 
191, the EPA standards for geologic disposal (currently being revised). Two approaches could be taken in specifying the regulations. One is to establish regulations on how to perform analyses as well as specifying the required performance objectives. The second approach is to establish the required performance objectives and provide guidance on how analyses are to be performed.

NRC's current requirements establish performance objectives for the total repository system - that is, both natural barriers and engineered barriers - as well as each of the system elements. In a regulatory strategy paper (SECY-88-285), the NRC identified several topics as requiring a rulemaking. One of these topics is demonstration of compliance with the EPA standards. We believe that rulemaking in this case is not appropriate and have advised the NRC that this is our position.

\section{Suggested original options for initiating a discussion}

Option 1. We could petition the NRC to change its regulations by specifying only total-system performance objectives, without performance objectives for particular elements of the system.

Option 2. Without petitioning for a change in regulations, we could request the NRC to abstain from rulemaking on the topic of performance demonstration but to provide us with guidance through regulatory guides.

Option 3. We could hold further discussions with the NRC on the topic and evaluate alternative approaches.

\section{Synopsis of workshop discussions}

Some participants preferred regulatory guidance to rulemaking, especially since flexibility is necessary in a first-of-a-kind licensing, while others saw merit in a rulemaking because it would reduce the complexity of issues to be resolved during licensing. We need stability in the rules. It would therefore be useful to "get the rules on the table now," get them litigated, defined. To the extent that the NRC procedures can be defined beforehand, it would help if any changes were done by rulemaking to permit open discussion.

Similarly, while some felt regulatory criteria should be restricted to the total system, there were strong arguments against our attempting to change the regulations. Such attempts might create the perception that we are trying to get around something. This view was also expressed during discussions of other issues. The participants recognized that some changes are inevitable and that these necessary future changes may hurt more in terms of public perception. A credible process for making changes 
is needed so that we are not forced to forego the ability to apply what we have learned. An approach that might help is to make a clear commitment that any rule change will be made to improve safety rather than bureaucratic convenience.

A major topic in the discussion was the status of EPA regulations, with some participants stating that concerns about NRC regulations were premature until the EPA acts. Without the EPA standards, the NRC criteria are meaningless, and our plans for performance assessment are built on quicksand.

Other discussions involved taking credit in the regulatory analysis for engineered barriers. Opinion on this topic was divided. Some felt that it is premature to think about using engineered barriers to complement isolation provided by the natural barriers; it reduces confidence in the program, as there is no experience with engineering for 10,000 -year periods. Other participants, however, felt that the concept of engineered barriers should be part of the overall performance allocation.

\section{DOE response and current plans}

The NRC's regulation is generally not prescriptive, recognizing that a repository has never been built and operated. The regulation states, for example, that, provided the overall system performance objective is satisfied, the NRC may approve or specify subsystem performance objectives other than those specified in 10 CFR 60.113. We fully agree with this philosophy and believe it is prudent to retain the flexibility to propose alternative approaches to demonstrating compliance rather than being required to meet specific interpretations established by rule.

We favor option 3 until alternatives are more clearly defined after 10 CFR Part 60 is revised to reflect the revised EPA standards.

We believe that it is our responsibility as a potential applicant and licensee to propose our position on the issues. Our proposed positions should be evaluated by, and discussed with, the NRC and should be considered by the NRC in making decisions on the need for, and the nature of, regulatory guidance. The NRC could provide guidance on this issue in NRC staff technical positions or in regulatory guides, or the NRC staff could review our topical reports on the issues and document their findings in safety evaluation reports as they do for the nuclear power industry. 


\section{PHASED LICENSING FOR THE REPOSITORY}

\section{Background}

As specified in the NRC regulations in 10 CFR Part 60 , the licensing of a repository will include authorization to construct a repository; a license to receive and possess radioactive waste at the site, to be issued after the repository is constructed; and an amendment of the license permitting the repository to be decommissioned and permanently closed. One reason for phasing the licensing in this manner is to allow the NRC to evaluate additional information about the expected safety performance of the repository.

Since a repository is a first-of-its-kind facility, its licensing, especially the first phase, is expected to be the most difficult challenge of the repository program, and there is concern that the information included in our license application may be deemed insufficient for a favorable finding. To increase the probability that we will be able to provide the information required for licensing we have evaluated a number of options, including several that are based on licensing the repository in phases.

\section{Suggested original options for initiating a discussion}

Option 1. If the site is determined to be suitable, we could seek to obtain a construction authorization for a full-scale repository, as assumed in our current plans.

Option 2. Instead of attempting to obtain a construction authorization for a fullscale permanent repository, we could attempt to first license pilotscale facilities at a repository site. These pilot-scale facilities would be used to obtain information needed to complete and refine the design of a repository and a waste package, and to conduct tests in order to collect more data for the next licensing phase. They would be eventually scaled up to a repository subject to additional licensing.

Option 3. We could petition the NRC to divide the licensing process into two distinct phases. In the first phase we would seek to receive a construction authorization, under 10 CFR Part 60 , for a temporary storage facility in the underground repository. This facility would not be licensed as a repository. In the second phase, which would occur years later, we would seek a license for a repository.

Option 4. We would seek to license a repository, but we would use the approach of incremental licensing for individual blocks of underground 
waste-emplacement areas, using waste-acceptance procedures and criteria agreed upon by the NRC.

\section{Synopsis of workshop discussions}

There seemed to be general agreement that we should stay with option 1 , our current plans for licensing. The other options were viewed as offering no significant advantages and having the potential to adversely affect public perception as an attempt to get around regulations or an attempt to permanently emplace waste before the repository is licensed. There were, however, some criticisms of our current approach on the grounds that we do not plan to construct the entire underground repository before waste-emplacement begins. (We plan to construct two panels of wasteemplacement rooms and start waste-emplacement while simultaneously developing other panels.)

One participant commented that option 2 (license for pilot-scale facility at repository site) would yield no data that would not be obtained through the regular licensing process. This option was seen as just an additional licensing process with the potential for litigation.

Option 3 (licensing in two distinct phases) was not clearly understood. We explained that it had been put forward by some other parties, not us. The objective is to use the repository for retrievable storage for perhaps hundreds of years, doing tests during that time. If the repository passes the tests, then it should be licensed and closed; if not, the waste should be retrieved. Though it is a radical option, we felt obliged to include it here.

Little merit was seen for option 4 (incremental licensing for individual storage area blocks).

\section{DOE response and current plans}

Option 1 remains the current program plan, although we are in the process of evaluating licensing alternatives. In this evaluation we are examining a wide variety of options that encompass both conventional and novel approaches. It should be noted that the current licensing process is actually a multi-step process with NRC approval for construction, operation, and closure. Furthermore, options 2 and 3, and possibly option 4, would require legislative amendments. And we heard at the workshops that alternatives could carry disadvantages in terms of unfavorable public perception. However, other alternate licensing strategies, e.g., accelerating the license application date, may have value. 


\section{CONTINGENCY PLANNING}

\section{Background}

We are evaluating whether the Yucca Mountain candidate site in Nevada is suitable for a repository. To complete this evaluation we plan an extensive program of testing both from the surface of the site and underground, at the depth proposed for a repository if the site is found suitable. Issues related to the determination of suitability have been discussed earlier in this chapter.

We were directed to evaluate the Yucca Mountain candidate site by the Nuclear Waste Policy Act as amended. This law also specifies that if the site is found to be unsuitable, then we must notify the Governor and the legislature of the State of Nevada and recommend to the Congress, within 6 months, actions that should be taken to ensure safe disposal. By the decisions we make now, we must put the United States in the strongest position in the event that the Yucca Mountain candidate site is found unsuitable.

\section{Suggested original options for initiating a discussion}

Option 1. We could abstain at present from specific actions to prepare for the possibility that the Yucca Mountain candidate site might prove to be unsuitable, other than responding to requests from the Nuclear Waste Negotiator.

Option 2. We could increase our participation in international scientific investigations of disposal to be better prepared for considering host rocks other than the volcanic tuff present at Yucca Mountain.

Option 3. We could change our approach to the development of the waste package; instead of developing a design specific to the Yucca Mountain candidate site, we could develop waste package designs suitable for a variety of potential host rocks.

Option 4. We could identify, on the basis of available information from our earlier activities and data from international programs; host rocks and areas that might provide potentially suitable sites for a repository.

\section{Synopsis of workshop discussion}

The workshop broadened the discussion to the need for contingency planning in general. There was general agreement that such planning is indispensable to a 
program like ours. The participants strongly recommended that we develop a serious contingency plan.

\section{DOE response and current plans}

We fully agree that contingency planning is essential, because our program is a first-ofa-kind undertaking marked by controversy and contention. We have performed contingency planning in the past, but these efforts lacked the formality and documentation needed to assure affected governments and interested parties that a substantial effort was being devoted to contingency planning.

Our planning staff began developing a process of strategic and contingency planning last summer that is an outgrowth of a Department-wide planning initiative. In September 1990, we delivered to the Secretary of Energy a strategic plan stating, among other things, that we will investigate alternatives that could be implemented in the event that the Negotiator is not successful. The need to consider this issue was reiterated in the multiyear program plan sent to the Secretary in December 1990.

We recently began to develop and evaluate contingency planning processes. It is clear that we need to plan for a variety of near-and long-term contingencies in a comprehensive, rigorous way. Above all, we need to develop contingency plans to address the following two issues:

- What should we recommend to the Congress in the event that the Yucca Mountain candidate site is found to be unsuitable as a repository? What decisions can we make now to put us in the strongest position to respond in the event that the Yucca Mountain candidate site is found to be unsuitable?

- What should we do in the event that the Negotiator is not successful in finding a volunteer MRS site?

Our plans are to continue the development of a contingency planning process that supports overall strategic planning.

\section{GEOLOGIC DISPOSAL FOR WASTES OTHER THAN SPENT FUEL AND HIGH- LEVEL WASTE (GREATER-THAN-CLASS C WASTE)}

\section{Background}

In 10 CFR Part 61, the NRC has defined three classes-A, B, and C-of low-level radioactive waste in order of increasing radiation hazard and longevity. Waste that exceeds the radioactivity concentrations permitted for Class $\mathrm{C}$ is known as "greater- 
than-Class $\mathrm{C}$ waste." This waste comes from a wide variety of sources, including the operation and decommissioning of reactors, medical activities, and research. It varies in physical characteristics, composition, and radioactivity. At present, this waste is kept in storage at the sites where it is generated.

The actual quantities and characteristics of greater-than-Class $\mathrm{C}$ waste are presently being determined. Most of it will be radioactive metals from decommissioned power reactors, but it is believed that a portion of this waste could be "mixed waste" - that is, waste that contains both radioactive materials and hazardous chemical substances as defined in the Resource Conservation and Recovery Act of 1976.

The DOE, through its Office of Environmental Restoration and Waste Management (DOE-EM), is responsible for the disposal of greater-than-Class $\mathrm{C}$ waste under the Low-Level Waste Policy Amendments Act of 1985; DOE-EM is currently conducting a comprehensive study directed at determining the quantities and characteristics of this waste. In the past, the DOE has proposed providing for such waste special "intermediate-level" disposal-that is, disposal at depths on the order of 100 feet below the surface. Such disposal would provide greater isolation than do lowlevel waste sites and would be much less costly than a geologic repository. (Management of greater-than-Class $\mathrm{C}$ waste is not covered under the Nuclear Waste Fund established by the Nuclear Waste Policy Act unless the NRC determines that such waste must be disposed of in a geologic repository.)

Responsibility for classifying waste and determining which waste requires geologic disposal rests with the NRC. The NRC has not determined that greater-than-Class C waste requires geologic disposal. However, in its rule on the disposal of low-level waste, 10 CFR Part 61, the NRC proposed geologic disposal for this waste "unless proposals for the disposal of such waste in a disposal site licensed pursuant to $10 \mathrm{CFR}$ Part 61 are submitted to the Commission for approval." We have encouraged the NRC to resume the effort of redefining the classes of radioactive waste, distinguishing between greater-than-Class $\mathrm{C}$ waste that requires geologic disposal and that which does not require such costly disposal.

\section{Suggested original options for initiating a discussion}

Option 1. DOE-EM could complete the characterization of greater-than-Class C waste. The OCRWM should then evaluate how much space this waste would require in a repository, how it might affect licensing, and how it might affect the performance of the repository.

Option 2. We (the DOE's Office of Civilian Radioactive Waste Management) could petition the NRC to develop specific performance criteria for the packaging and emplacement of this waste, regardless of the 
method of disposal. We should also petition the NRC to identify the greater-than-Class $\mathrm{C}$ waste, if any, that should be isolated in a repository.

Option 3. We could petition the NRC to develop specific regulations for the disposal of greater-than-Class $\mathrm{C}$ waste.

Option 4. DOE-EM could plan to provide interim surface storage for this waste.

Option 5. DOE-EM could start planning to develop special "intermediate-level" facilities for this waste.

Option 6. We could defer planning for the disposal of this waste until the decision on the need for a second repository is made. We could then plan to emplace all this waste in a second repository if one is needed.

Option 7. We could start planning to accept some greater-than-Class $\mathrm{C}$ waste in the first repository.

\section{Synopsis of workshop discussions}

The topic of greater-than-Class $\mathrm{C}$ waste was not specifically addressed in the workshops, and therefore the options suggested above were not discussed. However, the disposal of this waste was included in discussions of site-suitability because it is pertinent to the question of disposal capacity. It remains a significant uncertainty in terms of waste volumes requiring disposal, because of the statutory limitations on the loading of the first repository before having a second repository in operation. Several participants strongly argued that the need for a second repository should be addressed now.

\section{DOE response and current plans}

Consistent with its responsibilities under the Low-Level Waste Policy Amendments Act of 1985 , DOE-EM is determining current and future quantity and the characteristics of greater-than-Class $\mathrm{C}$ waste. DOE-EM has assigned this task to the Idaho Operations Office, which in turn contracted EG\&G-Idaho to do the work. We are participating in the review of the results of EG\&G's analyses. This effort is still ongoing, and a final report is expected later this year. The present "best estimate" volume of unpackaged greater-than-Class $\mathrm{C}$ waste by the year 2035 is approximately 300,000 cubic feet.

If the NRC were to determine that the greater-than-Class $\mathrm{C}$ waste is high-level radioactive waste, OCRWM would have to provide for its disposal in a geologic 
repository under the NWPA as amended. As this determination has not been made, OCRWM is not planning to include greater-than-Class $\mathrm{C}$ waste in a repository.

A decision to emplace greater-than-Class $C$ waste in the first repository (option 7) could substantially affect the planning, design, cost, and licensing of a repository. It would require detailed analyses of potential effects on the preoperational safety of the repository, the long-term isolation capability, the waste-emplacement configuration, and many other factors. We will continue to discuss with the NRC the disposal requirements for greater-than-Class $\mathrm{C}$ waste.

\section{USING A DEMONSTRATION FACILITY TO INCREASE CONFIDENCE}

\section{Background}

Proceeding to develop a repository at a more deliberate pace and in smaller, but perhaps surer, steps might contribute significantly to confidence that a repository will perform safely over both the near and the long term. One way to implement such an approach is to include in the repository-development process a demonstration project that would allow us to develop and demonstrate disposal technology with real waste in a geologic setting that is the same as, or similar to, that of the proposed repository.

The objective of a demonstration project would be to decrease uncertainties, thereby supporting licensing and increasing the confidence of the public. If the demonstration facility were co-located with the potential repository, the project could also significantly increase the amount of site information that is available for licensing. The role that a demonstration project would play in reducing uncertainties depends on the type of facility that would be used, the location of the facility, the tests that would be performed, and the time at which the demonstrations could be performed.

We will construct an exploratory facility at the Yucca Mountain candidate site to provide access to the horizon that would be used for a repository if the site is found suitable and to provide underground excavations for various tests needed to determine the suitability of the site. None of the tests currently planned for that facility will use actual waste. However, in principle, the facility could be used for the demonstration tests discussed above, although more underground excavation might be necessary and the scope of the testing would probably be increased.

\section{Suggested original options for initiating a discussion}

Option 1. We could perform the demonstration in the exploratory facility to be built at the Yucca Mountain candidate site. We could start by constructing a shaft or ramp to the proposed depth of a repository, 
excavating repository-size drifts, and boring waste-emplacement holes in which tests would be performed.

Option 2. We could develop an underground research laboratory near, but separate from, a repository block. This research laboratory would be completed before the exploratory facility and could be used for prototype testing, demonstrating the suitability of the rock horizon proposed for a repository, and examining the spatial variability of the rock. This option would be subject to continuing NRC analysis.

Option 3. We could develop at the Yucca Mountain candidate site a test-andevaluation facility pursuant to Sections 211 and 305 of the Nuclear Waste Policy Act as amended. The Act authorizes the construction of such a facility for demonstrating the technology needed for geologic disposal and for tests related to site evaluation and the operational aspects of waste disposal. For these tests it allows the emplacement of up to 100 metric tons of spent fuel under continuing NRC review. This facility would be used only if the Yucca Mountain candidate site is determined to be suitable for a repository.

Option 4. Before proceeding to construct, license, and operate a full-scale repository, we could construct and operate a repository as a pilotscale facility with limited waste-emplacement and licensing in increments.

\section{Synopsis of workshop discussions}

There was little support for a demonstration facility in the discussion. In view of the long time required for isolation-thousands of years - a demonstration facility with tests conducted over several years might not add much to public confidence. And using spent fuel in a demonstration facility would likely be adversely received in Nevada.

Once the repository starts operations, it itself will be run as a demonstration project, with information gathering continuing for over 50 years, during which time all emplaced waste is to remain retrievable. If the demonstration is to involve further studies and hence additional costs, the utilities will not support it.

\section{DOE response and current plans}

We are currently evaluating the need for a prototype facility, but one in which we do not anticipate a need to emplace spent fuel. The benefit of a prototype facility must be evaluated recognizing that we will later construct an exploratory facility at the site consistent with NRC regulations. Because data collected away from the site may not 
be considered representative, it might be necessary to duplicate some work in the exploratory facility. However, there may be compensating benefits for the overall test program in terms of flexibility, experiment design, and implementation.

\section{RISK ASSESSMENT IN SELECTING TRANSPORTATION MODES AND PREFERRED ROUTES}

\section{Background}

We are taking various steps to ensure the development of a comprehensive program for the assessment and management of transportation risks. These steps include the development, enhancement, or evaluation of various computer models, including models based on well-established probabilistic techniques of risk assessment. To support these models, we are also developing a transportation data base; this includes the preparation of a standard reference document for transportation assumptions, the collection of data on accident rates for rail and road transport, and the development of risk factors for national transportation network analyses.

We have kept the Nuclear Waste Technical Review Board informed regarding our work in the development or revision of computer models and codes, and the Board has responded with comments and suggestions. We anticipate a similar working relationship with the Board regarding the development of plans for the application of these models and codes.

The methods and models used for risk assessment could be applied to the selection of transportation modes (truck or rail) and preferred transportation routes. We have not yet made a final determination about transportation modes. However, it is currently our intent to ship waste by rail where possible. For shipments from the MRS facility to the repository, we currently plan to use dedicated trains.

\section{Suggested original options for initiating discussion}

Option 1. We could use risk assessment as the primary method of selecting transportation modes.

Option 2. We could use risk assessment as the primary method of identifying transportation routes.

Option 3. We could use risk assessment as a tool in supporting decisions on transportation modes and routes. 
Option 4. We should not use risk assessment in these transportation applications.

\section{Synopsis of workshop discussions}

Participants acknowledged that although the actual risks from transportation are likely to be low, transportation is likely to be the major issue in waste-management, and the public is likely to be extremely concerned about its safety. The participants cautioned us on the use of risk assessments, saying that such assessments are of questionable technical value and can be misconstrued by the public. They did not distinguish between the use of risk assessments specifically in decisions on route selection and transportation modes. Several participants advised us to carefully consider public concerns, to attempt to understand the issues in the terms of the ordinary person, and to address them thoroughly, even if public perceptions of risk are not consistent with the results of technical risk assessments. In evaluating measures with the potential of improving transportation safety, we should be concerned with increasing regulatory approval and public confidence and not be concerned only with the probability of the incident that is to be prevented or mitigated.

We should be careful in interpreting the results of quantitative risk assessments and using them as proof of safety. Even a small transportation accident would damage the credibility of those assessments since the public does not relate to averages or probabilities. To address the concerns of the public in our analyses, we should consider real situations and include worst-case scenarios, even if they are so unlikely as to be incredible. We were advised that we need to answer such questions as what it means in terms of real world exposure to have a truck stop next to you. If the Yucca Mountain candidate site is found suitable, the Nevada routes to the repository will be secondary roads through small towns. The implications for the people living there must be addressed.

We were cautioned not to attempt to "sell" program safety, but rather to concentrate on establishing productive communication with the public. There was also a suggestion that, if risk assessment is to be used, it should be performed by State and local organizations rather than us.

\section{DOE response and current plans}

Although risk assessment is an important tool in the consideration of transportation impacts, other factors must also be considered in selecting shipping modes and preferred transportation routes. The Department of Transportation (DOT) has established specific regulations for the highway routing of spent fuel shipments. In these regulations the States have an established role in the designation of preferred routes for these shipments within their boundaries. Although there are no DOT 
regulations for the routing of spent fuel shipments by rail, the Congress has recently directed the DOT to study the advisability of establishing such regulatory requirements and review the overall factors that should be addressed by both shippers and carriers in the selection of both routes and modes of transportation. If after DOT's review, new regulations are needed, the DOT will promulgate them. In selecting transportation modes and routes, we will ensure that our selections are in full compliance with regulatory requirements.

Another major element that we must consider in our transportation planning is the physical security of spent fuel shipments. The NRC has established specific regulatory requirements for the protection and safeguarding of these fuel shipments; they include specific security factors that will affect mode and route selection. We will ensure that our selections are in full compliance with the NRC's regulatory requirements.

There is a reasonably clear consensus that risk assessment should be used cautiously to support transportation decisions. Risk assessments often provide important insights to tradeoffs but by themselves are unlikely to adequately address public concerns about transportation risks. Moreover, as indicated above, the assumed risks are so low that they may not discriminate among various route selections. It is therefore not appropriate to rely on risk assessments as the primary method of making decisions on routing or transportation modes. At the same time, we recognize that risk assessments do yield important insights, and there is no advantage to us or to affected governments and interested parties to abandon the use of this technique entirely.

In the area of risk assessment, we believe that public confidence will be enhanced by State and local agencies making independent evaluations. To assist them, we have made available our RADTRAN computer code on the TRANSNET system. We are currently completing the documentation of this code.

We propose to implement option 3 and use risk assessment as a tool, where appropriate, to support decisions on transportation modes and routes. We will seek to obtain the views of the affected governments, interested parties, and the public on these risks and will address their concerns, as appropriate, through the following outreach activities to be included in our risk-management program:

- Meeting with affected governments and interested parties to identify their concerns.

- Attempting to reach consensus with affected governments and interested parties. 
- Keeping the affected governments and interested parties informed about our activities in risk management.

- Conducting public information meetings and publishing periodic update reports.

- Providing means for communicating directly with us.

\section{DEVELOPMENT OF DUAL-PURPOSE CASKS FOR TRANSPORTATION AND STORAGE}

\section{Background}

A dual-purpose cask is a metal container that has been designed and approved to be used for both transportation and storage of spent fuel. Dual-purpose casks must satisfy the requirements of 10 CFR 72 for certification by the Nuclear Regulatory Commission (NRC) for use as storage casks and must also satisfy the requirements of 10 CFR 71 for certification as transport casks. To date no casks have been certified by NRC for dual-purpose use, and some certification issues remain to be resolved. However, a cask vendor (NAC) is currently involved in obtaining an NRC certification for a dualpurpose cask.

We are considering the use of dual-purpose casks for the first phase of an MRS facility. These casks would allow earlier waste acceptance because they could be shipped to an MRS site and stored. Since the fuel shipped in them may not need to be unloaded or handled in any way, they would permit waste acceptance before the waste-handling building of an MRS facility is completed. However, dual-purpose casks are not at present included in our program for developing transportation casks. For use in the first phase of the MRS facility, these casks would be demonstrated and certified by commercial vendors and the utilities or by a cooperative demonstration program.

\section{Suggested original options for initiating a discussion}

Option 1. We should not include any dual-purpose casks in our shipping-cask fleet.

Option 2. We should include a limited number of dual-purpose casks in our cask-development program for the initial phase of MRS operations. 


\section{Synopsis of workshop discussion}

Diverse views were expressed on the issue of dual-purpose casks. Some participants favored including a limited number of dual-purpose casks in the program on the grounds that this option would help to minimize the handling of spent fuel; yield benefits in overall system costs, particularly if casks would allow the closing of storage pools at the sites of decommissioned reactors; and provide for more system flexibility. The major concerns were NRC certification (receiving NRC permission to ship the casks after long-term storage), compatibility with utility plans for storage, and cost. The latter seemed to be the principal issue, since the casks are expensive (though their costs might be reduced by a large procurement), and any savings would be realized later, whereas the utilities would have to make the investment now. The costs should be thoroughly analyzed in terms of system economics. Benefits in both licensing and costs might be obtained if the cask to be developed was mainly a storage cask with a one-time transportation certificate.

There was also concern that the use of dual-purpose casks might affect MRS siting if it creates the impression that the DOE is rushing into storage at an uncompleted facility. The issue was that the public might not be comfortable with the notion of simple storage on a construction site.

An alternative approach that might achieve the benefits of dual-purpose casks at less cost would be to divide the three functions of the dual-purpose cask (store and protect at the reactor site, transport safely, and store and protect at the destination site). This could potentially be achieved by packaging the spent fuel in multi-assembly storage canisters that would be free of external radioactive contamination, thereby simplifying transfer operations at storage sites. The multi-assembly canisters would be placed in reusable containers for transportation, allowing the reuse of the most expensive components.

\section{DOE response and current plans}

Although our current cask-development program does not include dual-purpose casks, commercial vendors have proceeded with the design and development of these storage and transport casks. Should these vendors be successful in receiving NRC certification for storage and transportation, we will evaluate the use of their casks as part of early waste acceptance at the first phase of an MRS facility. We will first consider the overall system costs and benefits. We will also examine their operational safety and the NRC's dual certificates of compliance in particular. If these issues cannot be resolved quickly enough to permit us to acquire a sufficient number of the casks by 1998, there will be no advantage in developing these casks. If these issues are satisfactorily resolved, we will determine whether cooperative projects with industry should be funded to further develop and use dual-purpose casks. 
The situation is similar with regard to the utilization of a system based on the use of multi-assembly storage canisters. A spent fuel storage system consisting of multiassembly storage canisters within concrete horizontal modules has been developed by a vendor (NUHOMS) and is currently being utilized at two reactor sites. The multiassembly canister has not at this time been approved for use as a component of a certified transportation cask.

Our decision on the use of either of these technologies will be based on their safety, cost effectiveness, usefulness in the waste-management system, feasibility for the intended use, the use of these technologies by utilities and the regulatory issues. Also, input from a volunteer host will be factored into decisions on the selection of technologies to be used at an MRS site. We expect to make our decision after NRC has issued certificates of compliance for the technologies.

We recognize that, regardless of the ultimate role that we see for such technologies to accomplish our goals within the Federal waste-management system, many utilities are making decisions now to deploy such technologies to meet their current storage requirements. We will continue to monitor their decisions and work with them to ensure that the systems are compatible and the spent fuel can be safety and easily transferred to the Federal Government.

\subsection{MANAGEMENT ISSUES}

\section{ROLES OF UTILITIES AND THE FEDERAL GOVERNMENT IN THE MANAGEMENT OF SPENT FUEL BEFORE DISPOSAL}

\section{Background}

Our standard contract with the owners/generators of spent nuclear fuel, signed in accordance with the requirements of the Nuclear Waste Policy Act, states that in 1998, after commencement of facility operations, we are to start accepting the spent fuel stored at reactor sites. Since the schedule for the repository has been delayed, we plan to ship the spent fuel to a central storage facility, such as an MRS facility. If spent fuel transfer to a central facility cannot begin as currently planned, it will be necessary to develop substantial additional capacity for storage at all or some reactor sites. This issue concerns the appropriate and effective distribution of responsibilities between the Federal Government and the utilities in the management of spent nuclear fuel before disposal in a repository. 


\section{Suggested original options for initiating a discussion}

Option 1. Utilities are responsible for the storage of spent fuel until the fuel is transferred to the Federal Government. Transfer occurs when the spent fuel is loaded into government-owned transport casks and leaves the reactor site for a Federal waste-management facility.

Option 2. Utilities store spent fuel and also prepare it for further storage or disposal in a Federal waste-management facility in order to facilitate the operation of Federal facilities. Two variations are available for implementing this option (1) the utilities retain title to the spent fuel and perform the waste preparation under contract to us or (2) they transfer title to us before preparing the fuel.

Option 3. Utilities are responsible for providing for spent fuel storage until we pick up the fuel. However, for storage after 1998 we would pay with monies from (1) the Nuclear Waste Fund or (2) general revenues.

Option 4. After a specified date, we assume responsibility for, and take title to, spent fuel at the reactor sites. Until transferred to a Federal facility, the fuel would remain in storage at the reactor site in (1) a utility storage facility or (2) a storage area controlled by us.

Option 5. Utilities are directed to collect and store spent fuel at a small number of commercial-reactor sites as (1) part of Federal waste management, with costs paid from the Nuclear Waste Fund, or (2) at their own expense.

\section{Synopsis of workshop discussion}

Participants showed little interest in options 3,4 , and 5, which would require changes in the contract and legislation. The utilities may not want us involved in at-reactor storage. Furthermore, they are not interested in long-term at-reactor storage, regardless of who pays for it, because it creates difficulties for decommissioning plants. In regard to option 3, a participant commented that payment from general funds would be preferable.

On the other hand, some participants said that spent fuel storage at reactor sites is preferable to storage by the government. They felt that to achieve public acceptance the fuel should be kept at reactor sites with a rebate from the fee. 
There seemed to be some agreement that we should not take title to spent fuel at reactor sites because it would split responsibility for spent fuel management and cause problems in accountability.

In regard to option 2, there was little support for the utilities performing wastepreparation functions. However, one requirement clearly emerged: since the utilities are pursuing options like consolidation to increase the capacity of existing storage pools, they need to know what we will accept. The utilities would have a better basis for their waste-management decisions if they knew, for example, whether we would accept consolidated fuel.

\section{DOE response and current plans}

Our current planning for the Federal waste-management system is representative of option 1, which is also consistent with the existing institutional, contractual, and legal structure.

In response to the workshop discussion, we have developed the following strategic principle: "strive to diminish uncertainties related to spent fuel management by the utilities." This principle has been added to Chapter 2 under "Management Principles." We plan to implement this principle by identifying pertinent technical interfaces with the utilities and providing the utilities, in a timely manner, the information they need to coordinate their waste-management activities with ours. This would include acceptance criteria for spent fuel and information on the compatibility of treatment technologies that might be used at reactor sites, such as consolidation or loading into special storage canisters.

\section{PRIVATE-SECTOR INVOLVEMENT IN THE DEVELOPMENT AND OPERATION OF AN MRS FACILITY}

\section{Background}

An MRS facility can provide significant benefits to the Federal waste-management system by improving the development of the overall system, providing timely and adequate waste acceptance, enhancing confidence that the waste-management problem can be managed in a predictable and timely manner, and providing a flexible coupling between at-reactor waste-management operations and repository operations by acting as a buffer between systems with dissimilar needs and characteristics.

The MRS facility will provide the Federal waste-management system with the capability to accept commercial spent fuel beginning as early as 1998 . The facility will be designed to receive, store, and stage shipments of spent fuel to the repository for 
permanent disposal; it will also provide the flexibility to perform additional functions that may be beneficial or required as the design of the waste-management system matures.

Technically suitable sites for the MRS facility can be found throughout the continental United States. The Nuclear Waste Policy Amendments Act authorizes two siting approaches for the MRS facility. One is negotiation with a State or Indian Tribe that can offer a technically suitable site on reasonable terms; to implement this approach, the Congress created the Office of the Nuclear Waste Negotiator. The other is a survey-and-evaluation process conducted by us.

As a way to expedite the siting and development of an MRS facility, the privatization of some or all of the development process has been proposed.

\section{Suggested original options for initiating a discussion}

Option 1. The MRS facility should continue to be a federally owned facility operated by a contractor.

Option 2. A storage facility could be sited, constructed, and operated by private industry. The utilities would contract directly with the owner of the facility for spent fuel storage.

Two variations are possible for option 2 as follows:

1. The facility could be developed by private industry, as in option 1 , but, we, instead of the utilities, would purchase storage space and services. The utilities would deal with us.

2. We would lease storage space from the private developers of an MRS facility and hire a contractor to operate the facility for us.

\section{Synopsis of workshop discussion}

The workshop participants showed little interest in discussing private-sector involvement. The participants questioned why this issue was being discussed and said that this issue had already been settled by law. In addition, participants felt that other MRS issues (e.g., need, siting, co-location, and cost) are more relevant. One participant stated that the issue of who owns and operates an MRS facility is wrapped up in the larger issue of finding a site. We were reminded that ownership does not affect who does the work, and even in a Federal facility much of the work will be performed by private contractors. One of the participants felt that siting might be facilitated by private-sector involvement: if the Negotiator could clearly state early in 
negotiations with a potential host State or community that the facility will be developed by the private sector, rather than the DOE, the response may be more favorable.

We also received comments from parties who were not able to attend the workshops but who reviewed the strategic principles discussion draft. They stated that the law authorizes an MRS facility owned by the Federal Government, and our approach should therefore be Federal ownership. To the extent private initiatives are successful in providing an alternative, we may wish to evaluate those alternatives, which might involve a number of options for ownership and operation, at some future date. At this time, there is no need to adopt a strategic principle that calls for a change in the ownership of the facility as authorized by law.

\section{DOE response and current plans}

We agree that the privatization issue does not by itself, deserve the status of a strategic principle, although we believe that privatization may be able to expedite the development of an MRS facility. We will, as suggested by one commentor, evaluate private-sector involvement to the extent that it is successful in providing alternatives.

In regard to MRS siting, we agree that the efforts of the Nuclear Waste Negotiator offer the best opportunity to site an MRS facility. Consequently, our nearterm role in MRS siting will be to monitor the progress of external efforts to find a volunteer host and to support those efforts as appropriate.

\section{USE OF THE NUCLEAR WASTE FUND FOR STORAGE}

\section{Background}

If an MRS facility is developed as an integral part of the waste-management system and the acceptance priorities for spent fuel are based on the current contract with the utilities, then there seems to be no question that the Nuclear Waste Fund should be used to pay for its development and operation. However, as discussed in the preceding sections, a number of other options for providing storage could be used, and the means for paying for their costs should be determined.

\section{Suggested original options for initiating a discussion}

Option 1. An MRS facility is developed as an integral part of the Federal system. All of the costs of this option are paid from the Nuclear Waste Fund.

Option 2. An MRS facility is developed as an integral part of the Federal system. The costs of MRS development are paid for from the Fund, 
but the utilities using it for storage pay for the incremental operating costs of storage from the start of waste acceptance, assumed to be in 1998 , to the start of operations at a repository.

Option 3. An MRS facility is developed to provide storage for utilities needing additional capacity. The full costs of development and operation are borne by the users.

Option 4. The Fund is used to develop and operate commercial storage facilities or facilities provided at selected reactor sites.

\section{Synopsis of workshop discussions}

Very little interest in this topic was evinced in the discussions. The participants were more interested in other storage-related topics. One participant commented that the issue of funding had already been settled. Another pointed out that some of the options do not necessarily have cost implications. Since ratepayers are paying for storage, transportation, and disposal, their dollars are traded internally, and trading money internally does not really have a cost impact. The differences among options are more political than monetary.

\section{DOE response and current plans}

Because of the lack of discussion regarding this issue, we propose to drop it from further consideration as an issue of strategic importance.

\section{USE OF PEER REVIEWS}

\section{Background}

A peer review is a documented critical review performed by persons who have technical expertise in the subject matter of concern but are not directly involved in the analysis, study, or plan under review. Peer reviews are management tools for interpreting and verifying or validating assumptions, plans, results, or conclusions critical to the success of a program. Although the following discussion is directed at the Yucca Mountain project, peer reviews will be used as appropriate in other parts of our program.

Since our program has traditionally relied on peer reviews, the issue here is not instituting peer reviews as a new practice. Rather, it is a question of establishing guidelines for the use of peer reviews. 
Peer reviews yield multiple benefits. The expert appraisal of plans, methods, analyses, and results bolsters technical confidence, and the use of recognized independent authorities strengthens our credibility. Peer reviews may also generate fresh ideas and approaches to problems.

\section{Suggested original options for initiating a discussion}

Option 1. We should conduct special peer reviews as necessary on high-visibility issues of critical importance to ensure that the best available resources are mobilized for key decisionmaking.

Option 2. We should institute regular peer reviews in the routine conduct of the program such as the certification of data, comment on research conclusions, etc.

\section{Synopsis of workshop discussion}

The options suggested for discussion are not mutually exclusive, and there seemed to be agreement that we should use both options, depending on the circumstances. Furthermore, some of the discussion went beyond the topic of peer review to internal technical reviews and reviews mandated by law, such as those performed by the Nuclear Waste Technical Review Board.

Option 2 was deemed important from the public-confidence perspective, and we were advised to give serious consideration as to how peer reviews could be used to bolster public confidence. There also seemed to be agreement that most of our work should be internally reviewed, with the important work being externally reviewed and that, as recommended by the National Academy of Sciences, we should more frequently submit our work to outside experts who are not involved in the program.

The use of independent experts in the actual studies or activities versus their use as reviewers of those activities was discussed. Also, the scarcity of independent external experts was noted, as was the potential for the extensive use of peer reviews to result in cronyism. Finally, we were advised that peer reviews should not be limited to technical issues; institutional programs, socioeconomics work, and even management issues should get the same treatment.

We also received a number of specific suggestions, including the following:

- International peer review should be considered.

- It is important to have really independent reviewers rather than using mainly DOE contractors. 
- Peer-review panels should include technical critics.

- Need to find reviewers who will ask the hard questions, play the role of the devil's advocate.

\section{DOE response and current plans}

We will continue to use the peer review process as an important mechanism for ensuring the quality and credibility of our work. We will respond to the recommendations of each peer review and incorporate those deemed appropriate into our plans and operations. The peer-review process will be used in accordance with applicable quality-assurance procedures, and the findings therefrom will be considered part of the management decisionmaking process.

In determining when to use peer review, we plan to weigh the benefits and costs of a peer review before the review is initiated. This evaluation will consider other review mechanisms that are routinely employed. For example, plans, procedures, and reports receive extensive technical reviews within the Office of Civilian Radioactive Waste Management, including reviews by the national laboratories and participating contractors, by our project offices, and by other DOE organizations. These reviews may carry a document through several cycles of qualified technical review. In addition, reviews are performed by the NRC staff, the Nuclear Waste Technical Review Board, and affected governments (e.g., the State of Nevada). Often these reviews by oversight groups occur on an ongoing basis during the conduct of the activity.

We recognize that peer reviews are generally limited in scope and duration, and they may not be sensitive to regulatory, institutional, and management concerns. In responding to peer-review results, we must consider these other factors and incorporate any impacts in our response. This subject is also discussed under the issue "Building Public Trust and Confidence."

\section{ALTERNATIVE MEANS OF MANAGING THE WASTE MANAGEMENT PROGRAM \\ Background}

Several alternative approaches to managing the program were identified and evaluated in response to the requirements of the Nuclear Waste Policy Act by an advisory panel 
that submitted its report to the Secretary of Energy in December 1984." The panel's report was reviewed by a senior DOE group.

The panel identified several options for managing the program, but its preferred option would have required amending the NWPA. Because spokespersons for both the States and the utilities had advised strongly against attempting any amendments to the Act at that time, the DOE review group concluded that no major organizational changes should be initiated until several significant program milestones had been completed. Furthermore, the DOE review group concluded that most of the problems faced by the program were inherent in the nature of radioactive waste management and the Nuclear Waste Policy Act and could not be solved by changing the nature of the organization or management.

The issues identified by the panel have since been repeated by other parties. Most often cited are the DOE's credibility problems, lack of internal flexibility, and lack of cost-effective management.

The panel concluded that several organizational forms would be more suited than we for managing the construction and operational phases of the program. The option preferred by the panel was the creation of an independent Federal corporation. The panel also concluded that no modification of the DOE/OCRWM organization would provide adequate stability and continuity.

\section{Suggested original options for initiating a discussion}

Four options for managing the program were identified in 1984 by the advisory panel as follows:

Option 1. The present management structure should be retained.

Option 2. An independent Federal agency or commission should be established to manage the program.

Option 3. A mixed public-private corporation should be established.

Option 4. A private corporation should be established.

*Report of the Advisory Panel on Alternative Means of Financing and Managing Radioactive Waste Facilities, December 1984. 


\section{Synopsis of workshop comments}

There appears to be little support for turning over management of the program to another entity at this time. However, a number of participants saw merit in considering the possibility that another entity should manage the program during the later phases of implementation.

Participants cited three reasons for turning the program over to another entity: our credibility is so low as to render us incapable of carrying out the task; it was not clear that we have a stake in disposing of the waste; and an entity less bureaucratic than a government agency might be desirable. Among the arguments against a change were that no single company would have all the necessary capabilities, so that a consortium would be necessary; that the slow pace of progress is due not to government ineptitude but rather to checks and balances, which would apply to another entity as well; and that appeal for Congressional intervention would be less effective than it is with an executive agency.

\section{DOE response and current plans}

We believe that we should manage the program at this time because the primary current issues involve legislative and regulatory adjustments. We need to establish the program's system aspect and scientific basis. The entity running the program now should be "at parity" with the other governmental entities shaping the program's future.

We agree, however, that, as the program enters the implementation stage (construction and operations), some other type of entity might be better suited. We will continually weigh the merits of turning over responsibility to another entity at the implementation stage. The decision process will be set in motion early enough that if the Congress decides to transfer responsibility, the transfer can be done with no loss of momentum.

Meanwhile, we intend to continue looking for ways to improve program management. We have already implemented a number of initiatives directed at enhancing the management of the program. They included direct-line reporting from the Yucca Mountain Site Characterization Project Office to the OCRWM Director, the appointment of a permanent OCRWM Director, consolidation of contracts, an independent review of the management structure and procedures, a reorganization of the OCRWM, and signing a contract with a management-and-operating contractor. 


\section{COST CONTAINMENT}

\section{Background}

The Nuclear Waste Policy Act of 1982 as amended established the Nuclear Waste Fund to provide funds for the permanent disposal of spent nuclear fuel and high-level waste. The owners and generators of spent nuclear fuel are required to pay into the Fund a fee of 1.0 mill per kilowatt-hour of electricity generated and sold. In 1985, President Reagan decided that separate facilities for commercial spent fuel and highlevel wastes from defense programs were not to be pursued, but that each party must pay its full respective share of the total program costs. Through September 1990, the owners and generators of spent nuclear fuel had paid $\$ 4.6$ billion into the Fund. In 1991, \$5 million was provided to start payments for the disposal of defense high-level waste.

We take very seriously our responsibilities to provide proper management and accountability for the funds entrusted to us.

\section{Synopsis of workshop discussions}

Participants at the workshops pointed out that the discussion draft did not explicitly address cost containment. The issue of cost was either neglected or treated as an issue secondary to technical and management decisions, even though it has a significant effect on the program. We were urged to revise the draft to reflect the importance of cost and schedule control to the success of the program and to add cost containment as a strategic principle. We were also urged to use the concept of "total enterprise cost"; that is, we should analyze the cost impact of a concept all the way back to the utilities.

\section{DOE response and current plans}

We agree that cost containment should be a basic policy and management objective of the program. We have, therefore, revised the list of strategic principles in Chapter 2 to add cost containment. Two aspects of cost containment are important; one is costeffective design of the waste-management system, while the other is cost-effective management of the program itself.

Within the context of making program decisions affecting system design, costs have always played an important role in major decisions. The decision in 1985 to include defense high-level waste in the civilian repository and the establishment of the DOE position on the MRS Facility issued in 1989 are examples where the cost of alternative actions were considered along with other factors before these decisions were 
made. We will continue using cost as an important consideration in making major program decisions.

We agree that the cost of the waste-management system must be viewed as the total system cost, including the cost impacts that are experienced by the utilities and are not covered by the Nuclear Waste Fund. For example, in the MRS System Studies performed in 1988 and 1989 that were used in establishing the DOE position on the MRS facility, total system costs, including those paid by utilities for out-of-pool spent fuel storage, were estimated and used in determining the preferred system configuration. Cases studied included systems with or without rod consolidation, having consolidation alternatively performed at the repository or the MRS facility, having spent fuel alternatively packaged into the disposal containers at either the repository or the MRS facility, and alternative deployment schedules for the MRS facility. The total system cost estimates, particularly those for at-reactor storage, were a prime factor in the decision to have an MRS facility, without consolidation, which could be deployed relatively quickly and thus minimize at-reactor storage needs.

Since the program's baseline change proposal system was initiated in the mid1980s, cost impact assessments have been required, along with technical, regulatory, safety, schedule, and other impacts to accompany change proposals brought before the Program Change Control Board. As specified in the program's change control procedures, the Board members are required to evaluate the validity of the cost impact (and other impact) assessments in the review of the proposed change. Changes to the program's baselines (technical, cost and schedule) must be formally approved by the Chairman of the Change Control Board only after receiving the recommendations of each of the Board members. Thus, the change control system provides a formal means of incorporating costs into the program's decisionmaking, as well as enhancing accountability and traceability in our decisionmaking process.

Regarding cost-effective management, we have conducted several activities over the years to promote cost control. Since the passage of the Nuclear Waste Policy Act, several of the key program elements established performance measurement baselines, in conformance with DOE Cost and Schedule Control Systems criteria, designed to allow management to track program progress. To enhance this tracking process, a Program Management Information System was established to collect these performance data in a meaningful way and report them to management, accompanied by evaluations of variances and plans for corrective actions. With the passage of the Amendments Act in 1987 and the announcement of the restructured program in 1989, the program's cost and schedule baseline has been significantly changed from the earlier performance measurement baselines which were developed. With the implementation of a more meaningful baseline, the continued enhancement of progress reporting systems, and adherence to the formal change control procedures mentioned above, more effective cost control will be fostered. 
One of the best means of providing cost control is afforded by the steps embodied in the budget formulation process. Each year, we issue program guidance to all field offices establishing OCRWM planning assumptions including key programmatic milestones and budget constraints. For a given year's budget, the formulation process spans a period of about two calendar years over which oversight by groups both internal and external to the program exercise control. In addition to the OCRWM management's review of the budget, the Department's Internal Review Board, the Office of Management and Budget, and the Congress itself provide reviews and direction for formulating the budget. Because of the many interaction points with these parties, the budget is subject to much scrutiny. Workscope, priorities, and schedule attainment are constantly revisited by management before execution of that year's budget begins.

We prepare total system life cycle cost estimates to establish the reference longterm cost for the program. These estimates are submitted to the Congress and published. The cost estimates are reviewed by both the DOE's Office of Independent Cost Estimating and the General Accounting Office (GAO). These regularly performed external assessments have helped make the cost-estimating process one which is thorough and accountable. In addition, the independent auditing firm of Peat Marwick Main annually reviews the financial management of the Nuclear Waste Fund. Also, having our technical work subject to the scrutiny of the Nuclear Waste Technical Review Board, as well as DOE's Inspector General and the GAO, contributes to providing a sounder basis for the cost estimates.

In addition to the Program Change Control Board activities described earlier for managing the baselines, the Department has strengthened the project management system by establishing an executive level Baseline Change Control Board to be chaired by the Acquisition Executive. By establishing an executive-level change control process, the Department provides the Acquisition Executive and senior DOE management a formal means for timely involvement in major program decisions.

The management of the program has not been as cost-effective as we would like because of the time needed to implement a quality assurance program that meets NRC requirements and the delay in obtaining access to Yucca Mountain. The quality assurance program has now been fully implemented, and we hope that access to Yucca Mountain will be obtained soon. There are certain fixed costs that continue through periods of delay, causing inefficiencies in the management of the program. We are, however, seeking to improve our management efficiency. We have completed a comprehensive review of our contracts and have consolidated a number of them. We expect further consolidation now that the management-and-operating $(\mathrm{M} \& \mathrm{O})$ contractor is on board. We expect the M\&O contractor to implement improvements in costeffective management, improve efficiency in the performance of the technical work, and 
to also improve cost effectiveness in the design and operation of the waste-management system.

Another important initiative for controlling costs is the redirection of the site characterization program to focus on detecting, as early as possible, conditions that would indicate that the site is unsuitable as a repository. Site characterization will be a major driver of program costs for the next several years, and our current efforts to develop priorities for both surface-based and underground tests will increase the costeffectiveness of site investigation.

\subsection{INSTITUTIONAL ISSUES}

\section{BUILDING PUBLIC TRUST AND CONFIDENCE}

\section{Background}

The subject of building public trust and confidence developed during the workshops; though the discussion draft distributed before the meetings included several strategic institutional issues, it did not include building public trust and confidence as a single issue. It was added to the agenda, and now to this revised document, in response to the comments of participants. Participants identified public trust and confidence as a key issue that should be addressed in considering most of the topics on the agenda. Many participants suggested possible initiatives that we could undertake in the technical, institutional, and management areas of the program to address concerns about credibility.

Prior to the workshops we recognized the importance of this issue and had been engaged in a major effort to identify and formulate initiatives directed at increasing public trust and confidence. We would like to propose these initiatives here for comment from a broader audience. The initiatives include measures to enhance participation by affected governments, interested parties, and the public; to improve communication; and to build public understanding. Initiatives that could contribute to public trust and confidence are not limited to this section; others appear in the technical and management sections of this revised document.

\section{Suggested original options for initiating a discussion}

The discussion draft proposed several options for enhancing participation under the headings "Timing and Means for Predecisional Participation by Affected and Involved Parties" and "Gaining Public Acceptance of Waste Transportation." 
follows:

The options for participation originally included in the discussion draft were as

Option 1. We could attempt to establish a partnership in which Federal, State, and local governments jointly develop decision alternatives for the program in consultation with the public.

Option 2. We could establish mechanisms for predecisional dialogue.

Option 3. We could limit involvement to postdecisional dialogue.

\section{Synopsis of workshop discussions}

In discussing the issue "Timing and Means for Predecisional Participation by Affected and Involved Parties", participants generally agreed that (1) we cannot "share" ultimate program decisionmaking responsibility, nor would affected governments and interested parties want a share in decisionmaking in all cases, and (2) we should emphasize affected government and interested party participation in framing policy options at a very early stage in the decisionmaking process, not just in the review of completed drafts.

In discussing the issue of gaining public acceptance of waste transportation, and throughout the workshops, a recurring theme was the participants' insistence that we must improve our communication with the public and commit appropriate resources to accomplish this objective.

\section{DOE response and current plans}

We propose to build on option 2 as a concept for predecisional involvement, expanding the original definition to include the concept of "joint development of decision alternatives" featured in the original option 1.

In order to build public trust and confidence, we propose to implement the following actions:

Develop a clear and realistic concept for predecisional involvement by affected governments and interested parties in program decisionmaking, and commit the resources needed to make it work.

1. Identify significant technical and programmatic issues requiring action and the process by which related decisions will be made. This initiative would involve assessing current technical, institutional, and management issues; determining when significant decisions related to these issues must be made and the 
manner by which affected governments and interested parties could participate in shaping decision alternatives; identifying the appropriate mechanisms for involvement; and determining how input will be incorporated into decisionmaking.

2. Create ongoing forums and mechanisms for the involvement of affected governments and interested parties. Use appropriate forums, such as workshops and informal committees or working groups, and mechanisms, such as rulemakings or cooperative agreements, to involve affected governments and interested parties in decisionmaking.

3. Demonstrate responsiveness to input. We will provide clearly identifiable responses to predecisional input.

Build cooperative relationships with affected governments, as defined in the Nuclear Waste Policy Act as amended.

1. Seek to develop innovative agreements with affected governments. Build on the current effort to develop an understanding which governs interactions and communication with Nye County, Nevada, by seeking similar agreements with other affected governments, as appropriate.

2. Replace the current participation grant program with direct payments to affected governments. The President's budget for fiscal year 1992 includes a proposal to replace the current participation grants with direct payments, in order to afford recipients greater flexibility, streamline the financial-assistance process, and reduce the administrative oversight involved.

3. Support an independent and clearly defined oversight role for affected governments. Work with affected governments to enhance their review and oversight of our activities.

\section{Enhance our internal interaction and communication resources.}

1. Use independent experts to evaluate and recommend improvements in institutional program efforts. Subject institutional program elements to evaluation and assessment by outside experts. The review body would provide assessments and recommendations leading to continuing improvement in the institutional aspects of the program.

2. Enhance our institutional resources. Commit appropriate resources to institutional efforts, including increased upper-management involvement and augmented staffing, training, and materials. 
3. Increase integration of technical and institutional staff. Provide opportunities for technical and institutional staff to interact and to work together on program issues. Provide opportunities for staff to receive training in disciplines outside their area of specialty.

Build a communication program that covers the entire Civilian Radioactive Waste Management Program.

1. Use nationally recognized experts to help design a communication program, including extensive staff training. We have already begun this effort by engaging nationally recognized communication experts to conduct staff training workshops and assist in designing a risk-management program. These efforts will be expanded by planning a comprehensive communication program, extending participation in training to a broader range of our personnel, and conducting more-intensive training for communication and institutional personnel and those who interact directly with affected governments, interested parties, and the public.

2. Drawing on risk-communication principles, strengthen our communication efforts. This initiative would involve such efforts as developing messages about risks, simplifying and strengthening information materials to convey these messages, developing visuals to help convey important messages, actively seeking opportunities to communicate with a wider variety of affected governments and interested parties, and eliciting and responding to concerns expressed.

Work to increase public understanding of nuclear and radioactive waste issues through the promotion of education in the science, mathematics, and engineering disciplines.

1. Enhance education materials and activities. Expand current efforts to develop educational materials on nuclear and radioactive waste issues, assist in curriculum development, and enhance teacher training to increase the quality and availability of resources for use in elementary and secondary schools. Expand current cooperative agreements and projects with universities, our fellowship program, and support for Historically Black Colleges and Universities in order to encourage careers in science and engineering.

2. Expand our participation in joint education projects with other DOE offices and national and international organizations. This participation will include working with other DOE offices in implementing the Secretary of Energy's education directives and with the education programs of the League of 
Women Voters in the United States and the Nuclear Energy Agency of the Organization for Economic Cooperation and Development.

\section{SHARING OF DATA ON A TIMELY BASIS}

\section{Background}

Vast quantities of data will be collected by the waste management program. The purpose of the data will be to support an evaluation of site-suitability and, if the site is suitable, to support repository design and preparation of a license application to the NRC. As such, the control and assurance of the quality of the data must remain paramount in the management and dissemination of data to affected governments and interested parties. While access should not be restricted to any data, we must be able to certify those data to be used in determining suitability and in the license application and to justify the dismissal of data not used, whether suspect for technical or qualityassurance reasons. These considerations will also apply to an MRS facility and to transportation casks.

Another important point to consider is the following: scientific investigators consider that they have the right to present or publish data, analyses, and interpretations, and the premature release of data jeopardizes this right. The publication and presentation of project data and results in peer-reviewed journals and at professional conferences by scientific investigators also contributes to the credibility of the project.

\section{Suggested original options for initiating discussion}

Option 1. We could make raw data and supporting information available to all concerned parties as soon as is practical after data acquisition.

Option 2. We would release data only after they have been processed, reduced, and analyzed.

Option 3. We could release data along with analyses and conclusions as formal published reports.

\section{Synopsis of workshop discussion}

Participants were generally in agreement on the desirability of early access to data but did not clearly favor any particular option. For example, while some participants clearly expressed support for option 2, others rejected it on the grounds that it takes too much time, thus preventing timely access to data by affected governments and 
interested parties; furthermore, raw data are sometimes needed because they may lead to conclusions other than those officially reported. The discussion clearly indicated that another option is needed-an option that under the proper circumstances allows examination of the data as they are acquired, but limits widespread dissemination of data until such time as the investigators and we are satisfied with its quality. The question of academic publication was seen as less important than getting the data out.

\section{DOE response and current plans}

We are committed to the premise that all scientific and technical data collected for this program are public property and must be made available, within a reasonable timeframe, to anyone requesting them. These requirements must be balanced with the need to ensure that the instrumentation used in data collection was functioning properly and that the data are adequate for their intended purpose.

Beginning in October 1991, we will release a quarterly catalog of data which has been collected by our investigators. The catalog will list all acquired or developed data types or information, and provide descriptions of the data, the location where they were acquired, the date and time of acquisition, the method of acquisition, and the location where, upon request, the data may be examined. Data will be reported to the system which generates the catalog within 45 days of completion of the acquisition process or, otherwise, on a DOE-approved schedule. Data listed in the catalog would be available upon request.

Once the Licensing Support System is developed, information will be available through it. The rule under which this system was established contains provisions for raw data, especially for data entry after quality-assurance requirements have been satisfied, and specifies how and when the data are to be made available before licensing.

\section{SOCIOECONOMICS}

\section{Background}

The issue of potential socioeconomic effects was addressed in section 4 (Background) of the discussion draft of the strategic principles document. That discussion noted the potential for favorable and adverse socioeconomic effects associated with wastemanagement. It also pointed out that the Nuclear Waste Policy Act as amended, specifies a process for avoiding, minimizing, or mitigating adverse socioeconomic effects, to the maximum extent practicable and provides for financial assistance to affected governments. 


\section{Synopsis of workshop discussions}

In the discussion of socioeconomic concerns we received a number of practical comments and suggestions. A number of participants expressed the view that the subject of potential socioeconomic effects should be elevated in the hierarchy of the program's priorities and that socioeconomic issues be addressed for all components of the program-the repository, the MRS facility, and transportation. They asked us to make socioeconomics a program priority.

In addition, participants suggested the need for greater flexibility to conduct their socioeconomic programs in connection with scientific investigations of the candidate repository site. They also suggested a more cooperative approach toward the management of socioeconomic effects and said that we and affected governments need to agree on methods for assessing socioeconomic effects and on procedures for impact assistance. Participants also recommended that we treat work in socioeconomics in the same way we treat other technical work, including the use of peer reviews as appropriate.

\section{DOE response and current plans}

In response to the comments of the workshop participants, we have established a strategic principle with respect to potential socioeconomic effects. Understanding and addressing socioeconomic concerns will be critical to the success of our program.

Before the strategic principles workshops, we had begun to address many of the issues outlined above and to develop a more active approach for the socioeconomic program. Concerns regarding potential socioeconomic effects have been a major issue in Nevada, and they will also be an issue to potential MRS hosts and to States and Indian Tribes through whose jurisdictions waste may be transported.

We recognize that to be effective our socioeconomic program should cover all components of the waste-management program and should involve the active participation of affected governments and interested parties. We are now beginning to involve affected governments in developing and implementing our socioeconomic program. For example, the consultation draft of the Yucca Mountain Project Socioeconomic Plan was distributed to affected governments and interested parties for review and comment. We are now in the process of consulting individually with commentors to discuss their concerns and address them as appropriate. We also are involved in a cooperative effort with Nye County in Nevada to develop a protocol for addressing socioeconomic monitoring and assessment issues. In addition, affected governments are currently provided grant funding to enable them to participate in the program and to conduct appropriate socioeconomic studies. We are also working with affected governments to enhance the Socioeconomic Monitoring Program for the Yucca 
Mountain Project. Periodic reports are currently produced to disseminate data from the Socioeconomic Monitoring Program.

In cooperation with affected governments, we plan to initiate or continue the following activities:

Establish policy guidance for implementing our socioeconomic program, including socioeconomic-impact assessment and mitigation activities for each program component, as appropriate.

Expand our current Socioeconomic Monitoring Program for the Yucca Mountain Project.

Expand our cooperative efforts with affected governments by encouraging their active participation in the development of the socioeconomic program and fostering working relationships with officials and planners from affected governments.

Develop our capability to address perception-based (special) impacts and to evaluate the theoretical and empirical bases for studies conducted by affected governments and interested parties on perception-based impacts.

Establish a policy, process, and procedure for peer review of socioeconomic activities.

\section{EMERGENCY-RESPONSE PLANNING AND TRAINING}

\section{Background}

Section 180 (c) of the Nuclear Waste Policy Act as amended requires us to provide technical assistance and funds to States for training the public-safety officials of local governments and Indian Tribes through whose jurisdictions waste shipments will pass. We are developing a program plan and policy to implement this requirement. The plan will incorporate issues raised by the regional groups overseeing our transportation activities. It will address both routine transportation and assistance for accidents requiring emergency response. A significant issue related to our responsibilities under Section $180(c)$ is the timing of assistance for training in emergency response.

\section{Suggested original options for initiating a discussion}

Option 1. We could start assistance 3 to 5 years before shipments begin. 
Option 2. We could start assistance immediately.

\section{Synopsis of workshop discussion}

While the discussion yielded no explicit recommendation on the options presented, other issues were clearly of interest to participants, especially the need for establishing local capabilities for responding to transportation emergencies. We were told that, contrary to the findings of a recent NRC report, many local communities are at a loss over how to deal with waste transportation; their emergency-response teams often consist of volunteers who have no training, protective clothing, or equipment. The first responders (i.e., fire departments) want to have specialized (HAZMAT) teams to supplement their usual capabilities. "It may be necessary to develop specialized teams that would have nuclear safety among their other responsibilities.

Not all participants agreed with this assessment of the situation, stating that an enormous amount of guidance is available and that many and varied capabilities are in place both at the State level and in small towns. In addition, there is in place a greatly expanded emergency network among nuclear power plants.

We were also advised to pay attention to local governments on transportation issues, to recognize that in terms of public acceptance transportation is likely to be a bigger problem than the repository, and not to attempt to "sell" transportation safety when we should be responding to the concerns of the citizens. We were advised that there is a need to integrate the different DOE transportation programs (OCRWM, WIPP, and others), and to consider the need for uniformity of State regulations.

\section{DOE response and current plans}

\section{Section $180(c)$ Implementation}

The OCRWM's approach to evaluating and resolving Section 180(c) issues comprises continued identification, coordination, research, and resolution of the issues through a combination of DOE studies, work with regional and national groups of States, Indian Tribes and technical organizations, and interactions with affected governments and interested parties. Before assistance can be administered, key implementation issues must be clarified. The clarification process continues through workshops with affected governments and interested parties; interaction and research through cooperative agreements with regional and national groups; coordination with other DOE programs; cooperative efforts with other Federal agencies; and conflict resolution.

Once key issues are clarified and resolved, three documents (a policy options paper, the OCRWM assistance policy statement, and an implementation plan) will define the OCRWM's policy decisions on the assistance and funding process. As the 
drafts are issued, further workshops will be held and comments will be solicited from affected governments and interested parties. The OCRWM will review all comments and, where appropriate, incorporate them in the revised policy. The final policy statement will be published in the Federal Register and distributed to all participants involved in the review and comment process. Training assistance will be conducted in phases. The process will be outlined in the policy statement and the implementation plan. Program recipients receiving Section 180(c) technical assistance and funding will be notified formally in writing of their eligibility.

A preliminary draft Section 180 (c) Strategy was presented at the Transportation Coordination Group (TCG) meeting, held concurrently with the first Strategic Principles Workshop in December 1990, for discussion and comment. We are in the process of integrating comments received from TCG members. The final draft Strategy is expected to be released for public comment later this spring. The Federal Register notice will be published at that time and formal comments taken.

Activities with the Commercial Vehicle Safety Alliance (CVSA) may contribute to the development of assistance to States and Indian Tribes for routine safe transport. The CVSA, in a cooperative agreement with OCRWM, convened a Task Force on Nuclear Waste Transportation in 1986 to draft procedures for highway shipments of spent fuel. The draft inspection procedures, developed in November 1987, which can be used by State inspectors to inspect shipments at point of origin and destination, include inspection of driver, shipping papers, vehicle and package. In August 1989, CVSA renewed its cooperative agreement for a 5-year pilot program to test these procedures by inspecting WIPP shipments from INEL to WIPP. If the outcome of the pilot program is favorable, adoption of these procedures would create inspection and enforcement standards that could minimize the strain that differing State regulations would place on the OCRWM Transportation program.

\section{Assistance to Local Jurisdictions}

The issue of inconsistency among local responders' responsibilities, needs, and capabilities to respond to a spent fuel or high-level waste transportation accident was echoed at the TCG meeting that paralleled the Strategic Principles Workshop in December. This issue is still under discussion with affected governments and interested parties, including the Interagency Task Force for public assistance under the Hazardous Materials Transportation Uniform Safety Act. OCRWM recognizes the benefits in facilitating local government involvement in the policy dialogue as the Section 180(c) Strategy is developed. OCRWM will endeavor to enter into a cooperative agreement with a national organization representing local governments, and continue to work with the Interagency Task Force and other organizations. 


\section{DOE Integration Activities}

The Hazardous Materials Transportation Uniform Safety Act (HMTUSA), effective in November 1990, contained several important provisions that may affect how the DOE implements the requirements of Section 180 (c). One provision that may have a broad impact requires that all Federal departments minimize duplication of effort and expense in public sector training and planning. We will coordinate with the Department of Transportation (DOT) to ensure that training needs are met within this HMTUSA requirement. Other agencies that offer funding and training programs are the Environmental Protection Agency and the Federal Emergency Management Agency. We will work with the Federal Radiological Preparedness Coordination Committee (FPRCC) to develop roles and responsibilities with DOT and the other agencies.

The DOE has also begun development of the Transportation Emergency Preparedness Plan (TEPP). This plan will coordinate all DOE transportation emergency preparedness activities, and, among other activities, undertake to devise a uniform training program. When in place, the TEPP will minimize the demands on time and resources for State and local transportation and emergency response personnel who must deal with OCRWM, WIPP, and other programs, and streamline administration of these programs. OCRWM is a member of the TEPP Steering Committee under the framework of the DOE Emergency Management Coordinating Committee (EMCC). The Steering Committee includes members from all DOE elements having a nonweapons transportation emergency preparedness responsibility, and provides information and recommendations to the EMCC Secretariat regarding transportation emergency preparedness activities. A subcommittee of the Steering Committee is being formed that will focus on DOE training programs for States, Indian Tribes, and local governments.

\section{Timing of Training Assistance}

According to a report issued in March 1990 by the Western Interstate Energy Board (The Timing of Emergency Response Training Under Section 180 of the NWPA as Amended), general planning for training should take from 2 months to 2 years, while the period required for the training itself is 2 years.

Training assistance will begin in those jurisdictions through which waste will be first shipped. The actual training sequence will depend, in part, on the shipping plans. As the number of shipments and number of routes increase, the assistance will increase accordingly. Our first priority will be to determine the timing required for assistance for the initial shipments. 


\section{DISCUSSION NOTES \\ ON THE \\ FIRST STRATEGIC PRINCIPLES WORKSHOP}

Salt Lake City, Utah

December 4 - 5, 1990

U.S. Department of Energy

Office of Civilian Radioactive Waste Management 


\section{DISCUSSION NOTES \\ ON THE \\ FIRST STRATEGIC PRINCIPLES WORKSHOP}

Salt Lake City, Utah

December $4-5,1990$

TABLE OF CONTENTS

Page

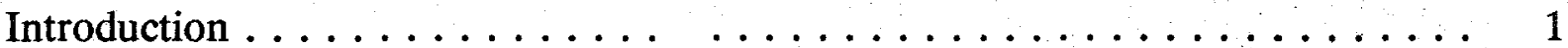

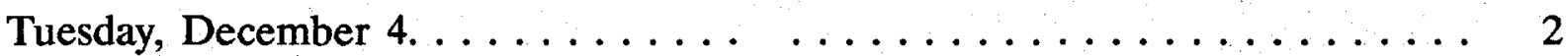

Welcome/Program Review . . . . . . . . . . . . . . . . . 2

Workshop Agenda, Objectives, Scope, Content .............. 2

Should DOE Be Managing The Waste Management Program? . . . . . . . . 4

Cooling Spent Fuel . ...................... 7

Demonstration Facility . . . . . . . . . . . . . . . . 9

Public Trust and Confidence ..................... 10

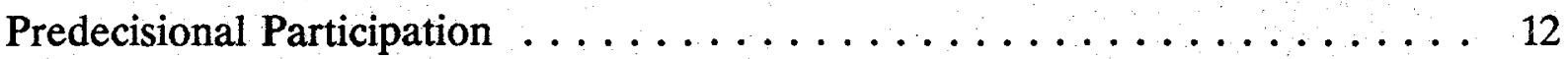

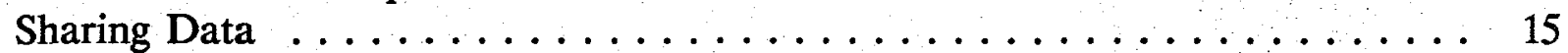

Peer Review ........................... 17

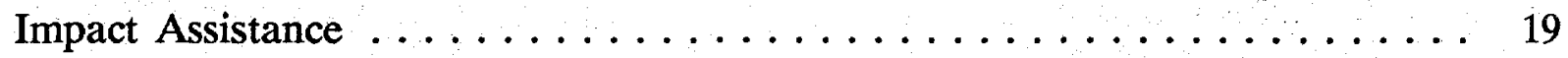

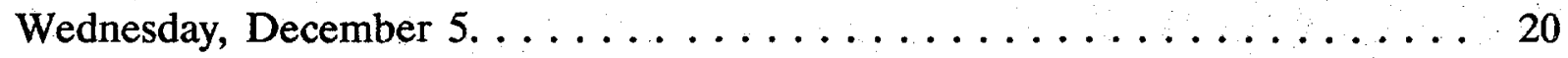

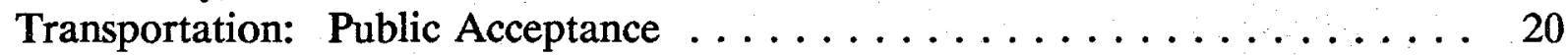

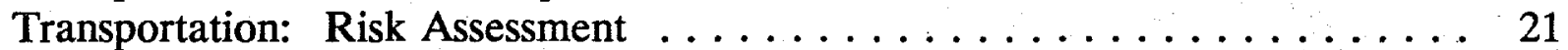

Transportation: Emergency Response ................. 22

Monitored Retrievable Storage: Privatization/Use of Trust Fund . . . . . . 25

Waste Packages: Exceeding Standards . . . . . . . . . . . . 27

Timing and Criteria For Determining Suitability $\ldots \ldots \ldots \ldots \ldots \ldots \ldots$

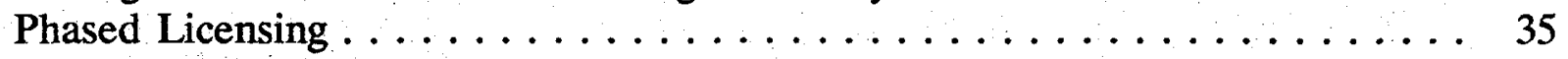

General Comments $\ldots \ldots \ldots \ldots \ldots \ldots \ldots \ldots \ldots \ldots \ldots \ldots \ldots \ldots \ldots \ldots$

Wrap-Up .......................... 39 


\section{INTRODUCTION}

On December 4 - 5, 1990, the Office of Civilian Radioactive Waste Management (OCRWM) of the U.S. Department of Energy (DOE) conducted the first of a series of Strategic Principles Workshops in Salt Lake City, Utah. The Workshops are intended to provide an opportunity for affected and interested parties to participate in developing strategic principles which will be used to guide the nation's radioactive waste management program.

The Salt Lake City Workshop was hosted by OCRWM Director John Bartlett and conducted by a professional facilitator. Seventeen invited participants associated with various affected and interested parties joined Department of Energy staff and about a dozen outside observers at the Workshop, which was open to the public.

Workshop discussion generally addressed points raised in a "Discussion Draft on Strategic Principles for Planning and Decisionmaking in the Civilian Radioactive WasteManagement Program" ("Discussion Draft"), produced by OCRWM on November 21, 1990 and forwarded to participants prior to the Workshop. The following summary references chapters and page numbers of the Discussion Draft parenthetically at various points when the discussion focused on that document. (For example, "(3-3)" refers to an analysis of options regarding waste package design in Chapter 3 , page 3 of the Discussion Draft.)

This document presents notes on comments made during Workshop discussion; it is not a verbatim transcript of the proceedings, nor does it represent an analysis of the discussions. Because participants were assured that the discussion was on a "not for attribution" basis, bullets ("•") are used to identify comments by participants other than Department of Energy staff or the discussion facilitator. 


\section{TUESDAY, DECEMBER 4, 1990: 8:00 AM SESSION}

\section{WELCOME/PROGRAM REVIEW}

DOE: This is your meeting; DOE is here to listen. The Nuclear Waste Policy Act (NWPA) is very broad. We need to shrink the number of its options. To this end we need predecisional input from involved, affected, and interested parties. We are looking for guidance on which strategic issues in Discussion Draft should be converted to strategic principles and included in the Mission Plan Amendment (MPA) which will be released approximately a year from now. Need to think about the interactions among the issues, and take an overall systems approach.

\section{WORKSHOP AGENDA, OBJECTIVES, SCOPE, CONTENT}

Facilitator: This workshop is evidence of DOE's new stance of greater openness. Objective is to have full and free exchange of views, but not to achieve consensus. Suggest starting with specific issues and then move to broader ones. What are participants concerned with addressing?

- Particularly interested in socioeconomic issues.

- Question of spent-fuel consolidation is an open issue that needs resolution.

- See objective of design capacity of the repository as the prime question, to which fuel cooling is a secondary issue. The first repository is limited by law to no more than 70,000 metric tons of heavy metal (MTHM), but the program implies at least that amount. Need to inventory all sources of waste, not just spent fuel. Waste other than spent fuel might be 20-30 percent of total. Once total waste to be addressed has been determined, could lead to an optimum-sized repository of 30,000-50,000 MTHM capacity, rather than statutory limit of 70,000 MTHM.

- Concerned about workers' health and safety.

- Compliments John Bartlett for initiating the workshop, something that wouldn't have happened a few years ago. Regarding the agenda, feels it will be difficult to discuss specifics before some broader issues are addressed. How was the list of strategic issues for discussion determined? Has copies of a DOE memo on issues associated with the National Energy Strategy (NES), including basic issues that are likely to underlie specific issues to be discussed. How did the NES memo evolve? If we are going back 
to such basic issues as who shall run the waste management program, this demonstrates the need to talk about the underlying issues. Concerned about meeting being held outside Nevada, which doesn't give Nevada public an opportunity to attend--suggest meeting in Nevada next time.

- Will the workshop address the U.S. Environmental Protection Agency (EPA) standard under the "allocating performance" issue?

Facilitator: Yes.

- Why not have an EPA representative at workshop?

Facilitator: Will check that during break.

- Public acceptance is not just transportation related. Whole area of public acceptance needs more attention. Must demonstrate the need for the facility. Need to talk about retrievability, trying to reduce waste volume, and reempowerment of local government. Need shared management, not just predecisional involvement. Question of perceived versus actual risk also important.

- Question of public perception and acceptance should be considered with regard to most of the topics on the agenda. Doesn't like the term "public acceptance" - prefers "understanding."

- Also like "public trust."

- There are three or four areas in the strategic principles where public confidence is a critical factor - agree with other participant on that.

- Concerned with cost control and overall management issues - don't run out of time before discussing these areas.

Facilitator: The second workshop in Washington is intended to focus more on management.

- Supports constructive dialogue, as John Bartlett has described it.

- To what extent will DOE respond to these points?

Facilitator: They mostly want to hear from you but they will be responsive.

- That's not realistic. It's DOE's program. How can we discuss the issues without DOE taking an active role? 
DOE: We will be a participating party. We will respond as you wish, but basically want to listen.

- The list of issues is long. We need to set priorities on the most important. We may need a third workshop.

- Maybe participants should express their reactions to the Discussion Draft document. Where did it come from, how were the issues selected?

- Agree. Are these the right issues to be discussing?

DOE: Options document intended only as starting point - "here are some things we have thought about".

- Where does this workshop exercise fit in larger sequence of DOE activities? How does it relate to other things going on, like the National Energy Strategy?

DOE: Things in the discussion document are things "analytic" personality types like things to be managed. Happy to let the workshop agenda go where participants think the discussion should go.

- Maybe have brief presentation of DOE perspective as each new issue comes up.

Facilitator: Key issues hearing from participants are 1) suitability of DOE to continue to run the program, and 2) public trust in the broadest sense. Doesn't feel qualified to drop any of the issues. Suggests starting with hour or so of discussion on general issues, as was suggested by one participant, then make time for discussion of public confidence tomorrow after addressing specific issues.

- DOE should tell us which issues need to be decided first. Maybe we could concentrate on those.

- Many of the questions would depend on whether DOE continues to run the program.

SHOULD DOE BE MANAGING THE WASTE MANAGEMENT PROGRAM? (3-32)

- Shifting waste management from DOE to some other entity is reportedly an option under consideration for the NES. What does this mean? 
DOE: Admiral Watkins has very strong sense of responsibility to accomplish the missions entrusted to him. Bartlett has asked himself if DOE is the right vehicle for the program. The Advisory Panel on Alternative Means of Financing and Managing Radioactive Waste Facilities did recommend in its 1984 report ("AM-FM report") that a "Federal corporation" manage the program. Rationale for the recommendation was largely that DOE was not well equipped for the job, with its background mainly in national security programs. Also because of the need to winnow down the number of sites, something DOE did not do well. The report came out, but nothing much happened in the way of follow-up. The circumstances underlying the AM-FM report have changed greatly, and the things that most immediately need to be done are different now as well. Bottom line: DOE should be managing the program at this point because of the key issues that are current, primarily legislative changes and regulatory adjustments. DOE should run the program while we establish the system aspect and the scientific basis. Right now, the entity running the program should be "at parity" with the other governmental entities which will be shaping the future of the program (Congress and the regulatory agencies). As program moves into the implementation stage (designing, licensing, and operations), some other type of entity might be better suited. However, that would still leave the question of what kind of alternative entity. No single private contractor would have the broad range of capabilities needed, so that private operation would probably require a consortium of contractors, with one lead. That raises the question of what difference there would be between a prime private contractor and OCRWM. Nor would a private operator necessarily be more efficient or faster. Much of the slowness attributed to governmental entities actually stems from procedures aimed at assuring fairness to stakeholders. The same safeguards would need to be applied to a private operator as well.

- Worked on a study of this question in 1981-1982. It concluded that this was not something the government did well--taking short term heat for long term benefits. AM-FM report proposed a truly independent operating entity. Didn't see this approach as compatible with guarantees of stakeholder involvement then, but agree that it is appropriate to rethink the question.

- The Edison Electric Institute (EEI) is not pleased with DOE's running of the program, but less displeased since Watkins and Bartlett in charge. Industry never had a unified view on AM-FM--some members agree with the need for a Federal "preemptive presence". From perspective of certain management issues, might have been better off with different operating entity.

- Have had problems in the past with getting OCRWM commitments fulfilled, at the same time there has been micro-management. Maybe John Bartlett will do better, but remains to be seen. Dealing with a Federal agency, people feel they have the protection of their Congressional delegation. Independent agency might relieve some 
bureaucratic problems, like lengthy grant application development demands.

- Who are we actually solving the waste disposal problem for? Maybe nobody has the proper incentive. It is not clear that DOE has a stake, as compared with the utilities. In Europe the locals have far more input. Here the Federal approach dilutes that.

- You don't locate a repository in the U.S., but rather in a county in a state.

- Counties feel on periphery of decisionmaking. Would like more flexibility to define programs from their own perspective, object to "micro-management" in DOE grant oversight.

- Think there is "grass is greener" factor in looking at alternative entity - don't see much to be gained in switching from DOE. Alternative entity would have to have major stature, but also be subject to checks and balances. Entity doesn't have to be Federal to deal with other Federal agencies, but generally don't see much advantage or disadvantage in changing.

- Experience in 1985 of dealing with Tennessee Valley Authority (TVA) was no different than dealing with conventional Federal departments.

- One new point heard more in last couple of years has to do with local empowerment and how it might affect acceptability.

- Overriding concern is public confidence, and DOE's is at all-time low. Thinks licensing and implementation stages may call for different kind of entity.

DOE: Regarding the NES, none of the elements have been adopted as yet. OCRWM was asked to contribute some candidate elements for Presidential policy, but nothing has been resolved as yet.

- Regarding managing entity, a 2-way breakdown should be considered: 1) governmental versus non-governmental (leans towards governmental because of defense wastes and need for checks and balances), and 2) if government, where in government is most appropriate? (DOE, with its weapons complex problems, does have a credibility problem so bad that it may never be credible enough to do the job.)

- Doesn't want workshop to degenerate into "DOE bashing." Does see need for greater outside involvement in efficient management ("cost and control"). Concerned about defense payments, where DOE has dropped the ball. U.S. is most expensive program. 
DOE: Not so. Just looked at this, and U.S. costs about same as several European programs examined.

- Ours is the most expensive in terms of what we have paid in and what we have to show for it. In any case, should have similar process for outsider involvement in the program as the French model.

\section{TUESDAY, DECEMBER 4, 1990: 10:30 AM SESSION}

\section{COOLING SPENT FUEL (3-2)}

- What is the design basis of the repository? The issue is not timing but rather how much hot fuel you are trying to get in the repository. Do we have a hot or cold repository? If the repository is hot, Yucca Mountain may not be able to handle it. Therefore, we may not want to use a hot repository. If not, there are three ways to accomplish a cold repository: 1) cool the fuel, 2) place less fuel in each of the packages, and 3) place the packages less densely in the repository. With either of the latter two, you must do something else with the remaining fuel (i.e., develop more storage or construct more repositories).

- Another issue that we must contend with is what to do with the large amounts of other radioactive waste that must be disposed of in addition to spent nuclear fuel. The DOE should inventory this other waste and look at residual capacity (i.e., the nooks and crannies of a repository) for placing this waste. Such a step would not change the basic repository capacity as regards spent nuclear fuel. We should not forget the need for a second repository.

DOE: If you add up all the waste, excluding Greater-Than-Class-C, you would have a need to dispose of 200,000 MTHM. Scientific American reported that the world would need a 70,000 MTHM repository every 9 years for the next century.

- Once you decide on the cooling, you want to start taking the waste from the reactors. EEI has calculated that the average age of the fuel in 2003 will be 19 years. If you want a hot mountain, you need younger fuel (thermal pulse loading delay). However, the current contracts will not allow that, and the DOE cannot stipulate which fuel it wants. Raising the second repository issue will mean a hard fight because there is no authority to do it.

- Is a "hot hole" consistent with simple and proven technology?

- A very hot temperature raises many complex issues, such as safety of workers, effect on the mountain (fractures in the rock), or an elevated surface temperature causing 
harm to flora and fauna. Also, it is not simple and proven technology.

- To do this (hot mountain) is to go into an intricate balance. Thermal density and/or packing density is a tactical aspect of design.

DOE: To put it in hot, you drive out the water. After 200 years, the mountain cools. The question is, after the water cools (post thermal-pulse phase), what happens? When you come to licensing, you need to be able to show the effects of what you are doing. Licensing requires looking at post thermal-pulse phase. Start out cold and look at the evolution.

- Two important issues. First, one of the options calls for "several Monitored Retrievable Storage (MRS) facilities." Can you site even one? Second, the MRS facility needs to have a technical underpinning. We do not want to be in the position of having to build an MRS because one of the options "drove us in that direction".

- What are the comparative costs of a "hot" Yucca Mountain versus a "cold" one? What about a second or third repository? What about cost versus risk?

- We need to keep in mind the risk factors.

- How long do you need to store the waste to get a cold hole without reducing the amount of waste you can emplace?

DOE: After 30 years you don't gain much in further cooling.

- We don't yet know. It depends on packing density. The Project Office has said it is 80 years.

- The question of hot versus cold storage is one that cannot be answered until site characterization.

Facilitator: Does anyone have a preference?

- No real preference, but if you talk of extended cooling, utilities will not pay $\$ 500$ million per year for storage.

- Extended cooling is not the only solution. Storage temperature is a variable of several functions, not just storage time. The first repository capacity is 70,000 MTHM.

- Can Yucca Mountain hold more than 70,000 MTHM? 
DOE: Won't know until we characterize the site. We think it could hold somewhat, but not a great deal, more, depending on design. Management risk is the question. You could go with thicker canisters but this gets even more expensive.

Facilitator: Does anyone want to propose a second repository?

- Given how slowly we're moving on the first, we may have no time to lose.

- It is an issue that ought to be on the table.

- Industry must take the lead on this issue.

\section{DEMONSTRATION FACILITY (3-6)}

- For years EEI has favored phased licensing and the concept of incremental learning. Look at technical and economic questions. However, to the extent that Bartlett's earlier remarks mean more study (and thus more money), the answer from the utilities would be no.

- What is it that you hope to demonstrate? The demonstration of isolation is such a long process that it is very difficult to demonstrate anything. But a lot of demonstrating is done during characterization of the site. For example, if you predict something regarding the rock, you drill and see how close you were to being right. But to emplace waste for five years, so as to predict the next 50,000 , is meaningless.

- The demonstration should be more than public relations.

- Maybe people gain confidence from the way the testing and analysis are done.

- But this is just quality control, which must be a part of everything.

- No major accomplishments resulted from the Climax Mine experiments.

- To emplace spent fuel would dismay the people of Nevada, who would see it as the "done deal" they have long feared.

- To do this kind of test may face the public with the prospect of failure.

- Waste tends to stay where it is put. If waste goes down the shaft it will stay there. If waste is emplaced, the repository has opened. The public may lose rather than gain from such a process. 
- The same could be said for an MRS. You do need to monitor. There is value in the data gained from a demonstration.

- But doing all the right things, which you must, still leaves the public with doubt.

- If you put in only a small amount it is clearly just an experiment. A very small amount is not a repository.

- There will be a sense that finally we have started, that we have turned the corner.

- Onsite storage, indefinitely, is perfectly feasible, but it is an unacceptable policy solution. The flaw with the nonexperimental view is that the only acceptable answer is DOE failure.

- Environmental organizations support a geologic repository.

- The operational stage is phased. The operation will continue to gather information over 50 years. Regulatory requirements mandate retrievability in case of a fatal flaw. Is there, in a short time, a test which can be made which shows that this facility is the right one? That would be "test emplacement." Design is necessarily phased, as is construction.

- Want phased licensing, not just operation. The waste would go in only once. This would start to build public confidence. The public would see that it is working.

- Want to make two points. First, there is a danger that emplaced waste becomes permanent. But at the same time, you need real evidence on the record. Note the limits of testing.

\section{TUESDAY, DECEMBER 4, 1990: 2:00 PM SESSION}

\section{PUBLIC TRUST AND CONFIDENCE}

Facilitator: Before we deal with the subject of this portion of the afternoon, I'd like to 1) allow for discussion and public comments on the various areas we've already covered, and 2) let people say anything they want to say about the way things are proceeding.

- I'm familiar with the issues and I think it's productive to open up for questions like you have. 
- We need to look at a number of things. My main point is that it's useful to look at the management principles presented in the document as well as in the options we've discussed. For example, the institutional principles on (2-4) and (2-5)--in supporting educational programs, you need more social science or more people who understand the science/nonscience interface. Cooperative work would have benefits. What is your definition of an affected party? There are also two questions you have to deal with regarding DOE and its commitments. 1) Can DOE live up to its commitments? It has problems in New Mexico with speaking for other Federal organizations like the Department of Transportation (DOT), and with guaranteeing commitments by Congress. 2) What about the effect of changes in DOE leadership--new leadership has questioned past commitments.

- I have some comments on the earlier comments about the Climax Mountain Demonstration Facility. First, fuel that goes into the ground does in fact come out. This happened at Lyons and Climax, where fuel was put in and then retrieved.

Second, we did produce some useful data. Brine migration results came out of Lyons. We also had benefits in public perception with the technical data. You need the real stuff in there to get data; the big question is that of scale. Third, getting people to believe you is a problem. Most of the benefits derived were technical.

- The fuel was taken out in Lyons because the state demanded the fuel go.

- Yes, there is a gap in the technical data. We were never able to predict brine results as well as we wanted to. We didn't focus on using the facility as a permanent repository.

- The utilities are stiffing the Nuclear Waste Fund for $\$ 1.5$ billion. When will DOE ante up for defense waste? What are your plans at this point?

DOE: The utilities are not stiffing the program. The deferred payment option they are taking is legitimate. The defense contribution depends on Congress. We're trying to get Congress to put payments in the appropriations bill for the coming fiscal year.

- There are a number of options in getting the money, but no action has been taken.

Facilitator: What about credits? Is that an issue?

- Defense is trying to evade its obligation by going back in time to take credit for past research. This is not credible.

Facilitator: This is a resource management issue. Let's move on. 


\section{PREDECISIONAL PARTICIPATION (3-19)}

- Federal officials like Option 3, post-decisional dialogue, but it has to be Option 1 or Option 2. There is a real difficulty here. There's little possibility of constructive dialogue when the state or the localities are subject to Federal preemption and given no authority. It's hard to hide that preemption exists as a backup for the Federals. State and local people are intimidated by their lack of authority.

- Even so, it's not easy to arrive at a decision.

- True, you wouldn't have a program without the option of Federal preemption. And political power is used by the affected parties. It is not a rational decision process.

- A clarification of the discussion of Option 1 on (3-20) is needed. What was in mind? The discussion implies that considerable powers can be extended to the affected parties.

Facilitator: The spectre of preemption makes it impossible. DOE is looking for advice on how to proceed.

- Let's talk about the political implication of Consultation and Cooperation (C\&C) agreements. The binding nature of the agreements with the Federal Government is illogical from a state perspective. They are not equal partners.

- It's a question of sovereignty. There are C\&C agreement problems. For example, the Secretary of Energy determines adjudication procedure. Cooperation is hard to define, but it's necessary to establish a cooperative working relationship when working with the Federal Government. There are no clean simple answers to difficult questions like these.

- Let's look at that question of binding Congress to a particular management approach. What would be the effect of having an independent corporation operate the waste management program on this?

Facilitator: The issue is how you see this relation playing out. Any other arrangement allowing more participation?

- I'd want an arrangement that gives a state the ability to shut down the facility and remove the waste. That would be a good alternative in the short-run. 
- Notes the arrangement that Swiss utilities have with canton governments, though notes the Swiss government isn't involved in this. The linkage was that the deal had to be renegotiated in 25 years. If the community says take it out, the utilities have 10 years to remove it.

- For all intents and purposes, the Swiss government is the Swiss utilities. European relationships are not at all like US relationships. France and Sweden are entirely different as well.

- There are other issues here. We need to separate the issues of siting, operation, and many other issues.

Facilitator: Short of a State or local veto, to what extent are they to be involved in lesser decisions? Let's explore the range of the role they are to have in decisionmaking. The low-level waste law in Illinois lets localities say no at a point in the process. Pennsylvania gives localities temporary shut-down authority.

- How much meaningful decisionmaking involvement is there?

Facilitator: There's a difference of opinion.

- The statement on (2-4) doesn't leave much room. The discussion on (2-4) really says that DOE can't share these technical and program decisions. It must make them. It's a big caveat.

- What about scientific and peer participation? What role do we have? We could be of use in redirecting bad studies.

- The statements on (2-4) and (3-20) are not contradictory. They don't mean letting them make decisions. One big advance would be to have DOE help state and local governments participate in formulating the alternatives to be considered. The preemption question is a funny one. The Ninth Circuit avoided the preemption question in its decision. Does preemption mean the Federal Government can go ahead and put a repository in Nevada, or does it have more to do with regulations?

- I don't see any single answer to this question. It depends on many things, on each case, on the issue on the table, and who you're talking to. Some officials you can trust, some you can't. 
- The important issue is who we're dealing with. The Federal, state, and local governments don't always represent the broad public interest. They are not always representative. This doesn't always fulfill past obligations. What about consultation with the public? You need to establish public involvement in decisionmaking. That's how you get representation of a broad array of views. It's a question of representation.

Facilitator: Questioned DOE on the options on (3-20). What kind of partnership was envisioned? Is DOE operating any current program like Option 1 , or is it a new initiative in powersharing?

- Spell out situations so that this is more concrete.

DOE: It tries to present reasonable options for discussion. Don't read too much into these. We don't intend to decide here which of the three is right, but instead what kinds of things should we do that would be more effective. We want the options to open up discussion.

- There should be more participation in the decision process. More opportunity for real input to affect Federal decisions, like in the rulemaking process.

- We still haven't come to an agreement on meaningful involvement. This should be on a case-by-case basis. There is no formula.

- You want shared authority, but to be able to pass on certain decisions. You want to pick and choose your involvement. Do you want decision authority?

- It depends on the decision. Maybe.

Facilitator: Are any current relationships partnerships? Does DOE work on this model? Can DOE grant it?

- Can DOE give up decision authority?

DOE: The NWPA as amended doesn't really grant any State authority except the right to disapproval.

- That's a typical bureaucratic answer that drives me nuts. DOE should go back to Congress to get the law changed. Why shouldn't the MPA say, "Change the law?"

- DOE is interjecting itself into local decisionmaking. There are no broad answers to this question.

DOE: What should we take a fresh look at? Where is there room for improvement? 
- We see an ability to look at alternatives, but no consistent reception of outside suggestions. We have both satisfactions and frustrations.

- We prefer Option 1, defined as "equal partners in decisionmaking," but experience says that isn't realistic. Nye county is closer to Option 2. We're working on a protocol to establish this.

- We need more specificity regarding the mechanisms, too. Many can be used to improve public participation. They can take many forms, especially with quick access to information and documents, and access to resources. We must do a detailed thinkthrough on these, with an overall plan relating the various issues and mechanisms. Flesh out Option 2.

- There should be better definition of the options. DOE must define decisional alternatives. DOE could do better at allowing participation in developing a framework for these documents, and not just in review of completed drafts. I'm not sure our County would want Option 1, in the sense of making decisions. Option 2, in the sense of helping to frame options, would be a "yes."

- Did the January 1990 meeting that Isaacs chaired deal with predecisional involvement? What about the transmittal of information and specific things that can be done to enhance communication with the public?

DOE: We did try to implement the recommendations we received, but most were not very specific, like sensitizing DOE staff to the need to do things to involve the public. We got no real specific option frameworks.

- You can't please everyone all the time. It's hard to involve people without framing options. You need a clear analytical basis for the decisions made. I see progress, an evolution in DOE in this area. There are perennial problems, though.

Facilitator: DOE needs to open itself to a variety of relations. Who feels comfortable doing what. This group has expressed enough interest in Option 1 that DOE should entertain that; it's up to some of the interested parties to approach DOE with initiatives on this, to define relationships.

\section{SHARING DATA (3-18)}

Facilitator: Now I'd like to get your views on data options. It seems to me that Option 1 contains a danger of the release of raw data which can be misused by the parties and the press. 
- Option 1 is mischief-ridden. So is Option 3. The program is subject to public scrutiny. Option 2 is the norm. Go with Option 2, with a clear and easy ability to trace back to the raw data when necessary, to who is the data producer. You must tolerate some misrepresentation and misuse.

- If the data is defensible, there should also be somebody available to inhibit its misuse. Data should not just be available but also useful, usable, accessible, not just in Washington.

- See a question of academic publication as an insignificant distraction, when the really important concern is getting the data out. Refers to Morgan-Davis agreement concerning DOE/Nuclear Regulatory Commission (NRC) data-sharing (1983 Procedural Agreement Between the U.S. Nuclear Regulatory Commission and U.S. Department of Energy Identifying Guiding Principles for Interfaces During Site Investigation and Site Characterization [FR 48:38702]).

- Option 2 is a "no-go". It demands an inordinate amount of time. Incidentally, Morgan-Davis is on the table.

- I haven't heard so. I think well of Morgan-Davis for data-sharing purposes. It's been around five or six years. It should remain in place.

- A formal understanding is okay, but it isn't always the answer.

- You can't always leave it an open question. Boundaries are needed.

- Analytical results and evaluations are relevant and significant data, but are hard to define. It's often more important to get timely access. One thing I appreciate about the DOE is that it says data aren't data until the NRC says that they are data.

- It's hard to get data from the DOE. DOE claims it needs to "certify" data. This causes problems. There is a need for timely information.

- The form in which the data are made available is important, like on a computer format. Does the agreement cover that?

- Sometimes people want raw data. Cites example of study of the health of defense plant workers and the question of unclassified information. Wants access to Environmental Impact Statement (EIS) raw data, as well as the refined data. Usual public documents like EIS contain interpretations of raw data. Look at raw data can lead to alternative conclusions. I realize that in some cases this is inappropriate. You need more broadmindedness in this area. 
- Data-sharing decisions have some subjectivity. Some of the organizations here may do Option 3 themselves but want Option 1 from DOE.

Facilitator: I sense some agreement here. There is agreement on the need for caution on questions concerning the distribution of raw data.

DOE: After the state permits are attained, the Licensing Support System (LSS) is to go into place to try to make information available.

- There are challenges to credibility involved on both sides. Both have experienced leaks and suppressed information.

- DOE should look at the LSS rule provisions for raw data, especially data entering after Quality Assurance (QA) and made available to prelicensing. LSS takes care of all the problems these discussions have raised.

\section{TUESDAY, DECEMBER 4, 1990: 4:00 PM SESSION}

Facilitator: Public comment?

- Should seek outside input at the conceptual stage, as at this meeting, rather than through comments on documents. Having so-called predecisional papers may not do much good. Once something is on paper it has a life of its own. Also, regarding use of raw data, they should be provided with preliminary assessments that have been carried out.

- Support Option 2. Needs to be an improvement in communication. Need to shorten the lines of communication. See the process as improving.

\section{PEER REVIEW (3-31)}

- Approach to peer review depends on what the peer review involves: overall system overview, like the Board on Radioactive Waste Management/National Research Council (BRWM/National Research Council) position paper, or focus on some more specific component of the system.

- Look first at structured peer review, like the BRWM/National Research Council review and position paper. Most of the high-visibility issues will be pretty well covered in that way. Then need to look at the underlying needs for review, and concentrate on 
maintaining a sustained, day-to-day review process. Between that and the structured peer review mentioned before, should have an effective combination. But DOE needs to ensure that it is not relying entirely on this process.

- Note difference between routine QA review versus review of high-stakes issues with significant public confidence implications.

- Option 2 is important from the public confidence perspective. In the past, DOE hasn't approached this as systematically as it should have. Perhaps the Nuclear Waste Technical Review Board (NWTRB) could play that role. Somebody besides DOE needs to be looking at the work. John Bartlett is getting off to a better start with this. This area is not adequately covered by the options presented.

- Accounting firms are not inclined to point out tactical mistakes as readily as peers will.

- Two points. 1) International peer review is needed - this was mentioned repeatedly at the Nuclear Waste Conference at Airlie, Virginia (November 30 - December 2, 1990). 2) Should include on peer review panels technical critics who in the past have been dealt with unfairly, even though they were sometimes right. They should be brought inside the program.

- Think DOE has responded well to technical critics.

- Some past peer reviews have been of questionable independence.

- Waste Isolation Pilot Plant (WIPP) tried to include people of disparate views on review panels, and have had some success in bringing people to consensus. Peer review has been excellent but we don't get much out of it in terms of public confidence. Also, there has been a tendency to avoid publishing bad news. In fact, it would improve DOE credibility to be more open about negative developments--it would instill public confidence that the system is working.

DOE: There is a lot of international exchange through the International Atomic Energy Agency (IAEA), which also fosters international peer review. IAEA will sell peer review services, and the Swedish program has a consulting service. Question: what is the relationship between those activities and "trust mediation" (that is, the process of improving the professional credibility of the program)? Does peer review contribute to the professional credibility of the program?

- Need more than technical peer review - need social and economic review also. 
- Need to put the kind of people on panels who will ask the hard questions. The Secretary's Energy Advisory Board (SEAB) is good, in its devil's advocate role.

Skeptics have gained a measure of trust in it.

- Peer review is frequently associated with technical issues. Need to expand it, but not to such issues as business management.

- Peer review should be more than just scientific. Also, the concern should be about how to use peer review to build public confidence.

- Having really independent reviewers is key. Most of DOE's work should be internally reviewed, with the important work being externally reviewed.

BRWM/National Research Council took the position that DOE does need to "go outside itself" more. Need to think about all aspects of the program.

- NWTRB can't do it all - additional peer review is needed. It is a concern that many people on review panels are DOE contractors.

- There is a definite place for on-going NWTRB-type review, but also for ad hoc BRWM/National Research Council-position-paper kinds of review effort. The latter are most useful in situations that require going beyond purely technical review.

\section{IMPACT ASSISTANCE}

- Is the socioeconomic area still of concern? Maybe it could be discussed in more detail at a subsequent session. Impact assistance grantees need to be given more flexibility to deal with potential impacts. They feel micro-managed.

- DOE sometimes views Congressional intent rather narrowly, particularly when that intent was to make things easier for the local jurisdictions receiving assistance.

- Industry would want some restrictions, such as the prohibition on using assistance funds for lobbying or litigation, to be maintained. Nor can the amounts be so much that it hamstrings OCRWM's ability to do the job. Otherwise, would favor putting people through less "Mickey Mouse" requirements to get the money. The utilities have learned the value of not being overly bureaucratic regarding their own assistance efforts ("go ahead and buy the fire truck if the fire chief says he needs it").

- Our County needs increased assistance, but also recognizes the increasing pressure to spread the finite amount of national funding available among more and more entities. DOE should seek outside advice on allocating funds. The County has not been encouraged by DOE's response to the "grants equal to taxes" issue--DOE's 
position on that seems to bode ill for future assistance from and County relationship with DOE.

- DOE treats assistance recipients like contractors rather than grantees. DOE should put more emphasis on scrutiny after the fact. There is too much absurd micromanagement of proposed use of assistance funds.

- Would prefer not to lump grants and impact assistance in the same category. Congress tends to ignore the impact on individual communities. There is wide divergence of perception as to what an impact is. See it as something which results from the program and for which money is given to mitigate. Also, DOE has been unwilling to look at impacts identified by state and local governments.

Facilitator: Definition of "affected state" was too complex for Congress.

WEDNESDAY, DECEMBER 5, 1990: 8:00 AM SESSION

\section{TRANSPORTATION}

\section{Public Acceptance (3-21)}

Facilitator: The record of transporting nuclear waste has been good. The question is how great a public issue this is going to be.

- A significant event has taken place since the Strategic Principles were formulated, namely, passage of the Hazardous Materials Transportation Uniform Safety Act. It requires that DOE carry out over the next two years studies of transportation issues and inspection procedures. It stops short of imposing any actual requirements, merely calling for studies, and the studies are similar to previous studies.

- Having an MRS does not much alter the transportation system except for inspections. But it makes the transportation system easier, especially if the MRS is in the East. There are no rules on railroads.

- The NRC has safeguards on rail and highway routing. The hazards of transportation in certified casks are so low that longer distance shipment is advantageous only in economic--not safety--terms.

- The issue is one of trust. What kind of activities promote public trust and confidence? So far the transportation record is good, but the public does not perceive this. The DOE needs to create its own record as a new player and not rely on the 
industry's record. More or less start over.

- The Strategic Principles document is a technical rather than a social document. The workers and public do not trust DOE and DOE needs to take that into account in preparing such a document. The document says workers and their families are taken into account, but this is not so. DOE should set up protocols to monitor workers at different dose levels and establish medical and epidemiological studies to monitor exposure. We don't want to be in a position twenty years from now of saying, "We didn't know". Protect the workers and the public! Nuclear engineers are not concerned with workers. DOE needs the right kind of personnel, Occupational Safety and Health Administration specialists, along with a public education campaign. DOE might consider helping to develop independent radiation biologists.

- Do you distinguish between workers at 127 DOE plants and those at the commercial plants?

DOE: No.

- Do both. You need the context of exposure plus communication to workers.

- The question is whether it would make any difference if it were a FedCorp as opposed to DOE.

\section{Risk Assessment (3-17)}

- DOE has the right to self-certify casks, but it has not done so, going instead to the NRC for certification. The track record here is good. But there is no design yet for the WIPP Remotely Handled-Transuranic cask. With WIPP, neither DOE nor the state wanted to specify particular routes that the common carriers had to take. If you are going to do it (i.e., implement a program), do it early, not like WIPP, which after 13 years still has no certified cask. There is lots of experience in WIPP that would be relevant to OCRWM. There is a need to train people early even if they subsequently quit and you need to train new ones.

- Risk assessment does not help the public. Communication is what helps and DOE has not yet said how it plans to improve communication.

- County citizens say it's nice to talk about Probabalistic Risk Assessment (PRA), but it means nothing to the man in the street. There has got to be a better understanding of risk that does not use PRA. This means better education, not films of trains crashing. DOE needs to answer such questions as what it means in terms of real world 
exposure to have a truck stop next to you. The Nevada routes will be on secondary roads through small towns. What does this mean for the people living there?

- Rather than selling program safety, we need demonstration/explanation. The Hill will be interested. Dozens or even hundreds of representatives will want to know what is being done to prepare for emergencies. DOE went to court when Colorado insisted that its regulations, which were not onerous, be observed. This soured the climate. DOE should try to deal with states and use preemption only as a last resort. Otherwise the public gets the wrong idea. Don't pick a fight on principle, because to do so creates ill will.

- DOE needs to refine the transportation criteria, to make sure that economics is not the main driver. Don't like Option 3 on (3-17). PRA tools may not be appropriate.

- True. The issue is, who does risk assessment? State and local officials are more credible than DOE. They should do it and DOE should be removed. Bring in trainers to work with the locals.

- The difference in degree of risk is so small that trying to make decisions on the basis of those differences becomes almost technically unsound. The only way to gain the public trust, if it is possible, is by local people talking to locals. Train local cadre.

- The NWTRB has held three hearings on transportation. It is a subject of primary concern to the public. $\mathrm{Be}$ as objective as possible. The scale will be larger than in the past. Don't use PRA as a crutch. An approach in which we say, "the black box says it is safe and so it is," won't work. The concern is not just in Nevada but throughout the country.

\section{Emergency Response (3-21)}

- There is necessity to train locals, which brings them into the process. DOE should take as a given the need for emergency response and training. It should take the DOT Hazardous Materials (HAZMAT) study, make the results available and deal with the facts as they come out. According to an NRC study, locals are ready for emergencies.

- A recent firemen's study indicated just the opposite. A County study shows communities at a loss over how to deal with waste transportation. DOE will need to reconsider how they deal with transportation. The DOE seems to have put it on the back burner while they solve the repository problem. Transportation has the potential for creating far larger problems than the repository. OCRWM leadership should be at the Transportation Coordinating Group (TCG) taking place this week. Perhaps DOE should think not of acceptable risk (i.e., $10^{-6}$ ), but recognize that the public grows ever 
more wary of technological fixes. Pay attention to local governments on transportation issues. How much uncertainty is unacceptable?

DOE: Key DOE people are at the TCG meeting. Have talked with state radiation control officers. The first responders (fire companies) don't have the capability and don't want it.

- Never heard that the locals don't want such a capability.

DOE: The locals want there to be such a capability but they do not want themselves to be the ones to have it. They want to have specialized teams to supplement their normal capabilities. There may be a need to develop specialized teams (SWAT teams) which would have nuclear safety among their other responsibilities. Sent a DOE team to Europe to observe the transportation situation there. There have been no radiological accidents in Europe in 27 years of transporting nuclear waste.

- All electric utilities have an emergency response network that works well. It was adapted to nuclear transportation ten years ago. The power districts mobilize SWAT teams. The only difficulty is that the vehicles are under control of the industry in the area.

- There was a recent incident of abandoned nuclear materials in Ohio.

- The responsibility should be DOE's, not the locals' or the utilities'.

- The criteria to be established will be very important. People will want to know how long until someone responds to a nuclear accident. The question of human performance needs emphasis.

DOE: The European criterion is a two hour response.

- DOE has a major legal/institutionalresponsibility (which flows from the Atomic Energy Act) to respond, as with Three Mile Island.

DOE: What are the elements of a response network? We could use DOE sites, military bases and/or state resources to establish the swat team network. It might be necessary to supplement the net somewhat. How would this fly in terms of a two-hour response? There was an incident in Somerville, Massachusetts of a railcar carrying toxic chemicals which overturned. The locals took the role of identifying the chemicals, protecting themselves and then letting others come in and handle the problem. They didn't want to deal with it themselves. 
- None of the small towns anticipates having such a capability. How do you get small communities to comply with the basic regulations? People have HAZMAT responsibilities but no training, proper clothes or equipment. They are all volunteers. Basically, all they do is keep onlookers away from the scene of an accident. But if there are compounding factors it gets more complicated. Concern is with who will come out to assist us.

DOE: There is a need for infrastructure and maintenance to give the locals a sense of confidence.

- Do communities in the west have chemical responsibilities?

- They have an isolation capability but no equipment.

- The same is true for radiological incidents.

- Don't like the way the discussion is going. People think nuclear waste is unique. The fact is that there is enormous guidance available. It gets to the point of micromanagement. There are also enormous capabilities in place both at the State level and in small towns. There is in place a greatly expanded emergency network among nuclear power plants. There are practical answers for the questions.

- There is current experience with nuclear accidents. An accident in Virginia earlier this year was handled very well.

- There is a need for uniformity. To have nuclear regulations as distinct from HAZMAT regulations is in itself hazardous. Changing regulations at state borders is another problem.

- Don't "sell" transportation safety. Receive the concerns of the citizens and respond to them. Too much DOE emphasis has been on cask safety and PRA demonstrating a low risk. People want to know about the consequences. They are reluctant to accept a repository because they are not confident they can control the risks. The idea of a network is good but it needs to be supplemented by local capability. Train people. 


\section{MONITORED RETRIEVABLE STORAGE}

\section{Privatization/Useof Trust Fund (3-29)}

- Why is the second option being raised? It has been settled. As to the issue of who owns/operates an MRS facility, it is wrapped up in the larger issue of finding a site. All these issues are part of the negotiating process.

DOE: Agree that the funding issue has been settled, but wanted to know the extent to which this effort could be privatized. Why should DOE learn to do things it does not do well and may never do well?

- The point is that, whoever owns the facility, there are certain things that DOE never does itself, always contracts out. Moreover, the ownership doesn't affect who actually does the work.

- A broader question is, if we go to a cold repository, who pays for the longer storage, the utilities or the government?

- This is a serious contractual matter which is not a subject for discussion here. The industry position is that by $1998 \mathrm{DOE}$ assumes the costs, but DOE does not agree.

- What should DOE be doing in the private sector to help secure a WIPP-type facility?

- You've seen the last of these types of siting processes. The Negotiator must find a more acceptable way of siting.

- Regarding a judgment about whether government or industry could better deliver an MRS, we need to consider the fact that systems analysis is not DOE's long suit. Utilities are increasing their own storage. The longer DOE waits the less value there will be to an MRS. The critical issues are on-time delivery, the capacity limits on the first repository and the uncertain status of a second and third repository.

DOE: The need for an MRS is not an issue. It will provide flexibility, among other things. It is not a temporary facility but a permanent part of the system. This is part of a whole range of issues for which DOE is linking technologies and developing system capabilities. 
- What is the reality of an MRS in light of the congressional reaction to the MRS report?

DOE: We see the need, the question is how? Through a Negotiator deal?

- Congress won't de-link. But if a negotiated deal is presented, Congress will be able to work with it. The conditions which apply to DOE siting an MRS do not apply to the Negotiator's siting of one.

- Doubt that any state will agree to host an MRS without linkages, especially in light of MRS Commission recommendations. How can a governor convince citizens to accept waste without a guarantee that a repository will subsequently take it off their hands? The environmental community supports the repository, but not an MRS, particularly an unlinked one.

DOE: It is an essential part of the management system, not a temporary parking spot. It is not a backstop for a failed repository. Can we convince the public that this is part of the management system?

- Selling it as part of a system is better than trying to sell it on the basis of transportation safety (i.e., the cask-mile effort). But if the MRS is to be part of the system, why not simply carry out the storage at the repository?

- The cask-mile argument, as a reduction of risk, is nonsense. The transportation advantage of an MRS comes from having a lot of short routes to an eastern MRS and one long haul to a western repository.

- The cask-mile issue is not a factor in the debate, in making the choice. An MRS at the repository would bother us from the standpoint of licensing. It raises the required investment, the institutional commitment and the acceptability issue to an uncomfortable level. The arrangement should be such as to limit the burden of proof and the investment. The linkages are important.

- Would NRC be concerned about building an MRS at the repository site after construction?

- No, this would be a residual risk at most.

DOE: We need some kind of handling and preparation in the system and you don't want to do this in 110 different places. 
- You first need to convince the public that an MRS is necessary. The idea of shipping fuel, first east to an MRS and then west to a repository, will not calculate well with the public.

\section{WEDNESDAY, DECEMBER 5, 1990: 10:30 AM SESSION}

\section{WASTE PACKAGES: EXCEEDING STANDARDS (3-3)}

Facilitator: This is an issue of demonstrating performance--whether there is some change in the existing approach, with weighting or balancing of waste packages with siting considerations.

- It's useful to look at regulatory strategy. The environmental standards are fundamentally risk assessment. Performance assessment should measure overall system performance. The NRC standard addresses three subsystem performance criteria that might in aggregate exceed the EPA standard. This gives "defense-in-depth," and gives an added margin of safety because the standard is less vulnerable to surprises in one area which might affect the overall system. You are tuning or balancing these criteria. My point is that you have to have both overall performance assessment and a prudent defense-in-depth addressing specific system elements, including engineered elements.

- Long-lived barriers for the repository are a good thing. However, waste packages should be viewed as a redundant safeguard rather than as a mechanism for compensating for deficiencies at a particular site.

- Extremely difficult to have a package that would be redundant to a site. Performance allocation takes advantage of package design, but ultimately the isolation provided by the site itself is the controlling factor in performance.

Facilitator: I'd like to address the issue of providing complete containment capability.

- Minimum package isolation is $300-1000$ years. "Enhanced package" refers to going beyond that. The question is, what would it cost and be worth to go to 1000 or beyond to 5000 years or more? Appropriate package ultimately depends on site. It's ok to exceed the minimum, but it still leaves the old uncertainties such as the possibility of human intrusion.

- People understand back-ups. Redundancy and defense-in-depth help build public confidence. DOE said earlier, ignore engineered barriers--the package--since they only address 1000 years or so, and this is not significant in light of a 10,000 year standard. Fortunately, DOE backed off that position. 
- It goes back to the EIS and mine legislation. They provide an impetus to robust packaging.

- About overdesigning--you are setting minimal, not the best possible standards. Exceeding a standard doesn't mean overdesign. That would be the wrong philosophy for DOE.

Facilitator: Will it make a difference in public confidence?

- It will obviously help in public confidence, but exceeding package standards to compensate for inadequate geology won't help.

- We've looked at the 10,000-year requirement. Given DOE's abilities and scientists, it seems DOE could do this. The question is, with lots of people around this table competing for the public's confidence, to talk in terms of a 10,000-year requirement is not to put this standard in human scale; the public won't understand it. Can this improve public confidence? It might be better to show them a display of a robust package they can actually touch.

- That's okay, but it still won't compensate for inadequate geology.

- Improving waste package quality could add to public confidence, but it won't add to the licensing process. I'm concerned about the added cost of exceeding standards. It could be enormous.

DOE: Our ultimate reliance is on the geological barrier. The only existing figure for barrier merit is groundwater travel time. Unfortunately, such issues raised here as human intrusion or volcanism are only addressed on an ad hoc basis.

- Ground-water transport is a poor surrogate indicator of barrier merit. I want a standard independent of performance assessment. WIPP doesn't have performance criteria outside geological isolation; there are problems in dealing with human intrusion, for example. Engineered barrier criteria could give you real margins in dealing with intrusion. There are real benefits of exceeding standards. Different standards would tremendously (and negatively) impact WIPP. It would be difficult to continue WIPP operation without a lot of changes.

- I'd like to comment on this issue. Issue is, should DOE do more than the bedrock minimum regarding the package? The current waste package is a carbon steel drum, 20-year design life. DOE seems to support that. NRC and EPA share regulatory responsibilities over DOE, and their performance is important; their philosophies are 
different. NRC requires demonstration of compliance with standards. We need separation of regulated and regulator personnel in agencies. We need independent analysis; its important for public confidence. I don't see any DOE commitment to engineered barriers.

Facilitator: I'd like to ask if there are any affected parties' responses on the impact of enhanced package design?

- Concerned about having a 10,000-year standard when in fact the waste will be harmful for 100,000 years or more. That causes public concern that requires public education. There is an educational problem here that must be addressed.

- I'm dubious on engineered barriers gaining much public confidence. There's too much uncertainty, which raises enough concerns. I see a role for engineered barriers, but the primary benefit won't be greater public acceptance.

Facilitator: Should DOE rely on site characteristics to provide the licensing-necessary containment?

- The public views the 10,000-year prediction with skepticism, and they feel the same way about DOE's technical capabilities. DOE must wrestle with this sort of thing in getting around its credibility problem.

Facilitator: These principles are posed in order to get your reaction as to DOE increasing its public acceptability by either of two courses. Should DOE continue to rely on site characteristics or change to combine the two? Is a 1000-year-plus container worth the investment?

- The public will view with alarm any tinkering with the regulatory environment. They'll see it as site-tailoring, whether it is or not. It will create a greater concern. DOE should live within the regulations. Citizen groups will view changes with suspicion as completing a done deal. DOE should live within the existing regulations, go beyond doing the minimum, but not compensate for geological inadequacies. DOE would help itself with the public by building to a higher standard without seeking credit against the geologic standard.

- The regulations don't need to be changed, but there is little information in them on how to implement them. We need implementation paragraphs written into the regulations, but don't change the requirements.

- I understand what's going on, but it will be a tough sell. 
- There isn't a hard and fast calculational methodology. Involve different parts of the scientific community in the process of setting standards. It would help.

- Nevada and the localities seem closed to the project. You can't convince the residents that the project has merit. As to the question of confidence, an engineered barrier would help if it shows clear benefits, but the argument for it should really be from a health and safety viewpoint. Show that revisions are an advantage to health and safety, and reduce the uncertainty issue. There would be value to it then. It would be more practically useful that way.

- There will be some sort of statistical statement of what a 1000-year package life means. This would be a statistical engineering statement to say what it means. (For example, what percentage of containers are expected to develop leaks after 10,000 years?) This opens the door for enhanced package lifetime to be an understandable benefit in public perception, and to play a role in meeting public concerns.

- The additional cost might be acceptable, if the value can be demonstrated clearly.

Facilitator: Option 3 was one of the ways of dealing with it.

- An enhanced package is healthier for individuals and would help; you'll always have potential problems from the site. The man in the street knows that nature is hard to predict, and the engineered barrier could help with public confidence.

- I have questions on the cost of packages. DOE assumes a development cost of $\$ 10$ billion overall, with $\$ 3.5$ billion of that going for waste packaging. The assumptions include 25,000 spent fuel packages and 15,000 Defense High-Level Waste packages. The cost per canister comes roughly to $\$ 100,000$ each. I'm concerned that enhancement could significantly increase cost.

DOE: That's true. Our scoping studies indicate that cost could be two, three, or four times as much, and that spending level doesn't get you extreme isolation durations comparable to the Swedish canister (10,000 years or more range).

- When EPA wrote the standard, everybody discovered they could manipulate it. A possible standard was the Carbon-14 term. It is not used--maybe they forgot this is a tuff site. The jury is still out. The important thing is not to jigger a standard to suit a site.

- Does anyone counsel deleting enhanced standards? 
- There is some counseling for deleting one set and going with another. This compromises defense-in-depth. You have performance allocation, using different standards in different cases. In my view this is a poor idea. I fight it.

- You need as many barriers as practical. This is reasonable, common sense.

- I have a statement. (A copy is available.) Nuclear engineers have looked at constraints and limits in design. Container design complicated by lack of knowledge of underground environment. Designing canister for 300-1000 years is an iffy proposition. Have opposed hard duration standards for canister. Instead, we recommend strong overall system performance requirements that also provide for employee safety, public confidence. All subsystem requirements should be flexible and site specific, relate to the environment.

- NRC licensing application review will require proof of repository protection against flooding. You have to design for it. (Indicated he felt the NRC sometimes required inappropriate requirements for design and licensing.)

- NRC licensing review decisions are appropriate. NRC reviewers impose design basis constraints; they review based on appropriate design. Inappropriate design basis has been applied in licensing on occasion. The review accounts for upset conditions, but package lifetime, etc., are explicitly as emplaced. Yucca Mountain may be dry site.

- The experience of the utilities says that NRC licensing review decisions are not always appropriate.

- To a degree you have to be prepared to answer non-mean questions, but I have seen no capricious analysis in licensing. If you focus on the worst-case possibilities all through, you tend to lose track of smaller problem contingencies and get the wrong answer.

- You're right.

- Don't compensate for geological medium inadequacy, but don't rely only on geological barriers. Public is more likely to accept a facility if it's over-designed. You need a whole-hog-for-safety approach, though it might not make a difference in changing minds in Nevada.

Facilitator: Are there any other nontechnical issues in waste package design?

DOE: The technical public is not being dealt with here. There is strong skepticism among technical people, especially metallurgists, about the feasibility of building a 1000 year package, let alone a 10,000-year package. You must convince the technical 
community that we can produce a 300-1000-year package. If not, you won't be able to convince the nontechnical community to come in. It's a formidable job, an uphill battle that needs a lot of attention.

\section{WEDNESDAY, DECEMBER 5, 1990; 1:20 PM SESSION}

\section{TIMING AND CRITERIA FOR DETERMINING SUITABILITY (3-9)}

- The discussion options presented suggest an "undue search for the holy grail." See the waste-management program as an $\mathrm{R} \& \mathrm{D}$ program, continuously posing the question of whether success is likely. The same is true regarding political acceptability. Won't be a single, dramatic indicator of unsuitability ("discovering the tomb of the Aztec princess under Yucca"), but more likely a profound, accumulating discouragement stemming from growing recognition that there will never be enough data to definitively demonstrate suitability.

- Regarding the "creeping depression" about ever getting enough data to demonstrate suitability--industry concerned about this representing a bottomless sink for ratepayer contributions. Believes he was able to develop a decision model (for less than $\$ 1$ million) at an earlier stage of the program, when DOE staff seemed to have no better idea than just throwing every possible test at the suitability question. Happy to see DOE switch to an early search for disqualifiers. Need to question constantly, "How about now? How about now?"

- Need good criteria for determining unsuitability. A false negative determination on suitability early on in the process is worse than a false positive. A false positive only costs maybe another year of wasted effort, while a false negative leads to killing the accumulated years of investment. Suitability does not have to be forever, merely is it suitable to continue for another year?

- DOE should focus first on disqualifying criteria like volcanism.

- What about the valuable minerals at the WIPP site (potentially attracting human intrusion)? There are such minerals at Yucca Mountain also. Would that kind of thing disqualify?

- Don't know about that. What would the equivalent be at Yucca, a gold vein, maybe? 
- The 1987 Act changed the whole DOE impetus from a search for a suitable site among options, to a focus on determining suitability of the one targeted site. This affects DOE's credibility, and DOE must address this through peer reviews and the other credibility-building aspects previously discussed.

- There needs to be a (decision) model exercised periodically by people not making money off data collection. Must be alert to a tendency on the part of those who are profiting from it to submerge negative factors in order to sustain the suitability determination process. (Department of Defense weapons development process presents many examples of this kind of problem--incentive is for people running process to suppress negatives.)

DOE: Have set up independent assessments in six areas of real importance, including site suitability. Got a broad-based group together to identify issues, to be developed for an external review plan for suitability determination. We will develop a management plan on site suitability before the end of the year.

- Is management review part of this process (one of the six areas)? What about the Booz-Allen results? Also, will the Golder study on site suitability be made public?

DOE: Booz-Allen results were not published but were used to undergird the reorganization and the Management Systems Improvement Strategy. The results of the Golder study will be made public.

Facilitator: Further comments on suitability criteria development?

- Using 10 CFR 60 is not attractive. 10 CFR 960 only useful up to a point.

DOE: In evaluating suitability, being asked to evaluate both the characteristics of a specific geologic setting and also an overall system (the planned repository and the setting). Part 960 identifies some specific disqualifiers. The Court cited 960 as a basis for its decision. The only numeric disqualifier is ground water travel time. State of Nevada looked at the data, and determined they were disqualifying. Bartlett sees data insufficient for that.

- See this somewhat differently (but admittedly, can't get agreement on this even from own staff). See success defined as successfully obtaining license. Prior to that, calling the site "suitable" only means asserting that all tests required for license approval will be passed. The ultimate suitability criteria are in NRC's 10 CFR 60, not Part 960. Only after you have a license do you know that the site is really suitable.

DOE: Believe it's both. Finally, it's a judgment call. What is the range of technical uncertainty? Has that uncertainty been reduced enough to call the site suitable? 
Easier to make a determination of "no" than "yes." Even trying to look just at the site, have to consider some source term assumptions as well.

Facilitator: Nobody seems to be suggesting any new criteria.

DOE: Issue is not to change criteria, but to adapt to them.

- Every morning, John Bartlett must decide whether the site is still worth pursuing. That is, whether there is still a reasonable chance of "winning" by obtaining the required licenses.

- How about annually, or maybe every other year, putting out a report on where suitability stands? Not wait until the point of making a final determination.

DOE: The vehicle for communicating with the public on this issue will be the semiannual site characterization update report. Site suitability analyses will be included in that report periodically, but not necessarily every six months. These will include a peer review and also will talk about the suitability of continuing the characterization.

- What will be in the reports?

DOE: The first few will probably conclude there is not enough data to make a suitability determination yet.

- Need to look at the promise of the system, not just the negative factors. Key question remains--is it appropriate to continue the suitability determination process?

DOE: We plan to tell the world how we plan to do this. The YMPO's management plan on suitability will be sent out in late spring/early summer.

- Are there some internal papers available on all this?

DOE: No. We are still working on this, but do plan to tell the world how DOE proposes to proceed on it. It might be announced in late spring or early summer of next year.

- What happens if DOE determines that Yucca is not suitable?

DOE: Very simple. DOE will inform Congress, and seek their guidance on how to proceed.

- Does DOE have a contingency plan for this? 
DOE: DOE is just looking now at what contingency planning would be appropriate.

Facilitator: This area can be taken up again in January (at the second workshop).

\section{WEDNESDAY, DECEMBER 5, 1990: 2:00 PM SESSION}

\section{PHASED LICENSING (3-25)}

- Confused about what Option 3 ("licensing in two distinct phases") is intended to represent. A lot of work will have been done on the site prior to seeking a construction authorization (for a temporary storage facility), so a lot will be known already. In all cases, see the licensing process aimed at licensing the full repository.

DOE: The Option 3 concept has been put forward by some others, not DOE. They want to use the repository for retrievable storage for perhaps hundreds of years, doing tests during that time. If it passes the tests, license and close it. If not, retrieve the waste. Many view this as a pretty radical option. Nonetheless, the concept has been raised, and DOE felt obliged to include it here.

- This is the worst of all worlds. The waste put in would not be viewed as disposed of until a decision is reached to make a complete variance and leave it in place. Appears to be the worst of the four options offered. Where would we transfer the waste?

- Licensing would include 1) construction license, 2) operating license, and 3) a license to close up the repository. If you don't get the last one, the waste has to be removed. Regarding Option 2 (license for pilot-scale facility at repository site), what data would be obtained that wouldn't be obtained through the regular licensing process? NRC is not structured to dole out the license piecemeal.

- Maybe it would be an opportunity to measure real thermal equilibrium.

- You could get that in the conventional licensing track also. Regarding Option 4 (incremental licensing for individual storage area blocks), need to look at overall repository size to fairly appraise this. Could license first block, with overall system in mind, and then license additional blocks as they are needed. Essentially an administrative decision on how to proceed through that incremental process, but don't see any real benefit to it. It would essentially ration construction authority out in segments, but to what purpose or benefit?

- How about licensing sequentially by subject area? 
- Have done this with nuclear plants, essentially by giving construction permits for certain excavation and other civil work. In a repository, wouldn't be practical to allow various pieces of construction on the basis of various parts of the case that must be made to secure overall approval.

DOE: Current system calls for us to approach NRC with one big request, which might be hard for them to swallow. To simplify things we were thinking of phasing. Option 2 represents a situation of putting in, say, 5,000 MTHM of retrievable waste before the entire mountain is explored. The approval might be for the 5,000 MTHM, with the requirement that 1,000 of that be pulled out again to demonstrate retrievability.

- Can deal with separate issues in parallel under the current standard. NRC sets up separate panels for different issues, mainly for efficiency purposes.

- Option 2 just means an additional licensing/litigatingprocess preceding the required steps for licensing a full repository. Doesn't really add anything, since the full licensing steps will still be required.

- If DOE has some but not all of the data it needs, and does not want to wait for it all, it could go ahead partially.

- Once DOE does this, things change. DOE would then be the applicant and NRC the regulator, which is very different from the way it is now.

DOE: Did make some final environmental findings based on earlier tests - don't plan to revisit these. During course of full site-characterization program, even after we have concluded that the site is suitable, may still want to demonstrate in situ that preliminary findings are right. It would be easier to do this with 5,000 MTHM than 70,000 MTHM.

Facilitator: Any clear preference among the options? (No response.)

- This would be different if NRC, as the regulator, is the one to set the 5,000 MTHM limit.

- Possible to come in for an operating license before construction is complete?

- Construction need not be completed first. However, burden of proof is "all 52 cards" in any case. (That is, all the operating license requirements must be met.)

DOE: Issue here is, consider the whole facility, but let DOE put in 5,000 MTHM of 
the ultimate 70,000 MTHM capacity, and continue confirmation testing in the meantime.

- Can't see meeting the 40 CFR 191 requirements on the basis of 5,000 MTHM.

- Public perception of this might be that going for the initial 5,000 MTHM is an attempt to slip by the full repository requirements.

- DOE would have to present the full 52 cards of proof in any case.

\section{WEDNESDAY, DECEMBER 5, 1990: 2:45 PM SESSION}

\section{GENERAL COMMENTS}

Facilitator: Where do we go from here? Wrap-ups, other invitees may want to make statements.

- A number of points: One, many problems arise from the continual changing of minds in waste disposal. I get no clear visions from our discussions, no clear paths or resolutions. Two, the documents are obsessed with timeliness, timing. Three, as to compliance, DOE needs to grind out more documents demonstrating it. DOE should emphasize getting stuff out dealing with both institutional and technical issues, but $99 \%$ of it is technical. DOE has been saying that institutional will receive equal weight with technical, but I don't see that happening yet. The 25 Comment-Response Document letters all have their own biases. The "we have no transport problems because we've never had one" approach is the kind of stuff that gets you in trouble. Lastly, I believe the cost estimates we've gotten are underestimated.

- A comment on the WIPP facility. It seems to me the largest potential failure mode for this program is WIPP. Its failure would shed doubt on the viability of geological disposal. If WIPP goes down the tubes, it will be a blow to DOE credibility and also geological disposal. John, plead with the Secretary to do it right.

- There are possible problems with the "we don't think we'll have problems" approach. It isn't the right approach.

- It takes a lot to stamp out the last vestiges of the old DOE mode. Don't use the hammer of preemption too early in the process. There are steps to be taken, mechanisms that must be worked out to allow things to happen. There is still much to be improved in the way DOE deals with the public. 
- A minor editorial observation on the Discussion Draft (3-10). Don't use the double negative that was used in the siting guidelines.

- Be more explicit about what you are doing on the basis of the comments you have received.

- A backup medium or site, that is to say, contingency planning is a thing of fundamental importance. It must be brought out. This is a task for the Negotiator, but he has other things that may divert his attention.

- You need a plan to get Congress to deal with the legislation you see as necessary. The MPA is a vehicle for talking to Congress and proposing changes to the program.

Facilitator: The contingency plans in there are vague, demonstrating a gingerly walking around the issue. Maybe this needs to be a part of the public consciousness.

- Chapter 4 presents a nice review of management issues; stands opposed to the less thorough material on management issues in (3-22), which is not real substantive.

- EPA standards are a critical yardstick. We need to be careful not to push too hard on standards and avoid weakening them. Avoid jiggering standards to fit specific sites. Let the EPA do its job, strengthen standards. The EPA is desperate for more resources to get the standards out. Another issue is whether or not it makes sense to impose a schedule through Congress for getting the standards out. (Not sure about stand regarding the issue of negotiated rulemaking.)

- What does it mean to strengthen standards? Does that mean more robust standards to withstand court challenges or more scientific affirmability?

- For one thing, it means standards consistent with the Safe Drinking Water Act, with assurance that things are done at the site according to the best possible standards.

- Regarding the BRWM/National Research Council report, BRWM did not advocate negotiated rulemaking. (NWTRB had so recommended at one point.) The report (on the September 17-18, 1990, Symposium on Radioactive Waste Repository Licensing) should be available in a few weeks. The report will review the issues and questions raised, without any recommendations or findings. At this point, no specifics on what will happen.

- EPA says they have hired a group to look at the question of negotiated rulemaking. My concern: Would negotiated rulemaking just drag out the process? 


\section{WRAP-UP}

Facilitator: Would appreciate suggestions for the next meeting in terms of invitees, topics, etc.

- Cost control is very important to my group. Will try to write something to strengthen cost-control areas of the Discussion Draft.

- EPA should have been here, include next time.

- We need more socioeconomic discussion next time. We also need the Negotiator or someone from his staff. What do they think should be addressed?

- Invite someone from a reactor state.

- A Nevada citizens group or some other Nevada affected group should be there. This has been good but it could have been better if it had been more of a dialogue. Put DOE at the table next time.

- From an historic standpoint, don't overwhelm the table with DOE staff. It would be bad to have a dialogue that would be like "decide/announce/defend".

- It was good when DOE staffers spoke up on specific points. Make better use of the DOE resource people.

Facilitator: The majority agreed with the suggestion about including a Nevada citizens group. How about materials?

DOE: The Discussion Draft was prepared to assist the discussion here. Reluctant to change it.

- We still need to address how this process fits in with the MPA and other DOE initiatives that are separate from the MPA.

- Discussion Draft was a real help, an improvement over the past. The flexibility to adjust the agenda was also good.

DOE: We will get out the proposed agenda on the next workshop in a couple of weeks. Thanks to all of you for the splendid participation. There will be more attendees next time, as well as more resources. But it is your meeting, and we will be flexible on the agenda. This is predecisional, so we owe you some feedback. Propose a third meeting, no sooner than March, at which we will give you the feedback. That 
is how we propose to use your input to the MPA. At that time we will identify specific new Strategic Principles for the MPA.

(Denver and Dallas were the two favorites for venue.) 


\section{LIST OF PARTICIPANTS \\ AT THE \\ FIRST STRATEGIC PRINCIPLES WORKSHOP}

Salt Lake Hilton Hotel--Salt Lake City, Utah

December 4-5, 1990

Dr. Bill Barnard

Executive Director

Nuclear Waste Technical Review Board

1100 Wilson Boulevard

Suite 910

Arlington, Virginia 22209

(703) 235-4473

FAX: (703) 235-4495

Dr. John Bartlett

Director

Office of Civilian Radioactive

Waste Management

U.S. Department of Energy

1000 Independence Avenue, S.W.

RW-1, 5A-085/FORS

Washington, D.C. 20585

(202) $586-6842$

Mr. Mike Baughman

Consultant

Lincoln County Board of Commissioners

35 Clark Street

Fiskdale, Massachusetts 01518

(508) $347-5040$

FAX: (508) 347-5445

Mr. Dennis Bechtel

Coordinator

Nuclear Waste Division

Clark County Department of

Comprehensive Planning

301 East Clark Avenue

Suite 570

Las Vegas, Nevada 89101

(702) 455-5175

FAX: (702) 455-5190
Mr. Robert Bernero

Director

Office of Nuclear Material

Safety and Safeguards

U.S. Nuclear Regulatory Commission

M.S. 6A-4

Washington, D.C. 20555

(301) 492-3352

For Courier:

11555 Rockville Pike

Room 6D-1, M.S. 6A-4

Rockville, Maryland 20852

Mr. Stephen Bradhurst

Consultant

Nye County Board of Commissioners

P.O. Box 1510

Reno, Nevada 89505

(702) $482-8181$

For Courier:

4720 Canyon Drive

Reno, Nevada 89509

(702) $323-4141$

Mr. Holmes Brown

Facilitator

Afton Associates

403 East Capitol Street, S.E.

Washington, D.C. 20003

(202) $547-2620$

FAX: (202) 547-1668

Mr. Mark Burtschi

Director

Legislative Programs

American Nuclear Energy Council

410 First Street, S.E.

Washington, D.C. 20003

(202) $484-2670$ 
Mr. Ronald C. Callen

Director

Nuclear Waste Program Assessment Office 1400 16th St., N.W.

5th Floor, Mail Box 18

Washington, D.C. 20036

(202) $939-3420$

Dr. Thomas Cotton

Senior Associate

JK Associates

1001 Spring Street

Suite 406

Silver Spring, Maryland 20910

(301) $587-7098$

Mr. Steven P. Kraft

Director

Nuclear Waste and Transportation

Edison Electric Institute

701 Pennsylvania Avenue, N.W.

Washington, D.C. 20004-2696

(202) $508-5512$

Mr. Robert Loux, Jr.

Executive Director

Nuclear Waste Project Office

State of Nevada

Capital Complex

Carson City, Nevada 89710

(702) 687-3744

Dr. Peter B. Myers

Executive Director

Board on Radioactive Waste Management

National Research Council

2101 Constitution Avenue, N.W.

Washington, D.C. 20418

(202) 334-3066

Dr. Robert H. Neill

Director

New Mexico Environmental Evaluation Group

7007 Wyoming Boulevard, N.E.

Suite F-2

Albuquerque, New Mexico 87109

(505) 828-1003

Ms. Nancy Pearson

League of Women Voters

Education Fund

6708 Bridgeport

Tacoma, Washington 98467

(206) $582-3543$
Dr. Chuck Reese

Assistant Director

Occupational Safety and Health

Laborers Health and Safety

Fund of North America

905 16th Street, N.W. (Lobby level)

Washington, D.C. 20006

(202) 628-5465

Mr. Dan W. Reicher

Senior Attorney

Natural Resources Defense Council 1350 New York Avenue, N.W.

Suite 300

Washington, D.C. 20005

(202) $783-7800$

Mr. Joe Youngblood

Deputy Director

Division of High-Level Nuclear Waste

U.S. Nuclear Regulatory Commission

M.S. $4 \mathrm{H}-3$

Washington, D.C. 20555

(301) 492-3404

For Courier:

11555 Rockville Pike

Room 4H-2, M.S. 4H-3

Rockville, Maryland 20852 


\title{
DISCUSSION NOTES \\ ON THE \\ SECOND STRATEGIC PRINCIPLES WORKSHOP
}

\author{
Washington, D.C. \\ January 15-16, 1991
}

U.S. Department of Energy

Office of Civilian Radioactive Waste Management 


\section{FOREWORD}

On January 15-16, 1991, the Office of Civilian Radioactive Waste Management (OCRWM) of the U.S. Department of Energy (DOE) conducted the second of a series of Strategic Principles Workshops in Washington, D.C. The Workshops are intended to provide an opportunity for affected and interested parties to participate in developing strategic principles which will be used to guide the nation's radioactive waste management program.

The Washington, D.C. Workshop was hosted by OCRWM Director John Bartlett and conducted by a professional facilitator. Twenty-eight invited participants associated with various affected and interested parties joined the Department of Energy staff and outside observers at the Workshop, which was open to the public.

Workshop discussion generally addressed points raised in a "Discussion Draft on Strategic Principles for Planning and Decisionmaking in the Civilian Radioactive WasteManagement Program" (discussion draft), produced by OCRWM on November 21, 1990 and forwarded to participants prior to the Workshop. Additional topics were discussed as agreed upon by the participants during the workshop.

This document presents notes on comments made during Workshop discussion; it is not a verbatim transcript of the proceedings, nor does it represent an analysis of the discussions. Because participants were assured that the discussion was on a "not for attribution" basis, bullets $(\bullet)$ are used to identify comments by participants other than Department of Energy staff or the discussion facilitator. 


\section{DISCUSSION NOTES \\ ON THE \\ SECOND STRATEGIC PRINCIPLES WORKSHOP}

Washington, D.C.

January 15-16, 1991

TABLE OF CONTENTS

Page

Foreword $\ldots \ldots \ldots \ldots \ldots \ldots \ldots \ldots \ldots \ldots \ldots \ldots \ldots \ldots \ldots \ldots \ldots \ldots \ldots$

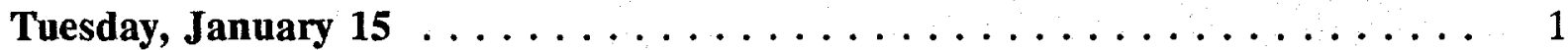

Welcome and Brief Program Review . . . . . . . . . . . . . 1

Agenda and Workshop Objectives .................. 2

Timing and Criteria for Determining Site Suitability,

Phased Licensing, and Cooling Spent Fuel . . . . . . . . . . . . . 4

-Timing and Criteria for Determining Site Suitability . . . . . . . . 4

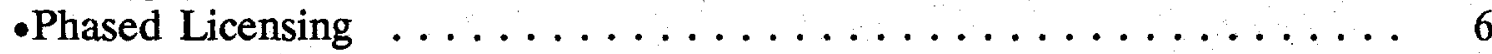

.Cooling Spent Fuel . . . . . . . . . . . . . . . . . . 9

Use of the Trust Fund for Storage and

the Roles of Utilities and the Federal Government $\ldots \ldots \ldots \ldots \ldots \ldots \ldots$

Dual-Purpose Casks .......................... 13

Gaining Public Confidence/Acceptance ................... 15

Public Comment ........................ 21

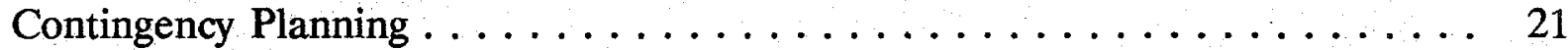

Wrap-Up . . . . . . . . . . . . . . . . . . 22

Wednesday, January 16. . . . . . . . . . . . . . . . . 25

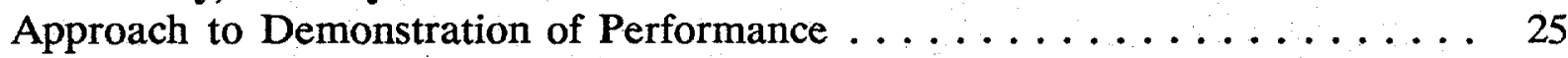

Controlling Program Costs ...................... 29

The DOE and Public Acceptance $\ldots \ldots \ldots \ldots \ldots \ldots \ldots \ldots \ldots \ldots \ldots \ldots$

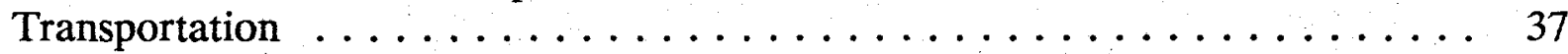

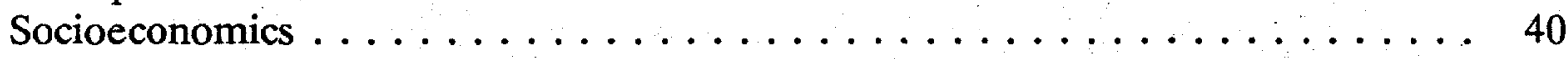

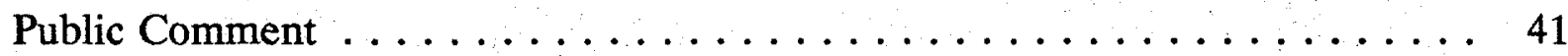

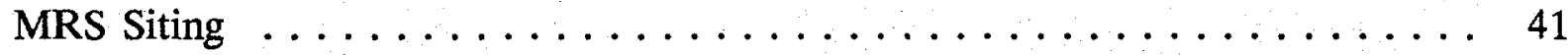

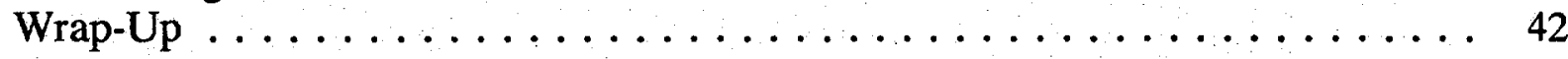




\section{TUESDAY, JANUARY 15, 1991: 8:30 AM SESSION}

\section{WELCOME AND BRIEF PROGRAM REVIEW}

Facilitator: This is the second of the meetings scheduled by the Department of Energy (DOE) to hear comments from interested and affected parties. Introduces Bartlett, then discusses agenda.

DOE: I'd again like to express my thanks for this opportunity to speak with you, and thank you for coming. The message I'd like to emphasize is that this is your meeting. The DOE is here to listen, learn, and serve as a resource. I want to get your comments and perspectives. The framework for the program provided by the Nuclear Waste Policy Act (NWPA) and the Amendments Act is flexible and broad; there are 2000 ways to implement the program. The DOE needs and wants guidance on how to make choices among the alternatives. It is important for program purposes to hold these workshops, which are intended to shape principles for the program. We have to make choices, convert the issues into strategic principles. We need the participants to help the DOE make determinations to select principles to guide future efforts. The products of these workshops will be manifested in the Mission Plan Amendment (MPA), which we foresee as coming out at the end of this calendar year. The process is one in which the inputs from the workshops will be used by the DOE and interpreted in terms of what we thought you said, of what is required for management implementation. We plan a third feedback workshop, at which we will inform you of what we heard, our actions in light of that, and we will come back to you with the results of your input. That is how we expect to proceed. After that, we expect to proceed to develop the draft MPA.

Facilitator: Thank you, John, for explaining the purpose of these meetings. This session addresses management issues, and I have a prospective agenda. I want to offer a quick review of our experience at Salt Lake City. It was a breakthrough in terms of the DOE/publicinteraction. Our intent is to encourage a dialogue and communication on the part of invitees. First, perhaps, I should give you a bit on my qualifications to be facilitator. I've been involved in these issues for some time. I worked with the National Governors' Association from 1979-1986. As part of the State Working Group, which was partly sponsored by the DOE, I was involved in the 1982 legislation. I'm familiar with the development of the program, and especially with State-public-DOE interactions. And I must say I'm encouraged by these initiatives. On to other items: (Notes schedule, breaks. Describes breaks as an integral part of the meeting for individual contacts, follow-ups. Encourages audience to question participants during breaks. Reads statement on packet regarding nonattribution of comments to foster open dialogue; reminds press, hopes for open discussion. Reminds that participants are speaking as individuals rather than as representatives of organizations. Notes the DOE 
is not striving for consensus among the participants.) This is not a formal advisory committee, is not subject to the Federal Advisory Committee Act, and the DOE does not expect formal recommendations. As to my facilitator role: our last meeting went smoothly. We have much to cover this time, with a larger group. I ask you to keep your remarks brief and to the point. Due to our larger audience, we are also allowing a half-hour public comment period in the afternoon.

\section{AGENDA AND WORKSHOP OBJECTIVES}

Facilitator: The agenda is tentative. I welcome your comments on the sequence of topics, and I want us to arrive at an agreement on the schedule. At the end of the day we will review the schedule for tomorrow. Let's start with the discussion on timing and criteria for determining site suitability; it's a good general topic to start with. We spent a lot of time in Salt Lake City talking about this. A lot of our discussion is contingent on how people will want to deal with it. Runs down list of agenda items to afternoon, next day.

- One item we were talking about in Salt Lake City was socioeconomics. We should look at that at some point.

Facilitator: Could you be more specific?

- We would like to have the DOE recognize as an objective looking at the question of, should the project proceed, what impacts it will have on communities, labor, resources. The DOE should recognize this as a program objective.

Facilitator: Let's discuss whether there is a way to frame that as a management issue during the break.

- What about coverage of environmental issues? I didn't get a good sense of discussion of it in the notes. Will you please point out who are the environmental experts so I can chat with them during the break?

Facilitator: Okay, we'll talk about that. Other topics?

- I have a number of points. One, the agenda doesn't recognize the kind of trouble the repository program is in. There are no Environmental Protection Agency (EPA) standards yet and that's a fundamental issue. Nothing meshes with the Nuclear Regulatory Commission (NRC) regulations. There is no resolution of health and environmental protection. The DOE hasn't been serious about addressing this issue. Are we going to limit environmental protection to arbitrary time periods? Are we willing to live with finite time limits? It has to be a subject. Two, we must deal with 
the general issue of overall program standards. We must examine the quality of science in the program and the poor response to external efforts, from National Academy of Science (NAS) and other independent parties, to help. Internal science has not been good. We must consider these. You can have workshops forever and nothing will happen; workshops alone won't help. Three, much defense waste is highlevel and should be treated as such, but isn't. The issue of space in the repository if the HLW classification is expanded is an important agenda item that needs to be addressed.

Facilitator: Let me respond in terms of the agenda. The quality of science of science and response to external input can be discussed on the demonstration of performance. The amount of waste can be discussed under timing and criteria. There was some discussion at Salt Lake City about estimates. In terms of overall or the EPA standards, we'll have the EPA representatives here and will discuss it tomorrow, during the demonstration of performance session. I want to give everyone the opportunity to raise issues, but within context.

- The DOE needs to make fundamental decisions on the consolidation of spent fuel. They have to answer that question.

Facilitator: Good issue. Let's consider that a subtopic under "Roles of the Utilities," and spend a lot of time on that in that session.

- A second point on the agenda, regarding private sector involvement in the MRS. Why a full hour when other issues aren't allocated so much?

Facilitator: It was done to arrange a sequence. Some topics take longer than others. We may not take the entire session, we may take less time. At the end of the day, we'll see how the discussion is going, and adjust accordingly.

- Controlling program costs is a central question. I'll be appearing in front of the Nuclear Waste Technical Review Board (NWTRB) tomorrow. The 11:30 AM discussion is too lengthy. I suggest you switch the topics of private sector involvement in the MRS and controlling costs.

Facilitator: I'm amenable to that. It will also arise in discussion on public trust.

- I have a strong interest in the approach to the demonstration of performance, and I'm also going to be at the NWTRB meeting. If it's possible, I'd like the issue adjusted.

Facilitator: How many others will be at the NWTRB meeting? Okay, if nobody minds, we'll work out an adjustment at the break. 
- It is a central issue to be discussed. Switch today's 11-12:30 session with tomorrow's performance assessment session.

Facilitator: I would prefer to juggle tomorrow's agenda. Let's discuss this at the break. Why don't we use this as a general framework and proceed.

TUESDAY, JANUARY 15, 1991: 9:00 AM SESSION

\section{TIMING AND CRITERIA FOR DETERMINING SITE SUITABILITY, PHASED LICENSING, AND COOLING SPENT FUEL}

\section{Timing and Criteria for Determining Site Suitability}

The facilitator referred to page 3-9 of the discussion draft and read out the options presented there.

- How does this work tie in with the environmental cleanup of the nuclear defense facilities? Are they independent efforts? What would be the impact on groundwater?

DOE: These are administratively independent programs, funded from different sources. They are on totally separate tracks as far as technology and time frame. The programs come together in that defense high-level waste is to be placed in the civilian HLW repository and become a source term for it.

- They come together in an environmental sense. The discussion draft did not discuss ground water.

- To demonstrate site suitability could take an inordinate amount of time. Instead of spending a lot of time on decisions about criteria and techniques, the Electric Power Research Institute (EPRI) prefers using the present EPA criteria to do a quick-anddirty analysis of the ability to meet key requirements, using tentative criteria and applying an iterative process. The analysis will be tentative and the results won't be definitive, but it will be revised as more data become available. It is important at this stage to do something, however imperfectly, with imperfect criteria, to get in the game of performance analysis now, even if the criteria change later.

- The DOE and the NRC have siting criteria, while the EPA does not. The Act expects an early cut to determine what sites are unsuitable. Some of the criteria for disqualification are built into the DOE's siting guideline, 10 CFR 960. These guidelines were promulgated by the DOE after a lot of argument and discussion with the States. They specify specific individual conditions that must be met. And the Ninth Circuit 
Court has ruled that they are applicable. Let's see how the DOE decides to interpret the guidelines. A leap now to performance assessment is not productive--it will merely be used to justify pouring more money in. Iterative performance assessment is totally premature.

- Citing from Waste Isolation Pilot Plant (WIPP) experience, the DOE vacillated on demonstrating compliance with the EPA standard; we are still waiting for a report on that, and the EPA is looking for it at the completion of the project. An evaluation is needed earlier than that.

Facilitator: The DOE is looking for guidance. A step-wise approach or a move right to full licensing?

- How does the schedule for site suitability tie in with the timing for waste emplacement?

- You can't separate the timing from the eventual closure of the issue in the licensing hearing. Making an early determination of suitability will not provide measurable tracks and that will lead to a later impact on licensing. Even though you investigate at length you are unlikely to find some magic indicator of suitability. You end up with more and more information, which may make a decision more difficult. You need early and continuous review and measurement against the licensing requirements.

- There is too much uncertainty, which impacts public confidence too seriously. The whole process will have to be repeated. Therefore, go to one-hundred year on-site storage and go back to the drawing board on geology in order to gain public confidence, rather than jumping into licensing. I don't see rushing into licensing.

- Clark County plans to draw water from upstate, about which it knows little. You've got to show the public you understand the mechanics of ground water.

- There was agreement on the disqualifying conditions--they were reviewed in the EAs. Until new site tests are completed, more cannot be done. What can be done to improve the process without getting on-site? Do you want to go so far as doing the EAs again?

- Yes, go back to the evaluation of sites. The EAs were perfunctory, not at all well done. Furthermore, a large amount of information was not used in the EAs or even analyzed because of the early cutoff date for the EAs. The DOE should take the existing data and submit it to a rigorous analysis and compare the results against the guidelines. We know more now than we did when the EAs were published. We have analyzed the data and shown that ground-water travel time will not meet the 
criteria in 10 CFR 960. We gave this information to the DOE 2 years ago but have had no response yet.

- The State's data should be submitted to peer review.

- There is a difference between site suitability and licensability. A site that is licensable may not be suitable. The Congress meant not to waste money on a site that seems unsuitable. The standards for suitability are the DOE guidelines. They were meant to be applied to the point at which the President recommends a site to the Congress. I agree that the entire site suitability process must be repeated. We won't make the schedule, and we should back off.

- I understand that suitability is not the same as licensability, but how is this to be implemented? One thing we can do is to determine how to address ground-water travel time. But we must consider other factors, not just ground-water travel time.

- How would the earliest determinations of suitability be determined? How should a finding of non-suitability be timed? This is not shown as an alternative. Should there be an announcement at the time of the earliest suggestion of non-suitability?

\section{Phased Licensing}

The facilitator referred to page $3-25$ of the discussion draft and read out the options suggested for discussion.

- Is the MRS the "Temporary Storage Facility" of Option 3 of Phased Licensing? What flexibility exists in this area: could you seek earlier emplacement of waste in the Temporary Storage Facility, as in Option 3? Are there other options for early emplacement?

- Is your concern that there would be emplacement before the NRC approval?

- Yes.

- There are semantic problems with "suitability." The DOE has defined it on the basis of performance, rather than testing against criteria. But how are we going to license the repository? The DOE has always planned phased construction for the underground repository, with excavation continuing after waste emplacement starts. But at the time of the NRC's construction authorization there will be a large mass of rock about which not everything will be known. If a bad block is encountered during construction, the DOE will say, "Work around it." The repository block will become a record of exceptions. Otherwise one would have to build the entire repository first, 
which nobody wants to do. In some other type of rock, you could do phased construction. But it is not possible at Yucca Mountain, which would become blocks of waste isolation surrounded by exceptions (faults, etc.).

- Right now, suitability could mean suitability for conducting additional tests. Is it worth putting more work into the site? Other suitability decisions would come later. The fundamental issue is not that the data show now that ground water travel time fails to meet the standard, but rather what is the probability that after further testing it will not meet the standard.

Facilitator: Can we hear from the utility representatives on the timing of acceptance? Will that have any effect on licensing schedules?

- The DOE must accept the spent fuel when specified by the contract. Elimination of uncertainty about waste disposal will eliminate one obstacle to nuclear power and the second generation of reactors. If it is possible to eliminate uncertainty, the consequences could be important. This affects utility planning for storage.

- Nuclear energy has a public perception problem. And the public perception problem will get worse when waste transportation starts. It is presumptuous to talk of schedule when the public perception has not been solved.

- Nye County is hurt within the State as time drags on--as witnessed by Bullfrog County. But safety demands the conservative approach, and from that standpoint, a phased approach is advisable. On the other hand, the longer you wait, the more you may get hurt.

- Much data are missing. The DOE is reluctant to go to licensing because it is a new thing; therefore, don't go too early, but use the step-wise approach because it will address issues early on and result in lower costs.

- Option 4 is attractive, because it would go back to a high threshold for natural barriers. Engineered barriers can be addressed later in licensing.

- Option 3 gives me the most trouble. There can be no rational licensing with waste already in the ground. Having the waste in the ground would be perceived as a fait accompli. The DOE would have no credibility. Remember the experience with WIPP. Option 4 gets to natural barriers; you will need to look at the entire system. Regarding option 2, you need an open technical discussion to determine if there is legitimate technical information that can be obtained. Without further information, option 1 seems to be the best. I have questions about option 4 .

Facilitator: Is there need to talk of a second repository? 
DOE: If you look only at the existing reactors, there will be approximately 86,000 metric tons of heavy metal (MTHM) of spent fuel, 10,000 MTHM of defense highlevel waste. The Yucca Mountain capacity is approximately 100,000 MTHM. Any significant increase--from added reactors, reactor life extension, etc.--would exceed the current estimated capacity of Yucca Mountain. This will have to be reevaluated in 2003.

- 100,000 MTHM is not the same as previous estimates. Is this based on heat management? It should be linked to the entire system.

DOE: There are potential trade-offs with cooling time, with extraction ratio, worker safety, etc., not just cooling. Any limit to less than $95^{\circ} \mathrm{C}$ is acceptable. Will waste be emplaced in 2050? 2080? This would require effective means of storage.

- 10,000 MTHM of defense high-level waste is questionable. What of Hanford? What is high-level waste?

DOE: 10,000 MTHM is a ballpark number.

- There could be a lot more than 10,000 MTHM in a worst case scenario.

- Not MTHM but metric ton uranium equivalent, at the start of exposure. Does the Act's limit of 70,000 MTHM include defense waste?

- The options are confusing. The temperature of spent fuel at the time of waste emplacement will affect licensability. Connected questions are repository design, performance, storage, equity for utilities. Just what did the utilities buy?

- Yucca Mountain has several emplacement horizons. Does 100,000 MTHM relate to a specific one?

DOE: We are talking about Topopah Springs, but the data base is very sparse.

- More of the present defense waste should be designated as high-level waste. The HLW glass will be heated up by the spent fuel. As a result, the whole question of area becomes complicated.

DOE: These are tactical near-field issues. We can handle this once we have a global strategy. We need data from the repository location for licensing. 


\section{Cooling Spent Fuel}

The facilitator referred to page 3-2 of the discussion draft and read out the options suggested for discussion.

- I favor at-reactor storage for 80 years or more, by which time the strontium and cesium concentration would be lower, resulting in lower transportation risk. The repository process will not yield a good site; therefore, long licensed dry storage is preferred, not at an MRS. Start the scientific process for a repository over.

Facilitator: One way to increase repository capacity is extended cooling and greater density.

- Yucca Mountain can't accommodate all the waste, therefore the second repository will be needed. The debate is needed now: the second repository must be outside Nevada, and the DOE must say so now.

Facilitator: The Congressional mandate excludes a second repository. How can the DOE address it?

- What does the present Mission Plan state?

DOE: The Mission Plan predates the 1987 Amendment Act and therefore speaks of a second repository. In 2003 we will have better knowledge. The 70,000 MTHM limit is only until the second repository is open.

DOE: We need to distinguish between the implementation of national policy and programmatic strategy. We have no authority to investigate the need for a second repository. With respect to storage, there are opportunities within the programmatic strategy. Storage can be provided in various places, and tradeoffs must be considered. To have a national policy of long-term storage, Congress would have to change the law. There are tradeoffs in cost, in affected parties, in inventories at different sites, etc.

- Do the technical and safety evaluations; there is a disconnect between the transportation cask and the repository. If you go to hot fuel emplacement, you will need to look at the whole system within the Act.

DOE: This kind of workshop is to point us to whichever is the most reasonable strategy. We need system studies because there are trade-offs. We are trying to narrow the field of system studies.

- Some of the DOE programs are being degraded. In the cleanup of the Nevada Test Site, ground-water monitoring has not been regularly performed in the last decade, 
although it used to be performed regularly. There clearly is an opportunity for the DOE to be a good environmentalist. There is a linkage between defense and OCRWM in people's perceptions. Slow down the process. Young people have a basic fear of radiation. The DOE needs to evaluate how it is perceived.

- Why can the Mission Plan not discuss the second repository? The DOE has the authority to look in the 2007-2010 time frame. The DOE can raise the issue in the MPA.

Facilitator: The advice is to include the second repository issue in the Mission Plan Amendment.

- Is it true that if it is not permitted by the Act it can't be included in the Mission Plan? Sweden may not phase out reactors by the year 2000, even though the law says so. We may have to extend nuclear power, and the strategy should account for that.

Facilitator: The DOE will respond to this advice at the third Workshop.

- With respect to potential waste volumes. The standard contract [10 CFR 961] accepts nonfuel components. According to new rules for low-level-waste disposal, the present practice of concentration averaging over the volume of the waste may not be allowed. This would make a big difference with Greater-than-Class-C waste. This may be the forcing function on repository capacity.

\section{TUESDAY, JANUARY 15, 1991: 11:00 AM SESSION}

\section{USE OF THE TRUST FUND FOR STORAGE AND ROLES OF UTILITIES AND THE FEDERAL GOVERNMENT}

Facilitator: Let me run down the issues and options we're going to discuss. First is the roles of the utilities and the Federal Government in managing spent fuel before disposal, which is found on page 3-27. Runs through options, relates to earlier discussions. We'll also look at the issue of use of the trust fund for storage, which is found on page 3-30. Finally, we'll consider the issue of dual-purpose casks, which is found on page 3-23. All relate to the issue of the respective roles of the Federal Government and the utilities regarding title and possession. The question of consolidation also arises.

- The consolidation of spent fuel is a developing technology. Utilities are pursuing options to increase the capacity of existing storage pools. At one time, it was considered to increase the capacity of dry casks. It is driven by economics. There is a 
question of the DOE acceptance of consolidation, which is also a transport question involving cask loading. The utilities need to know what the DOE will accept. The utilities might have better information about what they should or shouldn't do if they knew what the DOE was going to do about receiving or not receiving that consolidated fuel. I see it as a strategic principle. Also, utility people and nuclear fuel people in the audience should talk about this during the public comment period.

Facilitator: At what point should the DOE accept title and possession of spent fuel? Who should manage it? What preferences do you have? Any comments?

- The utilities think the DOE should accept possession. They want 1998 acceptance. They believe we have contractual commitments for the DOE to take the stuff away. They don't care where it is put, presumably at an MRS, but that's up to the DOE. They're not interested in long-term on-site storage. They'll have to decommission plants eventually.

- What are the nature and terms of the contract, default provisions?

- The contract isn't explicit regarding fault and default. It could become a dispute among lawyers. We believe there is an obligation, but we haven't settled it. We prefer from general funds.

- The DOE will have to take the fuel. Shutting down plants is not an option. No matter what the contract says, when the time comes the utilities will keep it on-site rather than shut down reactors. Don't assume the oldest fuel goes first. That is not a contractual obligation. It should be based on storage needs.

Facilitator: Oldest fuel first is an issue. Wouldn't that require the utilities to cooperate in determining the order of acceptance?

- There are downsides to continued on-site storage: decommissioning, fuel pools, the cost factors, the ratepayers won't be happy. The NRC says it's safe to extrapolate from current corrosion data, but ratepayers are unimpressed about having the stuff on site for long periods of time. Some advocate backing up and doing a lot of R\&D. This implies that ratepayer dollars will continue to flow for disposal. But I want to point out two things. One, I wouldn't assume so if the program steps back. The money goes for disposal. If there is no disposal, then put the money in reserve for when disposal goes forth, however long it takes. Two, you won't have an easy sell of nuclear energy if we have not solved the waste problem. The choice is the DOE accepting possession in 1998 versus continued utility management.

- I want to comment on this, about ratepayers and taxpayers. Are there deadlines on this? How about getting Defense programs to ante up? 
- Not one thin dime has been paid. It is the subject of current litigation.

- When the Federal Government is remiss in anteing up its fair share, this affects credibility. I'm raising it as a question, not an accusation. Possibly some of the R\&D work done by Defense programs may apply to the OCRWM program.

- In the Five-Year Plan of 1989 , Secretary Watkins committed $\$ 200$ million as the Defense contribution. The DOE hasn't gotten it. There's been no follow-through. Where did the slip-up occur?

- Slip-up implies it was forgotten about. It was stopped, and not at the DOE, which made a sincere effort, but on the Hill and in Office of Management and Budget. Are you saying that some Defense research work done for WIPP or other activities applies to OCRWM?

- No, I wasn't making that point.

- Well, the DOE is making that point.

Facilitator: Going back to the principal issues of who's paying and when, of who should manage waste, the DOE wants guidance on storage. Are there safety issues? There are legal pressures from the utility side. Any contrasting views for the record?

- If the industry is worried about public concern, it should recognize that spent fuel is better off with them than with the government. The way the DOE has handled their own HLW doesn't provide much confidence in their ability to handle utility spent fuel. There is no guarantee that the DOE will accept fuel in 1998, either. In the broader system, in a safety sense, the public isn't comfortable with the DOE handling of the program. The key issue is that ratepayers need to know the expense of storage beyond the contractual date. This is a way of making ratepayers aware of the whole cost, especially if you are looking to reactor license extension. An observation: the transportation of spent fuel is a sleeper issue for the public. Spent fuel isn't waste until you move it. In the experience we've had, the initial public reaction to on-site storage isn't nearly as bad as it was thought. If you want to keep the public quiet, store at reactor sites with a rebate from the fee. The DOE seems to want to get into utility storage. The utilities may not want this association. However, the utilities need relief from uncertainty about such things as consolidation. The DOE should better define what they'll accept, and what they'll do when they default. They shouldn't have any new role inside utility fences. Speak to Congress about the 1998 date.

Facilitator: Would someone in a State with at-reactor storage like to comment? 
- Going back to the issue of contracts. One, the Federal Government unnecessarily obligated itself to take fuel in 1998. Two, I don't like the notion of Federal title and utility possession. It's bad for safety and environmental protection. There are many problems with shared authority; the ball goes back and forth. Three, environmental groups accept geologic disposal. For both the near- and mid-term, we can do a good job of storage at reactors. But I raise questions over the long haul, so that's why we need geologic disposal.

- There is a problem with extending the DOE title at reactors. It's not good to split responsibility. Complex management leads to uncertainty in performing tasks. It adds to risks. You need a single organization. But what if you don't want to deal with shipping? In terms of systems-load, systems research, etc., you're better off with the Federal Government. Take the fuel and put it in the hands of those who'll manage it long term. Start this process early, set up a well-defined system early. Get people comfortable enough with it now. That's the only easy way to do it.

- Ratepayers are paying for at-reactor storage, transportation, and disposal. Some of these alternatives don't necessarily have cost implications. You are trading dollars internally. Ratepayers also have paid for the system in a cost sense. Trading money internally may not have a cost impact, but systems have cost impacts. These options have political, not monetary, differences. But there might be a cost impact by having an early, well-defined system.

\section{Dual-Purpose Casks}

Facilitator: Now I want to ask about dual-purpose casks. Do you have any comments or preferences? Should the DOE pursue this? Any advantages to it? You'll find this discussion on page 3-23. Of the real concerns about moving spent fuel, dual casks provide an option.

- I support option 2, including a limited number of dual-purpose casks in the program. It would be beneficial if the DOE was actively involved in the program early on. It would show benefits in overall system costs to the DOE and the utilities and provide for more system flexibility. Look at an overall system approach.

- As more utilities move to on-site storage, you get the transportation issues of loading and unloading. It's desirable to minimize the handling needed. Dual-purpose casks potentially alleviate this, particularly at the site. For example, the Rancho Seco site is closing. If they could use dual-purpose casks and close their pool, it would provide cost savings. The issue of pool maintenance is key. 
- There are other options beyond option 1 and option 2. Look at dual-purpose casks in system economics. There's much to do here. Who pays what, and when? To drive down costs, it might be possible to build a primarily storage cask with a one-time transportation certificate. Would it be licensed under 10 CFR 71 or 72 ? The fundamental concern of the utilities is that no one can order anyone else to do anything. It's unclear that the DOE can get the utilities to do what they think they ought to do. Incentives might be needed. These are complicated factors needing discussion.

- Let me refer back to other comments. The utilities and State public utility commissions (PUCs) are not monolithic. There are splits among both. Utility uncertainty regarding PUC preferences can drive them to different stances. For example, a commission in the State of Tennessee studied the question of dual-purpose casks. If it involves long-term ( 20 years) on-site storage, is the NRC willing to let the cask be shipped? The issue is not resolved. And how do you measure the savings?

- The DOE should consider whether using dual-purpose casks will affect MRS siting. Will it constrain the ability to site an MRS? Will it create the impression that you are rushing into it? You must factor this into the system. As yet, it hasn't been considered.

- Following up, the idea of early acceptance at an MRS may be a virtue of dualpurpose casks, but it still raises the red flag. If we go with an MRS system, we risk public acceptance and confidence if we talk about the shipment of waste to an uncompleted facility. The public would not find simple storage on a construction site acceptable or comfortable. I caution you against that kind of justification for dualpurpose casks. They are only an option when they are consistent with safety and environmental protection. There should be no pre-MRS storage; if we go with an MRS, it should only operate when it's ready--with all safety and environmental controls in place.

- Still, it is an advantage to have the option available. And it's also an economic question. Look at getting a larger procurement to drive the costs down.

- True, spending extra money up front to get dual-purpose casks could result in cost saving, but only later on. You are asking utilities to make the investment now. You must assure you get NRC's approval for transportation and realize the savings. It is a concern.

- The issue of the design life of casks is important, and not just abstract. At WIPP, container design life ( 20 years) has become a big issue because 20 years has passed since the waste was loaded into the containers. 
- With regard to the experience with modular vault dry storage in Colorado, I have a couple of points that arise in connection with modifying casks to dual purpose. One, there's a lot of cask handling experience in the utility community that would be useful to bring into review of the Mission Plan Amendment. Two, this is a good demonstration and pilot for the management systems approach, to see if it's worth having, to completely analyze the use of dual-purpose casks, the benefits to utilities and to the DOE. It's a classic "get your arms around a manageable demonstration." It would've helped a utility dismantle a site. You need this kind of cask.

- You're talking about three functions: store and protect at site, transport safely, and store and protect at destination. Think about a division of those three functions and design wrappers (reusable transportation overpacks) accordingly. Differentiate the wrappers. You can accomplish these functions by using wrappers on storage casks; reuse heavy and expensive components, eliminate handling. Perhaps you can find a middle ground in the handling process. You could achieve benefits at far less cost.

- You also have to look at the heavy fail-safe cranes required to handle dual-purpose casks, and look at it in terms of systems analysis.

Facilitator: In summary, we've looked at the range of options. The utilities cited their view of contractual obligations, and we haven't heard much from others on long-term storage. We don't have any recommendations for the DOE not to take title and possession right away. Any environmental costs or public concerns? No? Well, the DOE wants plans. Further comments can be submitted in writing. The DOE is still open to comment. Enough discussion of dual-purpose casks. It may be worthwhile for the DOE to pursue this in greater detail, get some research going on. Cost seems to be the principal factor.

\section{TUESDAY, JANUARY 15, 1991: 1:45 PM SESSION}

\section{GAINING PUBLIC CONFIDENCE/ACCEPTANCE}

Facilitator: The issue of public confidence was raised at the Salt Lake City meeting as one that should be added to the discussion. Many people said it permeates all other topics. For waste management activities of all kinds, public confidence is perhaps the chief factor affecting the pace and success of programs. It needs to be addressed. Unlike some of the more technical topics, everyone can address this issue. The DOE is interested in what types of practices, programs, attitudes, etc. they can adopt to foster public acceptance. Even the terminology has been an issue--should the goal be acceptance or just to inform the public? 
- Workers definitely have a degree of mistrust for the nuclear industry and for the DOE. Programs like the recent "60 Minutes" television show heighten this mistrust. While it is often said that workers are the most important resource, when costs are cut, worker health and safety programs get cut first. This conveys a bad message to workers. Workers are a grapevine--and should be treated as a communication tool. They can convey a good image that would show a commitment to health and safety to the general public. The perception exists that workers are not treated properly. This can be improved by proper monitoring, safety programs, protocols for worker safety, etc.

- I agree. Perception--based on Nevada Test Site workers--is that people in jobs related to safety and environmental protection are not skilled in those areas.

Facilitator: How would you rate public confidence in the DOE?

- I have had problems with what the DOE's been doing. I work with citizen and environmental groups, the media, and industry. From the technical side, the DOE is reluctant to admit that they made bad decisions. This has to come from the top. There is no internal process whereby the DOE admits mistakes. The DOE is always seen as brought kicking and screaming to admit very obvious faults. Then, there is the issue of abysmal work; for example, in the second-repository area recommendation report, the list of references showed a 1957 report as the most recent National Academy of Sciences report, and it failed to include many reports of significant work. That area recommendation report was a technically lousy report that did not consider many important issues. Thus, how can one have confidence that issues have been considered? Another example is "number cooking" with stress ratios at Hanford. This is a systematic pattern of bad behavior, on the military and civilian sides. It is not an information problem, it is an attitude and a content problem with the work itself.

Facilitator: You've given specific examples of confidence problems. If that is a generally shared perception, what can the DOE do to increase public confidence? Are there examples of good studies or procedures?

- Do people see a difference between Defense Programs and OCRWM? Or do they lump the DOE together as one unit? I see a difference but I'm not sure the public does.

Facilitator: If you cite examples, look at OCRWM. But, for a larger public confidence view, people lump them together. What can the DOE do now?

- There is a credibility problem with the weapons testing program. The Atomic Energy Commission (AEC) assembled a Public Health Service Commission to establish trust. It worked. There is a group in Las Vegas that carries out the off-site 
radiological monitoring program. OCRWM could use these people. There are professors at the University of Nevada doing sociological studies. The issue is the image of nuclear. The younger generation thinks of fall-out shelters; they think radiation is scary and bad. The DOE needs to understand public perceptions. They should get sociologists who understand.

- You need to get across the idea that science is the basis for decisions. The Nuclear Waste Technical Review Board is a good step. You could create a position of Chief Scientist to show that the DOE is not just bureaucrats. Make science the basis for decisions.

- I disagree. Science will not fix public perception problems. Scientists created some of these problems. They can't come to grips with the layman's view. They try to educate them into acceptance. You need to get scientists to be more empathetic with the public. Show them that we accept their values. Demonstrate this in decisions. After meetings like these, be very visible in what you've changed based on input. Show them there is a change, that their values are being considered and affect decisions, both in OCRWM and in the DOE. That may get them to accept the science.

- Going back to early days, at the public meetings, anger and hostility was great. As time went on, there were still confusion and questions, but some dialogue. At least with the State working group, channels were established for State people to talk to each other and to the DOE. Discussions of the second repository and of transportation will generate widespread interest. State Legislators are interested in these issues. Early discussion of these two issues involving all interested parties would help to anticipate the issues.

- I see more openness. It's good the DOE is having these workshops and having more meetings in Nevada. Need openness. The DOE comes across as if there isn't a problem. Need to acknowledge problems and get the public involved. For example, in socioeconomics, it is difficult for people to understand the technical jargon, needs to be more discussion of issues that people can relate to, such as the impact on the economy and tourism. Get issues of public concern on the table and into the MPA. Some people will never be convinced, some will never get involved, but most are willing to listen.

- There may be a difference between confidence and acceptance. The DOE may need to treat them differently. Confidence is related to trust. This program is plagued by societal distrust of technology. The idea that better science will do it is wrong. Often talk about acceptable risks. We've been focusing on risks, but not on uncertainty--how much uncertainty is acceptable. Uncertainty causes a great deal of anxiety in all aspects of the program. The public won't accept so much uncertainty. The program needs to consider benefit sharing. What is it worth to the nation to 
impose this on Nevada? The Amendments Act does include a benefits agreement, but the benefits were decided on arbitrarily. Why not look at the costs of failure? What is it worth to preserve the nuclear option, etc. Come up with realistic compensation. Until the compensation gets in the ballpark, and you have a basis for it, you don't have a chance. Also, there is the issue of distributional equity. Congress needs to address this. Nevada has no assurance that they won't get all the waste. On the other hand, if the second repository got going, it would make Nevada feel that the burden will be shared. Also, the DOE has not conveyed the need for the repository (or the MRS) adequately. Until you establish the need, people won't start to address the risks. It would be a tremendous benefit to think, document, and communicate the need. The DOE has fallen victim to a media hungry for sensationalism. The DOE, when it releases a report, needs to hold a press conference, be prepared to answer questions, to explain in layman's terms the significance or consequences of the report or decision, and get across the DOE's side of the story. If you don't, the reporters will pick out only selected, controversial aspects or facts in the report without the context. The press has relied almost entirely on government. We haven't heard from industry. Industry, if they really want to help, needs to step forward. The DOE is beginning to look at perceived versus "real" risks. The media is a major source of perceptions. When transportation begins, it will be a bigger problem.

- It may be helpful to look at the Oak Ridge experience when a large amount of mercury was reported missing. The DOE set up a citizens' advisory group. It has been in operation for eight years and is very knowledgeable and successful. It helps to communicate with the public and is trusted by the public.

- Another Oak Ridge experience was the DOE's original 1985-1987 MRS proposal. While the DOE did not handle the proposal well with the State of Tennessee, it did handle it well locally. The work done by Elizabeth Peelle is a good source of information. A second point, regarding the utilities talking to the media, is that often the media will not meet with industry. The New York Times, which recently published the article on Szymanski, would not meet with industry. We're in a hole only slightly less than the DOE. The utilities will keep trying to get the message out. It would be good to have independent technical experts, but there aren't many.

- People don't believe people from big cities or big government. The way is to get neighbors, people they trust. Utility experience in spent fuel shipping campaigns was to identify opinion leaders along routes, and to use field employees who know the local people to talk with them. For example, the DOE should talk to emergency response people and tap into their network. Build grassroots support, on a long-term basis. If you start early and work long to build understanding, you get acceptance of a facility. On the question of who do you have to persuade, you have to instill acceptance--not confidence, because people know that things break down--by getting people to say $\mathrm{OK}$, 
let them do it. The DOE may not have the infrastructure to do it down to the grassroots.

Facilitator: The DOE faces a number of constituencies, including people along transportation corridors, but also the media, scientific community, Congress, utilities, etc., whom they need to win over. It is hard to know how to target and where to expend resources.

- On the issue of credibility, take for example house builders, they are judged by the quality of their houses. Credibility is a function of how much confidence people have in the people doing the function. The waste management program, historically, is always changing its mind and its policy: from deep ocean disposal, to shallow ocean disposal, to open pits, to geologic disposal, etc.. The low-level waste facilities have a bad record. One reason the public is concerned is--do you people know where you're going? You don't even have final standards. There are still many fundamental issues that haven't been resolved. The MRS goes in and out of vogue. The second repository is not being addressed. There is a tendency to do the bare minimum--just meet the regulations and that's it, such as in transuranic waste.

Facilitator: We want constructive solutions, not just rehashing old problems.

- I looked back at resolutions passed by the Council of Radiation Control Program Directors over the last twenty years. These would support the strategic principles of standards of excellence and increasing scientific literacy. Education is very important. The transportation program is a good model, the cooperative agreements with the various professional groups are good. The DOE should pay attention to the broader mission--radioactive materials of all kinds. If you give attention to bigger issues you could broaden the base of support. The work would benefit not just utilities. Look at the bigger scherne, not just the repository.

- In State/local terms, gaining public confidence is very difficult. The discussion draft was 50 percent technical and 50 percent institutional. But, the DOE's spending has been well over 90 percent technical. Therein lies a problem--dollars need to be pumped into the institutional area, to raise awareness and let people know what's going on. Fairness and openness are key.

- In making public presentations, I have found a great fear of radiation. The DOE needs to get out and give talks at the grassroots level--high schools, communities. It's a very slow process, but necessary. Most utilities have speakers' bureaus. Need a willingness to take risks in public relations. Secretary Watkins has admitted that the DOE made mistakes. Initially, this hurts, but is necessary. OCRWM is accused of not releasing data and information until far along in its analysis, so you need to get out there early and say, here's what we know so far. 
- On the issue of uncertainty, people tend to maintain the status quo. For example, radon in homes, it is hard trying to get people to take it seriously. Press coverage increases uncertainty. You need to attempt to reduce uncertainty. Be very vocal with all the safeguards in the system--the EPA, the NRC regulations and oversight. There has been a concern that the EPA standards are "too strict." This does not help. The DOE should not be seen as criticizing the EPA standards as too strict. The DOE should say, yes, the standards are tough, we'll not only meet them, we'll go beyond them. We'll be even stricter on ourselves than the EPA and the NRC are. Go above and beyond. Follow up to fulfill mandates.

- It is not Nevada's job to solve this problem for everybody else. I agree that people are inordinately afraid of "nukes." But it's not our job to solve that. Talking about marketing the idea that it's OK, Nevada's gaming and hotel industries are run by the best marketers in the world. The Nevada economy can be adversely affected by the perceptions of people all over the U.S. and the world. The burden is bigger than convincing a few people in Nevada. Generally agree with what participants have been saying. The State of Nevada has no obligation to change the market that has been thrust on it.

- Dollars saved in just meeting the standards are usually spent in defending actions. Dollars spent on safety are dollars saved later on. You need to have grassroots education that addresses negatives in a positive way.

- There are two aspects, one is P.R.--go out and sell the program, the other is the internal response--by taking the program out to the public, the DOE plans to alter the program based on the input received. You need a complete loop. The defense programs were shielded from public view and witness the results--a nightmare with production ultimately stopped.

- The DOE has become good at hearing things, but no results have been shown. The loop is not closed. It goes in, but nothing comes out. I want to see a list of things the DOE did wrong, where, as a result of public comment, they changed something. Also, the DOE and the nuclear establishment are given to trivializing radiation risks, always downplaying them. There is a difference between natural and manmade risks-background radiation versus repository radiation. There is a difference between voluntary and involuntary risks. The DOE doesn't do correct cost/benefit analyses. I'll be convinced when I hear really frank lectures on radiation, on the civilian and defense sides; when I hear admission of problems. DOE needs the frankness and internal debate to discuss the dangers of radiation and the willingness to come up with a negative answer. 
Facilitator: People are asking for some kind of response to comments. These workshops represent a new initiative. The third workshop will give the DOE the chance to respond.

\section{TUESDAY, JANUARY 15, 1991: 2:45 PM SESSION}

\section{PUBLIC COMMENT}

- Regarding dual-purpose casks, our position is that we are not opposed to whichever technology is the best. We've worked hard to achieve optimum efficiency, including costs. However, we don't think dual-purpose casks fit. They are simply one of many available options. We need more information on them. Moreover, casks must be compatible with what the utilities are being forced to do in terms of storage.

- One of the options under the issue "Role of the Utilities" has the utilities packaging the waste. We have no interest in doing this, even if we were to be paid for it. The DOE should not count on us for this.

- Regarding credibility, the Department has tarnished OCRWM. OCRWM should distance itself from the DOE. Basically, what you have is a public relations problem, so you should go to a public relations solution. Have business cards printed which say OCRWM but not the DOE.

\section{CONTINGENCY PLANNING}

Facilitator: Four options are given on page 3-24 for the event that the Yucca Mountain candidate site is found to be unsuitable for a repository. These options are (1) no action other than responding to Negotiator requests; (2) increase participation in international scientific investigations; (3) design waste packages suitable for various potential host rocks; (4) using earlier data, identify other potential host rocks and sites.

- The bounds given by the options are too restrictive. The Secretary is not bound to think narrowly. He is not required to come back to Congress with another site. He is only required to come back with what he thinks is the right thing to do. This list of options is concerned only with finding another repository site. Based on what we know today, perhaps finding another repository site is not what we should be doing. We should not be looking just for a geologic disposal site; we may need to look at other possibilities. 
- Does 10 CFR 60 require contingency plans in the event Yucca Mountain is found unsuitable? If so, are any published? There should be a set of preferences if Yucca Mountain does not work out.

DOE: This is a question of retrievability, which is further down the line than what we face today.

Facilitator: Is it prudent for the DOE to look only at Yucca Mountain or should it be looking at other options as a fallback? Are there things the DOE could/should be doing?

- The DOE cannot avoid contingency planning. Any prudent organization has it. The NAS recommended it and the law requires consideration of sub-seabed disposal. The DOE cannot look at other than tuff as far as rocks are concerned, but it can look at generic things within the international arena.

- It may be necessary to look to alternatives in as little as a couple of years, given that the court cases could go against the DOE.

- Options 2 and 4 are not mutually exclusive. It is completely intolerable that no serious contingency plan exists up to now. We have got to have one. I am disturbed that we can look only at tuff. We have to assume that Yucca Mountain will fail. We also need to be looking at alternatives in terms of the need for a second repository or even a third repository.

- The DOE is in the same position as the counties. They assume Yucca mountain will be unsuccessful. I understand that Congress may take a dim view of alternative efforts but they are necessary. Yucca Mountain may fail, and the nation needs a contingency. The DOE should go back to the Congress for money for contingency planning.

- The answer is obvious. Contingency planning is necessary. The only downside may be a bureaucratic one, in that it indicates a weakness in the current program.

\section{TUESDAY, JANUARY 15, 1991: 4:30 PM SESSION}

\section{WRAP-UP}

Facilitator: Are there comments about the quality of comments, structure? Seems there was more spontaneous discussion in Salt Lake City. There were good comments today, but not as broad a discussion, or as much participation. General comments? 
Changes in format? The DOE is looking for suggestions and will respond. There will be an opportunity to comment on the DOE's response. Some discussion focused on failures of the past, rather than suggestions and creative ideas. This is really your meeting, your chance to give input. [no comments] Looking at possible additional topics for tomorrow, such as transportation--how will it impact the program, what are measures to take to anticipate public response. It seems that an underlying assumption on the part of many participants is that the DOE would have a difficult time saying no to a site--based on program history, bureaucracy. The perception that the DOE will not say no is a serious problem for the DOE. Many people in the Department feel they could say no. I felt discussion did not lead to constructive suggestions on how to deal with perceptions of how the DOE operates--locally and nationally. People did mention fears of radiation and scientific literacy. I would like to return to this topic.

- You've hit a key issue. The perception among a lot of Nevadans is that the decision is not technical, but political. The DOE always says, "by law ." You need to get beyond the narrow focus of the law. Learn lessons from the Nevada Test Site. We're all locked in a box--we can't do this, we can't do that. It just reemphasizes that it's political, not technical. The DOE needs to look carefully at ways to establish credibility.

Facilitator: So, as an additional topic, we'll ask for suggestions for public acceptance, credibility. The sky is the limit, get outrageous. Are there other topics?

- You should be indulgent. We will need to discuss past "sins". to explain problems.

Facilitator: OK--equal time: beat up the DOE for three minutes, offer constructive suggestions for three minutes.

- I want to discuss socioeconomics.

Facilitator: OK, worth pursuing, if we understand that there's micro level--to deal with bilaterally, and then there's macro level.

- The inordinate allocation of resources to the technical versus the institutional side of the house could be addressed under the rubric of controlling program costs. You could make the suggestion to reallocate resources over to the institutional side.

Facilitator: Yes, many people will say the problem is 50-50 technical and political. So, the program might be perceived better if it allocated more to institutional issues. We will address that. 
- We could discuss incentives--for example, for utilities to do more than point to the 1998 date, for contractors to spend less time studying, for the EPA to get the standards out, for the State--why should they cooperate.

Facilitator: You might want to raise that in controlling costs. Not bring in the auditors, but offer incentives to move forward. We'll have time tomorrow to revisit this. 


\section{APPROACH TO DEMONSTRATION OF PERFORMANCE}

Facilitator: The options are given on page 3-6. We could add to this a discussion on whether the DOE can get credit for an improved engineered barrier system.

- The DOE has two problems in this area: First, when the DOE petitions for changes in the EPA regulations, they are creating the perception that they are trying to get around something. Second, there is the practical problem--the discussion is premature until the EPA acts. In the licensing process there is a lot on the table; to the extent that the NRC procedures can be defined beforehand, it would help if any changes were done by rulemaking to permit open discussion. Rulemaking removes uncertainty, litigatory actions.

- But the DOE doesn't want rulemaking.

- An iterative process would be better for retaining flexibility in this first-of-a-kind venture.

- Flexibility is fine but would continue to lead to a distrust of the DOE. The parallel activities of site selection and the NRC rulemaking, and the absence of the EPA regulations are responsible for the current mess. 10,000 years is arbitrary; we need to protect maximally exposed individuals for as long as the hazard exists. There should be a detailed discussion by the DOE on that subject. The cited options are too narrow; they do not, for example, recognize the seriousness of operating without the EPA standard.

- We are wrangling prematurely over the regulations: The DOE must first show compliance with its own guidelines. Fiddling with regulations is perceived by the public as dishonest. If other sites are easier, questions over regulations would not be raised. The regulations should be generic. Let the EPA do their job as prescribed under the Administrative Procedures Act. Wrangling is not philosophical; it's due to the specifics of the Yucca Mountain site. Some day these regulations may have to be applied to another site.

- What issues are you referring to?

- Let the EPA produce a clean rule.

- The DOE will have to demonstrate some compliance. 
- Address this subject next week to the Advisory Committee on Nuclear Waste (ACNW). We need an ongoing process on what compliance means.

- The DOE is not dickering with the EPA, they have not made a plea or a suggestion. The criticism all comes from the NWTRB, ACNW, etc. The EPA is close with the NRC staff. Regarding expert judgment, the methodology of compliance with the EPA standards must be laid out in the rule or guidance, so as not to become a licensing issue at the hearing. The perception would be negative.

- We need certainty in the rules. Get them on the table now, get them litigated, defined. Total knowledge is not required, e.g., how to analyze ground-water travel time; this is not a well defined problem such as pipe support analyses in nuclear power plants.

- I agree. The EPA is merely applying a 2 man-year effort, while the DOE spends $\$ 300$ million a year. The original standards lasted 2 years but took 10 years to develop. Support the EPA now somehow, to get on with it. It takes time, so whatever we do, let's make it good. Without 40 CFR 191, 10 CFR 60 becomes meaningless. Performance assessment is built on quicksand. We know that self-regulation is perilous--WIPP is self-regulated, but in the spring of 1990 the EPA said they do not know how well the transuranic waste would be protected, when gas was found 15,000 feet under the site, which may become a natural resource.

- I'm very disturbed at the slow pace. 1983 was $\$ 3$ billion ago. We can't wait another seven years.

- I agree about public perception. A 10,000 year prediction is presumptuous. The DOE must be more humble. There is a good opportunity to do environmental studies at the Nevada Test Site.

- Regarding engineered barriers, it is premature to compensate for deficiencies in the natural barriers. It reduces confidence in the program. There is no experience with engineering for 10,000 years. The Europeans do not do it because they have a longer cultural memory. This does not mean there is no place for engineered barriers, but they should not be made to compensate for lack of natural barriers.

- OCRWM suffers from the DOE's WIPP image. It would be good if OCRWM could work cooperatively with WIPP.

- WIPP is not an OCRWM program. The DOE must get on the site. $10 \mathrm{CFR}$ 60.112 is reserved for the EPA standard. The NRC staff is working closely with the EPA and will put out its standard shortly after they do. 10 CFR 60.113 has flexibility in it. It is generic in nature. 10 CFR 60.113(b) may need to be changed. 
- The public image is of 45 years of AEC/DOE. The DOE is one agency--talk of separating OCRWM from it is not realistic. OCRWM's history is not so different from that of WIPP: screw-ups, bad science, reluctance to look for the best site, review the best literature, etc. The environmental community is Not In My Backyard (NIMBY). It must be responsible, but its ideas are not accepted by the DOE. All we get back is rationalizations for the status quo.

Facilitator: Pretend you're part of the DOE, then make suggestions. Let's get back to the demonstration of performance.

- First, the concept of engineered barriers should be part of the overall performance, including geochemistry, climatology, hydrology--all have a probabilistic basis. The Swedes have copper containment and take credit for it. Second, flexibility in communication is important. The EPA often lacks input from the implementers of their rules. Third, the DOE seems to feel the court has told it to use 10 CFR 960 as site disqualifiers. These were to be used for guidance for site selection, not for validating a given site. For example, ground-water travel time for a given site should be considered together with chemical retardation, etc. You might require legislation, but 10 CFR 960 is not useful now; don't use it.

- Knowledge is gained with time. A solution depends on science, not on public perception. Don't be constrained by past knowledge that keeps us from using the fruits of research.

- We are faced with a first-of-a-kind demonstration, but if you make a rule based on current knowledge then necessary future changes will hurt more in terms of public perception; that is the dilemma.

- I agree--this thing needs balancing. We must have some rules. The Nuclear Energy Agency in Europe is ahead of us but not in terms of regulation. Need methodology on the table.

- How can we change regulations later without having to retrofit? We need a credible process for making changes vis-a-vis public perception.

- We need a strategy paper for implementing 10 CFR 60.112 and 10 CFR 60.113. If the NRC has a chance, it will provide one for making a licensing case, but not for planning. There is no decision on that yet.

- Reactor licensing has been hotly contested, and the best case-rulings were made in licensing hearings. There, industry and the NRC could not think ahead; we can do so here. The Edison Electric Institute with EPRI in 1984 listed about a dozen items 
needing rules. So far the DOE has petitioned the NRC for one, the 5 rem [accident dose limit] rule last year.

DOE: The agenda of technical issues to be resolved in the licensing arena is overlaid with the probabilistic approach. How is that to be addressed? There is no hurry to codify this--the issues are so complex it would be inappropriate to march forward when we don't know what is required. We will have to work on it within the broad regulatory framework.

- I am encouraged by that comment, but don't wait until it is on the licensing table [during the hearing]. Have a rulemaking to keep it off the table.

DOE: A comparison of the SCP with the Consultation Draft shows the learning process. It shows the need to go now and sort the issues out. To go to rulemaking now is premature. The NRC rule on how to conduct certain uranium assays, for example, can be simple, but this is complex, probabilistic.

- If rules include specific processes and not specific methods, that is $\mathrm{OK}$; this is different than the NRC's Office of Nuclear Reactor Regulation.

- Reliance on expert judgment is OK. We could wind up with a rule on expert judgement.

- There has to be a clear commitment that if there is a rule change the result will be improved performance, including [such a finding through] independent opinion, but not for bureaucratic convenience.

- The issue is being driven by regulators and advisory boards. The DOE program can be expected to show that it can go through licensing, and where any rule changes are needed.

- The public knows that science is not perfect. A multi-disciplinary approach is needed, not a segregated one. Science is changing.

- There is an analogy here with mill tailings placed on a mesa: the slow movement of the mill tailings as the cliff erodes. If the method is accepted, then the conclusion is OK. Performance assessment can bracket the uncertainties [to the extent] necessary to continue. Look at the EPA's approach to systems analysis; break it down into risk assessment and risk communication. That approach builds risk literacy.

- The DOE should see rulemaking as an opportunity to enhance public confidence. The DOE could increase its credibility by trying a rulemaking, laying out the "technical spaghetti," telling what they know and don't know and getting the public involved. 
- Assigning a larger role to engineered barriers leads to compensating for less beneficial site features. I don't want that.

- In 1983 the DOE was opposed to engineered barrier systems. Performance requirements will be the public's focus regarding the safety of the biosphere. That was our perception at WIPP.

- To get back to dual-purpose casks (pages 3-23 to 3-24). The Strategic Principles must be clarified to matrix the relationship of waste packages and performance assessment. We must have at-origin inspections for conformance with waste acceptance criteria if the waste package is to have a larger role.

- With respect to contingency, if the site should prove to be unacceptable, this must be addressed in the license application, as shown in 10 CFR 60.21 .

- The plan is to provide alternatives in 10 years.

DOE: Not so. The license application will be submitted in 10 years.

DOE: Regarding the engineered barrier system--when it becomes associated with performance assessment the result is "technical spaghetti." This may be fun for the technical community, but it could be endless. We need a management mechanism to get results, resolutions. We need to keep an eye on the product.

- We talked yesterday about four items: cask, demonstration facility, Yucca Mountain methodology, and phased licensing. None should be locked in; leave open options. As early as possible, lay out the methodology for performance assessment anyway to delineate where options may need to be closed out. Phased licensing and demonstration facility decisions are too early, but lead in that direction.

- In the amended Mission Plan, scope the environmental impact statement (EIS) earlier than 1997. The "Sixty-Day Report" moved it from 1994 to 1997. Also decide whether the EIS will include national transportation issues or whether there will be a separate EIS for that. The MPA should explore these issues.

WEDNESDAY, JANUARY 16, 1991: 11:30 AM SESSION

\section{CONTROLLING PROGRAM COSTS}

Facilitator: This session is designed to address management issues, and the issue of costs versus potential benefits cuts across the board. This is an opportunity to 
generically talk about costs. There is no specific options paper, but it is a matter for discussion. Suggest to the DOE how to proceed, all the way from an austerity budget to an increase to progress to future savings.

- We can cast the issue just brought up in terms of cost. John's audience, the Congress and the Office of Management and Budget, is short-sighted. The difficulty is to sell upfront, short-run cost increases to get long-run savings, which isn't how Washington thinks. The salesmanship of this is difficult, but it is worthwhile for the program and the Nation.

Facilitator: Any specific recommendations? The DOE has the opportunity to fund a number of different projects. Do people have suggestions for promising projects? Individual ratepayers ultimately pay, but don't exercise as much oversight as people here. What is your view, your counsel on expenditures and costs?

- My observation is that most of the discussion in the draft neglects the issue of cost. In part, costs are dealt with as secondary to technical and managerial decisions, yet the DOE must pay attention to cost control. For example, the cooling spent fuel discussion-- the costs of storing fuel longer would be higher, but it would make licensing easier, resulting in ultimate savings. Another example is waste package design-- beefing up the canister would help licensing but is decidedly a cost item. Or suitability-- although cost isn't identified as part of this, it is clearly relevant. The sooner we know, the better. In managing spent fuel, costs are not highlighted. In other areas, cost is not mentioned, or if it is, is only briefly mentioned. The background section mentions cost as an objective only once. None of the principles mention cost; only the section on prudent management alludes to it. The program objectives don't mention cost. I can't find a tracing through of how the program will manage cost. What pain will be used to achieve what object? It is an important ingredient in many technical decisions. This reminds me of past major program decisions that said the DOE will issue cost documents later. Is there a discipline in the program to identify and control costs? Only so much money is there. You can't operate the program without discipline; money is a real and legitimate boundary to program performance. Cost and schedule control is vital to the operation of a successful program. I would like to see the document reflect that. I've drafted language to more clearly identify the issue, and I'll send it to you.

- At Salt Lake City, we asked where the strategic principles came from, but we didn't get an answer. I have some general suggestions as to strategic principles. One, from the standpoint of the utilities and the ratepayer (they have the same interest) if the DOE makes progress, the people paying for the program would be reassured. Progress is getting on Yucca Mountain and finding an MRS site. All the other stuff is okay, but is meaningless if you don't get those two things. Nobody here could disagree with that. Two, the concept of total enterprise cost. Analyze something you do, but analyze the 
cost of it back to what the utility will do (the cost from all pockets). The utilities are frustrated. You need a way to identify this. Early suitability is extremely important. This is why industry came up with a model. You need a way to identify the "black ball" early. Closer to home you have more near-term issues. For example, if you don't get on Yucca Mountain, at what point does the program run out of useful work? The DOE is struggling with this. It's developed a cadre of scientists for characterization, but if there is no work, what will you do with these people? Three, the M\&O contract. When the DOE has an M\&O contractor on board, it must back off and let the contractor manage and operate. This is especially true in areas the DOE people are not well suited for. Since John took over, I've seen an improvement in the DOE personnel, especially in quality assurance (QA). The $\mathrm{M} \& \mathrm{O}$ will need its own QA program, incidentally. The DOE must retain control of QA, but the M\&O should do licensing; let the licensing experts do their jobs. This is true for other areas. My main point is that if the M\&O contractor is just another $\$ 100$ million layer on the existing layer of contractors, there'll be hell to pay. I know that's not John's intent. The program must be in the hands of those who know how to do it.

- I want to talk about the downside of cost control. The Office of Management and Budget and the Hill often use cost control as a meat axe. Be careful how you do it. Don't cut costs now that will save later. For example, it looks cheaper to characterize one site instead of two, and it is if it works, but what if it doesn't? Don't cut out the redundancies that in the long-run give you greater confidence you'll get there. Nickel and diming can be counterproductive. Be sensitive to this.

- I affirm that point. Less spending isn't necessarily cost control. The key is getting on Yucca Mountain. But if you don't have your thoughts together on the program here, for example in licensing, you may save currently but total program expenditures could rise dramatically.

- The same problems in public perception and cost facing OCRWM are being raised in the clean-up of defense sites. The solution is for the parts of the DOE to talk to each other about this problem, to split-up the work. This benefits everybody. Work together. Get researchers working together. Get some of the money being spent on weapons sites.

- The estimated costs of the clean-ups range from $\$ 50-150$ billion at the generating sites. The EPA once estimated clean-up costs for some problems under their jurisdiction at $\$ 200$ million, and the cost came closer to $\$ 2$ billion, a cost overrun factor of 10 times. If this is applied to OCRWM, the program would come close to costing $3 / 4$ of a trillion dollars. The bottom line is that you need real consideration of the financial constraints imposed on the program. You can't do all the jobs you want. Commingling of projects may be important. I disagree with the idea that the $\mathrm{M} \& \mathrm{O}$ should be allowed to go off unsupervised. The DOE should have more control of this 
area, not less. Take a hard look at what we're doing in the next two decades. It may cause us to think through some things we aren't now.

- A reminder. If there is no second generation of nuclear power, no extensions of reactor lives, you will run out of ratepayers starting in 2000. You're starting to run out of money.

- My observation is that throughout the program's history, there's been a very high cost of sitting on site without doing anything. There will be high program costs for overoptimism about what would be done in coming years.

- Contractors often write and pursue their own research agendas that are not in the interest of the program. This is dangerous; how far do you let them go? There is a tradeoff between scientific freedom and the focus of the program. Get the focus on doing the job within a reasonable budget. There is merit in NAS and other bodies' recommendations. They give sound technical guidance to use to force contractors through topical areas. The DOE should also consider duplication of efforts; I'm most familiar with this in regard to local government research efforts. The DOE funds universities to do work that local governments are already being funded to do. Funding is often used as pacification, and is not being controlled. As to the DOE's cost control focus, Congress greatly weighted local government participation. The DOE should think on the focus of their cost control efforts; they tend to micromanage, do too much oversight of local government work. These meetings are an example. The money expended to bring everyone here is equivalent to the proposed cuts to local research budgets. Another observation: in terms of long-term costs, you have to do something about program personnel turnover. It's a plague. The average age of retirement means you're going to have many new faces around this table and in the program. Shouldn't the DOE cultivate up-and-coming agency stars to get needed continuity for the stages of licensing and operations?

DOE: I'd like to respond to these comments, all of which are well taken. This is a significant resource investment issue, and an issue of the differences between the possible and the necessary. The strategic principle involved is what is the appropriate level of redundancy necessary to do the program? To get and maintain the knowledge and scope of information needed? How much money should go into it, that will be sufficient now and in the future to accomplish program goals? As to turnover, there is significant program investment in education. It's a vital part of the program.

- Human resources investment is a relatively cheap institutional investment. Look at contractor cost control. Look at engineers. It's part of the technical-institutional equilibrium. Building a cadre is an institutional investment cost. 
- I have a number of observations. First, you need something in place to ensure you're not overlooking negative decisions and not justifying "maybe" decisions. As regards suitability, I don't know the practical content of this thing. The only rapid definitive decision on any site is unsuitability. There are rapid ways of making decisions, but "yes" is not a short-order decision. The question must be asked: What processes are in place to control a system in which a negative answer is not arrived at early because sufficient things weren't done? There has to be in place a process to evaluate how to arrive at a decision. Ignoring all the studies already done has huge cost implications; it can't prevent duplications and extension of deadlines. Second, you must have some kind of accounting that gets you talking about all of the costs associated with HLW, not just the program, and about which ratepayers or taxpayers are going to pay. The MRS question won't be quickly resolved. Don't count on the MRS being there. The costs of extended storage must be fit into the program. Third, as to other radioactive waste disposal costs, we must discuss system costs arising from the entire civilian radioactive program, including low-level waste, decommissioning costs, spent fuel, casks, etc. My view is that we need to look at delaying decommissioning to minimize the waste to be disposed. Factor that into on-site storage. You need a total cost approach to radioactive waste disposal. It will affect both cost and public confidence.

- I agree that time is money, and that we must get on with it. I'm shortsighted about costs. I'm concerned with the ability to collect from ratepayers to cover on-site storage costs after 1998. PUCs may not allow recovery after 1998. Get on with the MRS quickly. As to contractor and program costs, don't chase too many options.

- The DOE has thought about building a nuclear waste disposal system. Total costs should deal with total system disposal costs, and the DOE analyses should reflect this. Sometimes the DOE makes decisions to reduce their costs, but ends up costing others (i.e., the utilities) more. I'm also sensitive to the budget control process the DOE undergoes. They must look ahead one or two years on a thirty-year program which is controlled by people who look ahead only to the next election.

\section{WEDNESDAY, JANUARY 16, 1991: 1:45 PM}

\section{THE DOE AND PUBLIC ACCEPTANCE}

Facilitator: We had begun addressing the DOE credibility and I want to pursue it further. The DOE wants suggestions on how to increase its credibility. What is not needed is simply a public relations campaign. There must be significant changes to convince numerous publics. One issue is, can the DOE say "no" to a site? Our goal is 
an analysis of the DOE's credibility and suggestions as to what they can do and who they need to convince.

- On the issue of a site, no or maybe is key, and must be credible. The perception in Nevada is that once you sink a shaft it's a done deal. Thus, the NRC and the NWTRB and the entire process is distrusted. What can be done to make a credible decision on Yucca Mountain? The DOE needs to recognize that "no" has to be credible too. You will need a rationale for "no", for the utilities and the ratepayers.

- The word acceptance is a symbol of the problem. You can't sell the public something and have them buy it. They must believe that the decision made is a good decision. They must understand; they need education and involvement in the process. The meetings that the DOE holds with the public have a basic flaw. People representing the DOE are incapable. The DOE needs new people whose skills are in understanding people, who have experience interacting with people, rather than technical expertise.

- The DOE could benefit from developing performance assessment early on. In addition, one learns from the Myers-Briggs personality test that there are different styles of decisionmaking. Most people don't think like scientists and technicians. People likely to attend public meetings are even less likely to think like the DOE. The DOE has a bad reputation for not listening and not reacting to input. The people the DOE sends out are inappropriate. Screen the staff.

- Advisory committees bring a lot of credibility. The National Academy of Science has been pushing the DOE to use more external peer review. There is a question of the scarcity of independent external experts. But, there is much potential gain through increased credibility. So, use advisory committees and independent technical experts.

- The DOE should utilize local government skills more. There is frustration from the fact that by the time draft documents are released, they are already done. It is very difficult to change them at that point. The DOE needs to use local government skills to be involved early on in document development.

Facilitator: One hears about internal agency struggles to get drafts out--they have already cut deals internally--they may be unwilling to upset an internal consensus.

- One should examine the past to figure out what went wrong, starting with Lyons, Kansas. There is no internalization of failures. The DOE has generally needed external pressure to say no. Part of the Yucca Mountain decision was political, and people know this. Unless agency representatives are frank enough to admit this, they can't have credibility. You need a way for the DOE to acknowledge political aspects of decisions. Until individual DOE representatives can speak the truth, it will be very 
difficult. On the subject of radioactivity, for 45 years the DOE denied any dangers. This is a very bad history. You must say, yes, even a small amount of radiation increases the risks of getting cancer by a small amount. Everything involves risks. You cannot compare unlike risks, such as losing money by gambling or by getting mugged. You must present the dangers of radiation honestly. If you continue to act as though radiation will not cause any harm, you will never move forward. There is a cultural carryover from the Manhattan Project in the DOE, because it worked. There is a mindset that once you make a decision to do something, you don't need to test out the idea or have it reviewed by outsiders, you just do it. The DOE is always in a hurry. You need a step-by-step decision process--not all or nothing. There are critics with scientific capability outside the DOE in the environmental community. You can't just ignore us and pretend we will go away. There is a great frustration--the DOE acts like critics will go away--but there will be criticism, and it must be accepted by the DOE. The NAS/NRCRisk Report did not receive enough attention. You need to read and respond to external critics.

- For many years, almost every NAS report has said to get outside experts involved-in the actual process, not just as reviewers--i.e., ongoing peer involvement. For example, in Sweden, they asked international experts for input. It did increase their credibility, and the DOE could do the same.

- There is an issue of basic responsiveness. For example, after the NRC GreaterThan-Class-C ruling, the DOE committed to formulating options and never did so. Another example was a 1986 resolution by the Council of Radiation Control Program Directors, the DOE said they'd respond and did not. OCRWM has an opportunity to lead by example in the area of radiation control emergency response training, and maybe Defense Programs would follow at the WIPP site. Another opportunity is to demonstrate systems analysis and systems engineering--how to deal with interrelationships of issues. Pick one subarea and lay out the decision process.

- The word acceptance is inappropriate; understanding is better. The general public does not have a clear picture of the process. Our county has tried to educate the public by getting people in the community involved. We have advisory committees, workshops, and meetings. Congress did set up a process providing a safety net; unlike WIPP, the NRC is involved. The county's opinion is that the NRC will evaluate the project scientifically. The DOE needs internal work. The institutional shop and the technical shop need to work together; one senses that they're two different shops. Technical people need to understand that people have to be involved; technical people can't just blow off everybody and just get it done. My recommendation is to merge the two areas. Get the socioeconomic and institutional people involved with the technical side, so they understand. The DOE can't just send out a "fed with an overhead" every six months. You need real involvement. For example, the subject of local information offices. There's one in Beatty and there should be one in Pahrump; but the DOE said 
that there's no money. That's a good example of short-sighted savings. There's nothing more important than public education. Affected parties need to be plugged into the DOE's budget process; we need to work together early on. Advisory committees and sending people to meetings are expensive, but important; then you can get local people to educate others. Nye County has been pushing for a Nevada science museum for five years. If the DOE is serious they should do it. You could expose children to information about nuclear through a science museum.

Facilitator: Another aspect of this topic is when do you begin education and who do you target. It's a resource and an interest problem. People only pay attention when it affects them personally. The DOE has a number of constituencies. Another aspect is who can stop this program. One can target them and neutralize the opposition, rather than saying we need acceptance.

- There are several items to put on the table: (1) Method of disposal--need to lock in a national policy; (2) Risk communication--cannot compare unlike risks and it is not an excuse that there are greater risks, need to handle it better; (3) Bad news-- always in the media, no public confidence that bad news is getting out; (4) Lay off the us versus them mentality--the DOE speaks of "intervenors", of media coverage of defense waste sites as "really hurting us"; (5) Legal rights--this is a good system, rules should apply to everyone, if you use legal means, so can they; (6) Concept of educating the public--this is not a good idea, need to create an orderly system whereby issues can be addressed; and (7) Acceptance is an appropriate word--there should be compensation; NIMBY is a legitimate response.

- The National Conference of State Legislatures has had good communications with the DOE. There is always the tendency to want to send the best technical expert; bring them, but have a communicator talk to people. The DOE's vugraphs need improvement. On the transportation issue, communication at the earliest possible moment is very important. Education is presumptive--you need a two-way process; need to talk early before decisions are made. My bottom line is talk and talk early.

- I see a crisis in government, there is a bad image of government, people don't believe in the government, it is not attracting the best and brightest. Unlike many agencies, OCRWM does have money. It is incumbent upon OCRWM to do the best possible job to show people that government can do a good job. The most important thing is to educate younger people and to cultivate them within the organization. Peer review can become cronyism, it doesn't necessarily give you the best input. There is the perception that bureaucrats can't do anything. People in government have a responsibility to do a good job.

- The strategic principles does include public involvement; this section needs to be beefed up. The DOE needs to identify the various constituencies and strategies 
tailored to each. Constituencies include the Indian Tribes, State and local governments, environmental groups, scientific community, and non-affiliated public. The nonaffiliated public gets its information from the media. The DOE has virtually abandoned the media. The document should include much more on the public participation process. The DOE needs to weave in input from interested parties, not only technical experts--the question is how. This workshop is good. If you want to involve the public in the program, get input from groups such as this on program decisions.

- Involvement of the Commercial Vehicle Safety Alliance and the Western Interstate Energy Board are two successful examples of current OCRWM efforts.

\section{TRANSPORTATION}

Facilitator: Let's move on to transportation (page 3-17). This issue has come up several times. There is a widespread expectation that once routes are chosen and shipments begin, there will be considerable public interest and opposition. The DOE would like prognostications about public reaction and how to prepare for it.

- Transportation is a sleeping giant. It is dangerous to defer bringing in outside parties until after the repository is built. Studies show that absolute risks are small, but the number of shipments is much greater than ever before. All it takes is one accident with media attention to alarm the public. There are many examples of huge reactions to small incidents. The DOE should include credible worst case scenarios, based on external review. The public can imagine things that scientists may discount.

Facilitator: We did discuss emergency response in Salt Lake City. We're interested in what the DOE can do related to the public aspects of transportation.

- There is a whole set of transportation technical issues that the DOE must deal with in the Mission Plan Amendment: cask design, utility interfaces. We know that the DOE is doing an internal review. We will be providing a report on cask development. On the issue of public acceptance, we don't think like the public does. If I can do a probabilistic risk assessment to show that this scenario has a probability of 10 to the minus 10 , there is a responsibility to not spend money on analyzing this scenario. But it may be worth it to spend money to analyze some "wild" scenarios that the public is" concerned about. For example, a member of the public once suggested that, since casinos give out free drinks, there are a lot of drunk drivers in Las Vegas and they cause many accidents, and asked whether the DOE looked at that. Maybe you need to accommodate people's concerns. The right answer to that would have been, no, but we'll do it and then put in a few sentences on it in the next study. 
- I don't think we need to create situations as worst-case; real world situations can be used. You need early interaction with the public on transportation. Put out potential routes early. The DOE starts with the premise that the casks are totally safe but the public knows that mistakes can happen. The public won't accept assurances about cask designs. The DOE needs to be more honest about potential problems; must recognize that there are difficulties. The DOE has several programs involving transportation: OCRWM, WIPP, and others; you need to coordinate among these programs.

Facilitator: An interesting issue is that the real record to date is good and yet transportation is a big issue with the public.

DOE: With few exceptions, we're all analytic personality types. We're all comfortable with risk analyses that show the probability of radiation releases is very low. How much money should we put into the disparity between real and perceived risks? In the European transportation experience, they have never had a radiation consequence in 27 years. How do we get all of these issues together?

- The cost comparison should not be based on the question of "is this a negligible risk factor," but on "does doing this help us get licensed." Utility shipping campaigns have put a great amount of time and money into public education--because you can't move the material if the public stops you. Look at those efforts.

DOE: One of the reasons it's been so safe in Europe is that they are very cautious, they go to extremes in testing. Our situation involves much greater distances with long stretches of potential exposure. There is the question of communicating the difference between perceived and real risks. How do you inform them?

- Leave the analytic personality types at home and have an intuitive, feeling personality type go out and deal with the public.

- It is possible that the overall probability of an accident is low, but the analysis technique involves averaging data from all over the country. A member of the public would want to know about the tricky intersection near their home. You should analyze some particular traffic situations. Industry might want to spend money to fund research to validate the assumptions used in these models, because you can get disagreement among experts on the validity of particular models. Put resources into managing uncertainties in estimates. The public is aware of the effects of the bomb. The low probability/high consequence events like Chernobyl shape perceptions. People assume that we're going to have accidents and it'll be like Chernobyl. You need to compare different types of nuclear risks.

- My conclusion favoring long-term storage on site is partly based on the consequences of transportation accidents based on the age of fuel--the consequences 
decrease over time. If transportation accident consequences are really low, then the DOE needs to establish that. People respond very differently to catastrophic consequences. The public reacts one way to low probability-high consequence risks like AIDS and another way to high probability-low consequence events like a cold in the winter. No one buys insurance for colds.

- In our experience with shipping fuel years ago, the casks were then used for some spectacular transportation accident tests. The tests were very effective in demonstrating cask strength. The DOE should use spectacular tests like those.

DOE: Does anyone know how many fuel shipments there have been in the U.S. to date?

- The number of non-defense commercial shipments is 5000 to date. But, OCRWM shipments will be quantitatively greater. When you start moving 200,000 to 250,000 fuel elements farther, you'll be on the highways more and have more accidents. There will be traffic fatalities. We've tried this, but a good record and good arguments don't get too far with the public.

- From experience attending public meetings in Nevada, I have found that the DOE tends to underestimate the public. The DOE people talked down to the public; for example, one representative stood up and read out of old DOE regulations. One success story is at the Nevada Test Site (NTS) where they hired staff to take people on tours of the site. The evaluation forms distributed at the end of these tours have shown that people left with a positive impression. At Three Mile Island, after the accident, the DOE sent this group from NTS to help the utility deal with the public. You have to be careful when you hire contractors; they will cater to their client and tell them only what they want to hear. You need independent people.

DOE: You mean do it people to people rather than government to people?

- The name of the game is communication. You need to understand the differences in the way people perceive things. The Myers-Briggs personality test indicates that people use either values or logic as the basis for decisions. To deal with people who make decisions based on values, you must send someone out who understands and can relate to them.

DOE: We analytics are very concerned; we have limitations in dealing with the public.

- I believe the Federal Executive Institute is teaching men how to be intuitive.

- Perhaps the DOE should avoid emphasis on estimating incident probability at 10 to the minus 10 , because if (and when) an accident occurs, credibility will be hurt. 
- There is a whole set of transportation considerations that the DOE will need to address in the Mission Plan Amendment.

- There is a need to integrate the DOE programs. There are several kinds of the DOE shipments, and the shippers need to speak of common issues.

Facilitator: How much money should we put into perceived risk as opposed to real risk?

- Regarding the accident at Three Mile Island, some of the utilities had the foresight to admit at the time that they never expected such an accident. It helped retain some credibility. When we say that something has a one in ten billion chance of happening and then it happens, the public feels lied to.

- I agree that the public doesn't like to hear about averages. You have to talk about real situations; take the worst cases and deal with them. Instead of talking about roads in general, talk about I-70 in Denver, Colorado, which is often mentioned as a probable route. Talk about terrorism. Human factors will be raised. Take these head on. The DOE should challenge itself. The DOE also needs to deal with the differences between radioactive transport and chemical transport. Why hasn't it? Lastly, the DOE should be very careful in any instance where it might challenge State transportation regulations.

\section{WEDNESDAY, JANUARY 16, 1991: 4:00 PM SESSION}

\section{SOCIOECONOMICS}

Facilitator: Let's move on to the topic of socioeconomics.

- Most of the issues discussed are site-related. I urge you to elevate socioeconomics in the hierarchy of the DOE concerns. Local governments have a right to do impact studies; section 175 identifies potential impacts. Counties are at the bottom in all this. You have to consider the nearby communities, which includes three counties and the State. The Amendments Act does look for socioeconomic issues. Socioeconomics should be an objective, a priority, a strategic principle rather than background.

- Transportation and socioeconomics will come into play heaviest in the EIS. It should be a strategic principle that the DOE adopt a systems approach to the EIS, including the MRS and transportation. They should be interlinked. The DOE and the affected parties need to agree on socioeconomic analytical methods, on a methodology for impact assistance. Impact management should be given equal status with impact 
analysis. Then locals can handle impact management. Neighboring jurisdiction may get impacts, but no benefits. I want greater emphasis on the effects of site characterization. The DOE has written off the effects from earlier efforts. I'm certain that economic development is at risk because of the radioactive waste management program. There are projects in the State at risk because of the waste program. Minimize the duplication of efforts here. Also, there is not nearly as much formal peer review in this area as there is in technical areas. How are socioeconomic programs defined? Interactions are not good. Heighten attention to this area. I would like to know what input the DOE is seeking on its socioeconomic program. It hasn't been giving comments much consideration, likely because it doesn't consider the issue very important.

- I second his suggestions. Agreement on methodology could be very important. Intangible socioeconomic problems, too. Can be brought into evaluations.

- The DOE needs local expertise, and the DOE should rely on local expertise. It also needs independent judgment of what the impacts are, even if the work is possibly duplicative. The DOE should work with us to define impacts.

\section{PUBLIC COMMENT}

- The real problem with the nuclear power industry is public perception. It is not a technical question. It doesn't make any difference how much technical detail you provide. The failure of the repository program is not a technical one. The DOE needs to reverse everything. The technical questions should follow the institutional issues. Go with the things that work. For example, the Elizabeth Peelle paper out of Oak Ridge and the Hanford study.

- We shipped waste to West Valley in 1975 and took it back again in 1985 . That was a real learning experience. The DOE officials must speak to anyone who wants to speak to them. Start early, answer their questions. Go to them, don't wait for them to come to you. Go to the police and fire chiefs and to the town councils. And as regards shipping, experience from the past is valid for the future.

\section{MRS SITING}

- If there are no volunteers for the MRS, the DOE might wish to rethink the need for an MRS. If the Negotiator fails, the only option might be forced emplacement. Would that be worth the effort?

- Even if the Negotiator finds a site, OCRWM still needs to justify why it needs an MRS. 
- The DOE needs to have answers to the questions it will be asked before it goes out to the public and gets hit with these questions. If there is an opportunity for the private sector to operate the MRS, those decisions might be made before solicitation.

- Finding an MRS site would make Nevadans more comfortable, in the sense that they would know they are no longer being singled out as the only recipients of nuclear waste.

- The DOE has investigated an MRS for transuranic waste. I don't understand the DOE's problems. Why are we unable to move on the issue of retrievable storage?

- Perhaps it is because people feel that waste tends to remain where it is sent.

\section{WRAP-UP}

Facilitator: The DOE will respond to the comments received here at the third workshop and will indicate the direction in which they plan to go. It will be an interactive meeting between the DOE and the participants.

DOE: Prior to the April meeting, we will send to the participants notes from the second workshop, along with some other information.

- The notes from the first workshop were immensely difficult to understand unless you were a participant. The DOE comment-response efforts historically have not been good. The comment-response document for the Sixty Day Report was very complicated. These documents are very disheartening.

- For the next meeting the DOE might redo the draft Strategic Principles paper as a response. Broaden it by including new strategic principles that have come up during the course of our discussions and at the same time drop some of the options.

DOE: After April the input will be put into a draft MPA for public comment.

- Take the original and add pertinent comments in italics.

Facilitator: Clearly, some of the options could disappear.

- I felt that I was able to understand the notes from the Salt Lake City workshop. I was disappointed in their contents, that they contained nothing new, but I felt that I understood them.

- The response document should reflect the fact that there was no consensus. 
- Kudos to Holmes Brown for his efforts and to John Bartlett, for his fortitude in sitting through these two long sessions.

DOE: I want to thank the participants for their investment. We will use your inputs in that sense. Nothing new of a strategic nature has arisen here and that is comforting. Your suggestions for studies and subissues have been very helpful in the tactical implementation of the program. 


\section{LIST OF PARTICIPANTS \\ AT THE \\ SECOND STRATEGIC PRINCIPLES WORKSHOP}

Mayflower Hotel--Washington, D.C.

January 15-16, 1991

Mr. James Barker

Subcommittee on Energy and

the Environment

Committee on Interior and Insular Affairs

U.S. House of Representatives

Washington, D.C. 20515

(202) $226-2311$

Dr. John Bartlett

Director

Office of Civilian Radioactive

Waste Management

U.S. Department of Energy

1000 Independence Avenue, S.W.

RW-1, 5A-085/FORS

Washington, D.C. 20585

(202) $586-6842$

Mr. Mike Baughman

Consultant

Lincoln County Board of Commissioners

35 Clark Street

Fiskdale, MA 01518

(508) $347-5040$

FAX: (508)347-5445

Mr. Don Bayer

Legislative Council Bureau

Legislative Building

Capital Complex

Carson City, Nevada 89710

(702) 687-6825

Mr. Dennis Bechtel

Coordinator

Nuclear Waste Division

Clark County Department of

Comprehensive Planning

301 East Clark Avenue

Suite 570

Las Vegas, Nevada 89101

(702) 455-5175

FAX: (702) 455-5190
Mr. Stephen Bradhurst

Consultant

Nye County Board of Commissioners

P.O. Box 1510

Reno, Nevada 89505

(702) 482-8181

For Courier:

4720 Canyon Drive

Reno, Nevada 89509

(702) $323-4141$

Mr. Holmes Brown

Facilitator

Afton Associates

403 East Capitol Street, S.E.

Washington, D.C. 20003

(202) $547-2620$

FAX: (202) 547-1668

Mr. Mark Burtschi

Director

Legislative Programs

American Nuclear Energy Council

410 First Street, S.E.

Washington, D.C. 20003

(202) $484-2670$

Mr. Ronald C. Callen

Director

NW Program Assessment Office

1400 16th St., NW, Mail Box 18

Washington, D.C. 20036

(202) 939-3420

Dr. William Colglazier

Director

Energy, Environment and Resources

Center

University of Tennessee

327 South Stadium Hall

Knoxville, Tennessee 37996-0710

(615) $974-4251$ 
Dr. Dwight Connor

Program Director

Energy, Science, and Natural Resources

National Conference of State Legislatures

1560 Broadway

Suite 700

Denver, Colorado 80202

(303) $830-2200$

FAX: (303) 863-8003

Dr. Thomas Cotton

JK Associates

1001 Spring Street

Suite 406

Silver Spring, Maryland 20910

(301) $587-7098$

Ms. Norma Cox

President

Nevada League of Women Voters

3096 East Shadow Ridge Avenue

Las Vegas, Nevada 89120

(702) 435-0473

Mr. Alan B. Cutter

Vice President

Director of Special Nuclear Projects

Carolina Power and Light Company

Post Office Box 1551

Raleigh, North Carolina 27602

(919) 546-6111

\section{Mr. Steve Frishman}

Technical Policy Coordinator

Nuclear Waste Project Office

State of Nevada

Capital Complex

Carson City, Nevada 89710

(702) $687-3744$

\section{Mr. Floyd Galpin}

Chief

Waste Management Standards Branch

Office of Radiation Programs

U.S. Environmental Protection Agency

ANR-458

401 M Street, S.W.

Washington, D.C. 20460

(202) $475-9600$
Mr. Rudy Grube

Director

Fuel Management Department

Yankee Atomic Electric Company

580 Main Street

Bolton, Massachusetts $\quad 01740-1398$

(508) 779-6711

Mr. Richard J. Guimond

Director

Office of Radiation Programs

U.S. Environmental Protection Agency

ANR-458

401 M Street, S.W.

Washington, D.C. 20460

(202) 475-9600

Mr. Steven P. Kraft

Director

Nuclear Waste and Transportation

Edison Electric Institute

701 Pennsylvania Avenue, N.W.

Washington, D.C. $20004-2696$

(202) $508-5512$

Dr. Arjun Makhijani

President

Institute for Energy and

Environmental Research

6935 Laurel Avenue

Suite 204

Takoma Park, Maryland 20912

(301) 270-5500

Dr. Peter B. Myers

Executive Director

Board of Radioactive Waste Management

National Research Council

2101 Constitution Avenue, N.W.

Washington, D.C. 20418

(202) 334-3066

Dr. Robert H. Neill

Director

New Mexico Environmental

Evaluation Group

7007 Wyoming Boulevard, N.E.

Suite F-2

Albuquerque, New Mexico 87109

(505) 828-1003 
Dr. Frank I. Parker

Distinguished Professor

Civil and Environmental Engineering

Vanderbilt University

Post Office Box 1596, Station B

Nashville, Tennessee 37235

(615) 322-2697

For Courier:

400 24th Avenue South

Room 106

Nashville, Tennessee 37235

Ms. Nancy Pearson

League of Women Voters

Education Fund

6708 Bridgeport

Tacoma, Washington 98467

(206) $582-3543$

Ms. Judy Pensabene

Committee on Energy and

Natural Resources

U.S. Senate

312 Dirksen Building

Washington, D.C. 20510

(202) 224-3543

Dr. Chuck Reese

Assistant Director

Occupational Safety and Health

Laborers Health and Safety

Fund of North America

905 16th Street, N.W.

Washington, D.C. 20006

(202) 628-5465

Mr, Dan W. Reicher

Senior Attorney

Natural Resources Defense Council

1350 New York Avenue, N.W.

Suite 300

Washington, D.C. 20005

(202) $783-7800$

Mr. Robert Shaw

Senior Program Manager

High Level Waste and Spent Fuel Storage

Electric Power Research Institute

3412 Hillview Avenue

Palo Alto, California 94303

(415) $855-2026$
Mr. Ken Weaver

Senior Health Physicist

Radiation Control Division

Colorado Department of Health

4210 East 11 Avenue

Denver, Colorado 80220

(303) $331-8497$

FAX: (303) 320-1529

Mr. Joe Youngblood

Deputy Director

Division of High-Level Nuclear Waste

U.S. Nuclear Regulatory Commission

M.S. 4H-3

Washington, D.C. 20555

(301) 492-3404

For Courier:

11555 Rockville Pike

Room 4H-2, M.S. 4H-3

Rockville, Maryland 20852 
DISCUSSION NOTES

ON THE

THIRD STRATEGIC PRINCIPLES WORKSHOP

Denver, Colorado

April 4-5, 1991

\author{
U.S. Department of Energy
}

Office of Civilian Radioactive Waste Management 


\section{DISCUSSION NOTES \\ ON THE \\ THIRD STRATEGIC PRINCIPLES WORKSHOP}

Denver, Colorado

April 4-5, 1991

TABLE OF CONTENTS

Page

Wednesday, April $3 \ldots \ldots \ldots \ldots \ldots \ldots \ldots \ldots \ldots \ldots \ldots \ldots$

Welcome and Brief Program Review/Workshop Objectives and Agenda . . . . . . 1

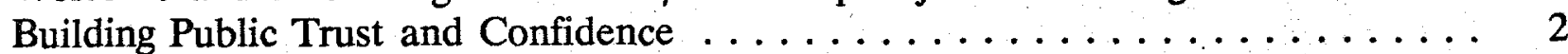

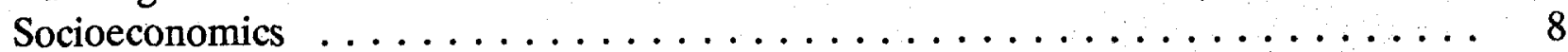

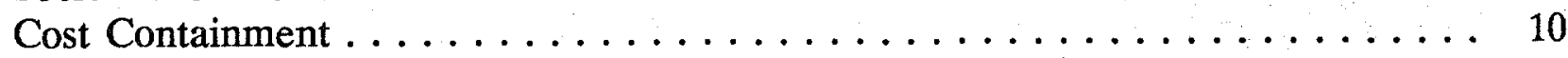

Phased Licensing for the Repository . . . . . . . . . . . . . . . 13

Disposal of Greater-Than-Class-C Waste . . . . . . . . . . . . . . . . 14

Risk Assessment in Selecting Transportation Modes and Preferred Routes . . . . . 17

Development of Dual-Purpose Casks for Transportation and Storage . . . . . 17

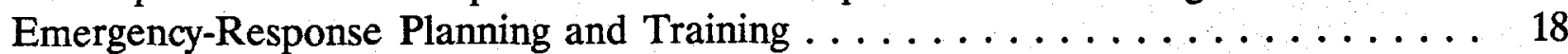

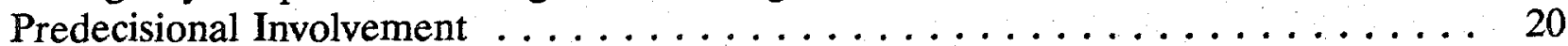

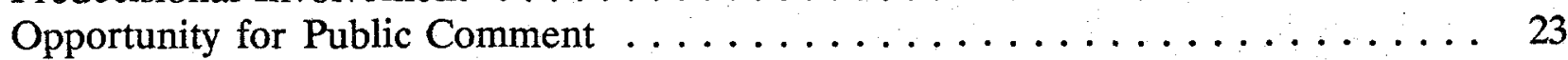

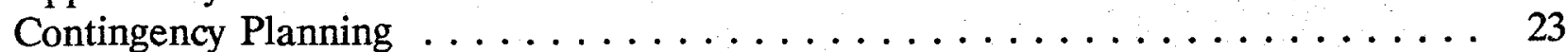

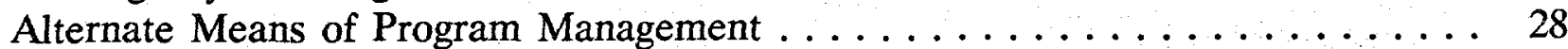

Comments and Review of Agenda ... . . . . . . . . . . . . . . 29

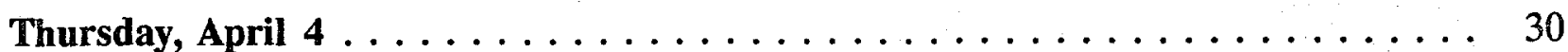

Expansion of Remarks on Contingency Planning . . . . . . . . . . . 30

Discussion of Mission, Policies, Objectives, and Strategic Principles . . . . . . . 31

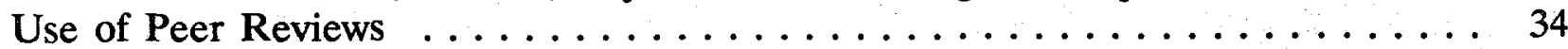

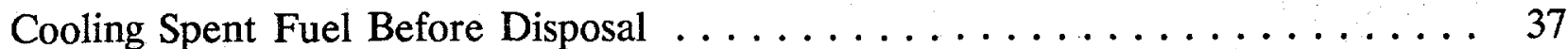

Designing Waste Packages to Exceed Requirements . . . . . . . . . . . 39

Timing and Criteria for Determining Site Suitability $\ldots \ldots \ldots \ldots \ldots \ldots \ldots$

Approach to the Demonstration of Performance . . . . . . . . . . . . 41

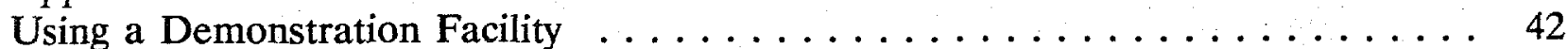

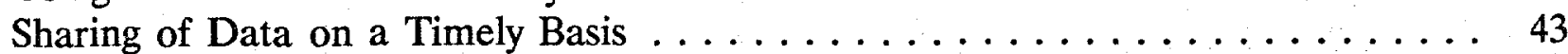

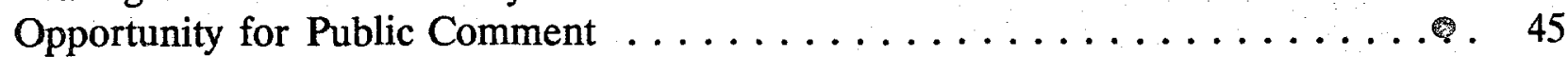

Roles of Utilities and the Federal Government . . . . . . . . . . . . . 46

Private Sector Involvement in an MRS Facility . . . . . . . . . . . 47

Use of the Nuclear Waste Fund for Storage $\ldots \ldots \ldots \ldots \ldots \ldots \ldots \ldots$

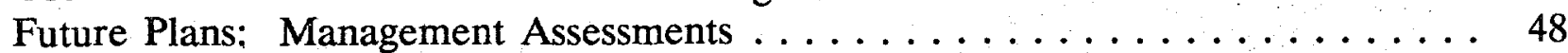

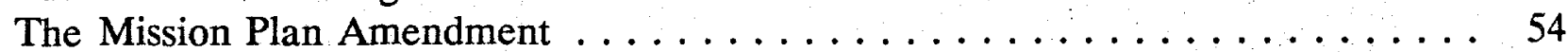

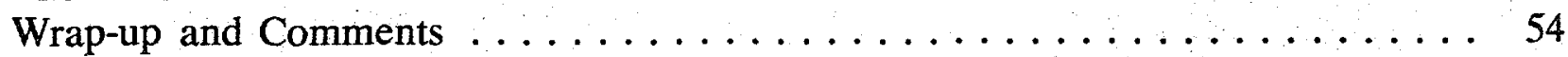




\section{WELCOME AND BRIEF PROGRAM REVIEW/WORKSHOP OBJECTIVES AND AGENDA}

DOE: I want to express my thanks to the participants for their time, effort, and intellectual capital. It's the first time DOE has provided feedback to the workshop participants. This is not the end of the process but the beginning. The workshops set the foundation for the future of the program. The results will appear in the Mission Plan Amendment (MPA), the document which charts our future course. The MPA draft will be issued in June and the final version will be published in December. I'd like you to consider whether there is a need for a workshop, perhaps in early July, to discuss the MPA draft.

I would like to make several key points:

One, the workshops did not introduce any entirely new concepts; therefore, there were no major deficiencies in our agenda.

Two, we have received significant guidance, and have added new principles:

a. consideration of public trust,

b. concern for cost effectiveness,

c. concern for timely distribution of data,

d. reduction of uncertainties,

e. evaluation of socioeconomic issues with affected parties.

Three, the major contribution of the workshops has been to clarify the connectedness of the entire waste management system (storage, transportation, and disposal). This confirms that we need to evaluate the difficulty of tradeoffs between system components. There is recognition for the need to make toplevel decisions, to identify which are the key decisions-and what are their cascading effects.

Four, we need to establish public trust and confidence. How do we earn it; what does it mean? Participation of the Secretary of Energy's Advisory Board (SEAB) should contribute to public trust and confidence.

Five, the workshops also showed that we need to pay closer attention to cost considerations. For example, switching to robust canisters. They're better, but are they worth the extra cost? There are soft cost tradeoffs, which means that we take an action now to achieve a future saving. How do we deal with this? The numbers are very fuzzy. 
It is not necessary to make some of the strategic decisions now, because we need more data. Some issues should not be cast in concrete now. In the MPA we will have to identify what needs to be evaluated. You will not see a cast-in-concrete MPA. As we do tradeoffs, we must avoid endless, unfocused evaluations. We must bear in mind that in the system linkage between storage-transportation-repository, storagetransportation must be available in 1998; we need to close on the latter, even if we have to leave open issues relating to the repository.

Facilitator: The Strategic Principles document has been extensively reworked from previous versions. Now is the opportunity for the participants to tell DOE how well they responded. Make the workshop interactive.

The appropriate DOE Associate Directors will present their respective sections.

\section{WEDNESDAY, APRIL 3, 1991: 9:00 AM SESSION}

\section{BUILDING PUBLIC TRUST AND CONFIDENCE}

DOE: Comments we received at previous workshops helped to define and emphasize this strategic issue, although we had been working on the issue before the workshops. This was not originally a separate strategic principle. Participants urged that public confidence be treated as a cross-cutting issue. Thus, we've added a new policy, "the program must be conducted such that public confidence is warranted," on page $2-1$, and a new management principle, to "consider public trust and confidence in program decisions," on page 2-3.

There were several options laid out in the original discussion draft under the heading, "timing and means for predecisional participation," seen on page 3-40. There was general agreement that actual decisionmaking cannot be shared-nor would external parties want a share in all cases. However, we will emphasize early involvement in defining and evaluating policy alternatives. A series of implementation actions are proposed (on pages $3-40$ to $3-43$ ):

One, we will develop a clear and realistic concept for predecisional involvement-an exemplary process that other Federal agencies would want to emulate. This process would include an early identification of significant upcoming program decisions in which interested parties should participate, and I ask you for help in creating ongoing forums and mechanisms for involvement; we also want to establish a systematic process to provide clearly identifiable responses to input received. The ongoing forums for involvement could include workshops similar to this one, committees, working groups, rulemakings, and cooperative agreements. We will watch how the Federal Advisory Committee Act applies. 
Two, we will seek cooperative relations with affected governments: pursuing efforts such as the current development of agreements to govern interactions with an affected local government; easing our and your administrative burdens through implementation of the proposal in the Fiscal Year 1992 budget request to provide direct payments to affected governments - to replace the existing grants program-with a certification process afterwards; and strengthening oversight roles, which is one subject of the agreements being developed.

Three, we will enhance internal resources-a concern that has been mentioned during these workshops. This could involve subjecting the institutional program to the same evaluation and assessment from outside experts that goes on in the technical areas. We will have increased upper management involvement and will pursue integration of technical and institutional staff.

Four, we will build an improved communication program, including the use of outside experts to train staff.

Five, we will work to increase public understanding through promoting education. One important aspect of this is to put radioactive waste issues into an overall context of energy and environmental issues. We're currently involved in curricula development and teacher training. This is a long-term proposition; we do not expect to see immediate results. Eventually, one could build a group of literate citizens who could make informed decisions. We will expand joint education initiatives.

This covers what we're doing. I welcome questions and comments, especially regarding what you think about how we can measure what we're doing.

Facilitator: This is one of the most significant additions and one of the most lengthy responses. People at the table represent affected governments and interested parties; this is an opportunity to look at DOE's proposals. DOE is looking for advice and counsel. Which of these programs will be helpful, which should be pursued, and how can DOE gauge the success of programs?

- I'm delighted to see that education has been included. We face tough choices as a society and we need to highlight these choices. Don't just talk about radioactive waste management. Is nuclear energy the answer? As I move about the community, I see that people don't comprehend the issues. We can get locked into a mindset and not see other ways of addressing issues. The answer is to start with young people-they will make future decisions. What are the problems with different energy sources? You should broaden the education curricula to put program issues into context.

DOE: I agree. We are working on the curricula, within the context of energy needs and choices, and putting the waste in context as a by-product. We have an advisory committee of universities. Secretary Watkins is very much interested in education, has 
strongly emphasized this area, supports DOE efforts; we are getting a good reception from the upper levels of DOE, and this provides us with a good environment.

- I see some positive things; all of these initiatives should be pursued-it's not either/or. Education is very important, but you also need to listen to the public. They have valid reasons why they're fearful. It's a two-way street. I'm very supportive of the direct payments concept. In the past there were problems with micromanagement. This will enable us to better set priorities. We have strong feelings about how certain things should be done. I support certification. You should be flexible on the amount of resources. When there is a fixed appropriation, it causes us to fight among ourselves, it constrains our oversight ability and creates fights among neighbors. We should have the opportunity to get into defining budgetary needs early in the process, and hope that DOE will support this. We need the flexibility and the resources to do the job.

- You've developed an excellent conceptual framework. When you incorporate it into the MPA, you should provide specific examples of the steps DOE is taking. Otherwise, it's motherhood and apple pie.

DOE: As we work on the MPA, over time, we'll expand and will cite specifics of what we've done and are doing, as well as what we intend to do. You will see deeds, not just words.

- Public confidence is a great concern, and we're glad DOE has recognized this. But, there are a few points that we would like to make:

One, we want an analysis of past history, including interactions with the public, and an analysis of what went wrong. This would show good faith-for DOE to look at its mistakes, to internalize failures. This was recommended at the last workshop.

Two, on the issue of communicating the risks of radiation, DOE has a poor record. You should give a full view of the dangers associated with radiation based on the latest studies. You should look at voluntary versus involuntary risks. DOE has made bad comparisons in the past. Give the public the details it needs to be able to make choices about risk.

DOE: Good point. I'm working with others in OCRWM on risk management and risk communication, including the areas of technical risk assessment and of factors in risk perceptions, such as the "outrage" factors related to involuntariness, stigma, and catastrophic potential. We need to recognize both elements. We will work on this and will need outside help. People validly worry about these aspects.

DOE: What society finds tolerable is a moving target. It would be useful to go back, but this program is just a microcosm of overall societal changes related to the siting of undesirable facilities. I've recently observed numerous examples of the difficulty of 
siting any type of facility, including a landfill in the mountains of West Virginia, a gas station in Miami, Florida, and a homeless shelter in Ward 3 in Washington, D.C.. The siting of the repository brings together all the emotional aspects of this issue in a more explosive, dynamic way-but is just the most extreme instance of the general siting problem. We have a risk-averse public. We need to come to grips with this issue. How do we as a society deal with these problems?

- There are two aspects of responsiveness: direct, by saying thank you for your comments, etc.; and indirect, by making program changes. Both must be considered.

- Training of staff in risk communication is paramount. I have had experience in a pesticide program where this was helpful. Safety is my ultimate concern. Safety needs to be addressed as a management function. Although it has been woven in-DOE did a good job on page 2-1; it should be under management. There must be explicit responsibility for safety. Using the word "safety," if it is not linked to people who are responsible for it, won't suffice and it will contradict what Secretary Watkins is saying.

- This is a good framework for public confidence, but it is an uphill battle. One issue is that the original siting process (i.e., mandated in the Nuclear Waste Policy Act of 1982) seemed fairer; the choice of the Yucca Mountain site seems arbitrary. You need to articulate concern for public health and safety as forcefully and specifically as possible. You need specifics about site suitability. Identify what would disqualify the site.

- I have several concerns:

One, past history. Indeed this would be instructive-to look at past decisions and their impact on public confidence. You should lay out the decision points, that took or didn't take place, and the dialogues that led to them.

Two, responsiveness. A continuing problem is timeliness of response. Nevada is still waiting for DOE's responses to our comments on the Site Characterization Plan. When DOE does publish responses, they often say, "see page $x$," rather than responding to the nature of the comment itself-the concern behind the comment. You need to address these concerns, rather than a broad-brush, "thanks for your comment, the decision is already made."

Three, public trust. You need contingency planning for other sites and for other troublesome issues.

- Several points:

One, responsiveness. It would be interesting and would build credibility to change a decision based on public comments-it would be a shock to me and it would build unbelievable public confidence. Take comments to heart and redirect decisions. 
Two, "experts." This is a tricky issue. Who are they? Are they publicly accepted? Blue ribbon panels, if they don't instill confidence in the public, won't help. The way DOE selects experts is critical.

Three, risk communication. You need to be very careful, it can easily backfire. For example, DOE's Office of Environmental Restoration and Waste Management (EM) decided, after much internal controversy, even though staff warned it would be a failure, to provide a display at public meetings on the programmatic environmental impact statement about risks from radiation compared to the risks of being bitten by a lion. There was an incredible controversy, the media picked up on it, it was dumb. I hope risk communication is really thought of in realistic terms. In some cases, you may not want to try risk comparisons. Let the public pick up the relationships themselves.

Four, curriculum development. This has the potential for backfiring. As hard as DOE will try, there will be public controversy, critics will say that DOE has an agenda and is slanting the facts, greasing the skids. You need to consider carefully, especially about the resources you put into it, if you do go ahead. You should get review outside the Department, get a seal of approval from a cross-section of people. I would rather see the dollars spent on more general science issues, not nuclear-specific.

I do want to say I agree with the principles, they are admirable. You have the proper intent, implementation is the key. There are potential pitfalls.

- This is my first workshop and I'm glad to be here. You need to write the materials in language the public understands. I've tried to talk to people. You need to start almost at the beginning. People are afraid, they don't know the history of nuclear energy: 40 years' accumulation of material scattered all over. Something has to be done about the waste. Talk to them in a way they can understand. One can explain it, one can convey that something needs to be done with all the waste. They'll agree it shouldn't be scattered. I believe that the public can be convinced that we can't drift along, we have to put the material somewhere.

- This is a good start. State legislators are especially concerned about public confidence. The problem is greater than this program. For example, the Rocky Flats facility in Colorado-the Governor of Idaho doesn't want the waste, despite broken contracts. People don't distinguish between OCRWM, EM, and defense programs. This is a challenge. On the subject of risk management, we've tried to deal with it for five years. Peoples' eyes begin to glaze over fast when you talk about it in the broad sense. When you take specific instances, like asbestos in your child's school, it is really impossible to think about probabilities and averages. There are some great things in the document. I agree that you need to actually change something. You could use a first case, an example of an issue where input will be taken into account. That example must work very well. 
DOE: One example is the exploratory shaft facility (ESF). DOE will be changing our approach based on comments from the Nuclear Waste Technical Review Board (TRB), the Edison Electric Institute, and the State of Nevada. We're in the midst of a detailed study now. That's an area where a number of parties said take a look. We'll be able to point to that when we make changes.

DOE: You can find examples where we have made changes; for example, test prioritization and the early determination of site suitability. In response to comments from the Nuclear Regulatory Commission (NRC), the TRB, and the State of Nevada, we changed the order of planned tests at Yucca Mountain. Maybe we need to publicize this more. We need to hear from you on when we're communicating.

DOE: Maybe our problem has been that we are very responsive to certain parties - the NRC, the TRB-rather than working at responding to the substance of the comment itself.

- Your intent is pure and your goals noble. But think about ten years from now, it will be difficult to quantify how much good will be done, how well was it implemented. I'm curious about how much money DOE will commit to pursuing these initiatives. What about organizational resources-will you create a public trust department? Is it the boy scout code or do you mean business?

A second point, radiation has many uses and society is not about to abandon it. Society is unwilling to face up to its responsibilities. It's not DOE's problem, it's society's problem. A related example is New Jersey's garbage problem. They set a goal of recycling $60 \%$ of their trash; people said it was impossible. New Jersey now recycles $42 \%$ ! The public gets credit-they started doing it. We have to get the focus to the point to where the public becomes convinced that it's their problem and their responsibility. Not only this issue, but others.

- You did a good job in the document. These issues are of great concern to local governments. You did a good job on the objectives. But these are general statements, not the end product. We want to see how it will be implemented. I have some specific comments:

One, predecisional involvement. Nye County has been working with DOE; two teams have been developing the framework for interactions and protocols for interactions. These are close to signature. We ask John to please push them to the top. This is a good example of the first case that has to work. If it doesn't work . . . Incidentally, the two words, "predecisional" and "involvement," DOE asked to take these words out of the framework and the protocols. Is there a change of heart at DOE? I invite other affected governments to take a look at this effort and join in. 
Two, independent experts. It is a good idea to have independent experts evaluate the institutional program. We wholeheartedly support it-it's long overdue. There are plenty of independent experts in this area.

Three, education. The Nye County Science Museum project has been a county priority for several years. We want to thank John for his support. We need to push it over the top. Our objective is to build a world-class museum with unbiased information about the nuclear world. This is another example of an area where follow-up is key.

- On the issue of examples of changes, affected governments and interested parties are viewed as part of this program. It's a tarbaby. Some residents don't believe the State. The ESF change in design or location is meaningless in terms of public confidence. You need to take what the public-not the institutional groups-is saying and then do it. For example, characterize multiple sites-DOE could recommend that in the MPA. Tell Congress what changes DOE wants. You need a fundamental return to objective site selection. Not miniscule technical changes.

- On risk communication, you need to stress that uncertainties will always exist about geologic disposal. The public will be disappointed when we don't have all the answers.

- "Education," the term bothers me. Too often it means change their thinking. Public education cannot simply be trying to get people to accept the program. Everything DOE does is "public education," whether intentionally or not. A couple of specifics on your response document: response time, and you could gain by looking closely at comments and trying to respond positively whenever possible-look for opportunities to agree. Avoid saying, "no, we can't do it," although I realize they can't all be yeses.

\section{SOCIOECONOMICS}

DOE: We've added a new strategic principle, "evaluate socioeconomic issues in cooperation with affected governments," (page 2-5). We will apply standards comparable to those applied to environmental and technical issues, including independent review, to socioeconomic effects. We had begun to address this before the workshops. It's been a major issue in Nevada, and will be for any future MRS facility site. We're beginning to involve affected governments in developing and implementing the socioeconomic program. We circulated the draft Yucca Mountain Project (YMP) Socioeconomic Plan for review and will follow up by meeting with parties to discuss their comments. We're developing a protocol with an affected county on socioeconomic issues and are working with affected governments to enhance YMP's socioeconomic monitoring program. We will undertake various activities, including those listed on page 3-46. 
- I'm gratified to see this as a strategic principle; it is very important to citizens. I'm glad to see that DOE recognizes the concerns of communities. In the text, I see a number of supportive items. However, the wording of the principle is a little confusing. Clark County has experts in this field. We need to be in charge of this area. We are working on a major baseline study now. We need to be in the driver's seat; need sufficient resources. I would recommend a change of wording in the principle to, "provide support for affected government socioeconomic studies."

- I'm also quite pleased this was elevated to a strategic principle. I was at a recent meeting at the Pentagon on base closings. They are preparing an EIS for bases on the list. The Air Force people said that over the years it has become very apparent that people care most about socioeconomic impacts and they have been forced by communities to focus on socioeconomic issues. The Air Force people didn't know that socioeconomic impacts are part of the National Environmental Policy Act (NEPA.) The Air Force has elevated socioeconomic impacts and will do a separate EIS on these alone. So, it looks like you folks at DOE are also acknowledging their importance. With respect to protocols, we want the county to perform socioeconomic monitoring and assessment, with DOE oversight. Analyses could be done by both. We'll spell this out in the protocols.

DOE: I agree with these points. It's a ripe area for us to work together in a complementary fashion, but we shouldn't duplicate efforts.

- This area may be somewhat new to DOE. You should check out the National Park Service; they have lots of experience and might provide assistance.

- I'm not anxious to pour cold water on anything, but we need to recognize that both DOE and the affected governments have responsibilities and roles to play independently. DOE will do an EIS; affected governments may submit impact assistance requests. The roles may not always be complementary; we may be at crosspurposes. Affected governments will need to make a case and there may be adversarial circumstances. We at the State anticipate we will have to take our cases to a courtroom. We might be able to agree on certain things, like establishing environmental and socioeconomic baselines-which DOE has not agreed to do.

DOE: What about sharing of peer review groups? We wonder if we can share experts in addition to sharing data.

- Well, I'm not sure about that. If this will be a contested issue in the future, we'll need to make a technical, legal case. The chance of a joint review group is fairly remote.

DOE: We would like to explore it. 
- The level of funding is an issue. The special effects arena was opposed by DOE; we wouldn't like to see pass/fail tests for local government efforts.

\section{WEDNESDAY, APRIL 3, 1991: 11:00 AM SESSION}

\section{COST CONTAINMENT}

DOE: We have responded to the earlier workshop discussions by adding a specific strategic principle on cost containment to the management section of the principles.

Generally, we see two aspects to cost containment: cost-effective design of the wastemanagement system, and cost-effective management of the program. Costs are considered in making program design decisions, subject to the mission priority to ensure health and safety and protect the environment. Regarding management decisions, we work under the DOE Cost and Schedule Control Systems criteria, a process that requires that costs be considered in decisionmaking.

The Strategic Principles sessions have definitely served to increase our concern about cost. We expect that the additional resources of the $M \& O$ contractor will provide the opportunity for additional efficiency studies, which will reduce costs further through improved management efficiency.

An effective cost-containment approach must weigh short-term savings against longterm benefits. For example, spending more on improved waste packaging could lead to substantial savings down the road. Once such trade-off decisions are resolved, we can proceed with long-term design.

Another cost containment mechanism is the Program Change Control Board process, which requires cost impact assessments for proposed program changes brought before the Board.

The DOE budget process also imposes effective cost control through review by a range of internal DOE, as well as external, bodies. These include the DOE Internal Review Board, DOE's Office of Independent Cost Estimating, the Secretary, OMB, and Congress. Thus we work under a system of outside checks and balances and internal reviews; we can't just spend the Fund as we please.

Narrowing to a single repository saved costs, but that has to be balanced against the effect on public confidence of not having more than one possible site. We are not looking for the best site, but rather one that meets the requirements. Finally, we need to remember that this is not just another construction project, but a process involving many contending parties. Decisions can't be made on cost considerations alone. 
- You're the nuclear experts. Maybe you should use more initiative in recommending program directions to Congress. For example, looking at just one repository site creates public confidence problems which could result in higher costs in the long run than exploring multiple sites, particularly if the single site proves unsuitable.

DOE: There is a lot to be said for that point, but we are limited by the way the law stands now. This doesn't mean we will bury our professional responsibility to recommend the best course. We do still have the question of how much it's reasonable to spend for "insurance" in the sense of alternative courses if current plans fail.

- DOE should recommend the program it thinks is needed from a scientific and public policy viewpoint. The MPA process should be used to determine recommendations for changes in the law.

- The question of one site versus multiple sites would be too narrowly considered if looked at only as an "either-or" case based on cost alone. If viewed as a backup and a possible second repository site, if one is needed, a second candidate site might make financial sense.

DOE: That's a good point. Even if all current reactors were to be shut down right now, there would be more than $70,000 \mathrm{MT}$ of spent fuel to dispose.

Facilitator: We seem to be discussing the scope of the MPA. I'd like to concentrate on cost containment at this point. Let me suggest two aspects we should be discussing: how to spend the money (budget), and how to get the most effective use of the money (management).

- I'm pleased to see substantial revisions in the Strategic Principles document in response to my letter. There is no question that DOE goes through many reviews in allocating funds. Program design is a critical stage in determining cost. Cost must be a consideration in design, though not necessarily the primary one. Spending less is not cost control; you have to spend more to have better control.

DOE has made some progress in recognizing cost considerations. At one point, for example, DOE said that the only way to characterize a site is to go through the entire process -at a cost of some $\$ 2$ billion. We seem to be past that now. Maybe the best way to determine the cost-effectiveness of a second site is to start one.

Another point I'd like to make is that we need to learn from the nine years of experience with the program. For example, John noted earlier that the QA program contributes to better cost-related decisions than in the past. Previous program administrators generally resisted GAO recommendations, including a recommendation for better contractor management. We applaud Secretary Watkins welcoming GAO 
comments. Pursuit of the "root cause" has internal and external elements; both should be pursued.

- Regarding the section on total system cost (page 3-37, paragraph 1), it says that total system costs were lower when using an MRS. Previously, DOE has indicated that it costs more when there is an MRS in the system. Also, regarding the reference to TRB (page 3-38, paragraph 2) ${ }^{1}$, I want to emphasize that TRB is not involved in cost review.

DOE: Understood. That reference only states that the TRB technical reviews provide a sounder basis for cost estimates.

- Are there any numbers available on what is actually being spent on various program components?

DOE: Absolutely, yes, we can provide those.

- GAO has criticized DOE for diverting funds appropriated for one purpose and using them for other purposes. For example, the ESF, what is the process for reprogramming?

DOE: When Congress appropriates less money than we requested, and cuts are not specified, it is up to DOE management to allocate the cuts. Also, while there is considerable detail in the budget, spending is not constrained line for line.

Management must make judgment calls in the best interest of the program, and States and localities may not always like the calls.

- What about the process, internally and externally, for monies held up?

DOE: Funds stay in place until released. The Secretary did make the decision to hold up the $\$ 6$ million for the State which was on condition of the Secretary certifying State cooperation. But that money was not lost, it remains available for future use since it was allocated for a specified purpose.

- Cost control is critical, but it's also relevant to public confidence-as when DOE tells the public it can't do something because it costs too much. Some members of the public say, we don't care how much it costs, it's important to us. DOE needs to be sensitive to that. Also, DOE must be very wary of letting costs drive the approach to

${ }^{1}$ Editor's note: The quoted paragraph stated that the total system costs were estimated and used in determining the preferred system option but did not state that the total system costs were lower when using an MRS. The MRS system studies showed that total system costs were somewhat higher with an MRS facility but the benefits of an MRS facility warranted the additional cost. 
health and environmental standards-some court decisions have rejected that. You need to meet safety standards, whatever it costs. Cutting environmental protection costs in the short run can mean massive costs later on; Hanford cleanup costs will clearly be in the tens of billions. The public will force the question of defense wastes onto the agenda, so it will be impossible to consider just civilian high-level waste in isolation.

- Why aren't affected governments participating in the DOE budget process and priority setting? What is your process? There's no external review. The budget involves setting priorities and affected governments should be involved.

Facilitator: Maybe that question gets too far off the topic of cost containment.

- I don't see how you can separate it.

- Management of the defense facilities is a good example of how doing the job right the first time would save money. On another tack, I recognize that DOE has many checks and balances in it's budget process, as the introduction to this topic indicated. But what, if anything, do you propose to do differently in response to the comments in my letter?

DOE: We'll try to make the process more open to the public and more traceable.

\section{PHASED LICENSING FOR THE REPOSITORY}

DOE: Current steps for the licensing of a repository include: the authorization to construct a repository; a license to receive and possess radioactive waste at the site; and an amendment of the license permitting the repository to be decommissioned and permanently closed. During these phases, the NRC will continue to evaluate additional information about the expected safety performance of the repository. Our current plans are that if the site is determined to be suitable, we will seek to obtain a construction authorization for a full-scale repository. Our understanding of the previous workshop discussions is that there was general agreement to continue with our current plans, as described in option 1. The other options were viewed as offering no significant advantages and having the potential to adversely affect public perception as an attempt to get around regulations or an attempt to permanently emplace waste before the repository is licensed. Our current position is that there is no change in our approach, but we will continue to look at alternative strategies to aid in speeding up the license application process.

Facilitator: Is this explanation satisfactory? This issue generated a fair amount of discussion previously-especially as it concerned public perceptions.

- I'd like a clarification of the final clause. What is meant by "speeding up"? 
DOE: It's a time issue. It means looking at ways to accelerate our schedule.

- How do you see the interface between the construction authorization and the license to receive and possess? You don't know what you will encounter during construction.

DOE: The general approach is that the construction authorization is based on a design for all the repository including facilities above ground and waste handling before emplacement. Then one or two panels would be constructed and waste would be emplaced in them before finishing repository construction. We would not go to the NRC for each panel emplacement. We would apply for a license to receive and possess, up front, even before finishing repository construction. During construction of additional panels, each panel will be inspected to meet the standards of the license.

- Then you plan to construct in segments, but not license in segments?

DOE: Yes.

\section{DISPOSAL OF GREATER-THAN-CLASS-C WASTE}

DOE: Since this issue was not discussed at either of the two previous workshops, it's important to give you some background on it. In 10 CFR Part 61 the NRC defines three classes of low-level radioactive waste, in order of increasing radiation hazard and longevity. Waste that exceeds the radioactivity concentrations permitted for Class $\mathrm{C}$ is known as "Greater-than-Class C." This waste comes from a wide variety of sources, including the operation and decommissioning of reactors, medical activities, and research, and it varies in physical characteristics, composition, and radioactivity. This waste is presently kept in storage at the sites where it is generated.

The Department's Office of Environmental Restoration and Waste Management is carrying out a study to determine the quantities and characteristics of this waste. Most of it will be radioactive metals from decommissioned power reactors, but some could be "mixed waste", which contains both radioactive materials and hazardous chemical substances.

The NRC is responsible for classifying waste and determining which waste requires geologic disposal. It hasn't yet determined that Greater-than-Class $\mathrm{C}$ waste requires geologic disposal. In its ruie on low-level waste disposal, the NRC did propose geologic disposal for GTCC waste "unless proposals for the disposal of such waste in a disposal site licensed pursuant to 10 CFR Part 61 are submitted to the Commission for approval." We've encouraged the NRC to make a determination on which GTCC waste requires geologic disposal and which does not.

With regard to our plans for this issue, the first thing I would say is that there is great uncertainty as to the quantities of GTCC waste requiring disposal. Some observers feel 
strongly that because of this uncertainty we should be studying the need for a second repository now. Our current plan is that we will not put GTCC in the first repository. As part of our contingency planning we need to quantify the amounts of GTCC, which, as I mentioned, EM is now doing. We believe there may be about 300,000 cubic feet of GTCC, which is about $10 \%$ of the volume of spent fuel and defense high-level waste.

A decision to emplace GTCC in the first repository could substantially affect its planning, design, cost, and licensing. It would require detailed analyses of potential effects on the pre-operational safety of the repository, the long-term isolation capability, the waste-emplacement configuration, and many other factors. We plan to continue discussing the disposal requirements of GTCC with the NRC.

- This offers an interesting example of system analysis. The system is set up by law and funded by ratepayers. It does not include GTCC. But if you broadened the system to include DOE, as opposed to only OCRWM, responsibilities, GTCC would come in. There are two choices. You can try to get funding to include GTCC in the repository or you can force the Secretary to get another repository program. I believe the practical national solution is for GTCC to be included in the repository, but that is not the current set-up. The questions are, what is it and where is it? Sealed sources are the only source of GTCC at the present time. This needs to be in your strategic plan. The only way to address the issue is to ask how many repositories DOE needs and how much waste does it have to dispose of.

DOE: I agree that we need to consider all this, but not for the first repository.

- DOE is reluctant to face the issue because the costs and the volumes are high and for certain other reasons which I don't buy. The cost per cubic foot at the repository is about $\$ 200$, which is the same as for low-level costs around the country. Since GTCC emits no heat, why not stick it in the repository? The problem is if it includes mixed waste. Where did the 300,000 cubic foot figure come from? OTA said there were 50,000 cubic feet. If there is mixed waste there is a problem.

- Apart from sealed sources there is going to be mixed waste and it will be a problem to meet both NRC and RCRA standards.

- There are licensing problems associated with mixed waste.

- Performance allocation and performance assessment, using current regulations, require a certain logic that says all different kinds of waste will have an assigned source term per cubic foot. I agree that GTCC can go in the repository even without backfill.

- You may see volumes of GTCC in excess of 300,000 cubic feet that are the responsibility of the "larger Federal system." You may have a greater volume of GTCC 
than you planned for. Some low-level waste compacts have refused to accept volume averaging of waste.

- GTCC is still defined as low-level, but NRC requirements are more rigorous than those DOE puts on itself. I think the estimate of $\$ 300$ per cubic foot is open to challenge.

- The numbers are soft. Defense wastes are the wild card. Some Hanford waste could end up as GTCC or even as high-level waste. RCRA is important and will come into play in the geologic repository. The Waste Isolation Pilot Project (WIPP) resisted RCRA for years and we should not relive the WIPP mistake. We should think now about how to deal with this. I believe you can reconcile NRC and EPA standards on mixed waste.

- DOE said there were $86,000 \mathrm{MT}$ of high-level waste and 10,000 MT of defense waste. There should be a strategic principle that focuses on the need for a second repository today. If Yucca Mountain can take only what exists today then we need to talk about the second repository now. It should be in the Mission Plan Amendment. This would be soothing to Nevadans, who could then see that they were not the only ones earmarked as owners of a repository.

DOE: The need for a second repository because of GTCC is a secondary question. Other wastes have greater bearing. If the lives of the current nuclear generators are extended there will be more than 100,000 MT of high-level waste. The law tells us to look at high-level waste. That's what pays the bills. We have to be careful of how far we go until we know what's out there, what are its characteristics.

- There is not a distinction between GTCC and high-level waste from a DOE perspective. The same DOE people who are generating high-level waste are also generating GTCC and the same is true on the commercial side.

DOE: I agree, but our authority is for high-level waste and the other waste is not under our authority.

- Your authority is for a single site but there's nothing to prevent you from raising the issue of a second site.

- You have an opportunity to look into this when we look at waste acceptance criteria.

Facilitator: This raises the question of how broad the MPA should be. Should it be confined to statutory authority or should it break new ground? 


\section{WEDNESDAY, APRIL 3, 1991: 1:30 PM SESSION}

\section{RISK ASSESSMENT IN SELECTING TRANSPORTATION MODES AND PREFERRED ROUTES}

DOE: We recognize that the public is vitally concerned about safety in transportation. Some participants at the preceding workshops suggested that risk assessment is of questionable value and can be misconstrued by the public. Several participants said we need to seek out and listen carefully to the concerns of the public. Recognizing that risk assessment is already required in the regulations, we propose to follow the third option stated in the Strategic Principles discussion paper: to use risk management as a tool in making decisions about transportation, but not as the primary method for making those decisions. Any comments or questions?

Facilitator: The revised draft does seem to fit the earlier discussion.

- What about transportation for defense wastes-are you doing anything on that?

DOE: We are taking lessons from the experience of the WIPP program. In view of the fact that there is no MRS site yet, we can't do too much more.

Facilitator: I'm assuming that the group's silence indicates agreement with the revised draft.

DOE: You could also assume we all just had a big lunch.

- Don't let 13 years go by without a plan.

\section{DEVELOPMENT OF DUAL-PURPOSE CASKS FOR TRANSPORTATION AND STORAGE}

DOE: A dual-purpose cask is a metal container that has been designed and approved to be used for both transportation and storage of spent fuel. Dual-purpose casks must satisfy the requirements of $10 \mathrm{CFR} 72$ for certification by the NRC for use as storage casks and must also satisfy the requirements of $10 \mathrm{CFR} 71$ for certification as transport casks. To date no casks have been certified by NRC for dual-purpose use, and some certification issues remain to be resolved. Although our current cask-development program does not include dual-purpose casks, commercial vendors have proceeded with the design and development of these storage and transport casks. Should these vendors be successful in receiving NRC certification for storage and transportation, we will evaluate their use as part of early waste acceptance at the first phase of an MRS facility. A similar situation exists with regard to the use of multi-element storage canisters. They are currently in use at two reactor sites but have not been certified for transport by the NRC. Our decision will be based on their safety; cost effectiveness; usefulness in the overall waste-management system; feasibility for the intended use; the 
use of these technologies by utilities; and the regulatory issues. Also, input from a volunteer host will be factored into decisions on the selection of technologies to be used at an MRS site.

- I agree that this assessment needs to be based on further study. Has there been consideration of what an overpack can add to overall safety?

DOE: This is definitely something to be looked at.

- The NRC currently has one dual-purpose cask design before it now for certification. The optimum size is so large that it hits the very limits of transportable weight (125-150 tons). It is difficult to have rail shipments of that weight. We looked at dry storage at the reactor site versus dual-purpose cask shipability, and probability of a potential accident or potential radiation leak from additional handling to see if dry storage had a significant advantage over cask storage. It did not.

- Do we need system studies? For example, anticipatory studies in case such a cask does get certified?

DOE: Yes. We have done some.

\section{EMERGENCY-RESPONSE PLANNING AND TRAINING}

DOE: As indicated in the document, we're required to provide training and funding for jurisdictions through which waste shipments will pass. We're developing a program plan and policy which will address both routine transportation and assistance for accidents requiring emergency response. We didn't receive any recommendations at the previous workshops. As a result of our conversations with regional groups we are continuing to develop our strategy. DOT will soon seek input to their implementation plan. With regard to the heavy turnover of personnel, our plan is to start training three to five years before initial shipments and then to repeat the training every three to five years because of staff turnover.

- All of our people are volunteers. They need training and we need help. They need special clothing and equipment. We need to build up a local interest in the subject.

DOE: We will try to build into the system the funding and capability for local authorities to do their own training.

- You may need to start earlier than three to five years before shipment, so as to build up public confidence. Local and State governments should handle the training. All over the country local communities will need equipment they wouldn't need if there were no shipments. You'll need to bite the bullet and agree to provide equipment all around the country. You need to have information to tell people how dangerous this 
stuff is. For example, how far back do you have to be from a cask with a breach? DOE's assumption is that the cask won't fail. An emergency responder must assume that the system will fail. State and local responders need to know the worst case.

DOE: We need to recognize that the role of first responders is to rope off the area, not to initiate recovery actions.

- DOE needs to understand the need to begin to respond to questions, even if it feels the scenarios raised are unlikely.

- Volunteers should be trained together so they can respond together.

- To clarify a point I made earlier, OCRWM needs to go through the process but not to reinvent the wheel.

- Pilot testing is very important. A three to five year lead time seems appropriate. All Federal agencies involved in emergency response should get together and put dollars into creating a self-teaching curriculum that is based on personal computers and becomes a standard. It could be available nationwide. Use an expert system for input. There is much to learn from past campaigns.

- Who is taking the lead for local jurisdictions? Do you have a list of local jurisdictions? What is the umbrella group you plan to work with? With whom do you have cooperative agreements?

DOE: No, we don't yet have a list since we don't have an MRS site and don't know the routes.

- All these topics go back to safety management. There is not much difference between responding to a hazmat spill and a high-level spill. EPA has had to shutdown hazmat sites for lack of an emergency response program.

- Waste has been and is being transported. Hazmat generally is treated the same way as radioactive waste. NRC has a national response center which responds almost daily.

- The recent meeting of the TRB in Albuquerque was good. They talked to WIPP on transportation problems. We need more of this.

- On page 3-47 it mentions the issue of inconsistencies in various State regulations. DOE should try to deal with them soon before you decide to litigate. You should make a strong effort to arrive at consistency through cooperation. Litigation is not the way to go! 
DOE: We have a cooperative agreement for looking into this subject.

- Radiocommunications need to be coordinated across jurisdictions. Be sure we're all on the same wave length.

- High-level waste can only be shipped over pre-approved routes. Each and every State must be notified in advance. This will be true for Yucca Mountain as well as for WIPP.

- For WIPP there will be 1200 shipments a year. You could be calling a state up to three times a day. You'll need to figure out some way to streamline the system.

\section{WEDNESDAY, APRIL 3, 1991: 2:30 PM SESSION}

\section{PREDECISIONAL INVOLVEMENT}

Facilitator: On the issue of involvement in decisionmaking and the choice of option 2, predecisional dialogue, the question is does this option being proposed by DOE reflect participants' wishes/views and what types of forums are appropriate? I'm curious to hear your views; would this constitute a satisfactory plan?

- I want to reiterate my comment about Nevada's ignorance of OCRWM's budget process, and the need to involve the affected governments in that. On this issue of peer review, there is the danger of back-scratching. You need to consider involving a truly independent, interdisciplinary review group. You should use a variety of groups, depending on the topic.

Facilitator: Will DOE identify significant programmatic and technical issues; would DOE involve external parties in identifying these issues?

DOE: Yes, that would be ideal. Trust and confidence goes both ways. DOE needs to be convinced that involvement won't cause unacceptable delays, costs, and failure to come to closure.

- In the variety of mechanisms officially established advisory committees are absent. You already have technical advisory committees. The institutional issues are more difficult than the technical issues. You need to have formal mechanisms; either add institutional experts to existing review groups, or create a new group. There must be an equivalent level of attention paid to the institutional issues.

DOE: You get into the Federal Advisory Committee Act (FACA), which may not be a problem. We will be looking at the SEAB, which is going to include academic experts. 
- There shouldn't be an inordinate fear of the FACA. The provisions are wise-sunshine is good. As much as the SEAB is a good institution, it won't bring in citizen representatives - theoreticians and academicians, yes-but not people who have gut concerns. You need a means of bringing in people who represent local citizens. For example, the Three Mile Island Commission included a local resident and was very successful. You need to bring in critics and grassroots people.

DOE: I don't think the SEAB is a substitute for public involvement. I have worked under the FACA and there was no problem. The more open a program is, the fewer problems.

- On the subject of the FACA, John Ahearne's Advisory Committee on Nuclear Safety for defense programs has been excellent-very open, very freewheeling, very successful. It's a model to study.

- An example from the WIPP: there is an internal DOE advisory board; I asked to be invited and was not allowed to; they said, "oh, this is only internal." Another example: there are concerns about the roof of the mine at the WIPP and about DOE experiments; DOE announced that they will bring in an expert panel and I was told I was disinvited because, "it would compromise the independence of the EEG." DOE launders funds for committees through contractors to avoid the FACA. You need an open, structured manner for a thorough, objective airing of views.

Facilitator: One of the objectives of this session is to dispel DOE's image of decideannounce-defend, lack of openness, and lack of real external party involvement. This represents an effort by DOE to substantially change. The question for this group is whether the proposals contained in the Strategic Principles' public confidence section are adequate to build public confidence. This is your chance to say whether or not the proposals are sufficient.

- People probably recall meetings in 1984 about consultation and cooperation and what it constitutes, with Roger Gale, the States, and Indian Tribes. Ultimately, we had a concrete commitment from DOE for involvement of affected governments early enough to make meaningful contributions to decisions. These strategic principles workshops are like deja vu. It is clear that affected parties need to be involved. Only DOE can determine when that is. When an idea begins to emerge, only DOE knows. It's a fine line to walk, there is no right answer. I can't help but remember discussions about the exact same subject.

- Last August, Nye County asked to be involved with OCRWM expert panels on the repository program. The response in December was, "no, it would slow down our progress." I hope this has changed.

- I had a recent experience with defense programs regarding an idea for a museum at the Nevada Test Site. There is a problem of separation of defense programs and 
OCRWM. You always get, "that's another side of the house, we don't know anything about that." It looks very bad. You need internal communication. For example, groundwater data needs to be coordinated.

Facilitator: How do you confirm that initiatives are working? One issue for the group is how do you assure that this commitment in fact happens? Where is the enforceability of this commitment? Maybe one of the elements of building public trust is to empower affected and interested parties to enforce this.

DOE: We're instituting a self assessment program. A strategic principle has been added on this. It is easy to talk about these things. I remember the 1984 discussions; probably both sides felt they made a good faith effort-but. . .

- It's not enough to just involve these institutional groups; the public regards us as part of the program. You need public involvement.

- One of the concerns is how to institutionalize changes. Advisory committees are one way-periodic review of the program, say every four to six months. Look for means to insure that the program stays on track. One thought on structuring the program is a Board of Directors, to oversee management, budget, progress, etc.. You could review before the year starts what changes you plan to make in the program and associated budgetary impacts and ask a small number of interested parties.

- Formal agreements such as the one governing the clean-up at the Hanford, Washington site between the State of Washington, DOE, and the Environmental Protection Agency (EPA) provide for an array of public participation and consultation. Missed milestones trigger specific actions. Also look at the consultation and cooperation agreement at the WIPP. That's one way of keeping the program in check.

DOE: The Act has provisions for formal consultation and cooperation agreements. DOE has begged States to enter into agreements. They found it would imply their consent to the program.

- I'm aware of this, but maybe a different type of agreement could set in stone commitments.

- This discussion has focused on process, which is very important. But substance is equally important. You need to respond to comments by making real changes. 


\section{WEDNESDAY, APRIL 3, 1991: 3:30 PM SESSION}

\section{OPPORTUNITY FOR PUBLIC COMMENT}

- I want to thank DOE for the time and effort they put into the meeting. I want to provide for distribution to participants a credo for siting facilities which was prepared by a prestigious group of experts in the field.

The SEAB Task Force will operate under the FACA.

Good science and good engineering, not emotional response from the public, should govern the program.

- Looking at public confidence issues may change decisions and may contradict cost and schedule factors. For example, training for transportation might start earlier and be more extensive, the waste package might be made sturdier-and thus more expensive-than regulations require, etc.. The key is to listen to concerns and respond to them. On page 3-42, under the communication program, the text puts "developing messages about risks" before "eliciting and responding to concerns." These items should be reversed.

\section{WEDNESDAY, APRIL 3, 1991: 4:00 PM SESSION}

\section{CONTINGENCY PLANNING}

DOE: This issue initially had a narrow context of DOE's legal obligation to recommend further action to the Congress if the Yucca Mountain site is found unsuitable. Comments received at the earlier workshops were that contingency planning is absolutely essential. Participants strongly recommended that DOE seriously develop a contingency planning program. We completely agree. We had been involved in an adhoc process for many years. Even if the program stays on schedule, it will last 100 years. Contingency planning isn't only prudent, it's essential. There are several activities going on:

One, the National Energy Strategy (NES) explicitly calls for OCRWM to do contingency planning for: a) if Yucca Mountain is found unsuitable; and b) if the Negotiator is unsuccessful in finding an MRS facility host.

Two, a process has been instituted for developing a contingency planning framework. We have held several meetings on contingency planning definitions, criteria, and analysis. You should see the beginnings of that framework in the MPA. You will see an explicit description of contingency planning. 
I want to cover some comments from earlier today. I have a list of myths that I keep, which grows longer all the time; subjects that over time have been cast inaccurately and have taken on a life of their own. I hope that we do take up the recommendation to look at the history of the program-we might be surprised at what we find. Some things to remember are that we are part of the Executive Branch and we operate in concert with the Congress. In programs as difficult as this one, the fact that we have an explicit Nuclear Waste Policy Act and that it has been amended reflect a country trying to grope with this problem. We encountered an array of problems in trying to carry out the 1982 Act; it was extremely difficult to try to characterize multiple sites; an adversarial situation eventually reached a stalemate. The changes made in 1987 were necessary; the 1982 Act could not work. Both laws were necessary for the program to go forward and the worm hasn't finished turning yet. Both laws were passed at the very end of the congressional session after difficult negotiations and both embody political compromises-but that doesn't mean it's wrong. Checks and balances in the political process must be recognized. This is a political issue.

A comment was made earlier about the public wanting to characterize more than one site. The public in other States might not agree. There was more support for narrowing down to one site than for continuing with three. Here's one myth. Bennett Johnston didn't propose Yucca Mountain as the only site-he proposed keeping all three sites for limited characterization and then picking one. It was the House that wanted to pick one site.

In this program there are certain boundary limits on the Executive Branch to do certain things. Contingency planning is for preparing for eventualities. There's been a question of why doesn't DOE propose a second repository or characterization of other sites. First, we have 50 years left before the first repository could be filled. Second, Congress found 2007-2010 appropriate to revisit the second repository. That's not irrational, given the first repository schedule. So, the focus of the program should be on upcoming issues and on its mandate. We're unlikely to put a high priority on reopening the second repository issue-and political issues are a factor.

- I've heard of positive spins on history, but ... Please quote me correctly, not incorrectly. The real reason the Amendments Act occurred was DOE's unilateral derailing of the second repository provisions of the Act. The one site idea was from the Senate Energy Committee; three sites was from the Senate Environment Committee. DOE has an obligation to inform Congress of the needs of the waste management program, regardless of the timeframes of the law. The Mission Plan Amendment is an appropriate vehicle for communicating to Congress.

In looking at the Strategic Principles document, the contingency planning section is the one most lacking in substantive content. It only addresses Yucca Mountain's geotechnical suitability, but not other salient issues. The discussion is too limited in scope. There is a whole variety of other potential failures. There is a document that 
the Secretary was given last fall about strategic planning; Nevada has not been given a copy.

DOE: Perhaps I didn't express myself clearly. I agree that the Strategic Principles draft started out narrowly-we do agree that the process must be broad-based. I think I'm correct about Johnston. I agree that the end of the second repository was one of the impetuses behind the Amendments Act. But the Amendments confirmed what DOE had done. The Mission Plan Amendment is meant to provide a plan for implementing the law.

- The concept of contingency planning is excellent. Only in America where we really don't need a repository for 100 years can we talk about alternatives. At the WIPP, the issues of the high-level waste standard and the waste package may delay the schedule for waste emplacement. It is essential that one do planning. We may need a transuranic waste MRS facility due to Colorado's limits on waste quantities. Another problem is what DOE will do with the waste if WIPP doesn't work out-we've heard not a word about that. DOE is reluctant.

- What I gathered from the write-up on contingency planning, is that plans would exist, but be kept in secret, because in adversarial situations, you can come under attack, because in a live environment, plans would get altered. I didn't hear a response on whether the strategic planning document is available.

DOE: There's no secret contingency planning document. The process will be open, it will involve external parties. The strategic plan is available, but it won't show you what our plans will be if Yucca Mountain is a no-go. That document hasn't been written yet.

- I know how difficult this is. The Department should be open to contingency planning. For example, in changing the linkages in the Amendments Act, DOE has done things and should be open to looking at other provisions of the Amendments Act as well.

DOE: The fact that many people in the Federal government are lawyers leads the players in the process to take a very narrow point of view of issues and the way to deal with them. When the law says, do this, they take a narrow view and feel that they can only do that. Officially, we have neither the authority nor the responsibility to do contingency planning. Politically-you don't want to stick your head up and get shot. Managerially, it would be imprudent not to think about contingency planning. What we're talking about is strategic contingency planning-not tactical, which we do all the time. For example, the issues of Yucca Mountain suitability and the second repository are strategic issues.

We should look at what is the basis of congressional action. Generally, the basis of Congressional action is either a bill on the table or crisis management. Contingency 
planning is the opposite of crisis management, it's trying to avoid crisis. Our opportunity to do contingency planning is constrained by our authority and responsibility as defined by Congress. We don't want to be caught cold, but we cannot be out there talking about all sorts of wild alternatives to the program-it is inappropriate and irresponsible. The question is when is something ripe for congressional consideration? How and in what form? Public products of contingency planning will be a significant issue. We aren't going to go out and make banner headlines on contingency planning.

- I agree completely. But, in order for people to begin accepting ideas, you need to plant seeds. This is a way to begin to change the way people think. For example, many people think we need only one repository.

DOE: The law says 2007-should we tell Congress now? Should we take that kind of initiative?

- Well, if your technical analysis shows we'll need a second repository. You don't want people saying, "DOE knew 15 years ago but didn't say anything."

- You give the impression that you're talking out of both sides of your mouth. On MRS facility linkages you're saying the law needs to be changed. Don't hide behind the law.

DOE: The issue is ripeness, not need-we will need it. It takes time to build the tremendous political capital required. For the MRS facility, it's immediate. Our preference is not legislation, but a negotiated agreement that changes the linkages.

- You're stating it on a technical basis, as opposed to the law.

- We have tons of spent nuclear fuel. Will Yucca Mountain be suitable? Many factors could be considered. In that context, one might conclude that the time indeed may be right.

DOE: We plan to look at what we should do about the suitability of Yucca Mountain, but that's separate from a second repository. We may need proposals for siting a first repository.

- I'm calling the "other" repository either alternate or second.

DOE: No, it's two separate issues.

Facilitator: The question is what is the purpose of the MPA? If it's descriptive, should there be another vehicle for explaining contingency planning? Does the group have a recommendation? Should we encourage DOE to suggest their thoughts on contingency planning to Congress? 
- This is a troubling issue. I've been tossing and turning. I think I heard DOE saying that it doesn't have the authority to deal with these contingencies under existing law.

DOE: I'm trying to say that opportunities are constrained under the current system.

- Your lawyers may have told you that, but there are a variety of ways to do contingency planning under your authority. For example:

First, as part of the NEPA EIS process, you should and must consider alternatives to the proposal, including those outside your legal jurisdiction.

Second, you can read the NWPA broadly.

Third, look at the NES. The Secretary and the Administration came forward with an array of proposals outside existing authority to do all sorts of things.

Fourth, you have authority under the Atomic Energy Act.

I understand your concern, but you may want to go back and look at these things-because I believe it's critical that you do this.

DOE: I may not have given the right twist to my words. The NES says do contingency planning, but doesn't say anything about contingency planning products. I don't see any crisis where we have to put the results and products of contingency planning on the table in the near term. I don't want to jump the gun. Vehicles exist, DOE routinely takes legislative initiatives when it's appropriate. The issues must be ripe for consideration. The question is when do you produce and what kind of product? These are difficult issues.

- In order to make the existing program work, by doing active, open contingency planning, this may allow current efforts to move forward. This will circle back and help the program function. Such as acknowledging a "no" alternative on Yucca Mountain.

- DOE is recognizing the need for public confidence. The record is clear about DOE's reluctance to open the second repository issue. This discussion has done nothing to change my mind about DOE's intentions. It shows the effort as hollow. The authority is there. Contingency planning is the right thing to do, both managerially and as a public confidence measure. DOE has been primarily involved in looking at the political costs of actions as its preeminent concern. Here's an opportunity, and yet there's a huge reluctance to look at anything other than Yucca Mountain. How can Nevada have trust in the Department? 
DOE: We are not reluctant to look at Yucca Mountain. Our sensitivity has been raised by non-DOE people. We're happy. We plan to, under our own obligation, do contingency planning.

- I understand the dilemma. Congress clearly doesn't want to look at three sites, but all the eggs are in one basket. Congress provided six months to report if Yucca Mountain is found unsuitable. How much time would it take to do studies, John, and to do modest thinking and planning? Do you have an estimate?

DOE: Six months is adequate.

\section{ALTERNATE MEANS OF PROGRAM MANAGEMENT}

DOE: The original recommendation of the Advisory Panel on Alternative Means of Financing and Managing Radioactive Waste Facilities was to create an independent Federal corporation. DOE felt that was premature at the time, but that once major program milestones were complete, it might be revisited. During the workshops, there didn't seem to be a great deal of support for alternate management. But some did support taking the program away from DOE during implementation. In the National Energy Strategy, we said we'd evaluate alternate means of managing the program. DOE will take another look at this issue. There's not much meat on the bones at this time, but I want to throw it open to discussion.

Facilitator: I believe the Strategic Principles document does reflect the consensus of previous workshops. From the absence of comment, I gather the group agrees.

- I've been tossing and turning from the contingency planning process versus the substance. We're really looking at process here-i.e., another management structure. It's a legitimate area of contingency planning; the two topics are tied together. You already have de facto private sector involvement by utilities and their experience feeds into contingency planning. In dry storage and MRS facility involvement this will increase in the future. You might look at a utility consortium idea. The health and safety issue is not significant for an independent spent fuel storage installation. Other forces could be seen as driving here. There really is a need to look at, for example, the Public Service of Colorado experience. It's a 10, 20, 30 year process.

- As I see it, Congress has passed the law and given a Federal agency this mission. Look at Public Service of Colorado-they've had a contract with DOE for 25 years to take their spent fuel. DOE has fulfilled the contract, and now the Governor of Idaho has refused to take the waste. How can a private entity fight an issue as Federal as this, one that crosses State lines? I can't imagine that it could.

- It is dangerous to assume that my silence means acquiescence. Please don't do that. Let me back up to contingency planning. Frankly, the contingency planning discussion left me very confused on what DOE will and won't do, will and won't put 
forward. The strategic principles document says, "our plans are to continue the development of a contingency planning process," (page 3-16)-what does this mean? NARUC, at its last meeting, identified contingency planning as a very important issue-top priority. If the lawyers are really giving you a problem, NARUC will send a letter supporting it. Tell your lawyers.

On the alternative means of managing the program, this is a very important issue. It relates to cost containment. I don't understand the correlation between the strategic principles document and the NES commitment-they seem to be contradictory. It's been nine years and three billion dollars-we've got some history! It seems that all of that should go into a thorough, intense, and complete study.

DOE: Reading from page 3-16, it seems clear to me that it says we're at the beginning of the contingency planning process. I think the text is unambiguous that we heard what the participants said and are responding.

- The strategic principles document does not say what are to be your public products.

DOE: It would be an articulation of issues and options and recommended course of action if contingencies appear. We are open to looking at any contingency that is ripe for discussion. We've begun to identify criteria to screen issues for consideration, such as major impact on cost, schedule, or technical program.

\section{WEDNESDAY, APRIL 3, 1991: 4:45 PM SESSION}

\section{COMMENTS AND REVIEW OF AGENDA}

Facilitator: One suggestion from the public comment period was to look at Chapter 2 of the document. Could I have a show of hands? Enough agree to add it to the agenda for tomorrow. There will be a public comment period. Tom Isaacs will discuss the possibility of a fourth workshop addressing the draft MPA. Anything you feel should be brought up?

- Actinide burning would be fun!

Facilitator: That's contingency planning-if you wait long enough, all high-level waste will become low-level waste, and that's a State responsibility!

- We could discuss the siting credo provided today.

- Regarding the licensing case for the repository, we've gone through that issue, but I feel uncomfortable about it. This will be the most arduous licensing process ever-have we worked that through? Were the options in the document the only possible ones? 
Facilitator: The original discussion draft included an array of elaborate options, which were discussed. I agree that licensing will be extremely complex, but I'm not sure that we know enough about it now to even discuss it meaningfully.

- There are issues tomorrow related to licensing-the demonstration facility and the timing and criteria for determining site suitability. These are very germane to licensing issues. It will be useful to discuss these. The concept of little watersheds is important. It would be a major contribution to licensing.

DOE: Recently we have begun discussing development of an annotated outline of the License Application, following the NRC's format and content guidelines. This exercise will be useful in developing an approach to licensing. It may point us to other opportunities.

\section{THURSDAY, APRIL 4, 1991: 8:30 AM SESSION}

\section{EXPANSION OF REMARKS ON CONTINGENCY PLANNING}

Facilitator: Please note that the agenda has been changed to permit discussion of chapter two of the revised strategic principles document. John Bartlett wants to return to the topic of contingency planning to expand on his earlier remarks.

DOE: I'd like to revisit the questions raised yesterday concerning contingency planning. I sense that the parties were talking about different things, and that DOE was not communicating well. I want to try to do a better job of explaining our view. Let me enumerate our views on the factors involved, why they are not the same, and how they will be dealt with in implementation.

First, we have, are, and will be doing contingency planning. Several factors are involved: the subject, the scope, the depth of effort, product, timing, and external involvement in production and review. Our view is that contingency planning comes in three categories or flavors: operational, program management, and what l'd call program framework. Operational is tactical, day-to-day, activities internal to the DOE family, things like setting up cost committees or dealing with contractors. Program management involves the larger issues of program strategy, implementing the program, NAS study kinds of things. For example, alternatives for the ESF if we find something unexpected. These are implementation features of the program. There is external involvement and impact, for example where the OMB and the Congress get in their budget-making mode. Program framework is implementation of the mission as defined by the MPA, where you get Congress involved in its legislation-making mode and OMB is involved in a policy mode as the chief operations officer of the Administration. 
There are distinct differences in contingency planning for management as opposed to framework issues. Within program framework, there are three issues: the MRS, alternatives to Yucca Mountain, and the need for a second repository. The existing framework addresses each of these issues and gives guidance. For example, with regard to a Yucca Mountain back-up, it gives us instructions. Secretary Watkins has proposed legislation to Congress that proposes removal of linkages. It assumes the Negotiator will be successful in finding a host for the MRS; we have contingency planning with respect to MRS siting. Regarding the Yucca Mountain back-up, we are operating with guidance from Congress to tell them within six months of failure, that is, site unsuitability. We can identify various options. The same for the need for a second repository. In all of these issues we can readily identify alternatives. These are the elements of contingency planning.

The question becomes one of timing; when does the program take action with respect to these issues? They're off in the distance, relatively speaking. Success in some depends on success first in others. In the question of DOE contingency planning on the MRS, we can (1) let the Negotiator go on and look at the potential consequences of delay in that respect, (2) encourage the Negotiator with a more beneficial package, and (3) have the DOE achieve a federal interim storage facility. We can identify options and plan with respect to them.

The question is what action to take regarding contingency planning and when. In many cases, it isn't appropriate to take action on these issues. The continuing issue for us is the timeliness: what are the signals for action as opposed to action itself? We can put plans on the shelves, but when do we activate them? I submit for your consideration that the timing isn't ripe for these issues at this stage. We will plan, monitor events, update the plans accordingly, and act when appropriate. But for now, we will be aware and maintain a state of readiness.

Facilitator: Are there any comments?

\section{DISCUSSION OF MISSION, POLICIES, OBJECTIVES, AND STRATEGIC PRINCIPLES}

Facilitator: I want to open discussion on chapter two. Are there any comments on the original or new principles, or suggestions for more principles?

- I have an addition where you talk about missions and policies. One concern locally is that if the repository happens, there may be effects on the quality of life in Las Vegas. Add consideration of that, of individual and community welfare. Add consideration of an item we're sorting out in our program, the economic effects of a repository. Change the wording to protect the health, safety, "and welfare" of the public. Also, on page 2-5, about the sharing of information and data: what does "appropriate" mean? It's too general. A phrase like "that will enable affected parties 
to conduct effective oversight activities" should be added. It's important that we have our own data and make our own judgment.

- What were the changes in the document? Are the changes suggested here going to be automatically reflected in the document? The rules of the Licensing Support System (LSS) were hard-fought and completely well delineated, and will tell how data is transferred. This is a good statement if it references the LSS.

- We have difficulties with "appropriate."

DOE: The purpose of this document is to provide for predecisional input. This document won't have standing by itself in the program. We will memorialize all documents used for the purpose of the workshops. Portions of the strategic principles document will appear in the MPA. However, the idea is to translate workshop comments into the MPA. It's okay to make working changes, but remember that the MPA will elaborate in detail.

- I advise caution on the use of such words as "standing." They have specific meanings in a legal context or in the NRC's adjudicatory rules. Be careful. He's asking for something, but don't just say okay. I'm saying wait a minute. Be careful with word meanings.

DOE: I'm explaining this document isn't being formalized.

- Public use of these materials makes them part of the decisional record. Be careful is what I'm saying.

DOE: We will.

Facilitator: We'll talk on data later today, and can clarify the term then. OCRWM will be talking on the MPA this afternoon and explaining the relation of this process and the MPA.

- An observation. I look on this as the credo of the program. I just want to know what you're getting at. I have a problem with the principle on evaluating socioeconomic impacts on page 2-5. Add something reflecting independence on the part of affected governments in the socioeconomic arena, and something about the need for resources. I've got modified wording. Should we do that now?

Facilitator: I think some may be reflected in chapter three and other areas. Are your concerns already reflected in chapter three?

- There could be some changes to better reflect our concerns. 
Facilitator: Chapter two should be consistent with chapter three. Submit suggested changes to the DOE.

DOE: Our vision of this document is that chapter two is like a credo. Don't expect dramatic changes. Chapter three is a discussion of specific issues. Material from this will be incorporated into the appropriate sections of the MPA, but will not remain in its present form.

- Dennis's point is even more valid now. Put in a more accurate description of the roles of parties. Thus, chapter two should definitely reflect that.

\section{DOE: I agree.}

- On page 2-3, the management principle on public trust. "Consider" is weak. I recommend saying "build" or "address" public concerns, as chapter three does.

- I endorse the principles, and I have no problems with their layout. In the MPA you might want to point out that you haven't established priorities among these principles and that their importance will vary depending on the issue, and that conflicts between principles require balancing. The real question is how you do that balancing. How that is done is important. How will you use these principles to arrive at resolution of issues? People will want to know.

- It is essential to identify responsibility. John has given us a clear vision, but it wouldn't hurt to say up front that, "the Director of OCRWM is responsible for this and must commit resources."

- Safety management should be added in here, because it's not just worker health and safety, but for the public and the environment as well. Include safety in design. I feared this area wouldn't be addressed. I want to see it here.

- A question. Can DOE describe a situation where the objectives are used to address a specific problem? Will they be operational and used on a day-to-day basis? It's easy to write principles, but will they be relevant to the conduct of the program? How do you solve problems with these, when will you work on it? Will you pull up these policies to test your solutions? How will you show us you really used these principles?

DOE: That is certainly our intent. That's why we're putting them forward. I had the experience of being in a company that had a corporate principles statement. We'd sit there and ask ourselves how are we doing. The point is to have it there. Make use of it. We have that on record and constantly remind ourselves. It becomes our responsibility. We'd have in place a credo, a statement of our basis for operation. You do have to remind yourself. We'll do our very best by it. 
- The point raised earlier is an interesting one. There are fashions in the corporate world, and strategic planning and corporate ethics are recent ones. Our staff doesn't fully understand our own credo. When someone brought up an inconsistency between the credo and a proposed policy, they were told to "sit down and shut up." You can have it on paper, but it's another thing to put it into effect. You can use different principles and justify different actions. You can decide something, then pick principles $a, b$, and $c$ to justify it. And credos have been raised to block action. Principles should be used to guide action, not justify it.

DOE: Let me add two points. First, as to how we plan on going forward. The MPA will be reviewed against the strategic principles document for consistency. Everything in the MPA will conform to the principles. It will explicitly recognize where we heard something and explain why we did what we did. Second, this afternoon we'll discuss the self-assessment principle, where we'll conduct internal assessments to check if we're taking the principles into account.

- This should involve not just DOE, but also the contractors. You have a whole new group coming in and it is not clear that everybody has the same credo and principles. Will the contractors adopt and implement them, too? This seems a relevant next step.

- Be careful. You may get trapped by the system. You need some hard program reviews from outsiders. You may not like what you hear, but it's necessary that you hear it. This should include the representatives of affected States.

Facilitator: I recommend that people give the area of how to incorporate the principles and how to use outside parties additional thought for this afternoon. Let's take one last comment.

- With regard to defense programs in DOE, I suggest an addition to the first bullet, to the first principle on page 2-1, with a phrase to the effect of "includes, but is not limited to, compliance with all applicable laws and regulations." Failure here has eroded public and State confidence.

\section{USE OF PEER REVIEWS}

DOE: Peer review means different things to different people, so the program has defined it broadly and generally in this context. The program is using peer reviews a lot, and I believe they are very valuable for some aspects of the program. We have technical review of everything. Do we want peer review of everything? Whatever we do, these will be in accord with Quality assurance procedures, and part of the management decisionmaking process. Look at the hydrology program review by $\mathrm{R}$. Allan Freeze and other outside, unaffected, and unbiased parties. Peer review helps us as managers make sure we haven't overlooked things. It should be of limited scope and duration, occurring in a focused and frequent manner. The ultimate ongoing review is done by the TRB, NRC, States, and affected counties. This will help build 
public trust and confidence. As you do this, the program will become better. For example, Jerry Szymanski's theories are being peer reviewed. This qualifies unqualified data.

- I have a question about that hydrology peer review. Who was invited to sit in the meeting room when the group convened? Were they outside the DOE complex?

- Nevada wasn't in it.

- I constantly find examples of credit taken for peer review done in secrecy. Secrecy limits how much confidence we can put in the review.

DOE: I hope that peer review includes dialogue. Certainly, all ESF alternative interactions are reported and available on record.

- It's not enough for DOE to say it will continue to use peer review as it has in the past. There are many examples of poor reviews. You should increase attention to more outsider review involvement and outside bodies who are not solicited, but comment anyway. I repeat - you must really be able to change things based on what the peer reviews say. Stress this in the future.

DOE: I agree with that. That's why we do them. Project management solicits reviews for that purpose.

- Often, the DOE response is to justify what it has already done rather than respond substantively.

DOE: I hope you mean the DOE broadly. I hope OCRWM is more responsive.

- A clartfication. This discussion of peer reviews has focused on structured peer reviews. I presume there is no intention to do less in the conventional peer review for publication and review by peers that way, as well as the international peer process. I presume DOE intends to sustain these, but the document is silent on this.

DOE: I agree; but I perceive that as part of the ongoing program.

- When you set up a panel, what process is used in selecting individuals?

DOE: We seek guidance from nationally recognized experts in the field. We assess what is available and who's involved in the program.

- Whe is an-expert is open to selection.

DOE: We try to choose unbiased experts. 
- The write-up should address the critical selection issue. Explain how you won't stack a panel.

- The bullets on pages 3-32 and 3-33 should reflect some important suggestions made here. Add a fifth bullet that peer review should be as open as possible. The document must react to suggestions in the third paragraph following - what about commitment to the inclusion of technical critics and such? Establish that as part of your operating assumptions, to go out and affirmatively look. Challenge yourself. DOE has not included these people. I can suggest names to you if you can't find them. It will improve the process of peer review if you include them. You could also increase public confidence this way. Stacking peer review will bite you. When you redraft this document, respond to each of those points.

- There's a big difference between reviewing a transcript and being on a panel. Have you had any requests to participate by interested parties? If so, have you denied any requests, and why?

DOE: I don't know. I can't address that with regard to the hydrology panel. I always say, sure, come on in and watch. Intuitively, I say they're absolutely open and I also provide transcripts. On the other hand, these are expert elicitations, not peer review, and some deal with our internal workings. In some things like that, $I$ don't consider them to be peer review.

- I don't want to get into internal workings, but outside bodies and panels can provide you assistance as well as help us. At a minimum, inform the affected parties so at least they can be on the back bench.

DOE: I encourage you to send representatives to the monthly TPO meeting, because that's where we set out meeting schedules. The TPO meetings are not publicly open, but are open to program participants. And every six months, we have public update meetings in three places in the State. That is our mechanism to inform people.

- I recommend the ACNW's approach to peer review as an example of what peer review can do. And also, regarding page 3-32, on matters beyond technical and information management, include some type of overall advisory body on the overall conduct of the program. I see no evidence in the draft of management peer review. I want to see a note if DOE is thinking about this.

Facilitator: The group seems to support adding another bullet here.

- You're not talking about peer review, you're talking about public review of things. The definition of peer is extremely important. You shouldn't be deciding peer review via the newspapers, where anyone who is quoted can claim to be an expert. Peer review is to get to a higher plane of scientific discourse. I recognize that panels can 
be stacked, and maybe there is a better way, but you must be very careful not to dilute the process. For example, Congress explicitly wrote the laws on the TRB to avoid those problems of stacking.

- I agree. A variety of things need review, and different mechanisms are appropriate to those different things. On program decisions, get people to advise those making the decisions. On matters of technical fact, go to people not connected to the program, like in technical journal reviews, in the NAS on important matters. The NAS process takes care of those concerns. DOE has no control over who is selected when NAS does the choosing or when the TRB is involved. Make maximum use of international review. Those overseas think about the same matters. This is an area that will help you rebuild public confidence.

- I did mean peer review when I addressed the issue of panel composition. I don't mean citizen activists or litigators. I mean actual technical specialists. You can identify well-respected critics on most issues who are on the record. You can find real experts, not mere celebrities. I encourage DOE to think in those terms. In the longrun it will be of great benefit.

DOE: I agree, and I hope that's what we're doing. We are getting the hard questions asked. It's a good point that when we ask the NAS for peer review, we have no input.

- I reaffirm that point. But we're talking about the need for a formalized process of doing that. Also, look at the pledge the NRC's Center for Nuclear Waste Regulatory Analysis makes nominees take; it does limit nominees, though. You need to establish a more formalized system, with ground rules up front to avoid the appearance of bias.

\section{THURSDAY, APRIL 4, 1991: 9:00 AM SESSION}

\section{COOLING SPENT FUEL BEFORE DISPOSAL}

DOE: How hot the rock will be has an effect on waste isolation. There are several ways to achieve a cooler rock. The spent fuel can be cooled before disposal, or it can be emplaced in a less dense array, or each canister can contain less spent fuel. So the question is how long do you want to cool it? The key element is to keep radionuclides away from the environment. We use heat to dry out the rock and to push the water away. Most of the previous discussion was on cooling first. Heat decay after five years is slow. The rock will dry out for hundreds of years. There is no serious problem with this approach, but it does require heat management. You can't put a hot batch in one place and a cool batch in another. You have got to do it evenly. We have chosen an areal heat density of $57 \mathrm{kw} / \mathrm{acre}$, because that will not be detrimental. After thousands of years, the surface temperature of the mountain will not increase by more than 1 degree Fahrenheit. We have to understand the response of the repository rock to heating. To emplace cool fuel would require many decades 
of external storage. One study showed that you could not emplace fuel until 2085 if you wanted to keep the rock below $212 \mathrm{~F}$. This would not be consistent with timely disposal, and therefore hot emplacement would be preferred even though it would result in some rock being above 212 Fahrenheit. The issue is coming up with the TRB in October and soon also with the NRC.

- There is a difference between temperature and energy. You must explain this to the public.

DOE: The maximum fuel temperature will be around 350 Celsius; the temperature of the rock at 1 meter will be 170 Celsius.

- How will the dry rock behave over decades? There is little experience. I applaud the sentence which says that the question of "hot" versus "cold" repository cannot be answered until site characterization is complete. We need tradeoffs. The TRB has raised the issue.

- The performance objective for the repository on page 3-2 does not mention the $70,000 \mathrm{MT}$ statutory limit. A lower design objective should be noted. The design variable of thermal loading has great significance and there ought to be a statement to that effect. For example, a 5 MT repository would not be worth doing. There is no guaranteed areal heat density. The density is dictated by program requirements, otherwise it is a waste of time.

DOE: Until we characterize the site, we don't know how much good rock there is. As for the $70,000 \mathrm{MT}$ statutory limit, it only applies until the start of the second repository.

- Change the title from fuel cooling to thermal loading.

- Regarding the time of waste acceptance, the timeframe should not constitute an obstacle to the future development of nuclear power options. We'll know if the program is on time, when we decide to build the next nuclear power plant. Don't add years of storage if it need not be done. Is steaming rocks an off-the-shelf technology?

DOE: At 1 meter or 10-yes.

- I see a lack of consideration to institutional issues. Add that the heat impact on worker health will be considered along with heat effects on retrievability and on the transportation system. Remember the conditions at the Virginia City mine. The tunnels must be kept habitable.

DOE: Your point is well taken. This is part of site characterization. We intend to keep the tunnels habitable without special protective equipment. 
- The document is disappointing. Responses, whether from the workshops, or system studies, should demonstrate the seriousness of an issue, what answers will be available, and when?

DOE: This is serious, and the amount of time given to it in site characterization shows that. Should it develop that we have a problem, we would need to do contingency planning.

- The U.S. program is the only one with rock temperature in excess of 100 C. All other countries are below that. If there is no need to complicate the issue, why do it? Hot rock introduces unnecessary unknowns.

- Germany uses cool waste, and their repository is in salt. The reason most other countries use cool waste is that they intend to put it in the saturated zone. We have Yucca Mountain, which is unique in its use of the unsaturated zone.

- Why do we have problems? It is a simple analysis of heat distribution. At what point do you get an unacceptable result?

DOE: At around $80 \mathrm{kw} / \mathrm{acre}$ areal heat density, based on preliminary results.

- To what extent are you going to develop a cold option if the hot one fails?

- What countries are contemplating geologic disposal?

DOE: We will work with you to answer your questions.

\section{DESIGNING WASTE PACKAGES TO EXCEED REQUIREMENTS}

DOE: If Yucca Mountain remains dry, most any package would exceed requirements. We have found rat middens which have been carbon-14 dated to be over 10,000 years old-and they have no containment, no waste package. We have a reference design, but will look further at other waste packages: bi-metal, ceramic/metal; we will look at feasibility, at performance, etc. We have discussions with the NRC staff regarding any credit we might receive for design beyond regulatory requirements. They say that, if it can be shown that a given container exceeds standards, we will receive credits. We are conscious that a more robust waste package cannot compensate for a bad site, but it can give added conservatism. We will use the parallel approach of a reference design and also look at alternatives. Final resolution on this will depend much on site characterization.

- When we speak of waste packages in documents or regulations, we are speaking of a system of 10,000 to 30,000 waste packages, packages for spent fuel and for other waste. How can they fail? In fabricability? Through corrosion? Waste packages 
cannot make up for a bad site. Look at the package system. Are there things beside glass logs?

- Adopting a robust package could be viewed as an attempt to make up for a bad site.

- We have a commitment to do more than what is needed. The WIPP drums have a stated design life of 20 years, but are actually shown to last longer. But our waste form has been shown to be both soluble and respirable. At WIPP we have had problems getting DOE to meet its own standards. Again we have a problem of credibility. This is a legacy you need to address.

DOE: Yucca Mountain will not contain drums.

- Commissioner James R. Curtiss (NRC) noted at the National Academy of Sciences (NAS) workshop that the Swedes are creating the world's largest copper mine-done to gain public confidence. They also have a more robust transportation system. Where will that stop? When is it good enough? Has the TRB decided that a robust container is needed?

- No. The Board members think so, but the Board as a whole says more study is needed.

- It is good that the document now recognizes cost as a factor to consider. When and how will the container question be resolved? We are now in the ninth year of spending, and each year incrementally costs more.

- The issue is tradeoffs. DOE doesn't yet know what the tradeoffs will be without more research. We need to know the costs for various degrees of robustness, and what that's worth. It must be viewed within the context of added certainty. The waste package is in a 1000-year context. The benefit of added robustness is not yet known.

\section{TIMING AND CRITERIA FOR DETERMINING SITE SUITABILITY}

DOE: The emphasis really is on site non-suitability. We are developing a general approach which will be made public this summer. Should we conduct periodic suitability determinations during characterization? To what extent should we obtain external peer reviews? Should we have periodic update meetings in the nature of workshops every six months?

- You'll be mining groundwater. What might happen underground? Especially in a hot repository.

- Regarding option 1, would such an assessment be conducted at regular intervals? 
DOE: We don't know yet how often.

- On page 3-8, in the first paragraph of the Background section, note that 10 CFR 960 is used in site screening and on a continuing basis. In the next paragraph, we find "...If the site is determined to be unsuitable..." The evaluation includes whether you can sell and license the product at the end of the trail. You should do suitability evaluations every two years.

DOE: How about disqualifiers?

- If one finds in the site evaluation a penetrating or nearby eruption to be sufficiently remote, then okay; that could be done well in advance of the licensing review. If site suitability finding has been performed, and if the work was done and illustrates the outcome well in advance of the licensing review, it should be submitted, and thus build a consensus early.

- Use of the double negative is very poor practice. Also, suitability versus licensability analyses use different tools. DOE needs to say that evaluations will be performed periodically. Nevada's evaluations, by the way, have never been refuted.

DOE: A comprehensive discussion may be in order. Shall we have a workshop?

- It would be better to have DOE put its answers on paper.

\section{THURSDAY, APRIL 4, 1991: 11:00 AM SESSION}

\section{APPROACH TO THE DEMONSTRATION OF PERFORMANCE}

DOE: The question is, if there is a problem with a given NRC regulation, should we seek a rulemaking to change it, ask them to provide guidance or just keep talking? Our position is to wait for 40 CFR 191 to be promulgated and then see where we are. There are people who think it is possible to meet EPA regulations but fail to meet all NRC sub-system requirements. We interact with NRC on this complex subject all the time.

- The need for a continued dialogue until 40 CFR 191 is out is clear. But in the meantime, there is great value in the tentative use of extant standards, to see how it comes out. This is especially true for carbon-14, for example, where there is no problem with individual risk but where the source term approach cannot be met. It's very important for $\mathrm{DOE}$ in its site suitability determination to openly analyze the issue. If the carbon-14 standard is inappropriate it should be changed openly through rulemaking. It's possible to have an exemption process if it's well documented. The same holds true with NRC regulations. 
- Is this section titled "demonstration of performance" or "regulatory compliance?" You should insert "regulatory" in the title, ie., "approach to the demonstration of regulatory compliance."

DOE: This is how well it performs in comparison to the regulations it has to meet. EPA has received comments on Working Draft 2 of 40 CFR 191 and will have Working Draft 3 out in a couple of weeks. It has been recommended that we seek a rulemaking and we are exploring that. When we finish depends on which path we take; if the negotiations are lengthy, then we don't know.

\section{USING A DEMONSTRATION FACILITY}

DOE: We did significant tests in G Tunnel, but they were not prototype tests. We are looking at a facility on Fran Ridge, near Yucca Mountain, to use as a prototype facility. It would be great for the public to be able to go to such a facility and talk to the scientists. Fran Ridge is in the same kind of tuff as Yucca Mountain.

- What kind of tests? Would you use spent fuel?

DOE: They would be similar to those we made in G-Tunnel: instrumentation tests, heater block tests, maybe tunnel boring machinery, but there won't be any spent fuel. G-Tunnel had 22 tests. We closed out those tests because upgrading the ventilation to regulatory requirements was too expensive.

- Is it useful to do a dry run of the licensing process?

DOE: There's no real answer. We tried this before and it didn't work. But tests at Apache Leap were a great help in drafting procedures.

- There is a fifth option since option 4 contains two possibilities: one is for licensing increments, the other-the fifth-is to look at alternatives as pilot-scale facilities to see how to reduce the time between licensing and the start of panel construction.

- A demonstration facility would be well worth it from a public confidence standpoint.

- What is the difference between an exploratory facility, a prototype, and a Test and Evaluation facility, etc.? After you excavate two panels, do you backfill?

DOE: No, we will keep the repository open for 50 years.

- What the public is really interested in is how it performs after backfilling. Could you backfill a small portion?

DOE: That's a very interesting idea. But I thought that backfilling gave a sense of finality that the public didn't want yet. 
- I don't think the whole thing has to remain open in order to comply with the regulations. But there will be both waste transport and construction ramps. Early closing may not be appropriate.

- Sounds like the justification you were looking for was to demonstrate to the public.

DOE: The scientists want something of a prototype. They miss G-Tunnel.

- Let's make sure that before we do something it is not just for the good of public confidence but also for the good of the program.

DOE: This may relate to the discussion of public advisory groups.

- Don't forget you need to get a license.

- There is nothing more useless than cosmetic experiments. Can you do tests that really contribute to substance? That would be the best.

\section{THURSDAY, APRIL 4, 1991: 1:30 PM SESSION}

\section{SHARING OF DATA ON A TIMELY BASIS}

DOE: We always have been committed to the principle of sharing data as soon as possible. The debate is over what constitutes "as soon as possible." The data are public property and must be available in a reasonable timeframe, but we want to make sure the data aren't in error. One issue is raw data. For example, results are often affected by instrument anomalies. If an issue arises that involves this data, the uninitiated could make erroneous interpretations from them. I believe that it is necessary to process the data to identify anomalies and then check to determine the cause. We have a new initiative for interested and affected parties. We will issue a quarterly data catalog that will list the data types acquired, a description of the data, the location the data were acquired, when they were acquired, and their availability. And we will respond to specific requests. We recognize people wanting data need a little better method for asking for what they want. I hope this will meet their need for timely data free of errors.

- Am I to assume this is option 3 ?

DOE: Option 2 is what we're articulating. Option 3 takes too long.

- I can see a need for unprocessed raw data at some point. 
DOE: I'm not precluding that. We will give out raw data with our interpretations of anomalies in it. You can still contest our interpretation. But the data will not be purely raw.

- All this discussion is related to scientific and technical data. I want a sense of how the project is evolving in terms of employment and other data. I would like the discussion to reflect that we are interested in other useful information: project statistics to aid us in creating a baseline to get at socioeconomic impacts.

DOE: Socioeconomic data is available on a quarterly basis. Very little, if any, is classified.

- We want other data.

DOE: I normally send out what information I get. If we're asked, we send it out. The catalog might not include some nontechnical data.

- About the next to last sentence in the synopsis, about the need to supply data as it is acquired, are you rejecting that need by screening out anomalies?

DOE: No, we're just identifying anomalies, not screening them out. We don't mean that we'll withhold data.

- The discussion at the last workshop indicated the need for data as it is acquired, and what you suggest doesn't fulfill that need.

DOE: Many things are available as acquired; satellite data, for example. We will look at it in specific cases, with legitimate requests. We'll still look at and note anomalies. As far as a waiting period, there's no general commitment, but there are special cases. Another issue here is the risk of academic proprietorship and publication. We've had problems with people taking data and going off and publishing it; this has been a problem for project scientists, preventing them from publishing. This is a risk of doing business.

- I want to say that DOE has shared data right at the site. It has worked out well. On the issue of classified data, what is the current status of strong motion (earthquake) data from the Nevada Test Site (NTS)?

DOE: I'm not sure. I know that some is available, and that many in the State are interested in that data. With some data, Weapons tells us it's classified.

- Some of this data is provided to the Soviets, but not to us.

- If you're willing to sign a treaty... 
DOE: We'll certainly get it in your hands if it isn't from the small amount of classified data.

- This issue is in litigation now, and is still quite difficult. Data has been given to the Soviets and not to U.S. scientists. You should make a greater effort to round up data and get it out to people. We've had a battle to get DOE weapons-plant worker health information. It's beginning to come out. This sort of thing would produce more public confidence generally.

DOE: We're not using NTS data to any extent, but we do want to get out what we have.

- We were turned down when we asked about attending the briefing given to Soviet scientists at the WIPP.

DOE: Some of Nevada's people accompanied Soviet scientists to Yucca Mountain. Our policy is to give people both sides of the story.

- I agree that we need other types of raw data, medical, epidemiological, etc. Other raw data should be available, catalogued or not.

DOE: Our policy is data will be available, within the confines of the privacy act. We'll let you know what we're doing so you can let us know what you want.

- I suggest you talk about the project's impact. Few people in Las Vegas realize the economic impact it could have. At Nellis Air Force base, every now and then they pay personnel with two dollar bills so everyone can see what the base contributes to the community. Make a conscious effort to get information to the public. It's worthwhile. Let them know how important you are.

\section{THURSDAY, APRIL 4, 1991: 2:30 PM SESSION}

\section{OPPORTUNITY FOR PUBLIC COMMENT}

- I'd like to reiterate the importance of the article on siting facilities that was distributed to you this morning. ${ }^{2}$ It cites examples of successful siting of LLW facilities. In some instances, people have offered their property. I urge you to understand this negotiation credo and practice it. If you followed the credo, you could get greater support.

\footnotetext{
${ }^{2}$ Lawrence E. Susskind, "A Negotiation Credo for Controversial Siting Disputes."
} 


\section{ROLES OF UTILITIES AND THE FEDERAL GOVERNMENT}

DOE: I refer you to the options in the section in the strategic principles document (page 3-26). Participants showed little interest in options 2 through 5, had some preference for at-reactor storage, and had some agreement that DOE should not take title at reactors. We've responded by planning to proceed with option 1. Also, we've added a strategic management principle that says we will "strive to diminish uncertainties related to spent fuel management by the utilities." Any reactions?

- We need to walk through this. Your background paragraph sounds like something your general counsel's office probably told you to write. We object to anything saying the 1998 date is conditional-I want to get that on the record. As to the other options, options 2 through 5 talk about what happens if the Feds fail to fulfill their role; it's not so much lack of interest as it is not planning for failure yet. If you fail, people will be very interested in them. On the bottom of page 3-27, it's good to reinforce my earlier point that there has been no scientifically-developed instrument to test that statement. That's a gut feeling, not data. It may not be true that the utilities are more responsible than the Federal Government. It should be looked into. We appreciate your added management principle calling for diminishing uncertainty. There are many uncertainties, types of fuel, acceptance criteria, etc., but the biggest uncertainty is when DOE will take title.

DOE: I agree with that point. There is uncertainty on the timing of the MRS site, but we could reduce other uncertainties. Thank you.

- The first three sections, the three issues on storage, are confusing. This doesn't clearly lay out the issues, and there are many issues here-where, who pays, how long. Is this the right time to raise the issue of storage? I suggest you wait, lay out the strategy in the MPA, then take up the issue again if it doesn't work. I'm uncomfortable with these three sections. Do we need to discuss these options before the policy and plans don't work out.

- The only option is 1 . All the others are remedies.

DOE: I want to remind people about the genesis of the strategic principles document. This was intended to put out issues so you could help us decide whether we need to deal with them now or wait for other important information. You don't need to have an opinion on it now. It's okay to say that this isn't the right time to deal with an issue.

Facilitator: The group appears to endorse option 1. I gather that subsequent documents won't include the other options? 
DOE: Yes, that's the message.

- I have the same comment regarding option 1 . I see a phrase on page 3-28, "in a timely manner." Pools are filling up day by day. My concern is that utilities do need guidance. When do you need to answer what questions and give the utilities the information they need?

DOE: I'm glad you mentioned that. We're developing with the utilities a list of things they need to know in the upcoming 18-24 month timeframe.

- I suggest that the MPA identify key decision points in this issue area of the program.

\section{PRIVATE SECTOR INVOLVEMENT IN AN MRS FACILITY}

DOE: I strongly feel that the MRS can provide significant benefits to the overall waste system, and will be a flexible link between two dissimilar operations, a buffer or surge tank to the system, if you will. The options for discussion are on page 3-29. There was not much interest expressed in the earlier workshops. The consensus was that there was no need to adopt a strategic principle on privatization. But we plan to keep looking at private sector involvement in any case.

- There's a need for consistency here. The MRS has gone in and out of vogue. One problem in public confidence is that virtually everything we've done, we've changed our minds on. Try to, but not blindly, get a consistency. Incorporate this into the strategic principles as well. Choose a course and stay on it.

- First, the law may be read that it is a Federal facility. But it's possible that through the Negotiator process, a host community may want a private facility. The Negotiator can go back to Congress with a deal. The MPA ought to recognize that there is an implicit contingency plan in the law already that you may exercise. Second, the MRS has never gone out of vogue with us. With Congress, maybe. But we've always seen that it would help. You're right that things do change from year to year, for example, subseabed disposal.

DOE: We agree, certainly, that the Negotiator could build the private sector into the MRS in a number of ways. We want also to look at potential ways for the private sector to be involved to help the MRS along.

- The cost of development of the MRS as a factor has been mentioned. I noted this in January. Why wasn't this mentioned in your section in the strategic principles? Would private versus Federal be a cost factor? Why don't you look at how it affects cost?

DOE: We'll definitely look at cost in this area. 


\section{USE OF THE NUCLEAR WASTE FUND FOR STORAGE}

DOE: Again, there was little discussion of this topic, and we propose dropping this issue from further discussion.

Facilitator: Any objections?

- Drop it in what sense? The reason for this exercise is to start coalescing planning, to identify potential issues for planning. Drop it as an issue, but just because it's being dropped from discussion doesn't mean we're giving up on it. I won't ever give up on it in that sense.

DOE: Drop it in the sense that option 1 (the status quo) is retained. Any other options may require legislative change. I propose we continue on with the current course of developing it as part of the Federal system paid for out of the waste fund.

- Silence doesn't mean people don't see it as an important issue. This issue has been debated and will continue to be debated. It could come back in vogue, depending on the situation. I agree maybe for the moment.

- I don't think legislative change would be required for option 2. Both options 1 and 2 involve the MRS as a Federal facility. Either is within the language of the NWPA. I raise this as a nontrivial difference between the options in terms of the use of the facility. It's free to the user, currently. There are incremental changes the other way because they get incentives to exhaust fuel storage capacity. Option 2 would require the utilities to pay for storage, which changes their incentives. If it's free, you'll send your fuel right away. If it costs, you'll try to avoid using it.

DOE: I agree this is something that may need further looking into; however, from my point of view, I don't agree that option 2 could be done without legislative change.

- Some of these options-clarify them. Refer only to them in terms of trading dollars.

\section{THURSDAY, APRIL 4, 1991: 4:00 PM SESSION}

\section{FUTURE PLANS: MANAGEMENT ASSESSMENTS}

DOE: I want to comment on management assessments. We want input to help us flesh out what we're trying to commit ourselves to. We've added a new strategic principle on self-assessment. There are things we do currently as a matter of course, that are a groundwork for adding on helpful things to meet this obligation. I want to get this group's suggestions. We'll put ourselves on the line, to be held accountable; 
now we have to produce and want you to help. We already undertake exercises to assess our performance, including tracking and information systems, program readiness reviews, the management systems improvement strategy, QA, forming internal assessment teams, and, under the Secretary's direction, we will be conducting an extensive effort to look within ourselves and assess our weak areas. Once we translate this document into an action plan in the MPA, we need mechanisms involving external parties to assess how well we listened and acted; a report card on how we are doing. I won't give you any of our recommendations because I want to throw this open to your reaction.

- From the perspective of affected governments, we have definite ideas on this. We want early opportunities to sit down with $\mathrm{DOE}$ and define what we need to do in a collective sense. That's what I'd like to see by way of interaction.

- The hardest thing for any organization to do is self-assessment. I don't know what you can use as a mirror. Similar forums to this can be an effective assessment tool.

- My question is how does TRW, the "supergorilla" contractor, fit into what we've talked about the last two days. Are they going to be as committed to what DOE has been talking about regarding openness and trust? I still don't see how they fit in. How will they adhere to the program and to the concerns this group has raised?

DOE: You're referring to the $\mathrm{M} \& \mathrm{O}$ contract, which is a new way of doing business for us. We're setting up an office that reports to the Director and has responsibility for business management aspects of the contract. There are many constraints: (1) the contract is an award-fee contract, and so is based on performance; (2) in terms of technical direction, project direction, they will be providing day-to-day operation support under rules and guidance provided annually laying out the work. In terms of commitment to the program, there is no question in our mind that they are fully committed. It's clear they're serious about putting the right team in place at the right time. They'll be no less open than we. I underscore that the DOE is ultimately responsible for any products, information, anything from our contractors. Look to us for that.

- The question at my level is how you folks make sure there will be this commitment to interact with affected parties. How will this be translated? How will TRW interact with affected governments; are they front and center or behind the scenes?

DOE: We expect they'll be behind the scenes. They'll participate, but they won't interact independently of DOE. In some way, there will be a Federal presence in any interactions with affected parties.

- I'm glad to hear that the DOE will retain control. If you look at the history of the Nevada Test Site, you'll see they lost control-the tail is wagging the dog. This is both important to do and hard to do. Sometimes you have stronger people in a contractor 
role than the Federal employees. You're going to have to figure out some ways you can address that. I urge you to get outside help, or people from this group, to make judgments. And you will have to go back to the money. A lot has been spent, but $I$ don't see us getting value for it. A job well done is how you get public confidence.

DOE: A comment on self-assessment. It's not really "self" as much as it is an assignment to have a dedicated function, under the direction of the Secretary, associated with our organization. There will be external participation, but dedicated to our organization. Something along the lines of this group might be helpful to do that. I invite you to consider the possibility. In the near-term, we plan a meeting on the draft MPA. I remember that Ed Koch, former Mayor of New York, used to go about asking, "How'm I doing?" Should we institutionalize this group on an annual basis for the purpose of contributing to an annual report card. How are we doing? Your assessment complements our internal functions. I want to throw this out for your consideration. If we set this group up that way, it will be done under the Federal Advisory Committee Act.

- I know from practical experience, including a recent visit to a meat packing plant, that it's hard to assess health and safety programs in a vacuum. You need to go out in the field to assess. It helps an organization build credibility. We could provide that outside alter ego to assist you in our areas of expertise.

- I have several comments and ideas on reviews. One, why not send your criteria for assessing TRW out for review and see what people think? Two, clearly, you need to ask outsiders; the idea of a yearly basis is good, but this is a large group. You also need to do this on a part-time, more individual basis, with interviews and working groups. Three, you can include the GAO, TRB, and OMB in this process, along with the NRC informally. Four, you might want to pick up on techniques at power plants that have been developed over the years to assess management. Five, another thought-contractor requirements, deadlines, and deliveries have been great trouble in the past. How well are these provided? Six, another thought-put out a historical rendering of where the program has been. Outsiders could help on this. Seven, borrow from the peer review process and have a peer management review focus on management issues. Eight, set up an advisory body of some character, like a board of directors, that would meet on a regular basis.

- DOE's primary function is not to protect public health and safety, but to develop energy resources. I stress the need to work with other agencies to protect public health and safety. I could give examples or suggestions from working with other agencies. One was to establish at UNLV a Department of Public Health, not engineering, concerned with the program. In the improvement of the image of the facility, DOE needs to broaden its horizons to include organizations having complementary functions.

Facilitator: John Bartlett invited the group to discuss the implementation of the 
review function by it or by another body like it. They've made a sincere request for suggestions to make sure they implement these proposals, and that includes internal and external review of implementation of strategic principles. Do you folks have suggestions, or are you willing to continue perpetuation of this group in some fashion? I'd like to get some indications of your opinion on that.

- I can see real advantages to proceeding with a model of that nature-something like a board of directors meeting on an annual basis. We remember what we've discussed and come back to reflect on it later. The difficulty is how does the group learn about what you really have done during the year. You would need to establish a planned, orchestrated, and managed process of communication with us, and a commitment to our active participation. We would have to commit to active participation, too. It could not be perfunctory.

- You mentioned a meeting sometime between the development and final issuance of the MPA. This could be a test. What about the timing of this meeting?

- I want further definition of the purpose of perpetuating this group. I'd like to have a better understanding of it. What's your vision, John?

DOE: To contribute to the assessment function. A good question is how do we do it? Should we institutionalize this group or one like it?

- EEI has a group that reviews the repository program. One fear I have about that is that it is hard, in a short period, to know what you're seeing or whether what you're getting is the unvarnished truth of the matter. It's very difficult. The DOE could do a dog and pony show. They have all the information.

DOE: That's a good observation. I heard in there the essence of a topically-oriented approach involving subgroups. If everyone thinks it's a good idea to convene for the MPA, we could explore this further at that time.

- There are other forums and opportunities for public comment on the record.

Facilitator: Any other options or comments regarding a fourth meeting?

- What do you mean by topical?

DOE: Within this broad group, there are subgroups interested in particular topics that could meet separately.

- My reaction is that you need a series of mechanisms to do this. I suggest that a fourth meeting, a board of directors, and topical subgroups all have some merit. You hold the information. The NRC has representatives that are inside nuclear plants every day. You can really get good and important information that way. 
DOE: We have assessors like that already, including the inspector general, and the GAO, NRC, SEAB, and TRB. Their oversight functions already cover the spectrum on a topical, expert, informed basis. There is a lot there already, chartered, capable, and enthusiastic. In addition, the Admiral has asked us to undertake internal assessment functions. It may be that you may be complementary with these functions.

- I go back to what I said earlier about a meeting to talk with you about how to implement these principles. One more meeting on the MPA would fit in with this series of workshops. This group was designed to give you answers to twenty questions, to narrow down issues. We've answered these. One more meeting is justified. Then what? Do we continue on as an elite group with special standing in the program? I don't know what we'll do next. Do we review the program? You've got more of that than you know what to do with. You already know what we think.

DOE: This is our commitment by us to ourselves. We need a kind of self-assessment mechanism. We can pull the wool over our own eyes. We think we need a mechanism to assess how well we're doing in implementing the strategic principles. Does it make sense to have this group as a sounding board?

- Doesn't that require that this group have ongoing authority to lift up the covers and really scrutinize? I think you're creating an extraneous institution; you have such institutions already. Conduct your self-assessments in public and publish them so those who are interested can pick up on them. I don't see the value of the perpetuation of this group as currently constituted.

DOE: I agree about the perpetuation of this group as constituted. This job is done, or will be done. But is there a different kind of perpetuation to a different purpose? The key contribution of this group is its diversity. It offers an infinity of bilateral interactions, a mix of information not often heard within the context of variety, a unique provision of mixed inputs. We do hear from each element-bilaterally. What we don't get are the interactions among the parties.

- I agree with Steve's point about not perpetuating this group. Other meetings are not needed; a variety of groups already exist. But relative to interactions, I agree with John. I suggest you can reconvene this group for a specific purpose, as required, but not on a continuing basis. I counsel an ad hoc approach.

- I find John's idea attractive. Diversity came to my mind. This is a diverse group combining many points of view. It's much more diverse than any of the others mentioned. It is a valuable group, and offers meaningful insights. A synergism occurs when this kind of group gets together. We could review this document in the context of our prior discussions; we could review one or more topics from it each year. I encourage you to go ahead and have another meeting on the draft MPA and at that time put forward a detailed proposal on how this group would function. 
- I think these three meetings were extremely productive. I see a lot of progress. I have been pleasantly surprised. It's a good idea to see how these workshops will go into the MPA. But I have the same reservations about formalizing this group without a specific purpose. We ought to discuss the ad hoc approach idea a little more.

- I think this forum has been very valuable. Being here gives me viewpoints from a variety of groups. I certainly agree that a fourth meeting is a good idea. It has some bearing on what we'll tell our constituents and the public. I favor a meeting. One small request: our county mental health department uses the same acronyms in its documents as you do!

DOE: We're their outpatients.

- Put a list of acronyms into the front of your document. Also remember that we aren't looking at this every day. Put in brief explanations of cites, information, and references.

- We're from a wide variety of organizations. Some have considerable access to information regarding the program, which influences the value different people see in meetings. Another difference is that some people here are critically interested in the entire program, while others have more limited interests that influence their sense of value. I found these meetings valuable in providing insight into this program. You may need different mechanisms.

- Formalizing this group will hurt its openness. Take that into consideration.

- I echo that point. Once created, how do you get rid of it? Also, there are any number of challenges we haven't met.

Facilitator: A fair number of people have expressed interest in a fourth meeting on the MPA. It would be a continuation of this group's charge, and a test for DOE to see how well they've absorbed your input and incorporated it. It's a first test of the application of the principles. Are people comfortable with this? I offer everybody an opportunity to comment. Can people endorse that?

DOE: I believe there is a consensus on having a workshop on the MPA. We could put out a strawman containing pros and cons of continuing this sort of thing with the invitation.

DOE: I suggest we call a fourth workshop and let those who are not interested decline. We'll go ahead and call a fourth workshop. Now I'd like to turn to the MPA. 


\section{THE MISSION PLAN AMENDMENT}

DOE: We've already discussed a lot about the MPA. One other benefit of these meetings is to help guide us in the preparation of the MPA. The MPA has not been updated since 1987. Nevertheless, our intent is to keep the document streamlined; it won't be fifty pages, but it won't be two thousand pages either. We plan to have one in draft in late June. Are there any comments or questions?

\section{THURSDAY, APRIL 4, 1991: 4:30 PM SESSION}

\section{WRAP-UP AND COMMENTS}

Facilitator: Then let's move to the wrap-up. I offer participants the opportunity for closing comments.

- The workshops were substantively successful and demonstrated an unusual degree of openness by OCRWM, which is a refreshing change. I congratulate John for bringing this change about.

- I agree.

DOE: I want to thank all of you, and especially Rebecca Burka, who coordinated the logistics of the workshops, for a splendid job. Becky, get in here and take a bow.

Facilitator: I also would like to offer my thanks to a number of people. To the ADs, for their presentations and comments. To John Bartlett; this effort does constitute a major change in approach, and you deserve credit for that. And I'd like to thank you participants for your commitment of time and effort. Finally, l'd like to point out a significant achievement that has not yet been pointed out: DOE presentations were free from projections and viewgraphs, with one minor lapse. If they can do that, they can build a repository. With that, I guess we'll adjourn. 


\title{
LIST OF PARTICIPANTS \\ AT THE \\ THIRD STRATEGIC PRINCIPLES WORKSHOP
}

\author{
Brown Palace Hotel--Denver, Colorado \\ April 3-4, 1991
}

Dr. Bill Barnard

Executive Director

Nuclear Waste Technical Review Board

1100 Wilson Boulevard

Suite 910

Arlington, Virginia 22209

(703) 235-4473

FAX: (703) 235-4495

Dr. John Bartlett

Director

Office of Civilian Radioactive

Waste Management

U.S. Department of Energy

1000 Independence Avenue, S.W.

Washington, D.C. 20585

(202) 586-6842

Mr. Dennis Bechtel

Coordinator

Nuclear Waste Division

Clark County Department of

Comprehensive Planning

301 East Clark Avenue

Suite 570

Las Vegas, Nevada 89101

(702) 455-5175

FAX: (702) 455-5190

Mr. Robert Bernero

Director

Office of Nuclear Material

Safety and Safeguards

U.S. Nuclear Regulatory Commission

M.S. 6A-4

Washington, D.C. 20555

(301) 492-3352

For Courier:

11555 Rockville Pike

Room 6D-1, M.S. 6A-4

Rockville, Maryland 20852
Mr. Stephen Bradhurst

Consultant

Nye County Board of Commissioners

P.O. Box 1510

Reno, Nevada 89505

(702) 482-8181

For Courier:

4720 Canyon Drive

Reno, Nevada 89509

(702) $323-4141$

Mr. Larry Brey

Manager

Nuclear Licensing and Resource Management

Public Service Company of Colorado

2420 West 26th Avenue

Suite 100D

Denver, Colorado 80211

(303) $480-6944$

Mr. Holmes Brown

Facilitator

Afton Associates

403 East Capitol Street, S.E.

Washington, D.C. 20003

(202) $547-2620$

FAX: (202) 547-1668

Mr. Keith Bright

Supervisor

Inyo County Board of Supervisors

Post Office Drawer N

Independence, California 93526

(Attention): Kelli Landshaw

(619) 878-2411

FAX: (619) 878-2241

For Courier:

c/o Inyo County Courthouse

168 North Edwards Street

Independence, California 93526

(Attention): Kelli Landshaw 
Mr. Mark Burtschi

Director

Legislative Programs

American Nuclear Energy Council

410 First Street, S.E.

Washington, D.C. 20003

(202) 484-2670

Mr. Ronald C. Callen

Director

Nuclear Waste Program Assessment Office

1400 16th St., N.W.

5th Floor, Mail Box 18

Washington, D.C. 20036

(202) $939-3420$

Dr. Dwight Connor

Program Director

Energy, Science, and Natural Resources

National Conference of State Legislatures

1560 Broadway

Suite 700

Denver, Colorado 80202

(303) $830-2200$

FAX: (303) 863-8003

Dr. Thomas Cotton

Senior Associate

JK Associates

1001 Spring Street

Suite 406

Silver Spring, Maryland 20910

(301) $587-7098$

Ms. Norma Cox

President

Nevada League of Women Voters

3096 East Shadow Ridge Avenue

Las Vegas, Nevada 89120

(702) 435-0473

Mr. Carl Gertz

Acting Associate Director

Office of Geologic Disposal

Yucca Mountain Project Office

U.S. Department of Energy

P.O. Box 98518

Las Vegas, Nevada 89193

(702) 794-7920

For Courier:

101 Convention Center Drive

Phase 2, Suite 200

Las Vegas, Nevada 89109
Mr. Bill Gunter

Director

Criteria and Standards Division

Office of Radiation Programs

U.S. Environmental Protection Agency

ANR-460-W

2800 Jefferson Davis Highway

8 th Floor

Arlington, Virginia 22202

(703) $308-8777$

Mr. Tom Isaacs

Acting Director

Office of Strategic Planning

and International Programs

Office of Civilian Radioactive

Waste Management

U.S. Department of Energy

1000 Independence Avenue, S.W.

Washington, D.C. 20585

(202) $586-2277$

Mr. Steven P. Kraft

Director

Nuclear Waste and Transportation

Edison Electric Institute

701 Pennsylvania Avenue, N.W.

Washington, D.C. $20004-2696$

(202) $508-5512$

Mr. Robert Loux, Jr.

Executive Director

Nuclear Waste Project Office

State of Nevada

Capital Complex

Carson City, Nevada 89710

(702) 687-3744

Mr. Brad Mettam

Planning Coordinator

Esmeralda County Board of Commissioners

Post Office Box 536

Goldfield, Nevada 89013

(702) 485-3541 (office)

(702) 485-3406 (Commission secretary)

For Courier:

Esmeralda County Board of Commissioners 233 Crook Street

Goldfield, Nevada 89013 
Mr. Ron Milner

Acting Associate Director

Office of Storage and Transportation

Office of Civilian Radioactive

Waste Management

U.S. Department of Energy

1000 Independence Avenue, S.W.

Washington, D.C. 20585

(202) $586-1116$

\section{Dr. Peter B. Myers}

Executive Director

Board of Radioactive Waste Management

National Research Council

2101 Constitution Avenue, N.W.

Washington, D.C. 20418

(202) 334-3066

\section{Dr. Robert H. Neill}

Director

New Mexico Environmental Evaluation Group

7007 Wyoming Boulevard, N.E.

Suite F-2

Albuquerque, New Mexico 87109

(505) 828-1003

\section{Mr. Frank Peters}

Deputy Director

Office of Civilian Radioactive

Waste Management

U.S. Department of Energy

1000 Independence Avenue, S.W.

Washington, D.C. 20585

(202) $586-6842$

Dr. Chuck Reese

Assistant Director

Occupational Safety and Health

Laborers Health and Safety

Fund of North America

905 16th Street, N.W.

Washington, D.C. 20006

(202) 628-5465

Mr. Dan w. Reicher

Senior Attorney

Natural Resources Defense Council

1350 New York Avenue, N.W.

Suite 300

Washington, D.C. 20005

(202) $783-7800$
Mr. Sam Rousso

Associate Director

Office of Program and Resource

Management

Office of Civilian Radioactive

Waste Management

U.S. Department of Energy

1000 Independence Avenue, S.W.

Washington, D.C. 20585

(202) $586-9116$

Mr. Jerry Saltzman

Acting Director

Office of External Relations

Office of Civilian Radioactive

Waste Management

U.S. Department of Energy

1000 Independence Avenue, S.W.

Washington, D.C. 20585

(202) $586-8875$

Mr. Robert Shaw

Senior Program Manager

High Level Waste and Spent Fuel Storage

Electric Power Research Institute

3412 Hillview Avenue

Palo Alto, California 94303

(415) 855-2026

Mr. Dwight Shelor

Acting Associate Director

Office of Systems and Compliance

Office of Civilian Radioactive

Waste Management

U.S. Department of Energy

1000 Independence Avenue, S.W.

Washington, D.C. 20585

(202) $586-5851$

Dr. Jane Stockey

Staff Geologist

Office of Geologic Disposal

Office of Civilian Radioactive

Waste Management

U.S. Department of Energy

1000 Independence Avenue, S.W.

Washington, D.C. 20585

(202) $586-1063$ 
Ms. Stacy Stubbs

Staff Engineer

Institute for Energy \&

Environmental Research

6935 Laurel Avenue

Suite 204

Takoma Park, Maryland 20912

(301) 270-5500

Mr. Ken Weaver

Senior Health Physicist

Radiation Control Division

Colorado Department of Health

4210 East 11 Avenue

Denver, Colorado 80220

(303) $331-8497$

FAX: (303) 320-1529

Mr. Joe Youngblood

Director

Division of High-Level Nuclear Waste

U.S. Nuclear Regulatory Commission

M.S. $4 \mathrm{H}-3$

Washington, D.C. 20555

(301) 492-3404

For Courier:

11555 Rockville Pike

Room 4H-2, M.S. 4H-3

Rockville, Maryland 20852 
The following number is for OCRWM Records Management purposes only and should not be used when ordering this publication.

Accession No: HQO•910930•0005 